\title{
FRACCIONAMIENTO DE ASERRÍN DE PINO \\ DESTINADO A UNA BIORREFINERÍA FORESTAL
}

\author{
Tesis de Doctorado
}

Romina Bettiana Otoffel

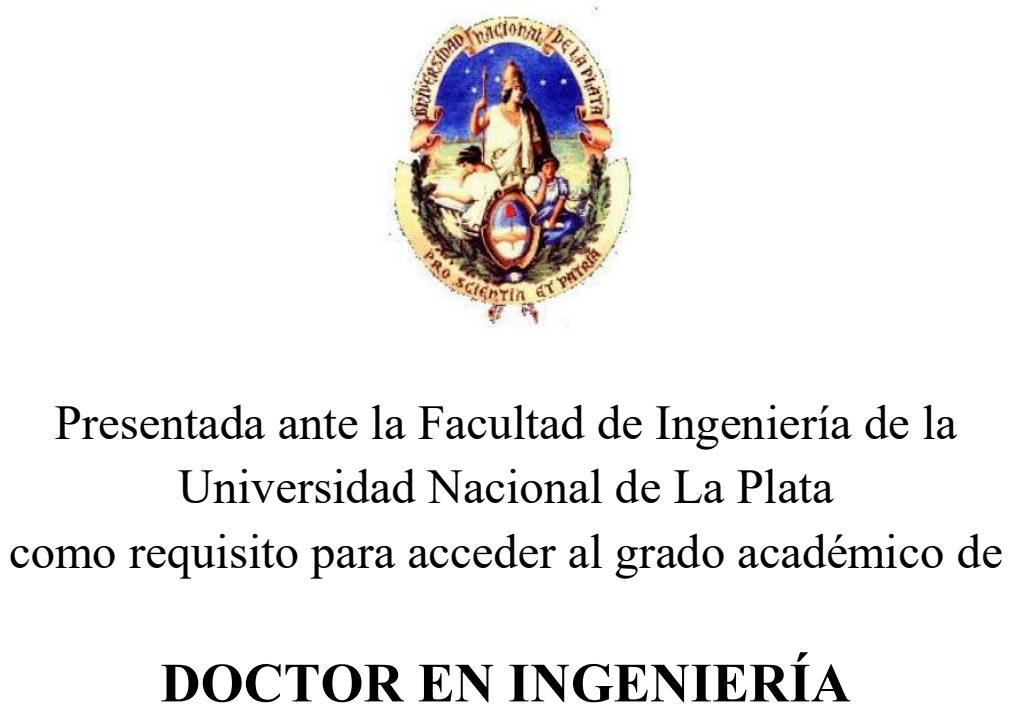

Director de Tesis

Director: Dra. María Cristina Area

Co-director: Ing. Liliana Mabel Gassa

Jurado de Tesis:

Dra. Mirta Aranguren

Dr. Miguel Zanuttini

Dra. Mirtha Maximino

Fecha de la defensa oral y pública: 22 de Marzo de 2016, La Plata, Argentina 
A mi familia... 


\section{Agradecimientos}

A Dios, por todas las oportunidades y por brindarme la fortaleza necesaria para avanzar en cada etapa de este largo camino.

A mi directora María Cristina Area por confiar en mí desde el primer momento y por apoyarme siempre, por todo el conocimiento y la experiencia transmitida, por las oportunidades que me brindó, la inspiración, el buen trato y la paciencia.

Al Dr. Fernando Felissia por enseñarme de manera desinteresada tantas cosas con infinita paciencia. Mi trabajo no hubiese sido posible sin su ayuda.

A Liliana, mi co-directora, gracias por haber aceptado dirigirme, sin ella esto no hubiese sido posible. Gracias por ser parte en este período tan importante de mi vida, por su buena predisposición y todo el conocimiento transmitido.

Al profesor Carlos Nuñez, por tantas charlas y mates compartidos, por enseñarme tantas cosas invaluables a nivel científico y personal.

Al Dr. Aprigio Curvelho Da Silva y a todo el grupo de trabajo del Instituto de Química de Sao Carlos, por su disponibilidad y colaboración en mi trabajo.

Al Dr. Luiz Ramos del Departamento de Química de la Universidad Federal do Paraná, por darme la posibilidad de realizar parte de mi trabajo en la planta piloto de esta institución, por su interés y valioso aporte a este trabajo. A todo su equipo, por pasar largas horas ayudándome con las explosiones de vapor.

A la Dra. Leyanis Mesa, por su ayuda incondicional, por caminar conmigo, por esas charlas interminables enseñándome no solo cuestiones técnicas sino también a ser mejor persona.

A mis queridos compañeros del PROCyP: Julia, Javi, Juancito, Laura, Nico, Yani, Cami, Ariel, Nanci, Shoshy, Julieta, Claudia y María por ayudarme siempre que necesité en el laboratorio, por los buenos momentos y risas compartidas. Ustedes hicieron más fácil y divertido este largo camino.

A mi familia, porque gracias a ellos llegué hasta este lugar. Por estar conmigo, brindándome su apoyo incondicional en cada etapa de mi vida. Este logro no es solo mío, sin ustedes no hubiera sido posible.

A Armando por acompañarme siempre, disfrutando conmigo los momentos lindos y bancándome en los momentos más difíciles. 

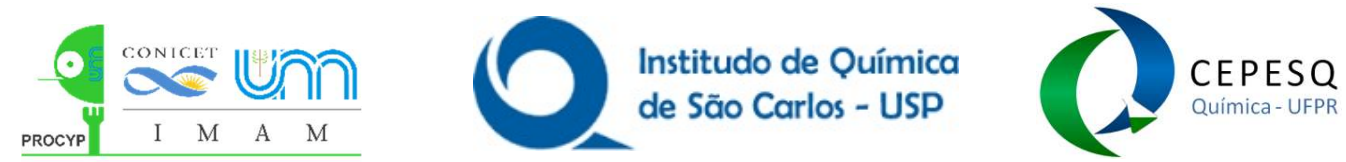

\section{Fraccionamiento de aserrín de pino destinado a una biorrefinería forestal}

El presente trabajo de tesis, para optar al título de Doctor de la Facultad de Ingeniería, fue realizado en el Programa de Celulosa y Papel del Instituto de Materiales de Misiones de doble dependencia (Universidad Nacional de Misiones (UNaM)- Consejo Nacional de Investigaciones Científicas y Técnicas (CONICET)), en colaboración con el Instituto de Química de Sao Carlos de la Universidad de Sao Paulo (Sao Carlos, Brasil) y con el Departamento de Química de la Universidad Federal do Paraná (Curitiba, Brasil), con el financiamiento del Consejo Nacional de Investigaciones Científicas y Técnicas (CONICET), de la Secretaría de Políticas Universitarias del Ministerio de Educación de Argentina y Programa Iberoamericano para la Ciencia, Tecnología y Desarrollo (Programa PROVALOR).

Tesista: Ingeniera Química Romina Bettiana Stoffel

Director: Dra. María Cristina Area

Co-Directora: Ing. Liliana Mabel Gassa 


\section{Publicaciones derivadas de este trabajo de tesis}

\section{Presentaciones en Congresos y Jornadas Científicas}

- "Biorefinería de aserrín de pino de aserraderos: caracterización de materias primas". VIII Conferencia Científica y Técnica de la Facultad de Ciencias Exactas Químicas y Naturales, Universidad Nacional de Misiones, Posadas, Argentina, 2011. Formato: Póster

- "Alkaline Deresination and acid treatment of pine sawdust for a biorefinery". $45^{\circ}$ International Congress of Cellulose and paper of ABTCP / VII Ibero-American Congress of Pulp and Paper Research, Sao Paulo, Brazil, 2012. Formato: Trabajo Completo y Presentación Oral.

- "Pine sawdust fractionation by an alkaline-acid sequence". $13^{\circ}$ International Congress of Metallurgy and Materials, International Symposium, International Symposium about lignocellulosic materials, Puerto Iguazú, Argentina, 2013. Formato: Trabajo Completo y Póster

- "Desresinación alcalina y tratamiento ácido de aserrín de pino para la biorrefinería", Conferencia Científica y Técnica, Universidad Nacional de Misiones, Posadas, Argentina, 2013. Formato: Presentación Oral

- "Biorrefinería a partir de residuos lignocelulósicos", I Conferencia de Jóvenes Investigadores, Facultad de Ciencias Exactas, Químicas y Naturales, Universidad Nacional de Misiones, Posadas, Argentina, 2013. Formato: Presentación Oral.

- "Strategy of fractionation of pine sawdust by steam explosión", VIII Ibero-American Congress of Pulp and Paper Research, Medellín, Colombia, 2014. Formato: Trabajo Completo y Presentación Oral.

\section{Publicaciones científicas}

- Stoffel,R.B., Felissia,F.E. Curvelo, A.A., Gassa, L.M., Area, M.C. “Optimization of sequential alkaline-acid fractionation of pine sawdust for a biorefinery", Industrial Crops and Technologhy 61, pp. 160-168 (2014).

\section{Capítulos de libros}

- Bengoechea, D.I., Stoffel, R.B., Area, M.C. "Pretratamientos o fraccionamientos" Capítulo 3 del libro: "Biorrefinería a partir de residuos lignocelulósicos. Conversión de residuos 
a productos de alto valor". Area, M.C., Vallejos, M.E. (Eds.). Editorial Académica Española. pp. 109-150, 2012. ISBN 978-3-659-05295-8.

- $\quad$ Stoffel, R.B., Felissia, F.E., Vallejos, M.E., Area, M.C., "Aplicación de la Biorrefinería”, Capitulo 5 del libro: "Biorrefinería a partir de residuos lignocelulósicos. Conversión de residuos a productos de alto valor". Area, M.C., Vallejos, M.E. (Eds.). Editorial Académica Española, pp. 171-182, 2012. ISBN 978-3-659-05295-8. 


\section{ÍNDICE}

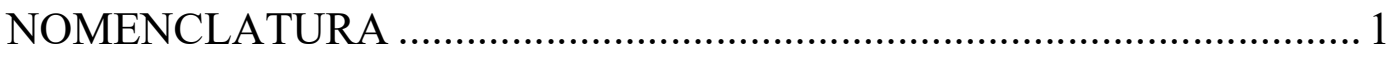

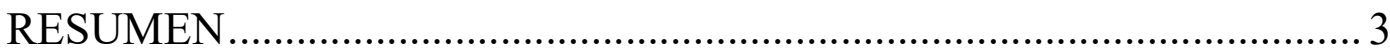

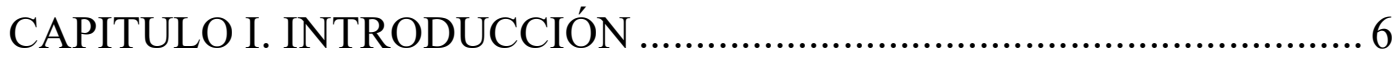

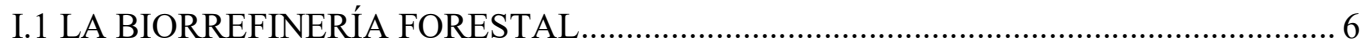

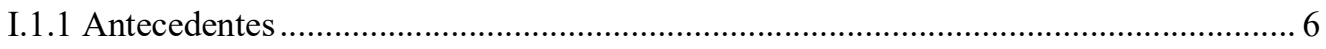

I.2 ¿DE CUANTA BIOMASA LIGNOCELULÓSICA DISPONEMOS? ............................... 10

I.1.2.1 Un tipo importante de biomasa lignocelulósica: los residuos forestoindustriales ... 11 I.3 COMPOSICIÓN QUÍMICA Y ESTRUCTURA DE LOS RESIDUOS FORESTALES . 16

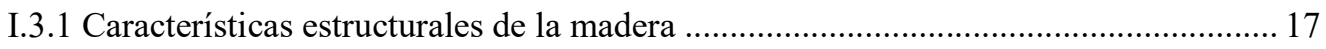

I.3.1.1 Ultraestructura de la pared celular .................................................................... 18

I.3.2 Composición química de los residuos forestales ..................................................... 19

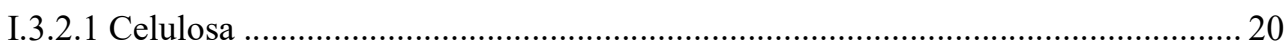

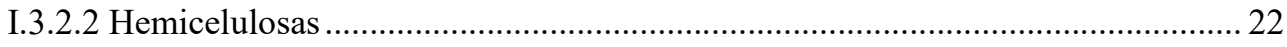

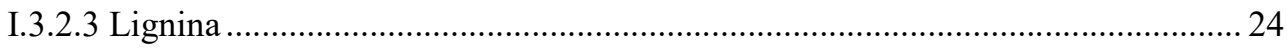

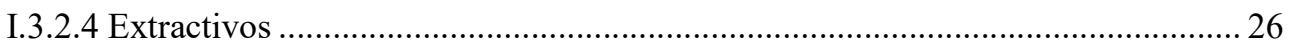

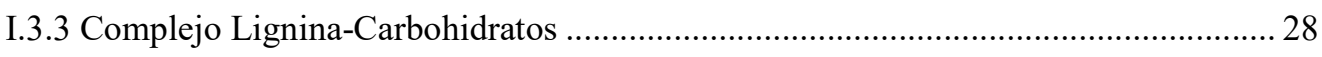

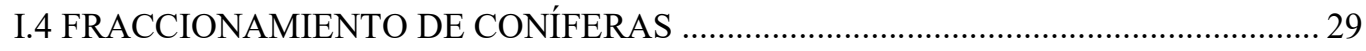

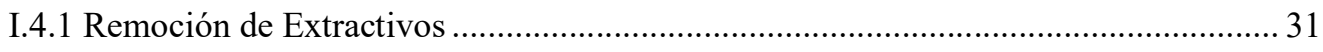

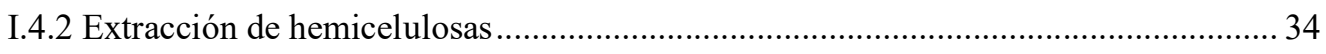

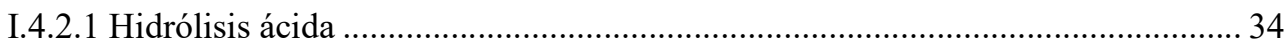

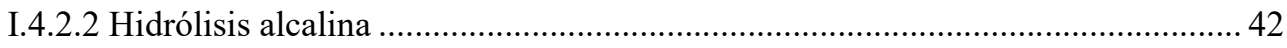

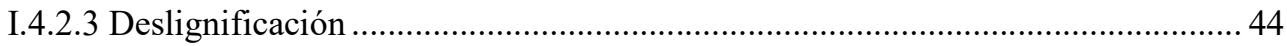

I.4.3 Cambios estructurales producidos durante el pretratamiento y su relación con la

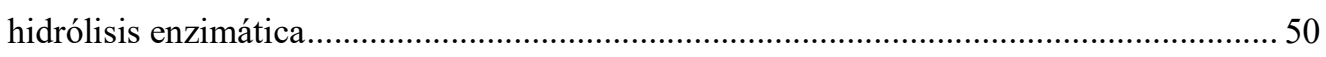

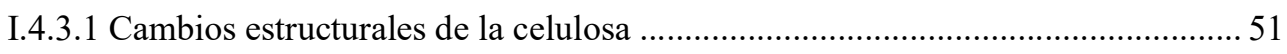




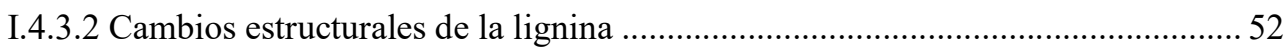

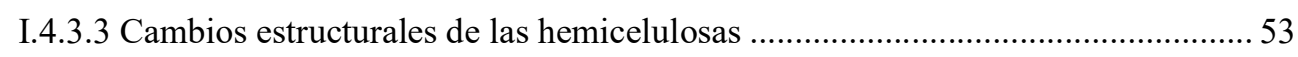

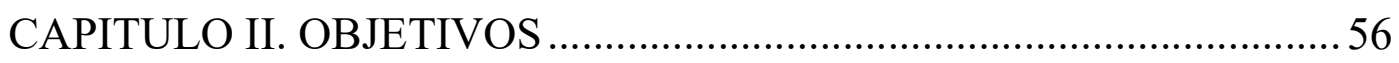

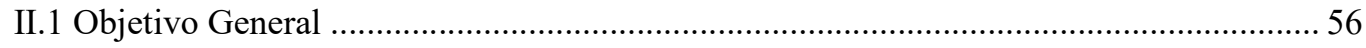

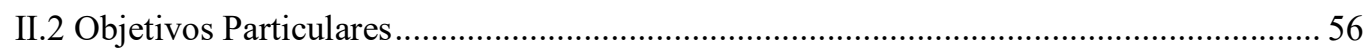

CAPITULO III. MATERIALES Y MÉTODOS .........................................58

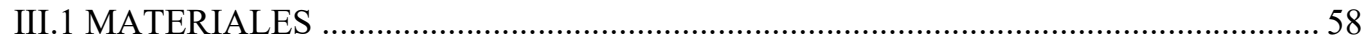

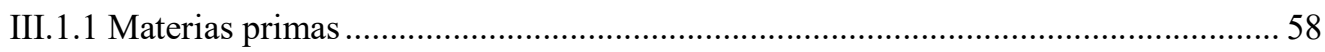

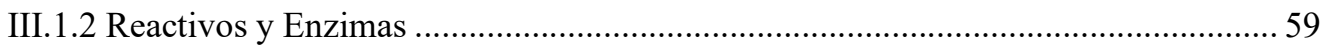

III.2 MÉTODOS DE CARACTERIZACIÓN......................................................................... 59

III.2.1 Caracterización química de muestras sólidas ............................................................59

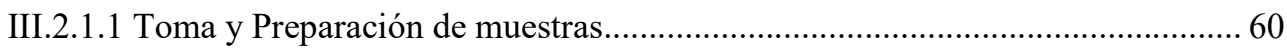

III.2.1.2. Determinación de sólidos totales y humedad .................................................. 61

III.2.1.3. Componentes extraíbles en agua y alcohol etílico ........................................ 61

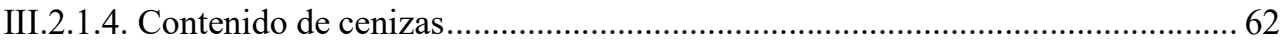

III.2.1.5. Determinación de carbohidratos estructurales y lignina ................................... 62

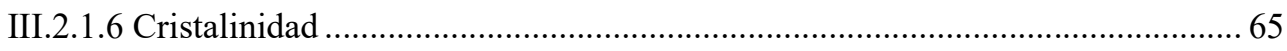

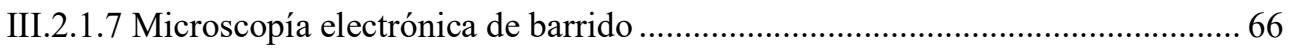

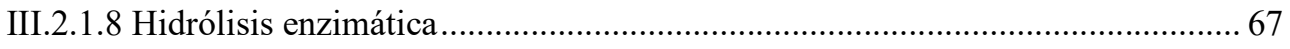

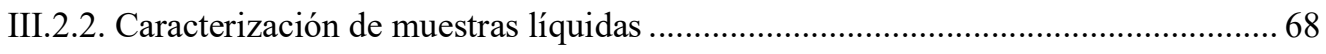

III.2.2.1. Cuantificación de azúcares, productos de degradación y ácidos orgánicos .....66 68

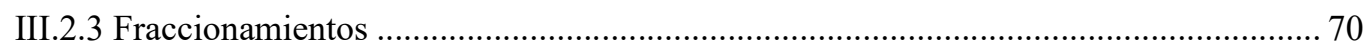

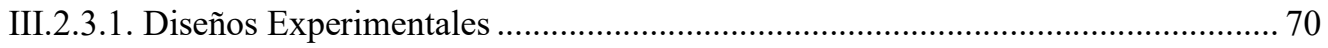

III.2.3.1.2 Optimización ...................................................................................... 74

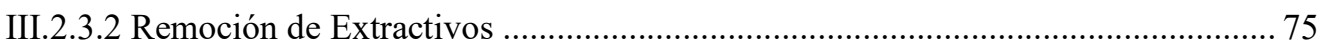

III.2.3.2.1 Determinación de álcali residual en el licor .................................................. 76

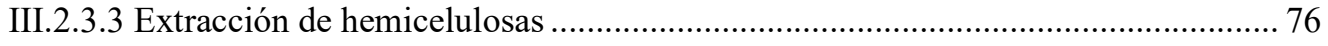

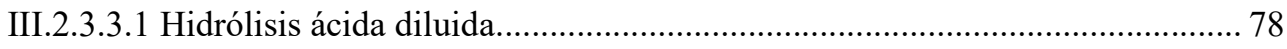


III.2.3.3.2 Explosión de vapor.

III.2.3.3.3 Tratamiento con ácido diluido de holocelulosa para determinación de

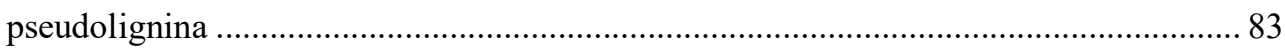

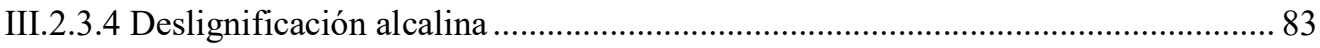

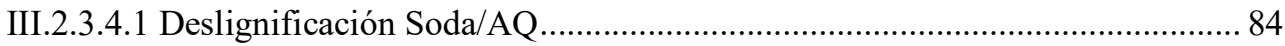

III.2.3.4.2 Deslignificación Organosolv alcalino ........................................................... 86

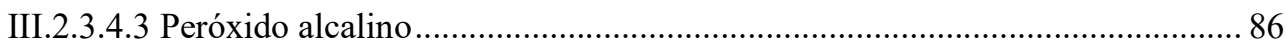

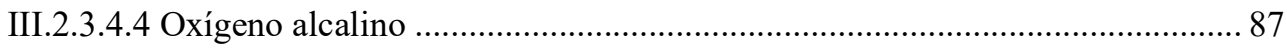

CAPÍTULO IV. RESULTADOS Y DISCUSIÓN .................................. 90

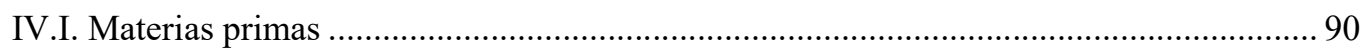

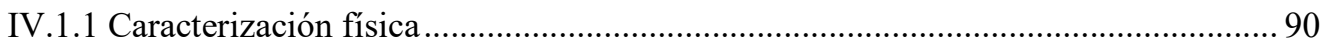

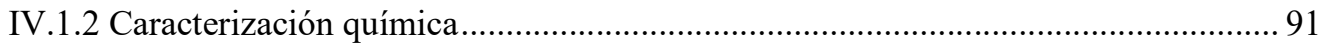

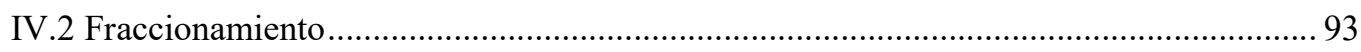

IV.2.1 Fraccionamiento alcalino: remoción de extractivos ................................................ 93

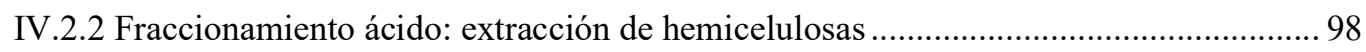

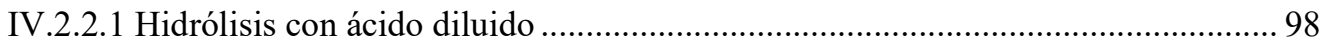

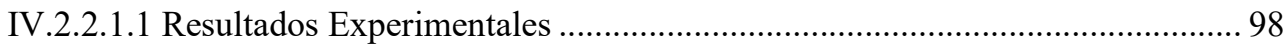

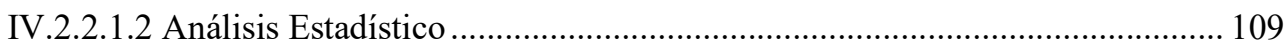

IV.2.2.1.3 Optimización estadística ………............................................................ 115

IV.2.2.1.4 Composición química del material solido pretratado................................... 118

IV.2.2.1.5. Hidrólisis enzimática.......................................................................... 121

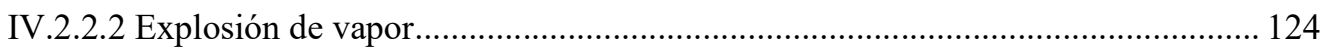

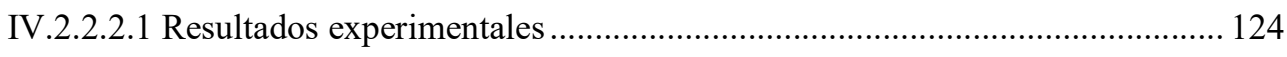

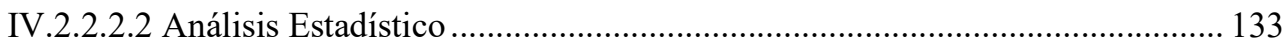

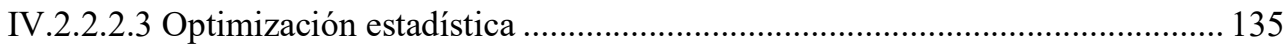

IV.2.2.2.4 Extracción de lignina mediante lavado alcalino........................................... 137

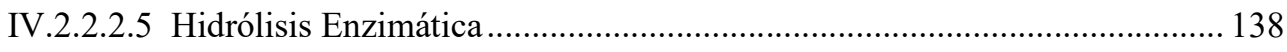

IV.2.3 Cambios estructurales de los materiales pretratados................................................ 140 
IV.2.3.1 Condensación de la lignina

IV.2.3.2 Cambios en la estructura del aserrín durante el fraccionamiento 143

IV.2.4 Balance de masa de la secuencia de fraccionamiento 145

IV.2.5 Deslignificación 149

IV.2.5.1 Deslignificación Soda/AQ 149

IV.2.5.2 Deslignificación Organosolv alcalino ……...................................................... 151

IV.2.5.3 Deslignificación con Peróxido de Hidrógeno alcalino........................................ 153

IV.2.5.4 Deslignificación con oxígeno alcalino ………………...................................... 154

IV.2.5.5 Hidrólisis Enzimática de Materiales Deslignificados .......................................... 156

IV.2.6 Propuesta de fraccionamiento para el aserrín de pino............................................... 158

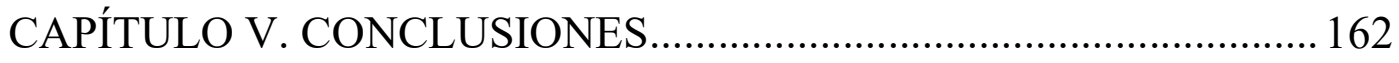

REFERENCIAS BIBLIOGRÁFICAS................................................... 167 


\section{NOMENCLATURA}

A: Energía de activación/Constante de los gases

A-EV: Aserrín tratado con explosión de vapor

A-EV-A: Aserrín tratado con explosión de vapor con un posterior lavado alcalino

APA: Aserrín pre-extraído en álcali

APA-EV: Aserrín pre-extraído en álcali y tratado con explosión de vapor

APA-EV: Aserrín pre-extraído en álcali y tratado con hidrólisis ácida diluida

APA-EV-A: Aserrín pre-extraído en álcali y tratado con explosión de vapor con un posterior lavado alcalino

AQ: antraquinona

Ara: arabinanos

ASTM: American Society for Testing and Materials

bs: sobre base seca

BTU: British Thermal Unit

C: celulosa

Cero sulfidez: sin agregado de azufre

CrI: Índice de Cristalinidad

DCC: Diseño de Experimentos Central Compuesto

DTPMA: sal pentasódica dietilentetraminpentacética

Ea: Energía de Activación

EV: Explosión de Vapor

Ext: extractivos

FPU: Unidades de papel de filtro

g/L: gramos/litro

Ga: galactanos

Gl: glucanos

GP: Grado de Polimerización

Factor H: Factor H que combina el tiempo y la temperatura 
H: hemicelulosas

HAD: Hidrólisis con ácido diluido

HE: Hidrólisis Enzimática

HMF: 5-Hidroximetilfurfural

HPLC: High Pressure Liquid Chromatography

IR: Detector de Índice de Refracción

IU: International Units

IUPAC: International Union of Pure and Applied Chemistry

k: velocidad relative de deslignificación

LD: Límite de detección

L/M: relación licor/madera

Lig: lignina

Log (R0): Factor de Severidad

Ma: mananos

Mr: masa molar del componente

NREL: American National Renewable Energy Laboratory

R: constante de los gases $(1.987 \mathrm{cal} / \mathrm{g} \mathrm{mol} \mathrm{K})$

sbi: sobre base inicial

SC: Severidad Combinada

SEM: Microscopía Electrónica de Barrido

SIFIP: Sistema de Información Foresto Industrial de la Provincia de Misiones

sli: sobre lignina inicial

Soda: hidróxido de sodio

t: tiempo

T: temperatura

USDA: United States Department of Agriculture

Xi: xilanos

W: peso 


\section{RESUMEN}

El cuidado del medio ambiente se ha transformado en un factor que agrega valor a la producción industrial, haciéndola más competitiva mediante la utilización de recursos renovables y tecnologías avanzadas. La biorrefinería forestal procesa biomasa lignocelulósica proveniente de la industrialización de la madera (aserrín, viruta, trozos de madera) para producir energía, productos químicos y biomateriales, en forma similar a las refinerías de petróleo. El aserrín de pino y eucalipto es uno de los principales desechos de la industrialización primaria de la madera. Esta industria es muy importante en la región Noreste de Argentina (Región NEA). Se estima que el 50\% de la madera industrialmente procesada se convierte en 2 millones de toneladas secas al año de residuos que no están siendo adecuadamente aprovechados.

La aplicación del concepto de biorrefinería involucra cuatro etapas básicas: fraccionamiento, purificación del sólido, separación y purificación de los componentes del líquido y elaboración de subproductos. El fraccionamiento consiste en la separación de los componentes principales de la biomasa en una forma química adecuada para que puedan ser aprovechados. Esta etapa constituye uno de los principales costos del proceso, y por lo tanto, el mayor obstáculo a superar es encontrar métodos eficientes y rentables de fraccionamiento.

La Hipótesis de trabajo es que se puede realizar el aprovechamiento integral de materiales lignocelulósicos, específicamente, de aserrín de pino de la región NEA, para obtener productos de alto valor, aplicando procesos de fraccionamiento rentables y de baja contaminación.

El objetivo general de esta tesis doctoral consiste en aplicar el concepto de biorrefinería a los residuos generados en la industrialización primaria de pino mediante el diseño y optimización de un proceso de fraccionamiento secuencial de la biomasa, para el aprovechamiento integral de todos los componentes del residuo.

Para esto se diseñó una secuencia de fraccionamiento de tres etapas: alcalina (remoción de extractivos) - ácida (extracción de hemicelulosas) - alcalina (deslignificación). El estudio de cada etapa involucró un diseño de experimentos para evaluar la influencia de la temperatura, tiempo y concentración de reactivos en el proceso. En vistas a la aplicación del material a la producción de bioetanol se evaluó la influencia de cada etapa sobre la hidrólisis enzimática.

Se realizó la optimización de la primera etapa alcalina suave para encontrar las condiciones que maximizan la remoción de extractivos en el aserrín y minimizan la disolución de los carbohidratos estructurales. El máximo rendimiento de extracción (91\% con respecto al contenido inicial) se logró a los $90^{\circ} \mathrm{C}, 5 \%$ bs (sobre base seca) de $\mathrm{NaOH}$ y 60 minutos. 
Se evaluaron dos tecnologías como alternativas de la etapa ácida de extracción de hemicelulosas: hidrólisis ácida diluida (HAD) y explosión de vapor (EV). Se llevó a cabo la optimización de ambas etapas para maximizar la remoción de azúcares hemicelulócicos minimizando la degradación de celulosa. La extracción de las hemicelulosas resulto más efectiva con el proceso de $\mathrm{EV}$, ya que se alcanzaron rendimientos más altos de remoción de hemicelulosas $\left(92\right.$ a $200^{\circ} \mathrm{C}$, $3 \%$ bs $\mathrm{H}_{2} \mathrm{SO}_{4}$ y $5 \mathrm{~min}$ ). En la hidrólisis con ácido diluido, el rendimiento máximo alcanzado fue de $57 \%$ con respecto al contenido inicial a $150^{\circ} \mathrm{C}, 30 \mathrm{~min}$ y $7,5 \mathrm{~g} / \mathrm{L} \mathrm{H}_{2} \mathrm{SO}_{4}$.

Con el objetivo de extraer la lignina y mejorar el rendimiento de la hidrólisis enzimática se evaluaron cuatro procesos deslignificantes: soda/antraquinona (soda/AQ), organosolv alcalino, peróxido de hidrógeno alcalino y oxígeno alcalino. El rendimiento de deslignificación obtenido con los procesos soda/AQ y organosolv alcalino fue superior al $60 \%$. Los procesos oxidativos (peróxido de hidrógeno y $\mathrm{O}_{2}$ ) no permitieron alcanzar un grado de deslignificación significativo.

Se evaluó el efecto de la secuencia de fraccionamiento sobre la hidrólisis enzimática (HE). La susceptibilidad de la celulosa a la hidrólisis enzimática no aumentó significativamente a pesar de la remoción de las hemicelulosas. El rendimiento de la HE del aserrín pre-extraído en álcali y tratado con HAD diluida fue de 7,5\% de glucosa a las $72 \mathrm{~h}$. El tratamiento con explosión de vapor permite alcanzar mayores rendimientos de glucosa en la HE (24\% a las $72 \mathrm{~h}$ ) pero continúa siendo bajo. La mejora de la digestibilidad enzimática de materiales tratados con EV es atribuida a tres factores principales: el incremento de área superficial causado por la fragmentación de las fibras, el incremento de la porosidad debido a la hidrólisis y remoción de las hemicelulosas y el incremento de la porosidad debido a la redistribución de la lignina

El máximo rendimiento (36\%) de la HE se alcanza posterior a la etapa con oxígeno a pesar del alto contenido de lignina de este material ( $44,2 \%$ bs de lignina) mientras que la degradación de celulosa es baja en comparación a los otros procesos de deslignificación.

En conclusión, la secuencia de fraccionamiento más adecuada para el aserrín de pino de acuerdo a los resultados de este trabajo, consiste en la aplicación de una etapa alcalina $\left(90^{\circ} \mathrm{C}, 1\right.$ h y $5 \%$ de $\mathrm{NaOH}$ sobre base seca) de desresinación, seguida de una etapa de explosión de vapor $\left(200^{\circ} \mathrm{C}\right.$, $3 \% \mathrm{H}_{2} \mathrm{SO}_{4}$ bs y $5 \mathrm{~min}$ ) para extraer las hemicelulosas y un post tratamiento con oxígeno en medio alcalino. El material lignocelulósico resultante tiene gran potencial para la producción de bioetanol dado su alto contenido de hexosas. En el marco de una biorrefinería, los componentes disueltos en los licores tendrían que ser separados y purificados para lo producción de subproductos. 


\section{CAPÍTULO I. \\ INTRODUCCIÓN}




\section{CAPITULO I. INTRODUCCIÓN}

\section{I.1 LA BIORREFINERÍA FORESTAL}

\section{I.1.1 Antecedentes}

En el último siglo, el petróleo, el gas natural y el carbón han sido la fuente más barata de energía y químicos, provocando una dependencia hacia los mismos del mercado energético mundial. Sin embargo sus reservas son finitas ya que se requieren millones de años para su reposición natural. El único recurso de carbono natural conocido, renovable y lo suficientemente abundante para ser utilizado como un sustituto de los combustibles fósiles es la biomasa (Klass, 1998).

En los últimos años y por analogía con las refinerías de petróleo, se ha ido desarrollando el concepto de biorrefinería que incluye una amplia variedad de estructuras productivas integradas con el fin de optimizar el procesamiento de la biomasa, haciéndolo más eficiente y minimizando los impactos ambientales que se originan a partir de los mismos (Trigo et al., 2011). El American National Renewable Energy Laboratory (NREL) ha definido el término biorrefinería como una instalación que integra procesos de conversión de biomasa y equipos para producir combustibles, energía y químicos a partir de biomasa (NREL, 2009).

La biomasa, a semejanza del petróleo, posee una composición química compleja sobre la base de cadenas carbonadas, por lo cual en una primera etapa es necesario separarla en grupos de moléculas intermediarias, para su utilización como materia prima para la industria química. Estas moléculas son subsecuentemente tratadas y procesadas para obtener subproductos. Debido a estas similitudes, muchos de los componentes químicos que se obtienen de los recursos fósiles también se pueden producir a partir de materias primas de origen renovable (Trigo et al., 2011). Una diferencia importante es el tamaño de estas industrias, ya que una refinería implica grandes plantas mientras que las biorrefinerías probablemente abarquen toda una gama de instalaciones de diferentes tamaños. En este contexto, varias bio-industrias pueden combinar sus flujos de materiales para lograr una utilización completa de la biomasa. Por ejemplo, el residuo de una industria es la principal materia prima de otra industria (Cherubini, 2010). Es decir, la escala productiva puede variar desde biorrefinerías relativamente pequeñas dedicadas a la producción de unos pocos insumos hasta conglomerados industriales de gran tamaño en los que se obtienen cientos de productos finales. 
La biorrefinería forestal utiliza como materia prima biomasa lignocelulósica proveniente de las plantaciones y de las industrias de la madera (chips, aserrín, viruta, corteza, ramas, $\operatorname{costaneros}^{1}$ ). La biomasa lignocelulósica presenta la ventaja de ser abundante, fácilmente disponible y es renovable. Sin embargo, poseen una composición compleja y heterogénea, y además pueden ser recalcitrantes $^{2}$ a los procesos de conversión (FitzPatrick et al., 2010).

El concepto de biorrefinería forestal surge inicialmente dentro de las fábricas de pulpa celulósica, debido a su necesidad de diversificación. Con una economía global y con el avance de la tecnología digital, esta industria se vio obligada a evolucionar desde una producción única a su combinación con la química sintética, la biotecnología y los procesos de obtención de nuevos materiales. En este contexto, la estrategia se dirige a la obtención de derivados con un mayor valor agregado, partiendo de criterios tecnológicos y de producciones flexibles, que utilicen los diferentes subproductos, y productos intermedios del proceso.

De acuerdo al grado de integración, las biorrefinerías se pueden clasificar como de primera generación, segunda generación y biorrefinerías avanzadas o de tercera generación. Las biorrefinerías de primera generación se centran en la producción de biocombustibles (etanol y biodiesel), a partir de materias primas como aceite de soja, almidón de maíz o caña de azúcar que son renovables pero son alimentos. El uso de alimentos para fines energéticos ha sido cuestionado desde el punto de vista ético y económico. Estas biorrefinerías no se encuentran diseñadas para hacer un uso eficiente de la biomasa, minimizar la utilización de energía y reciclar desechos de manera de optimizar el proceso económico. Requieren un uso de capital moderadamente intensivo, y una de sus principales desventajas consiste en que la fuente de biomasa que utiliza puede competir con la producción de alimentos. Por otra parte, tampoco no han sido diseñadas para la obtención de productos de alto valor y los principales subproductos que generan son derivados de bajo costo para alimentación animal. Las biorrefinerías de segunda generación hacen uso de la biomasa lignocelulósica. Para obtener la fracción celulósica a ser empleada en la producción de bioetanol y micro/nano celulosa, el material ligncelulósico debe ser tratado para extraer la mayor parte de la lignina y las hemicelulosas. Para que el proceso sea rentable se deben producir subproductos a partir de la lignina y las hemicelulosas. La principal ventaja de esta clase de biorrefinería es la recuperación de la fuente más abundante de carbono renovable en el planeta. Este tipo de biorrefinerías también optimiza la utilización de energía y el reciclado de residuos, lo que implica descensos en los costos de producción. Las biorrefinerías de tercera generación,

\footnotetext{
${ }^{1}$ Costaneros: parte de la biomasa leñosa que quedan al aserrar longitudinalmente una troza y que presenta en uno de los lados la superficie redondeada primigenia del árbol, total o parcialmente, con o sin corteza (FAO, 2015).

2 La recalcitrancia es la propiedad de la biomasa (lignocelulósica) de resistir al pre-tratamiento (generalmente con procesos termoquímicos severos para remover la lignina y modificar la estructura de las fracciones de celulosa/hemicelulosa de modo de facilitar la obtención de etanol) (ArgenBio, 2011)
} 
que están aún en fase de desarrollo, utilizan indistintamente recursos de la biomasa de la agricultura o de los bosques para producir múltiples tipos de productos como etanol, combustibles, agroquímicos y plásticos y logran un uso eficiente de los deshechos (Trigo et al., 2011).

Las biorrefinerías son clasificadas en dos diferentes plataformas para la generación de diferentes productos. La "plataforma de azúcares" que está basada en procesos de conversión bioquímica y se centra en la fermentación de los azúcares extraídos de la biomasa. La "plataforma syngas o termoquímica" que se basa en procesos de conversión termoquímica y se centra en la gasificación de la biomasa y subproductos de procesos de conversión (Kamm et al., 2006).

La biorrefinería ofrece un amplio rango de productos potencialmente atractivos, desde biocombustibles a químicos especiales. En adición a los commodities tradicionales, el NREL ha definido doce productos químicos bases (bloques de construcción o building blocks) que pueden ser obtenidos de los carbohidratos, ya sea a través de conversiones químicas o biológicas. Los "building blocks" son moléculas con múltiples grupos funcionales que poseen el potencial de ser transformados en nuevas familias de moléculas útiles. Los productos finales pueden ser utilizados por diferentes sectores industriales como textiles, salud e higiene. Las doce unidades básicas basadas en azúcares son: 1,4-diácidos (succínico,fumárico y málico), ácido furano- 2,5dicarboxílico, ácido 3-hidroxipropiónico, ácido aspártico, ácido glucárico, ácido glutámico, ácido itacónico, ácido levulínico, 3-hidroxibutirolactona, glicerol, sorbitol y xilitol/arabinitol (Werpy \& Petersen, 2004).

El enfoque de biorrefinería implica procesos multietapas en los cuales la primer etapa, seguido de la selección de la materia prima, es el fraccionamiento para separar los principales componentes del material y hacerlo más accesible para el procesamiento posterior. Seguido del fraccionamiento, las fracciones sólidas obtenidas son purificadas y los componentes de las fracciones líquidas son separados y purificados. Luego, los componentes de la biomasa son sometidos a procesos químicos y/o biológicos para la elaboración de subproductos. Las salidas de la primera etapa (químicos especiales o azúcares reductores) pueden ser posteriormente convertidos a buildings blocks para un posterior procesamiento. Adicionalmente, las fracciones obtenidas pueden ser convertidas a polímeros, biocombustibles y materiales compuestos, como se muestra en la Figura I.1 (FitzPatrick et al., 2010). 


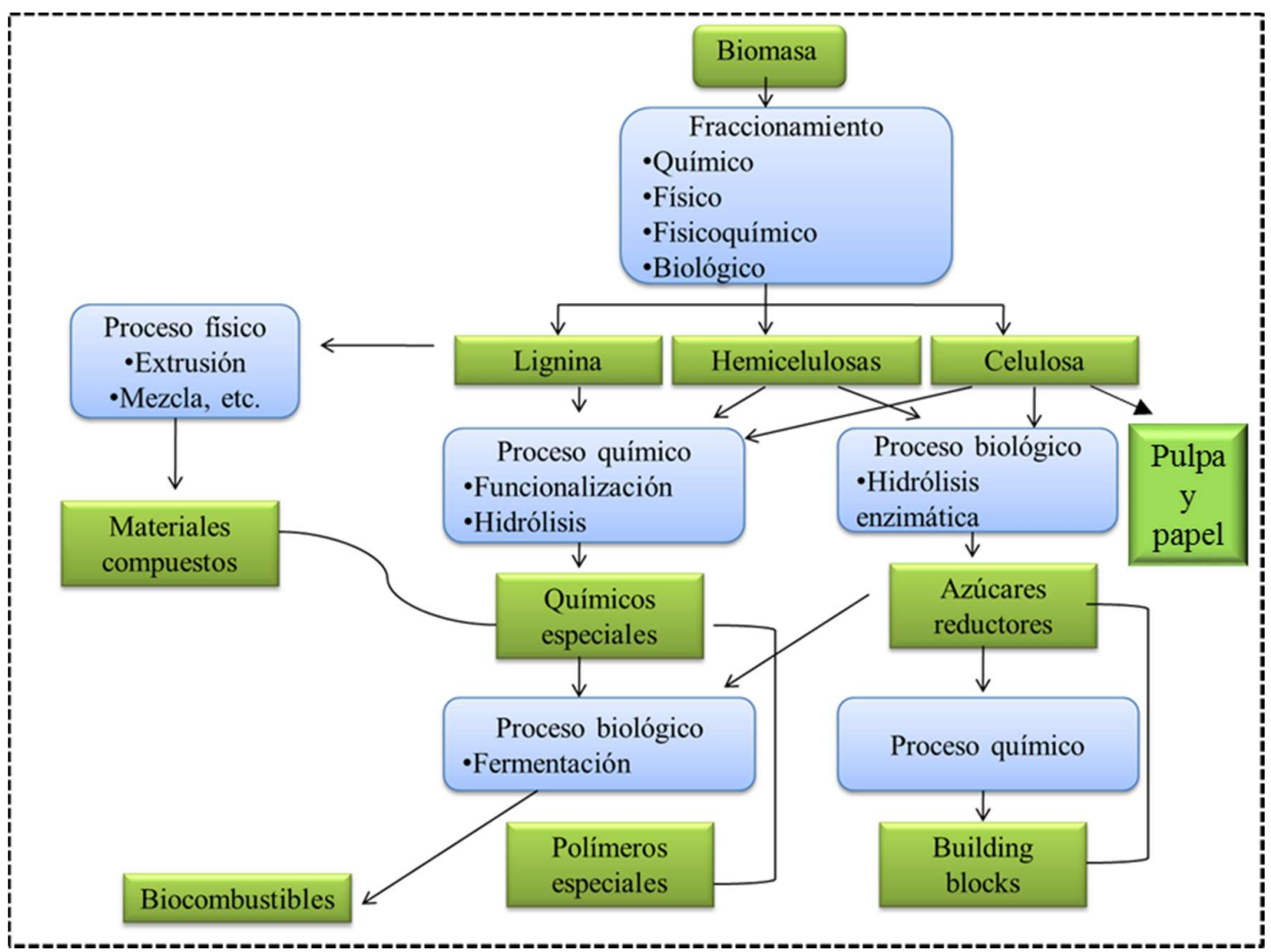

Figura I.1. Esquema del concepto de biorrefinería. Adaptado de (FitzPatrick et al., 2010)

La biorrefinería forestal es una oportunidad para las industrias de pulpa y papel para diversificar su gama de productos y generar ingresos a partir de nuevos productos aprovechando con mayor eficiencia la materia prima. La tecnología actual utiliza una estrategia destructiva para obtener un solo componente relativamente puro (celulosa) de la madera. Las otras fracciones son severamente degradadas y utilizadas para generación de energía de bajo valor agregado. La biorefinería provee una alternativa de aprovechamiento integral del material mediante el fraccionamiento del mismo en sus principales componentes a través de tratamientos secuenciales para dar corrientes separadas que pueden ser utilizadas para diferentes aplicaciones (Liu, 2010). Por ejemplo, las hemicelulosas típicamente disueltas en el pulpado y quemadas en la caldera de recuperación pueden ser utilizadas para la producción de productos de alto valor y la lignina recuperada para producir gas de síntesis que luego es quemado en una caldera de gas convencional y posteriormente refinado a biocombustibles o vendido en el mercado. La celulosa se blanquea y se utiliza para la producción de papel (Ostle, 2006).

El uso de una materia prima sustentable no es suficiente para asegurar el futuro de la biorrefinería, sino que depende además del desarrollo de métodos y técnicas que produzcan un impacto mínimo en el medio ambiente y que los productos finales sean ecológicos y sustentables. La generación 
de residuos sólidos, líquidos y gaseosos debe ser minimizada. Estos objetivos pueden ser alcanzados de dos maneras: usando todos los componentes de la biomasa para la producción de un amplio espectro de productos químicos en un solo lugar, o mediante la creación de bio-clusters, donde el intercambio de flujo de materiales entre diferentes plantas es promovido en orden de transformar el residuo de una planta en la principal materia prima de otra planta (Cherubini, 2010).

Las principales ventajas de la biorrefinería son (Rojas et al., 2006):

1. Aumento de la competitividad: productos con valor agregado y propiedades equivalentes a las que se obtendrían usando química convencional y química basada en el petróleo; incremento en productividad industrial, competitividad, empleo e ingreso; diversificación de las materias primas y de las fuentes de energía.

2. Desarrollo sustentable, beneficios para el ambiente, y la salud: materias primas renovables y que se constituyen en sumideros de $\mathrm{CO}_{2}$; balance global de $\mathrm{CO}_{2}$ más favorable; residuos fácilmente biodegradables; industria basada en el crecimiento sostenible de los recursos.

3. Beneficios sociales para las comunidades rurales y urbanas: incremento del valor agregado de la materia prima local; aumento del empleo, ingresos, mejora de la calidad de vida; incentivos para el mantenimiento del medio agrícola y forestal; mantenimiento de la población en el medio rural.

\section{I.2 ¿DE CUANTA BIOMASA LIGNOCELULÓSICA DISPONEMOS?}

La biomasa lignocelulósica es la fuente orgánica más abundante en la Tierra, con una producción anual en la biosfera de aproximadamente $1,7 * 10^{13}$ toneladas métricas (Klass, 1998). Los bosques cubren cerca del $9,5 \%$ de la superficie de la tierra o $32 \%$ de la superficie terrestre y representan el $89,3 \%$ de la biomasa total en pie, produciendo $7,3 * 10^{12}$ toneladas métricas o el $42,9 \%$ de la producción de biomasa total anual generada en los distintos ecosistemas del planeta. En términos energéticos, la cantidad sintetizada por los bosques es $10^{24} \mathrm{~J} / \mathrm{año}$, lo cual es equivalente a más del doble del consumo de energía primaria total mundial de aproximadamente $4,6 * 10^{25}$ cuatrillones de BTU en 2005 (Liu, 2010). 


\section{I.1.2.1 Un tipo importante de biomasa lignocelulósica: los residuos forestoindustriales}

La biomasa forestal es carbono neutral, es decir, utilizando material forestal no se producirá un desequilibrio en el ciclo de vida de las forestaciones. El dióxido de carbono se extrae de la atmósfera para el crecimiento de las plantas, mientras que la plantación, el manejo, la conversión de biomasa en productos, la utilización y descomposición de los mismos producen dióxido de carbono (Liu, 2010).

La superficie boscosa de Argentina consiste en unos 33 millones de hectáreas de bosques nativos y más de 1,1 millones de hectáreas forestadas de monte implantado según datos del año 2005. Respecto al bosque implantado, un $58,9 \%$ de la extensión, corresponde a plantaciones de coníferas, un $24,9 \%$ de eucaliptus, un $9,8 \%$ de salicáceas y el $6,4 \%$ restante de otras especies. En la Mesopotamia Argentina se concentra el $80 \%$ de la superficie forestada del país, donde un $66 \%$ de las forestaciones corresponde a las provincias de Misiones y Corrientes (Figura I.2.a) (Schwarz, 2010). A su vez, el Ministerio de Agricultura de la Nación estima que el país cuenta con 20 millones de hectáreas aptas para forestación, por lo que, aun cuando el sector ya haya registrado un crecimiento exponencial en los últimos años, se encontraría todavía muy lejos de su techo productivo.

La producción primaria de rollos extraídos de bosques implantados tiene dos principales destinos: la transformación mecánica (principalmente aserraderos) y la transformación química (pulpa celulósica, papel y cartón). La extracción de madera implantada fue de casi 5 millones de toneladas durante el año 2011 (53\% del total nacional) (Figura I.2.b), siendo la principal protagonista la extracción de coníferas (pino y araucarias) (Schwarz, 2010). 


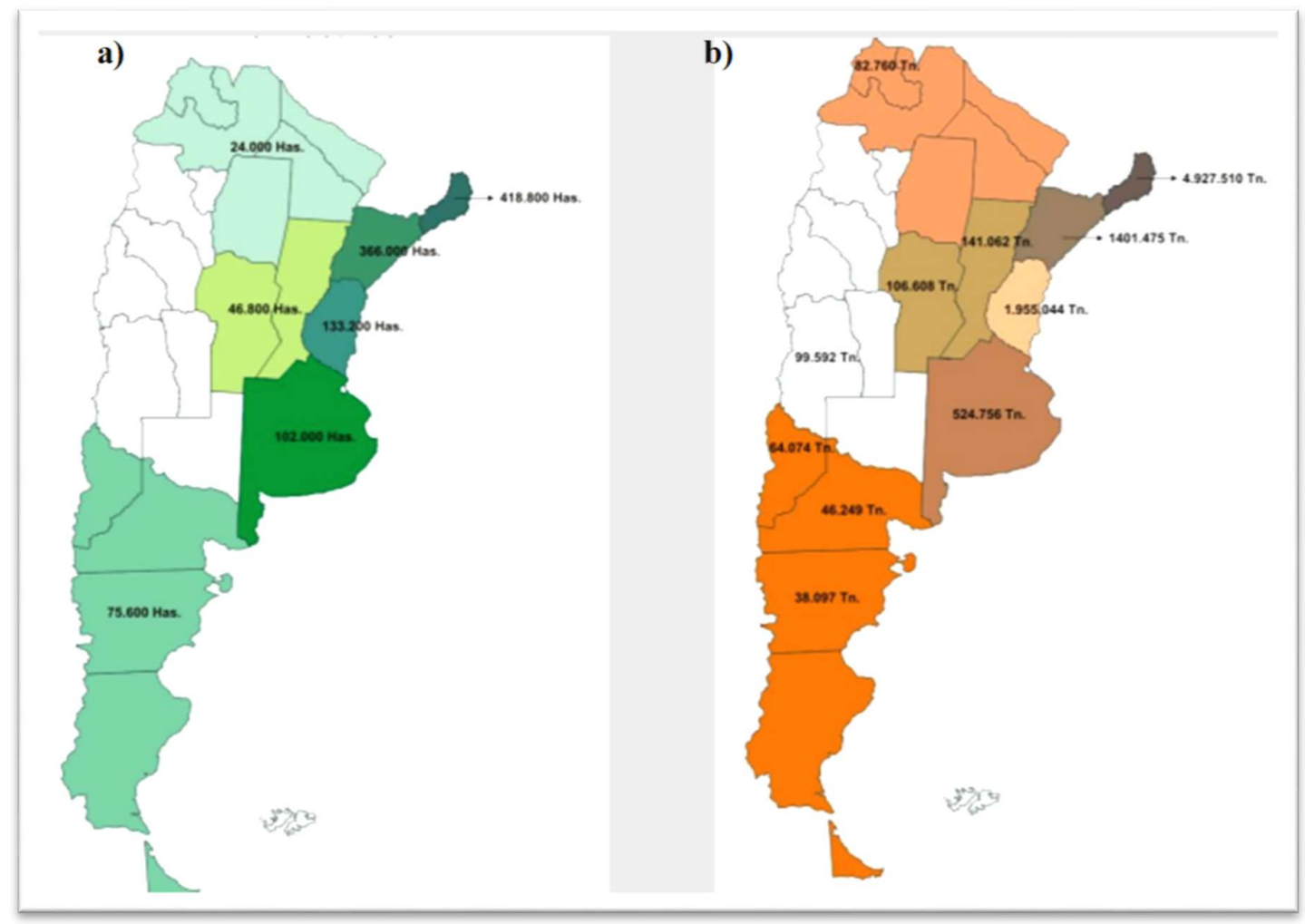

Figura I.2. (a) Hectáreas forestadas por provincia (2007). (b) Extracción de rollos de madera implantada (2011) (Schwarz, 2010)

En Misiones, se contabilizaron 365 mil hectáreas de bosques implantados, en donde el 83\% corresponde a pino, $7 \%$ eucalipto, un 4,5\% a araucaria y el restante a otras especies (Figura I.3). La existencia total de madera en Misiones alcanzó volúmenes de 53 millones de $\mathrm{m}^{3}$, de los cuales el $70 \%$ se encuentra en la zona oeste de la provincia y el resto distribuidos en porcentajes iguales en el este y centro-sur de Misiones (SIFIP, 2009). 


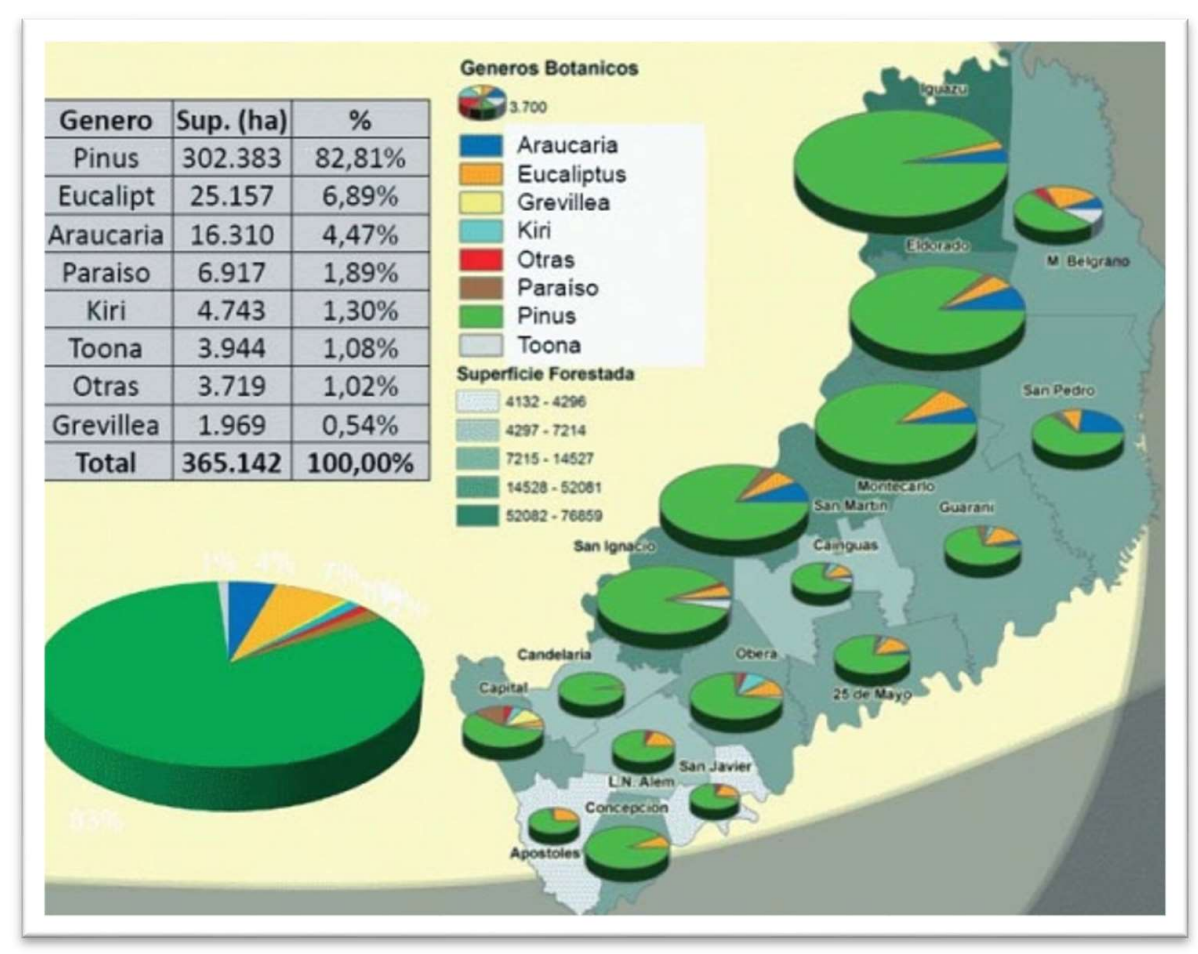

Figura I.3. Superficie de bosques implantados por género en Misiones (SIFIP, 2009)

En la provincia operan más de 900 establecimientos que procesan la madera de diversas formas (actividades celulósico-papeleras, aserraderos, laminadoras, fábricas de tableros, carpinterías de obra, remanufactura, producción de envases, fábrica de muebles y partes, impregnadoras de maderas, productores de leña y carbón y diversos establecimientos artesanales). La Figura I.4 indica la producción total mensual de madera aserrada y de remanufactura, que suman un total de $195.701 \mathrm{~m}^{3}$ por mes. Salvo unas pocas industrias de gran escala productiva, los establecimientos restantes del sector, son de muy pequeña dimensión y con serias deficiencias tanto en materia tecnológica como en aspectos organizativos y de información. El sector también es relevante para la provincia en materia de empleo ya que ocupa directamente alrededor de 30.000 personas en sus distintas actividades (viveros, plantaciones, extracción de rollizos, industrialización y transporte de productos de la madera).La importancia económica del sector foresto-industrial misionero es del orden del 15\% del PIB provincial. Si la comparación se efectúa respecto a los sectores productores de bienes, su importancia asciende al 50\% (Izurieta, 2004). 


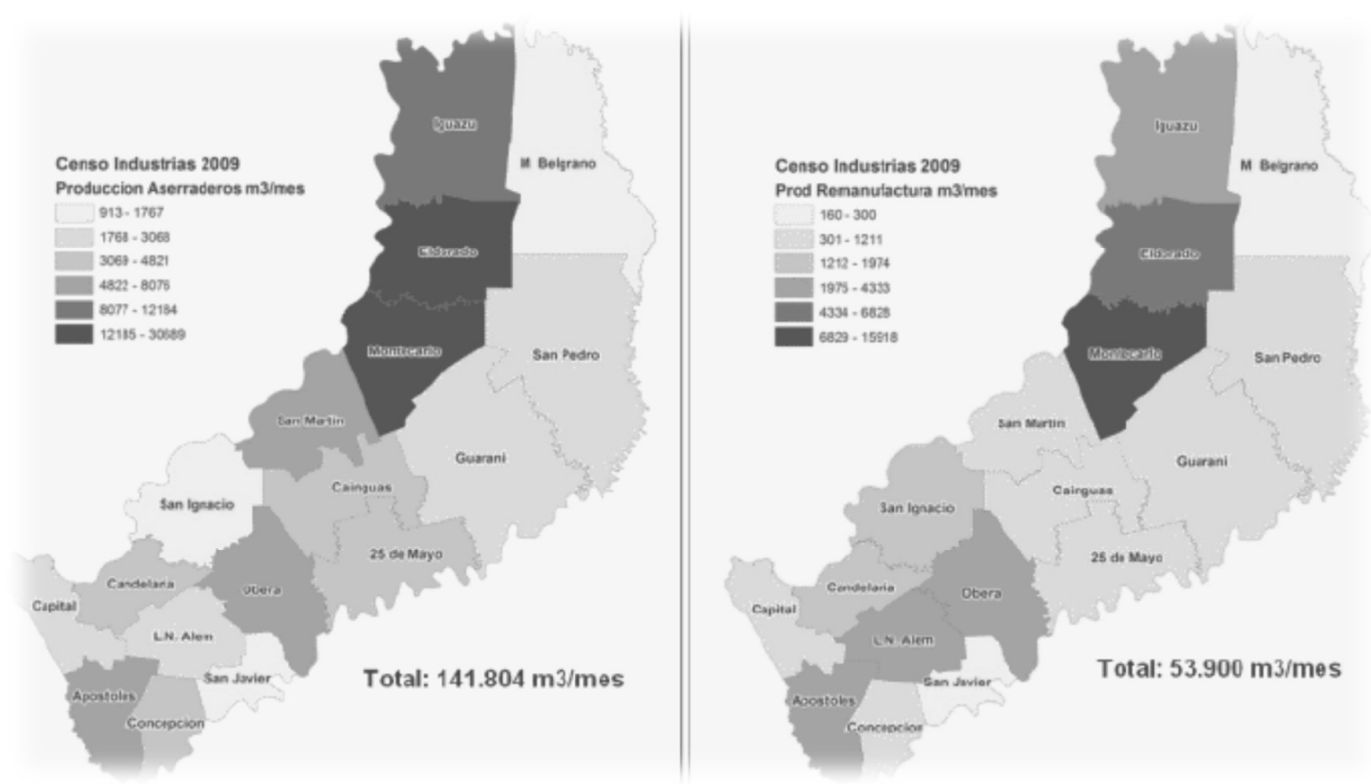

Figura I.4. Nivel de producción de madera aserrada y remanufactura en Misiones ( $\mathrm{m}^{3} / \mathrm{mes}$ ) (SIFIP, 2009)

Por sus características en cuanto a rendimientos, la industria forestal es generadora de una alta cantidad de residuos. En la figura I.5 puede verse un ejemplo de rendimiento del aserrado y fabricación de molduras de pino. En la primera transformación de la madera, se produce $41.8 \%$ de tabla seca y cepillada, hasta llegar a un rendimiento de producto final (molduras y tableros alistonados) de poco menos del 30\% respecto del rollizo con corteza. Esto demuestra la gran cantidad de residuos que genera el proceso productivo (Fahler, 2012). 


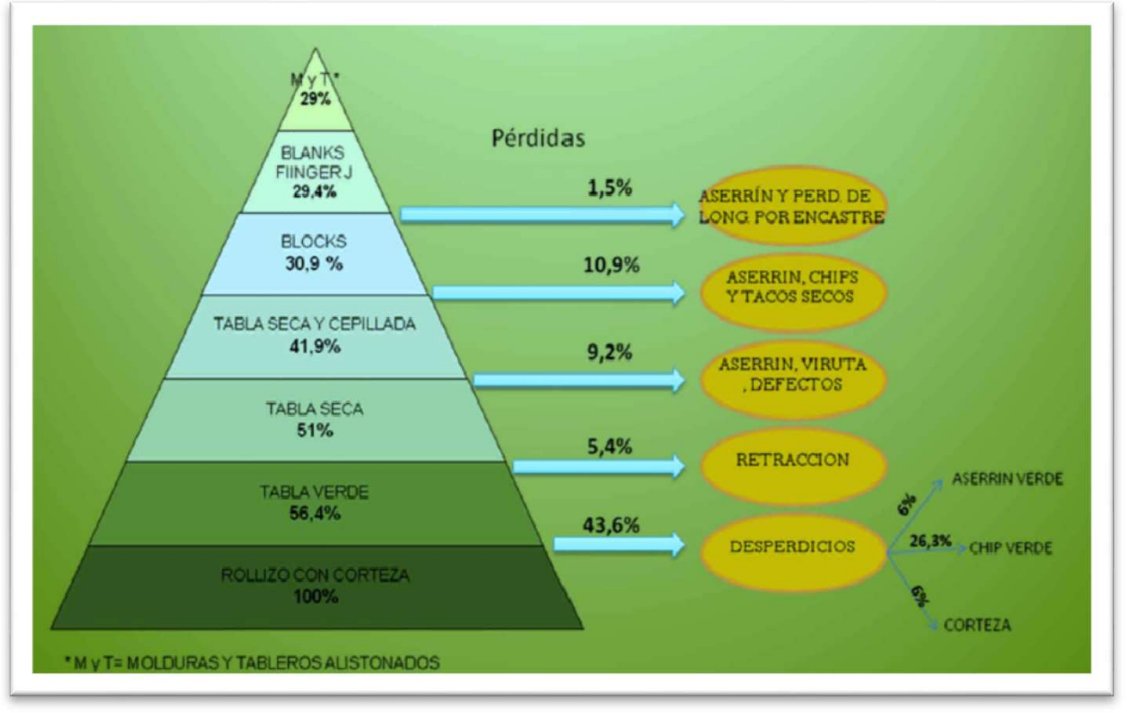

Figura I.5. Rendimiento del aserrado (Fahler, 2012).

Los residuos forestoindustriales constituyen recursos naturales renovables disponibles en grandes cantidades y a bajo costo. El aserrín de eucalipto y pino se encuentran entre los desechos más importantes de la elaboración primaria de la madera en la región NEA de la Argentina, la cual se constituye en una de las principales industrias de Formosa, Chaco, Corrientes y Misiones. Estos residuos no se aprovechan adecuadamente y su acumulación contribuye con la contaminación del entorno. Su único uso directo hasta el momento se basa en su valor energético tal cual. El tratamiento de estos residuos consume recursos en gestión, tratamiento y eliminación, siendo imperativo buscar una solución al permanente peligro de incendios que produce su acumulación. La contaminación ambiental generada por la quema incontrolada de estos residuos, preocupa a los pobladores de las localidades circundantes ya que afecta su calidad de vida y puede producir accidentes, como el incendio de las líneas de alta tensión. En este contexto, el proyecto de Ley XVI 106 de la Provincia de Misiones prohíbe a partir del 2012 la quema incontrolada de residuos biomásicos de la forestoindustria con el objetivo de promover el aprovechamiento múltiple y racional de los mismos, a fines de valorar el recurso renovable, disminuir las emisiones contaminantes y mejorar la calidad de vida de la población.

De acuerdo con el censo foresto industrial llevado a cabo en Misiones en el año 2009, la disponibilidad teórica de los subproductos de la industria de la madera alcanzo 2.1 millones de toneladas anuales. Los distintos tipos de subproductos se muestran en la Figura I.6 (Uasuf \& Hilbert, 2012). Como se aprecia en la figura, del total de residuos generados, únicamente el 1,8\% se utiliza para generar energía eléctrica y el $6,4 \%$ se quema en calderas para la generación de vapor. El mayor porcentaje se comercializa a las papeleras de la zona. Un 10,3\% se quema bajo 
una combustión no controlada y un $9,5 \%$ se desecha. Por lo tanto, se podría estimar que hay una disponibilidad del 19,8\% del total de los residuos generados en la provincia que no están siendo adecuadamente aprovechados, lo que equivale a 416.096 toneladas al año de biomasa forestal.

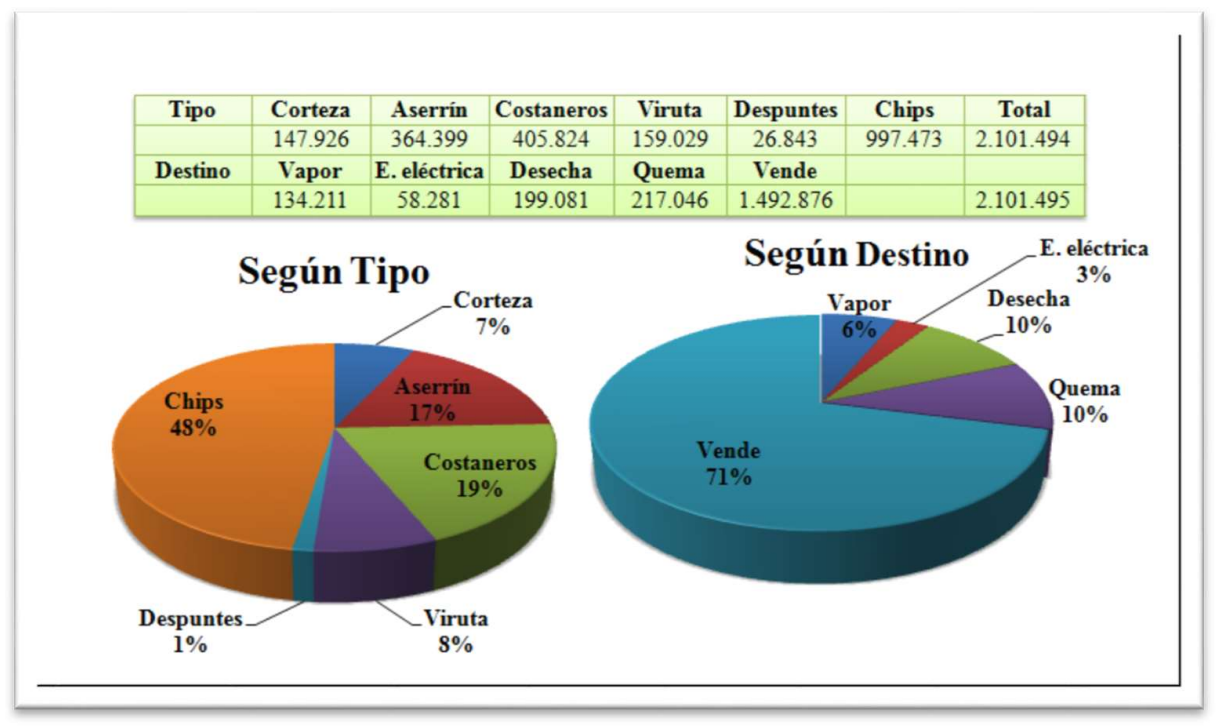

Figura I.6. Residuos forestoindustriales según tipo y destino. Adaptado de (Uasuf \& Hilbert, 2012)

Los planes de mejora de la competitividad del gobierno provincial están orientados a la integración de la industria de productos forestales en clusters para lograr el uso integral de la madera. El cluster forestal incluye la forestación, actividades de transformación primaria como aserrío, chapas, tableros, pulpa celulósica, actividades de transformación secundaria como carpintería, mobiliaria, papel y cartón, y finalmente comercialización, actividades de suministros complementarios, de bienes de equipamiento y servicios de apoyo. La biorrefinería es una cadena importante de estos cluster forestales, ya que procesa uno de los principales subproductos de la industria forestal: los residuos generados en la cadena de valor.

\section{I.3 COMPOSICIÓN QUÍMICA Y ESTRUCTURA DE LOS RESIDUOS FORESTALES}

La estructura, la organización en la pared celular y las reacciones de los principales componentes de la madera son de importancia fundamental para la comprensión de los aspectos químicos de la 
madera y su reactividad durante el procesamiento. En el futuro, la aplicación del concepto de biorefinería a partir de materiales lignocelulósicos y el progreso en el desarrollo de nuevos productos de alto valor de la madera dependerá en gran medida de un conocimiento detallado de cómo los elementos de las fibras interactúan en el material biológico.

\section{I.3.1 Características estructurales de la madera}

La madera es un material heterogéneo formado por un conjunto de células especializadas. El tronco está compuesto histológicamente de tres partes: xilema (sostén, almacenamiento, conducción), cambium (crecimiento) y la corteza (conducción, protección). Una sección transversal de un tronco revela las diferentes partes del tallo (Figura I.7). Desde el exterior del árbol hacia el interior están la corteza exterior, corteza interior, cambium vascular, albura, duramen, y la médula. La corteza interior viva es una capa delgada de tejidos de color claro en la cual hay un movimiento ascendente y descendente de carbohidratos que se realiza a través de los tubos cribosos y radios leñosos y la corteza exterior muerta es de color más oscuro debido a la presencia de células muertas y por lo tanto no tienen funcionamiento fisiológico. Los tejidos que van hacia el interior de la capa del cambium (sección interior) se les conoce como madera y está formado por traqueidas, radios y parénquima axial. La albura (sapwood) es la madera que se va agregando al árbol año tras año y tiene como finalidad conducir la savia (traqueidas), soportar la copa del árbol y almacenar alimento de reserva (parénquima). El duramen (heartwood) es la capa más interna y su función es sólo de soporte mecánico (Mogollón et al., 2008). 


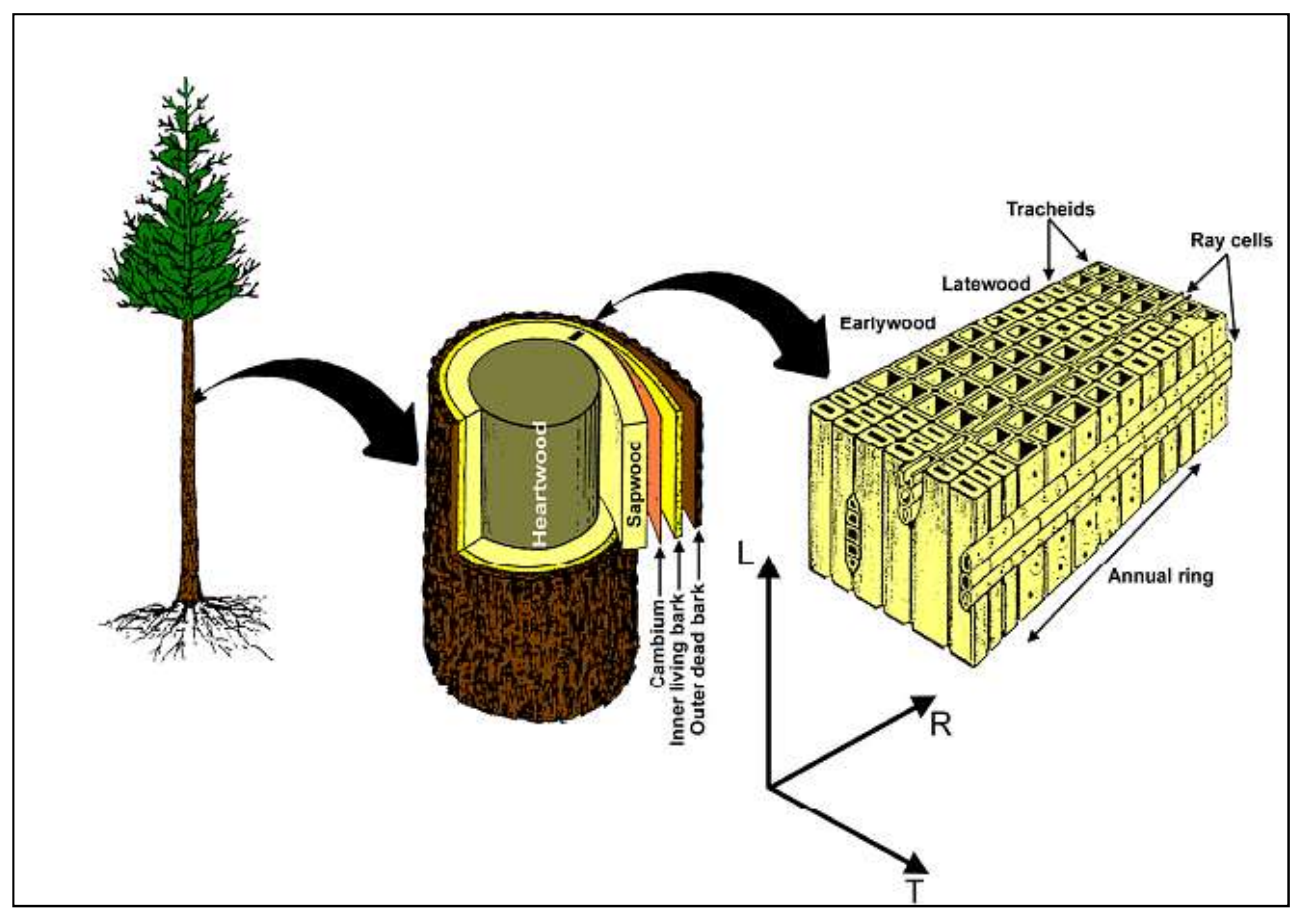

Figura I.7. Ilustración esquemática de la estructura morfológica de una conífera y las tres direcciones principales de la madera: longitudinal (L), radial (R) y tangencial (T) (Fahlén, 2005)

\section{I.3.1.1 Ultraestructura de la pared celular}

Un modelo generalizado de la organización típica de la pared celular se muestra en la Figura I.8. La celulosa forma un esqueleto rodeada por las hemicelulosas (matriz) y lignina (incrustante). El elemento más pequeño que conforman las cadenas de celulosa se denomina fibrila elemental con un diámetro de aproximadamente $3,5 \mathrm{~nm}$. La siguiente unidad morfológica más grande son las microfibrilas que se componen de un agregado de fibrilas elementales rodeados por cadenas más cortas de hemicelulosas. El diámetro de las microfibrilas es aproximadamente de 10 a $30 \mathrm{~nm}$. Las microfibrilas forman las fibrilas entre las cuales están depositadas la lignina y las hemicelulosas (Koch, 2006). 


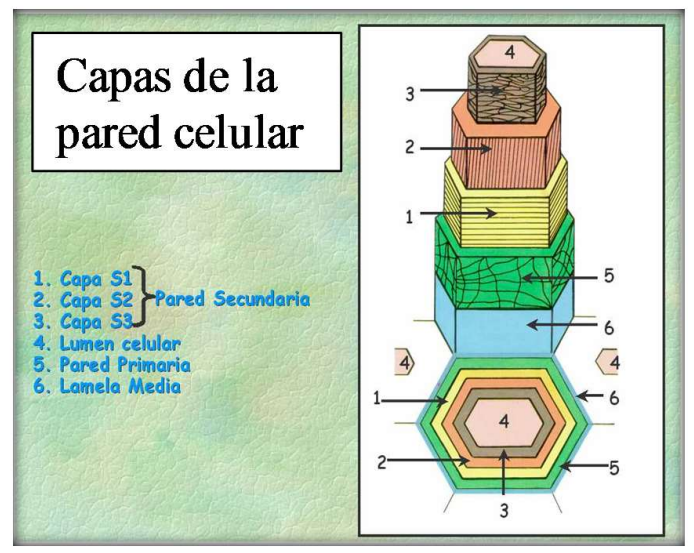

Figura I.8. Organización de la pared celular (UPV, 2015)

La pared celular está constituida por varias capas: lámina media, pared primaria, pared secundaria y lumen. Estas capas difieren una de otra con respecto a su estructura y composición química.

La lámina media está localizada entre las células y tiene la función de unir las células entre sí. Está compuesta por sustancias pécticas y lignina. La pared primaria es una capa fina $(0,1$ a 0,2 $\mu \mathrm{m}$ de espesor), consistente de celulosa, hemicelulosas, pectinas, proteínas y alto contenido de lignina. Las microfibrilas de celulosa forman una red irregular en la parte exterior de la pared primaria y en el interior están orientadas perpendicularmente al eje axial. La pared secundaria consiste de tres capas: capa interior (S1), la capa media (S2) y la capa exterior (S3). La pared secundaria $\mathrm{S} 1$ es fina $\left(0,2-0,3 \mu \mathrm{m}\right.$ de espesor) y las microfibrilas tienen un ángulo de $50-70^{\circ} \mathrm{C}$ con respecto al eje de la fibra. La S2 constituye la mayor porción de la pared celular, su espesor es de $1 \mu \mathrm{m}$ (madera temprana) a $5 \mu \mathrm{m}$ (madera tardía) en coníferas y el ángulo microfibrilar varía entre $5-10^{\circ}$ (madera tardía) y $20-30^{\circ}$ (madera temprana). Finalmente, la pared secundariaS3 es una capa fina (0.1 $\mu \mathrm{m}$ de espesor) con un ángulo fibrilar entre 50-90º (Sjöström, 1993).

\section{I.3.2 Composición química de los residuos forestales}

Los materiales leñosos son clasificadas generalmente como coníferas y latifoliadas. Estos grupos difieren tanto es sus características físicas como químicas. Las coníferas o softwoods son maderas de fibra larga y las latifoliadas o hardwoods son maderas de fibra corta. La composición química de los residuos forestales es variable dependiendo de la especie y de la región de la cual provienen y entre los principales componentes se encuentran la celulosa (35-50\%), hemicelulosas (20-35\%), lignina $(10-25 \%)$ y sustancias extractivas $(2-10 \%)$ Generalmente, las coníferas tienen mayor contenido de lignina que las latifoliadas (Alén, 2000), (Fengel, 1989). 
En Misiones, las principales coníferas implantadas son el pino elliottii y pino taeda, y en cuanto a las latifoliadas el eucaliptus grandis. Estas especies presentan diferencias químicas y estructurales. La composición química de las principales especies implantadas en Misiones se presenta en la Tabla I.1. Los residuos de aserraderos presentan, en general, mayor tenor de extractivos que las maderas papeleras. Esto se debe a que las especies no son las mismas y la edad de los árboles destinados a aserrado es mayor (Area \& Vallejos, 2012).

Tabla I.1. Composición química de maderas implantadas en Misiones (\%, g/100 de materia prima en base seca) (Area \& Vallejos, 2012).

\begin{tabular}{|l|cc|cc|c|}
\hline & \multicolumn{2}{|c|}{ Zona Norte } & \multicolumn{2}{c|}{ Zona Sur } & \\
\hline & Pino elliotti & Pino taeda & Pino elliotti $\quad$ Pino taeda & $\begin{array}{c}\text { Eucalyptus } \\
\text { grandis }\end{array}$ \\
\hline Hemicelulosas & 32,14 & 29,02 & 26,79 & 28,37 & $22-25$ \\
Celulosa & 41,5 & 42,76 & 44,06 & 44,37 & $42-48$ \\
Lignina Total & 30,77 & 29,24 & 28,62 & 27,74 & $27-30$ \\
Ext. Alcohol-Benceno & 4,04 & 3,08 & 1,84 & 1,87 & $1,5-2,5$ \\
Ext. Agua caliente & 2,42 & 2,42 & 3,94 & 2,79 & $1,5-2,5$ \\
Referencia & \multicolumn{7}{|c|}{ Area et. al, 1988 } & Nuñez, 2004 \\
\hline
\end{tabular}

\section{I.3.2.1 Celulosa}

La celulosa es un homopolisacárido compuesto por unidades $\beta$-D-glucopiranosa que están unidas por uniones (1-4) glucosídicas (Figura I.9). Las glucosas de los extremos difieren de las demás glucosas de la cadena y además entre sí. Uno de los monómeros tiene un hemiacetal reductor en el C1 (grupo terminal reductor), mientras que la otra glucosa final posee un grupo hidroxilo alcohólico en el C4 (grupo terminal no reductor). Solo a través del grupo terminal reductor se puede abrir el anillo. Las moléculas de celulosa son completamente lineales y tienen una fuerte tendencia a formar puentes de hidrógeno intra e intermoleculares (Sjöström, 1993). 


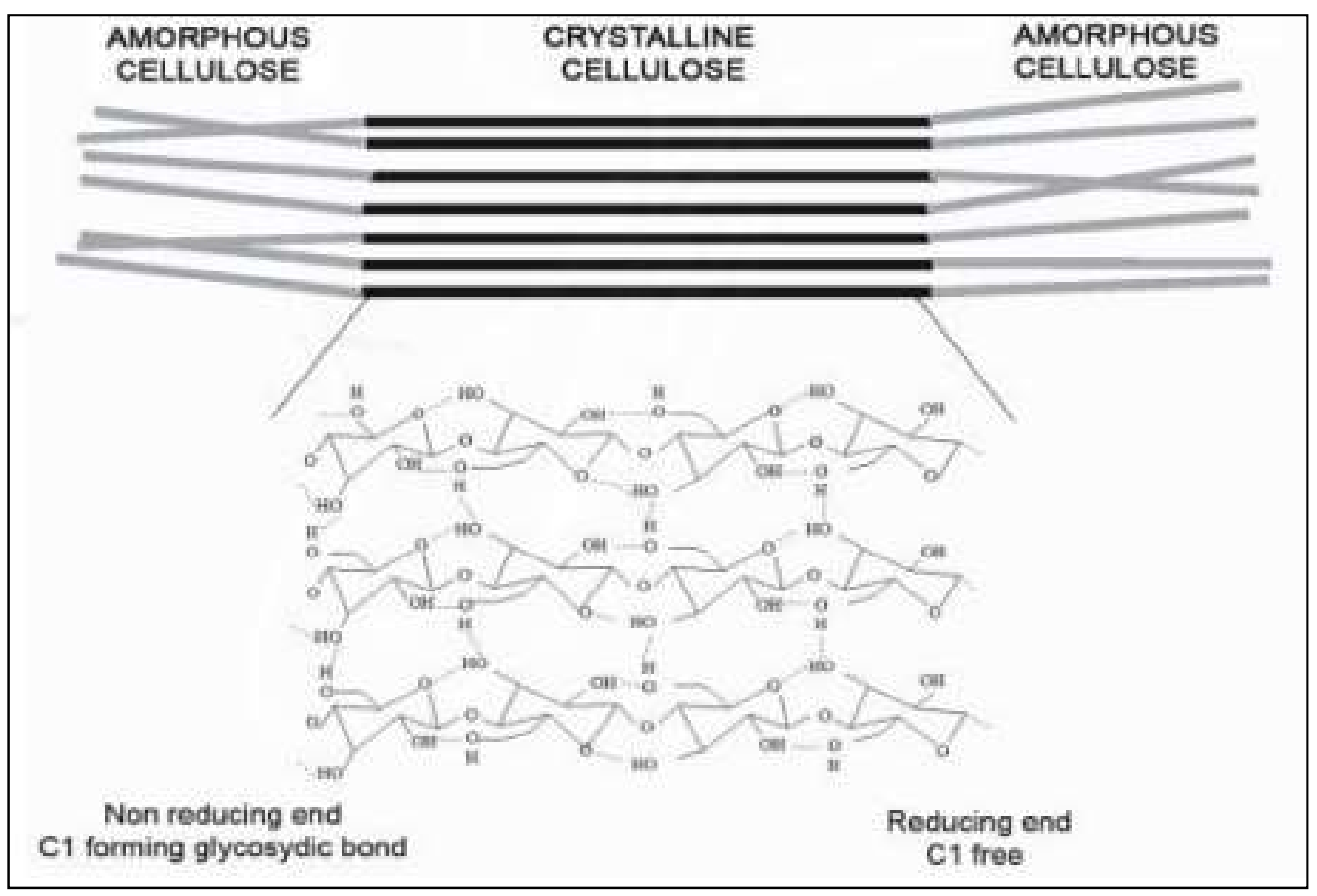

Figura I.9. Estructura de la celulosa (Quiroz-Castañeda \& Folch-Mallol, 2013)

Se han identificado cuatro alomorfos cristalinos diferentes mediante difracción de rayos $\mathrm{X}$ y resonancia magnética nuclear ${ }^{13} \mathrm{C}$ en estado sólido: celulosas I, II, III y IV. La celulosa I es la forma más abundante encontrada en la naturaleza. Su estructura cristalina es una mezcla de dos formas cristalinas distintas: celulosa $I_{\alpha}$ (triclínica) que es la forma predominante aislada de bacterias y algas de agua dulce e $\mathrm{I}_{\beta}$ (monoclínica) que es la forma principal en plantas superiores. Los cristales de celulosa son imperfectos y tienen una porción de celulosa menos ordenada, llamada frecuentemente amorfa (Park et al., 2010) (Figura I.9). En adición a las regiones cristalina y amorfa, se ha propuesto que la celulosa I contiene una porción para-cristalina intermedia que está más ordenada y tiene menos movilidad que la fracción amorfa pero es menos ordenada que la región cristalina (Pu et al., 2013).

El parámetro llamado índice de cristalinidad (CrI) se determina mediante difracción de rayos X y es utilizado frecuentemente para describir la cantidad relativa de material cristalino en la celulosa (Park et al., 2010). En general, las coníferas presentan un CrI mayor que otros materiales lignocelulósicos, como puede observarse en la Tabla I.2. El índice de cristalinidad (CrI) está basado en un modelo simplificado que considera a la celulosa conformada por una región cristalina y una región amorfa, lo que ha fomentado el estudio del polimorfismo de la celulosa mediante técnicas más avanzadas como Resonancia Magnética Nuclear en estado sólido, espectroscopia infrarroja y espectroscopia de Raman (French \& Cintrón, 2013) (Park et al., 2010). 
Tabla I.2. Índice de cristalinidad de la celulosa (CrI) para diferentes materiales (Pu et al., 2013).

\begin{tabular}{cccccc}
\hline & \multicolumn{5}{c}{ Material } \\
\hline & $\begin{array}{c}\text { Cascarilla de } \\
\text { arroz }\end{array}$ & Álamo & $\begin{array}{c}\text { Rastrojo de } \\
\text { maíz }\end{array}$ & Pino taeda & Switchgrass \\
\hline CrI (\%) & 57 & 49,9 & 50,3 & 62,5 & 44 \\
\hline
\end{tabular}

El grado de polimerización (GP) o número de monómeros de glucosa por cadena de celulosa depende de la historia y el origen de la celulosa. El GP de la celulosa nativa varía en un promedio entre 8.000 y 10.000 unidades de monómero (Sjöström, 1993).

\section{I.3.2.2 Hemicelulosas}

Las hemicelulosas son heteropolímeros, que al igual que la celulosa, funcionan como material de soporte en la pared celular. Las hemicelulosas están constituidas principalmente por tres hexosas (glucosa, galactosa y manosa) y dos pentosas (xilosa y arabinosa). Difieren de la celulosa, en el grado de polimerización (GP de las hemicelulosas $~ 200-300$ ), la presencia de ramificaciones y falta de cristalinidad (presenta una estructura amorfa, a diferencia de la celulosa que posee una acusada cristalinidad). Estas características hacen que sean fácilmente hidrolizadas por ácidos a sus componentes monoméricos (Fengel, 1989).

La cantidad de hemicelulosas en la madera varía entre 20 a $30 \%$ sobre madera seca. La composición y la estructura de las hemicelulosas en las coníferas difieren de las hemicelulosas de las latifoliadas. Las hemicelulosas de las coníferas tienen mayor proporción de manosa y más galactosa, mientras que las hemicelulosas de las latifoliadas tienen mayor proporción de xilosa y grupos acetilos (Koch, 2006).

Los galactoglucomananos son la principal hemicelulosa en las coníferas (cerca del 20\%). Su cadena es lineal o ligeramente ramificada, constituida de unidades $(1 \rightarrow 4) \beta$-D-glucopiranosa y $\beta$ D-manopiranosa. Pueden ser divididos en dos fracciones que difieren en el contenido de galactosa. Una fracción es rica en galactosa, con una relación galactosa:glucosa:manosa de 1:1:3 y la otra fracción tiene menor contenido de galactosa en una relación 0.1:1:4, que generalmente se denomina glucomanano. El residuo $\alpha$-D-galactopiranosa está unido como un grupo lateral simple a la cadena mediante un enlace $1 \rightarrow 6$. Una característica importante es que los grupos hidroxilos del C-2 y C-3 están parcialmente sustituidos por grupos acetilos, en promedio un acetilo por 3-4 unidades de hexosas (Figura I.10) (Sjöström, 1993). Los glucomananos son moléculas hidrofílicas y la presencia de grupos acetilos mejora la solubilidad en agua ya que inhibe la formación de enlaces de hidrógeno intramoleculares (Alonso-Sande et al., 2009). 


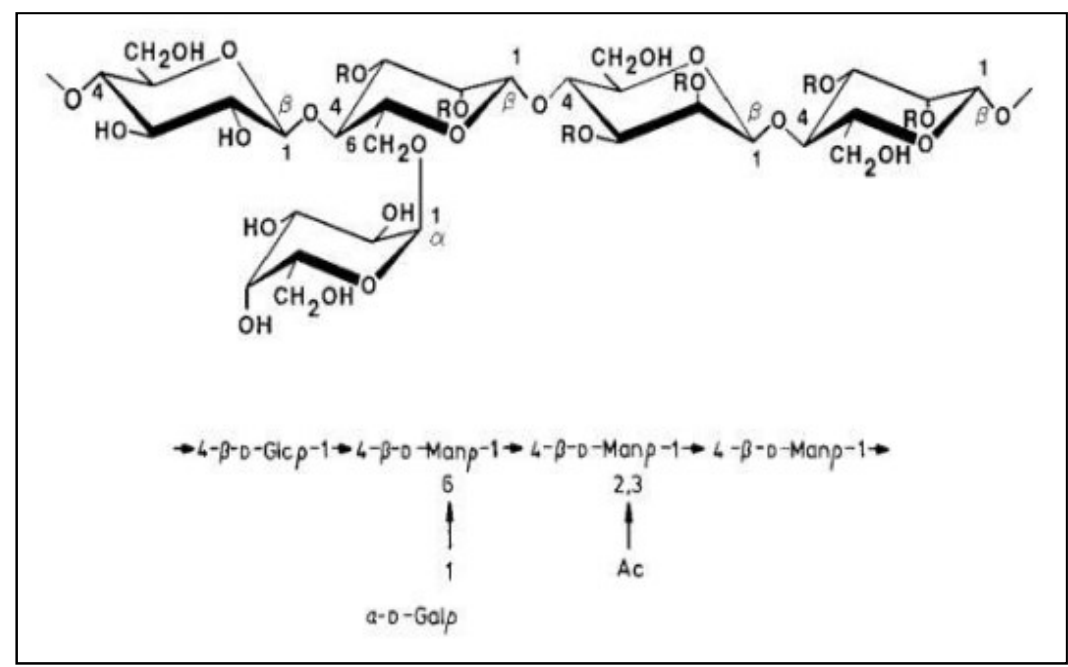

Figura I.10. Estructura de galactoglucomananos (Sjöström, 1993)

El contenido de arabinoglucoroxilanos es de 5-10\% en las coníferas. La estructura contiene unidades $(1 \rightarrow 4) \beta$-D-xilopiranosa, las cuales están parcialmente sustituidas en el C-2 por ácidos 4-O-metil- $\alpha$-D-glucurónico (Figura I.11), en promedio dos sustituciones por diez unidades de xilosa. En adición, la estructura contiene unidades $\alpha$-L-arabinofuranosa, en promedio 1.3 por diez unidades de xilosa. Debido a su estructura furanósica, las cadenas laterales de arabinosa son fácilmente hidrolizados a ácidos. Tanto la arabinosa como los ácidos urónicos estabilizan la cadena de xilano contra la degradación alcalina (Sjöström, 1993).

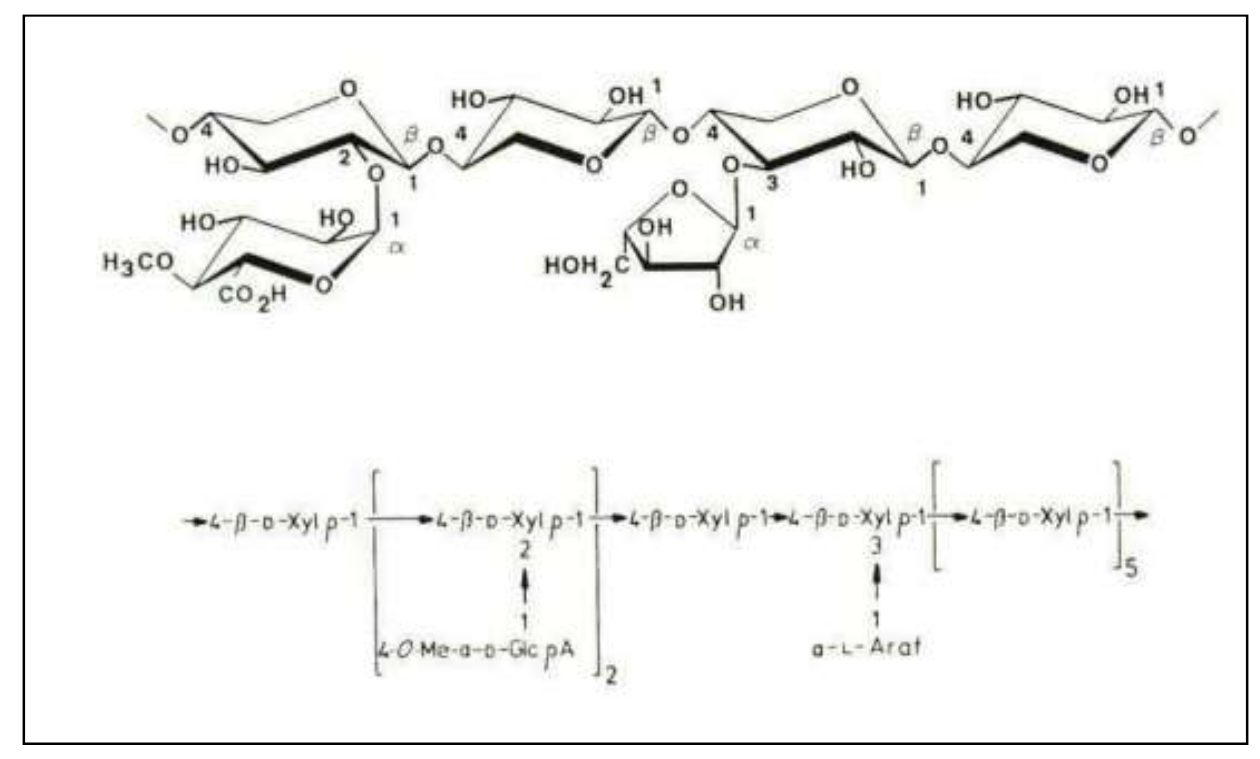

Figura I.11. Estructura de arabinoglucuroxilano (Sjöström, 1993) 
La cadena principal está unida por unidades (1-3) $\beta$-D-Galactopiranosa. Casi todas las unidades tienen una ramificación en la posición 6 , principalmente (1-6) $\beta$-D-Galactopiranosa y L-arabinosa (Figura I.12). Además hay algunos ácidos glucurónicos presentes en la molécula. La estructura altamente ramificada es responsable de la baja viscosidad y alta solubilidad en agua de estos polisacáridos.

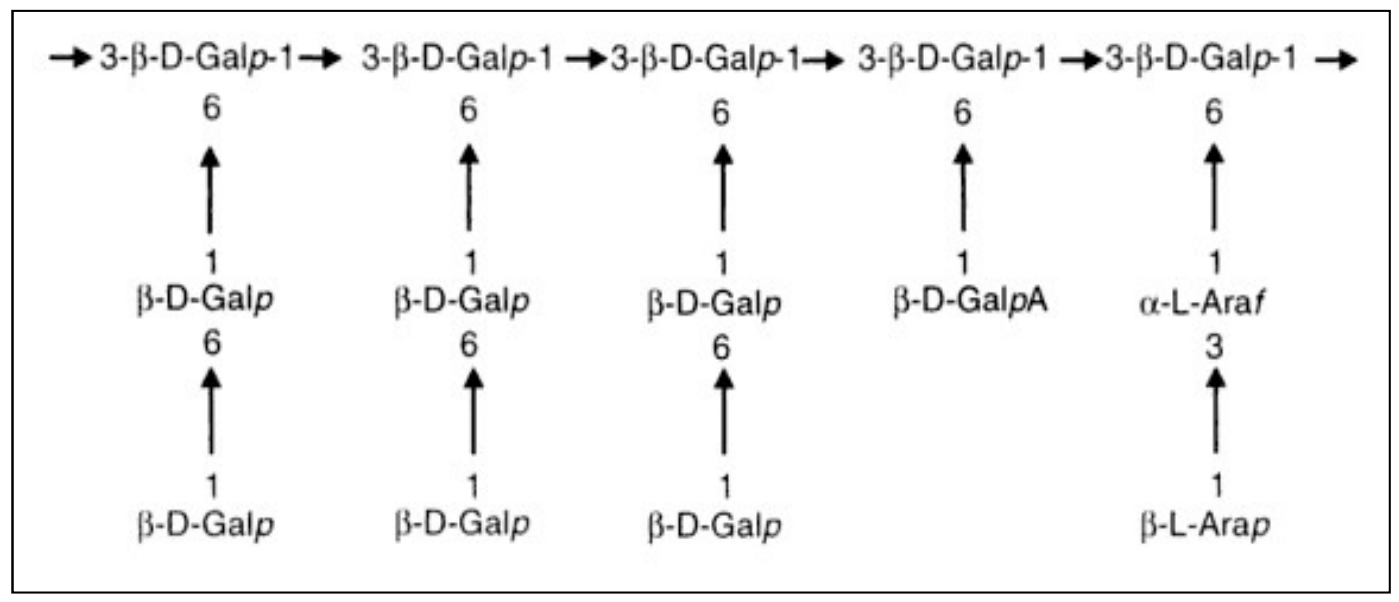

Figura I.12. Fórmula abreviada de arabinogalactano (Sjöström, 1993)

\section{I.3.2.3 Lignina}

La lignina es una macromolécula poliaromática tridimensional compuesta principalmente de tres unidades fenilpropano o unidades C9: p-hidroxifenil [H], guayacil [G] y siringil [S] (Glasser et al., 2000). En general, la lignina de coníferas está compuesta principalmente de unidades guayacil propano (Figura I.13.a), las latifoliadas de unidades guayacil y siringil propano (la proporción varía dependiendo de la especie) y las gramíneas pueden presentar los 3 tipos. La lignina de coníferas es más condensada que la de las latifoliadas debido a la diferencia en la substitución de sus precursores; C3 substituido y C5 no substituido en el guayacil a diferencia de C3 y C5 substituidos en el siringil (Liu, 2010). 
a)

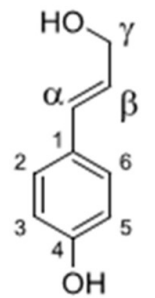

Monolignol: Lignin unit: $\sim$ SW content:

p-coumaryl alcohol p-hydroxyphenyl [H] $5 \%$<smiles>COc1cc(/C=C/CO)ccc1O</smiles>

Coniferyl alcohol Guaiacyl [G] $94 \%$<smiles>COc1cc(/C=C/CO)cc(OC)c1O</smiles>

Sinapyl alcohol Syringyl $[\mathrm{S}]$ $1 \%$

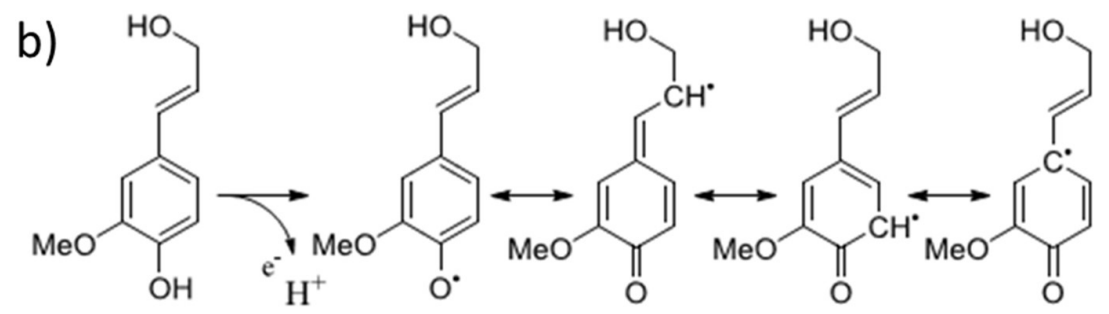

Figura I.13. a) Contenido de monolignoles (p-cumaril alcohol, coniferil alcohol y sinapil alcohol) en lignina de coníferas. Cuando se incorporan en la estructura de la lignina estos monolignoles son referidos como: p-hidroxifenil [H], guayacil [G] y siringil [S], respectivamente. b) Radical coniferil estabilizado por resonancia (Bylin et al., 2014)

Durante la biosintesís de la lignina se producen acoplamientos cruzados de los monolignoles a través de deshidrogenación enzimática y un mecanismo de acoplamiento radical (Sarkanen \& Ludwig, 1971). De hecho, la habilidad de los monolignoles de formar estructuras estabilizadas de resonancia (por ejemplo: radical coniferil, Figura I.13.b) gobierna la reactividad de la lignina, tanto en la formación como en la degradación de la lignina. Las unidades fenil propano se unen entre sí mediante enlaces éter (C-O-C) y carbono-carbono (C-C). En la figura I.14 se muestran los enlaces más comunes en coníferas y la abundancia de los mismos. El enlace dominante en coníferas es el enlace $\beta$-O-4.

El alto porcentaje de enlaces $\beta-\mathrm{O}-4$ es revelador en cuanto a la estabilidad y/o reactividad de las diferentes formas de resonancia de la unidad guayacil. 


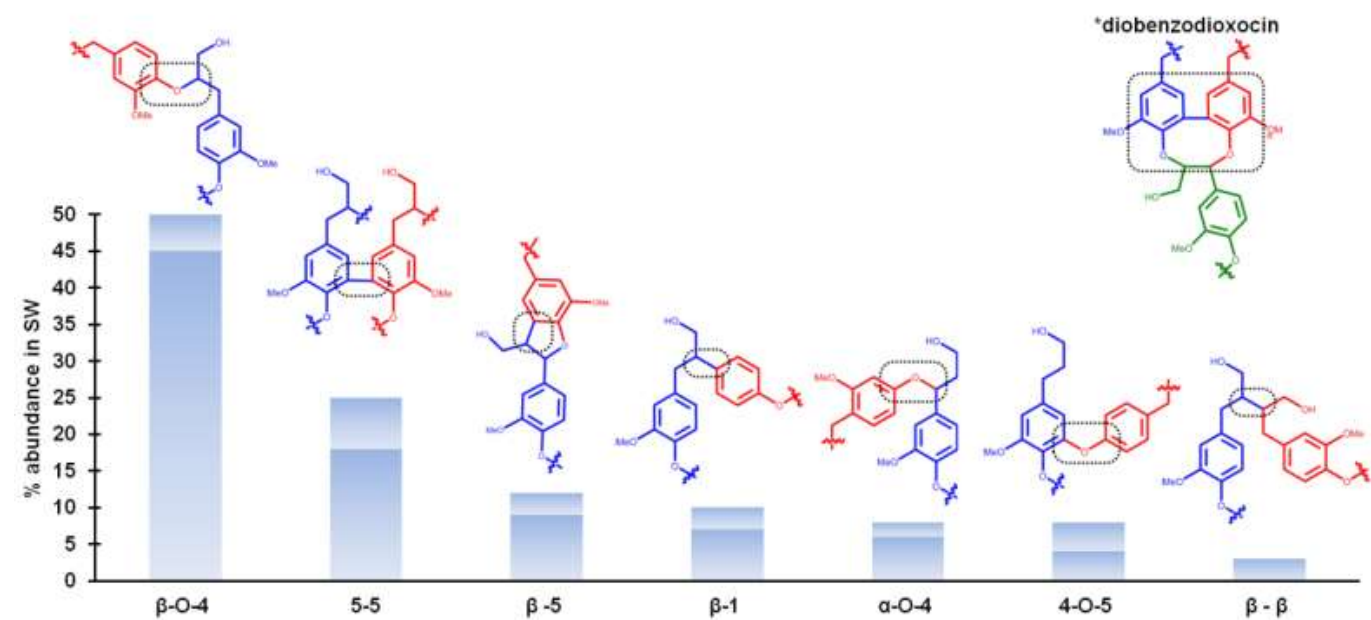

Figura I.14. Prevalencia de los enlaces más comunes entre unidades fenilpropano de lignina de coníferas (*dibenzodioxina es incorporado al enlace 5-5) (Bylin 2014)

La lignina posee una proporción átomos de carbono a oxígeno (2:1) más alto que el de las proporciones presentes en las hemicelulosas y la celulosa (1:1), por lo tanto, la lignina es energéticamente más densa. La estructura de anillos aromáticos provee una fuente de químicos funcionales excelente cuando es depolimerizada. Sin embargo, actualmente no hay tecnologías de depolimerización eficientes que actúen directamente y específicamente en la lignina (Liu, 2010).

La lignina es una causa importante de la recalcitrancia de la biomasa y es considerada el pegamento que une la celulosa y las hemicelulosas (Sannigrahi, Miller \& Ragauskas, 2010). La lignina es la barrera natural contra la degradación biológica de la celulosa y las hemicelulosas (Liu, 2010).

\section{I.3.2.4 Extractivos}

Los extractivos son compuestos orgánicos de bajo y alto peso molecular que pueden ser extraídos con solventes orgánicos (terpenos, grasas, ceras y fenoles) o agua caliente (taninos y sales inorgánicas) (Koch, 2006). La cantidad de estos compuestos en cualquier árbol depende de la especie, aunque los pinos generalmente tienen un contenido y composición similar de extractivos. A su vez, el duramen contiene más extractivos (ácidos grasos y resinas) que en la albura debido a que estos árboles cierran la estructura interna con resinas. El contenido de extractivos en latifoliadas generalmente es menor que en coníferas (Arshadi et al., 2013) (Hillis, 1962). 
Los extractivos están localizados en los canales resiníferos y/o en las células de parénquima. La oleorresina está compuesta principalmente por monoterpenoides y ácidos resínicos (diterpenoides). Los extractivos de coníferas contienen toda clase de terpenos desde monoterpenos hasta tri- $\mathrm{y}$ tetraterpenos, excepto los sesquiterpenos que son muy raros. El aceite esencial del pino denominado trementina está compuesto por monoterpenides, principalmente por $\alpha$-pineno, $\beta$-pineno y limoneno. Los diterpenoides (ácidos resínicos) son los constituyentes predominantes en la oleorresina. El ácido resínico más común en las coníferas son los terpenoides tricíclicos y estos son clasificados en pimaranos y abietanos. Los pimaranos predominantes son el ácido pimárico y el ácido isopimárico. Los ácidos abiéticos: levopimárico, palústrico, neoabiético y deshidroabiético son los principales abietanos en coníferas. Los extractivos del parénquima son principalmente grasas, siendo más de 30 los ácidos grasos identificados en coníferas y latifoliadas. Los principales ácidos grasos en el pino son el ácido oleico y el linoleico. Los monoterpenos líquidos, que son muy fragantes (el típico ‘olor a pino'), disuelven a los otros componentes que son los ácidos resínicos y los ácidos grasos (Sjöström, 1993) (Hillis, 1962) (Nuñez, 2008). En la Figura I.15 se representa la estructura química de los terpenos y ácidos resínicos más importantes de las coníferas.

Tanto la fracción de ácidos resínicos como los grasos están compuestos por una fracción denominada insaponificables o compuestos neutros, que no reaccionan con álcalis para formar sales. Estos compuestos incluyen hidrocarbonos, alcoholes superiores y esteroles y no tienen valor comercial. El pino es preferido para la producción de tall oil dado su bajo contenido de insaponificales (menos del 10\% del total de los ácidos resínicos) (Conner \& Rowe, 1975).

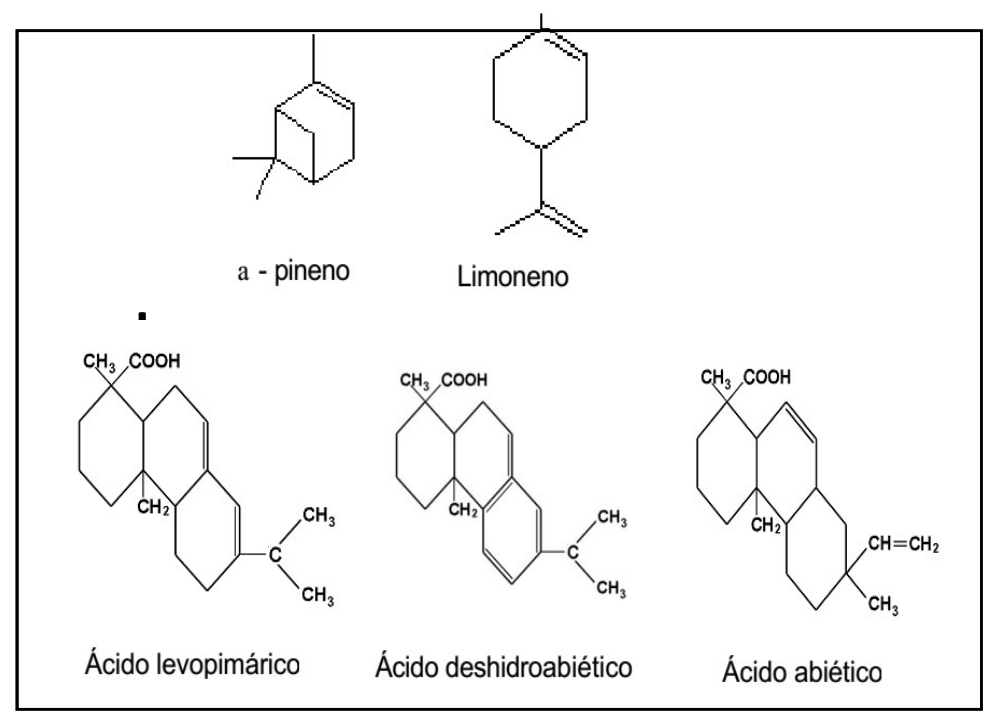

Figura I.15. a) Terpenos, b) Ácidos resínicos más importantes de las coníferas. Adaptado de (Nuñez, 2008) 
Los extractivos de las coníferas además contienen un gran número de varios compuestos fenólicos los cuales probablemente son residuos de la síntesis de la lignina. Además, lignanos, stilbenos y flavonoides forman parte de los extractivos de las coníferas (Koch, 2006).

\section{I.3.3 Complejo Lignina-Carbohidratos}

La existencia de enlaces covalentes entre la lignina y los carbohidratos ha sido uno de los temas más controvertidos en el campo de la química de la madera. En la pared celular, las hemicelulosas no están unidas químicamente a la celulosa, pero se encuentran íntimamente asociadas, físicamente y por uniones del tipo puente de hidrógeno. Por otro lado, existe una fuerte evidencia de que las hemicelulosas están unidas químicamente a la lignina. Varios descubrimientos con respecto a la distribución de la celulosa, de las hemicelulosas y de la lignina dentro de las capas de la pared celular proporcionaron bases para el desarrollo de modelos en la estructura supramolecular de los componentes de la pared celular.

Salmén y Olsson propusieron un modelo del arreglo ultraestructural de los polímeros de la madera en la pared celular que sugiere que los glucomananos están más estrechamente unidos a la celulosa y que forman una capa de moléculas asociadas estrechamente a la celulosa. Los xilanos están dispuestos en una mezcla con la lignina rodeada por la capa de glucomananos (Figura I.16) (Salmén \& Olsson, 1998).

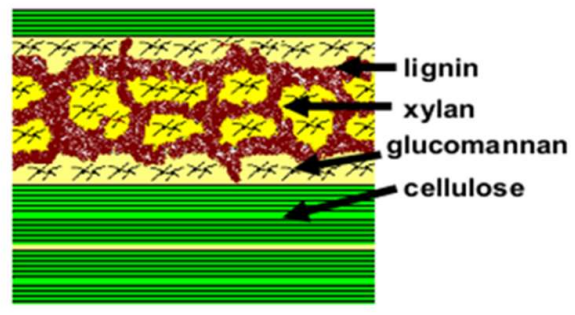

Figura I.16. Modelo propuesto del arreglo ultraestructural de los polímeros de la madera en la pared celular (Salmén\&Olsson, 1998)

En cuanto a la organización de los polímeros en la pared celular (Figura I.17), se encontró que existe una orientación preferencial de las unidades fenilpropano de la lignina a lo largo del eje de las fibras en las traqueidas de abeto. Esto implica que existe una estructura ordenada de la lignina en la pared secundaria de las traqueidas análoga a los de los polisacáridos de la pared celular (Akerholm \& Salmén, 2001). 


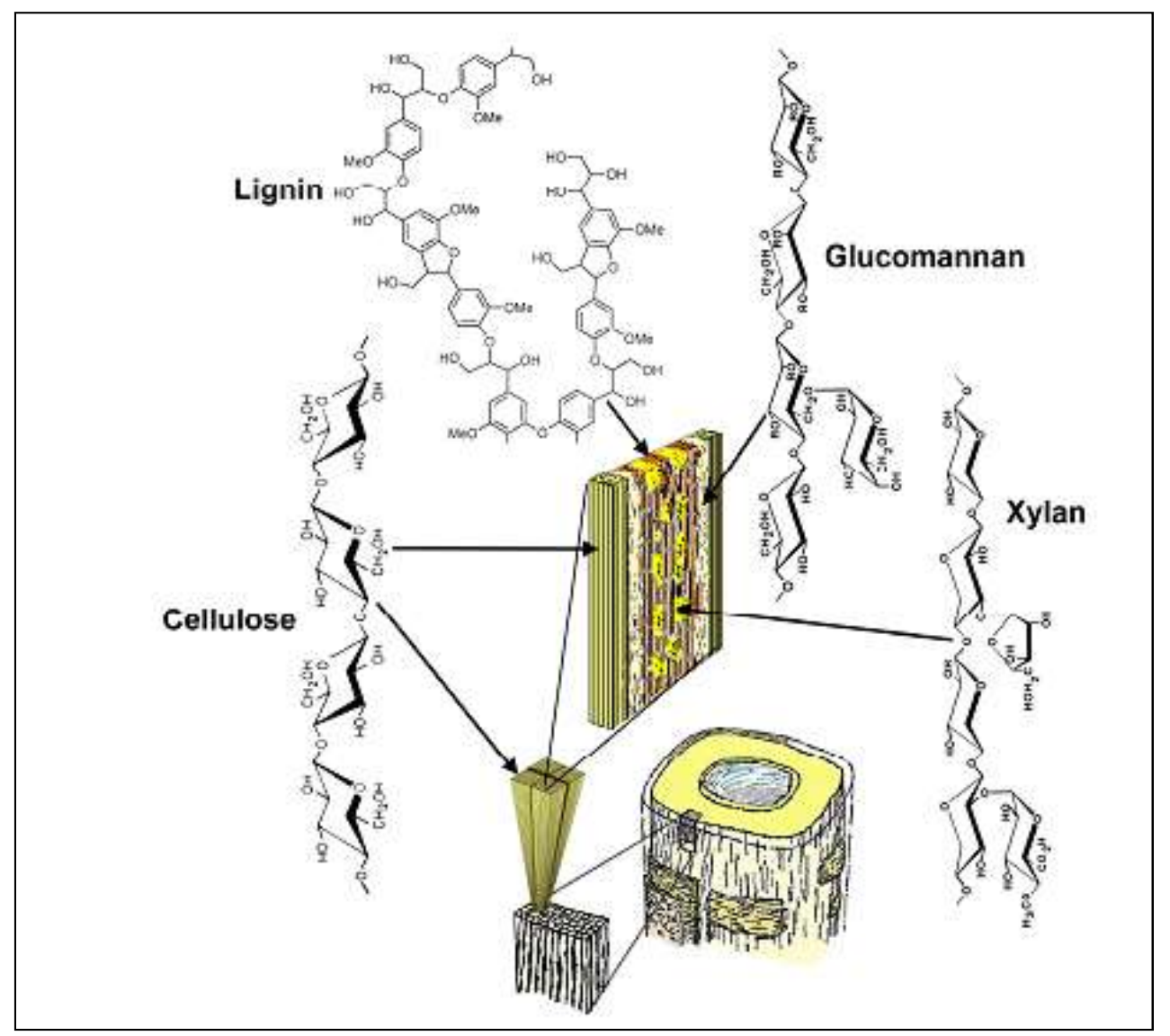

Figura I.17. Ilustración esquemática de la organización de los polímeros de la pared celular (Akerholm \& Salmén, 2001)

La lignina y las hemicelulosas pueden estar unidas químicamente mediante los siguientes enlaces: enlace bencil éter entre el grupo hidroxilo $\alpha$ de una unidad de lignina y un grupo hidroxilo de un carbohidrato, enlace bencil éster entre el grupo hidroxilo $\alpha$ de una unidad de lignina y un ácido carboxílico de un carbohidrato, enlace glicosídico entre un grupo hidroxilo aromático o alifático y un grupo reductor de un carbohidrato, enlace acetal entre dos grupos hidroxilo de carbohidratos y un grupo carbonilo de la lignina (Lawoko, 2005).

\section{I.4 FRACCIONAMIENTO DE CONÍFERAS}

Los biocombustibles de primera generación que son elaborados a partir de azucares simples, como los de la caña de azúcar, surgen como primera alternativa a los combustibles fósiles. Debido al conflicto originado por el uso de alimentos para la producción de combustibles surgen los biocombustibles de segunda generación que utilizan biomasa lignocelulósica. Los mismos poseen 
una estructura más compleja que requiere una etapa de pretratamiento para aumentar la accesibilidad del material al ataque enzimático. La mayoría de los pretratamientos estudiados hasta ahora tienen el objetivo de mejorar la biodegradabilidad de la celulosa mediante la remoción de la lignina y hemicelulosa para la producción de azúcares fermentables. La estrategia más promisoria consiste en ampliar el concepto de pretratamiento a un fraccionamiento del material, en vistas de obtener fracciones de todos los componentes, lo más puras posibles, para su aprovechamiento y transformación a productos de alto valor (Figura I.18).

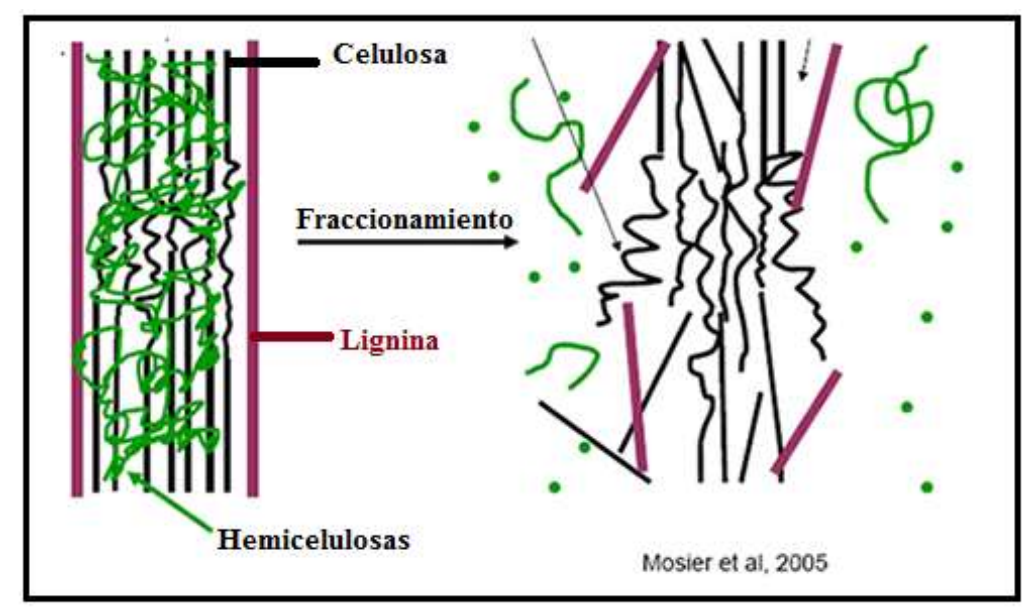

Figura I.18. Impacto del fraccionamiento (Adaptado de Mosier et al. 2005)

El fraccionamiento consiste en la separación de los componentes principales de la biomasa (celulosa, lignina, hemicelulosas y extractivos) de tal manera que estos puedan ser aprovechados. Actualmente, uno de los principales obstáculos para la aplicación del concepto de biorrefinería es encontrar métodos eficientes y rentables de fraccionamiento (FitzPatrick et al., 2010). La dificultad en los procesos de fraccionamiento radica en que existe una situación de compromiso en los niveles de temperatura, tiempo y concentración de reactivos utilizados ya que en condiciones más severas se obtienen altos rendimientos de extracción de hemicelulosas pero a expensas de mayor degradación de celulosa y lignina. El objetivo consiste en encontrar condiciones óptimas de fraccionamiento que permitan el aprovechamiento más eficiente de la biomasa. Es decir, en un enfoque de biorrefinería la efectiva utilización de los residuos forestales requiere la recuperación de la mayoría de los componentes del residuo incluyendo carbohidratos, lignina y extractivos en una forma usable y su subsecuente valorización como combustibles, materiales o productos químicos. 
Las coníferas son generalmente reconocidas como más refractarias que las latifoliadas y los residuos agrícolas a los pretratamientos, debido a que presentan una estructura más rígida y mayor contenido de lignina. Además, el contenido de acetilos es más bajo que en las latifoliadas por lo tanto con los procesos autocatalíticos (catalizados por los grupos acetilos liberados del material) no se producen rendimientos similares y se debe recurrir al uso de catalizadores, como por ejemplo el ácido sulfúrico (Galbe \& Zacchi, 2002).

\section{I.4.1 Remoción de Extractivos}

La importancia de la recuperación de los extractivos radica en que son una fuente importante de valiosos productos químicos pero a su vez pueden causar problemas operacionales, como la formación de espumas o partículas pegajosas (pitch) y generar toxicidad en los efluentes. Estas sustancias pueden ser extraídas con solventes o en medio alcalino. La extracción con solventes orgánicos es más cara y compleja industrialmente, por lo tanto el tratamiento alcalino puede resultar más adecuado para la desresinación. La principal desventaja del pretratamiento alcalino es que puede tener un efecto de degradación en los carbohidratos (Baptista et al., 2006).

Los ácidos grasos y resínicos pueden ser extraídos en condiciones alcalinas suaves, ya que se disuelven formando jabones de sodio. Por ejemplo, en el pulpado alcalino de coníferas resinosas (pinos), las resinas son disueltas en el licor de cocción con la formación de sales de sodio de los ácidos resínicos y grasos (Figura I.19). Posteriormente, el licor de cocción es concentrado permitiendo que estos jabones de sodio se separen por desnatación en la superficie. La acidificación con ácido sulfúrico de los jabones produce el "tall-oil" crudo el cual es posteriormente refinado por destilación a múltiples productos (Hillis, 1962) (Demirbas, 2011). El rendimiento de "tall-oil" crudo por tonelada de pulpa kraft seca varía en un rango entre 30 y 50 kg de "tall-oil" crudo (Sixta et al., 2006).Cuando los licores están muy diluidos y no es posible concentrarlos, los extractivos pueden ser recuperados mediante otras técnicas como la flotación, que es utilizada para separar los extractivos del agua en el proceso de pulpado termomecánico. Con esta técnica se alcanza una eficiencia de remoción de $80-90 \%$ de extractivos floculados (Tanase et al., 2010). 


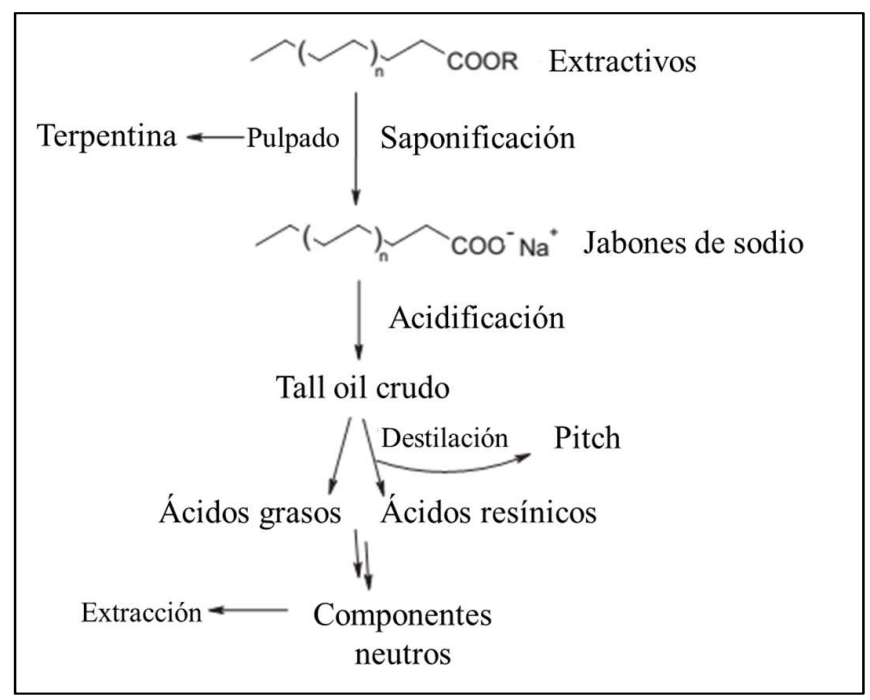

Figura I.19. Fracciones de extractivos obtenidos luego del pulpado Kraft (Sixta et al., 2006)

La extracción con solventes de madera para la obtención de oleorresina se utiliza desde principios del siglo 20. La oleorresina es actualmente producida por Pinova Solutions, Inc en Estados Unidos (USDA, 2014). El proceso consiste en mantener en contacto los chips de pino con el solvente a temperatura elevada y bajo presión por un período de algunas horas. La eficiencia de extracción depende del solvente utilizado. Posteriormente la solución extraída es separada en tres fracciones: solvente recuperado, terpenos volátiles y colofonia (resina). Tanto los terpenos como la colofonia deben ser purificados y el solvente reutilizado (Zinkel \& Russel, 1989). La compañía Virdia produce tall-oil como parte de su proceso de obtención de azúcares fermentables, pero este proceso de extracción no se encuentra difundido (Zviely, 2013).

No existe ningún solvente capaz de remover completamente los extractivos de la madera (Demirbas, 2011). Se han investigado el uso de varios solventes para la extracción de coníferas, como agua, acetona y etanol (Yuanlin, 2011), hexano, tolueno y dietileter (Yuman, 2011), diclorometano, mezclas etanol-benceno, etanol-tolueno, piridina, N,N-dimetilacetamida, N,Ndimetilformamida (Baptista et al., 2006). La elección del solvente va a depender de su disponibilidad comercial y precio así como de sus características químicas (volatilidad, miscibilidad con agua y poder solvente) (Zinkel \& Russel, 1989). Actualmente se está investigando la remoción de extractivos mediante fluidos supercríticos. Se obtienen altos rendimientos de extracción y productos de alta pureza, además se minimizan problemas de contaminación. La extracción de chips de madera resinosas con $\mathrm{CO}_{2}$ supercrítico es una interesante alternativa para la remoción de resinas previo a los procesos de pulpado (Demirbas, 
2001). La desventaja del uso de fluidos supercríticos es la elevada inversión requerida debido a las altas presiones de trabajo usualmente utilizadas (Zinkel \& Russel, 1989) (Knez et al., 2014).

Existen varios trabajos sobre la remoción de la resina y la trementina previo a los pulpados debido a que la cantidad de trementina que se recupera en los procesos de pulpado es generalmente menor que la cantidad de trementina disponible en la madera debido a una pérdida sustancial como resultado de su solubilidad en los licores de cocción a alta temperatura y presión, y además la calidad de la trementina disminuye debido a la contaminación con subproductos de la cocción, como los mercaptanos. La remoción de estos también mejora el rendimiento de los pulpados posteriores, las propiedades de la pulpa y disminuye el consumo de reactivos químicos (Caperos Sierra et al., 1990). Speaks et al propusieron un pretratamiento secuencial de extracción con solvente para la remoción de extractivos previo al pulpado, donde en la primer etapa utilizan un solvente hidrofílico que tiene alta afinidad por los componentes saponificables (acetona) y una segunda etapa de extracción con un solvente hidrofóbico (éter de petróleo) para extraer los componentes insaponificables (Speaks et al., 1997). Otro método consiste en la inmersión de los chips en una solución alcalina suave durante la destilación con vapor. De esta manera se obtienen una mezcla de dos fases, "tall-oil" saponificado y trementina, que deben ser separados (Drew, 1975). Con ambos procesos se obtienen alta remoción de trementina.

En condiciones ácidas, las diversas clases de extractivos se comportan de manera diferente, aunque todos ellos son muy propensos a reacciones de condensación. El pinosylvin del duramen de especies de pino inhibe eficazmente la deslignificación durante la fabricación de pulpa mediante procesos ácidos (pulpado al sulfito), incluso a concentraciones bajas, posiblemente a través de la formación de productos de condensación con la lignina (condensación de fenolformaldehído). Los componentes de la resina tienen la tendencia a coagular en medio ácido formando pegajosidades denominadas pitch, que se adhieren a las superficies metálicas de máquinas o del material fibroso, provocando problemas operacionales (Hillis, 1962), (Sixta et al., 2006).

La recuperación de los extractivos puede hacer más atractiva la producción de bioetanol a partir de pino (Frederick et al., 2008). Los extractivos tienen un efecto negativo para la hidrólisis enzimática. En adición, tienen un gran potencial para proveer varios productos tal como formulaciones antimicrobianas, así como productos químicos de altos valor y productos farmacéuticos especializados (Burkhardt, 2010). 


\section{I.4.2 Extracción de hemicelulosas}

En vistas a la obtención de bioetanol, uno de los objetivos de los pretratamientos es extraer las hemicelulosas debido a que la remoción de las mismas aumenta la porosidad del material y por lo tanto aumentan la accesibilidad de la celulosa al ataque enzimático (Behera 2014). A diferencia de lo que ocurre con la celulosa las hemicelulosas son heteropolímeros con ramificaciones no cristalinas que pueden ser extraídos como oligómeros y monómeros en condiciones relativamente suaves. Las hemicelulosas pueden ser extraídas mediante hidrólisis ácida e hidrólisis alcalina o enzimas hemi-celulasas apropiadas (Bacovsky et al., 2010). Los xilanos pueden ser extraídos fácilmente en medio ácido o alcalinos mientras que los glucomananos requieren condiciones más severas (Behera et al., 2014).

\section{I.4.2.1 Hidrólisis ácida}

La hidrólisis ácida implica el uso de ácidos concentrados o diluidos para extraer las hemicelulosas y romper la estructura rígida de la biomasa lignocelulósica reduciendo su recalcitrancia. Por lo tanto, ha sido aplicada satisfactoriamente como pretratamiento en la producción de bioetanol a un amplio rango de materiales lignocelulósicos, incluyendo coníferas, latifoliadas, cultivos herbáceos y residuos agrícolas (Hu et al., 2012), (Kumar et al., 2009). La hidrólisis ácida puede realizarse con varios tipos de ácidos, concentrados o diluidos, incluyendo sulfuroso, sulfúrico, clorhídrico, fluorhídrico, fosfórico, nítrico y fórmico aunque el ácido sulfúrico ha sido el más estudiado (Galbe \& Zacchi, 2002). Los procesos autocatilazados es decir sin adición de ácidos también han sido ampliamente estudiados.

Al tratar biomasa lignocelulósica con soluciones ácidas se obtiene una importante recuperación de hemicelulosas en forma de monómeros y oligómeros en la fracción líquida y una fracción sólida lignocelulósica. La hidrólisis ácida de las hemicelulosas no es homogénea y hay una porción que se hidroliza rápidamente mientras que el resto lo hace más lentamente (Figura I.20). Esta heterogeneidad puede ser explicada en principio por el hecho de que parte de las hemicelulosas están localizadas en la pared celular de tal manera que son fácilmente accesibles por el reactivo, mientras que la otra parte está localizada a mayor profundidad y está firmemente retenida entre las cadenas de celulosa. También se debe a las diferencias químicas que existen entre las estructuras poliméricas de las hemicelulosas y por el grado de asociación con la lignina mediante los enlaces lignina-carbohidratos (Lee et al., 1999). 


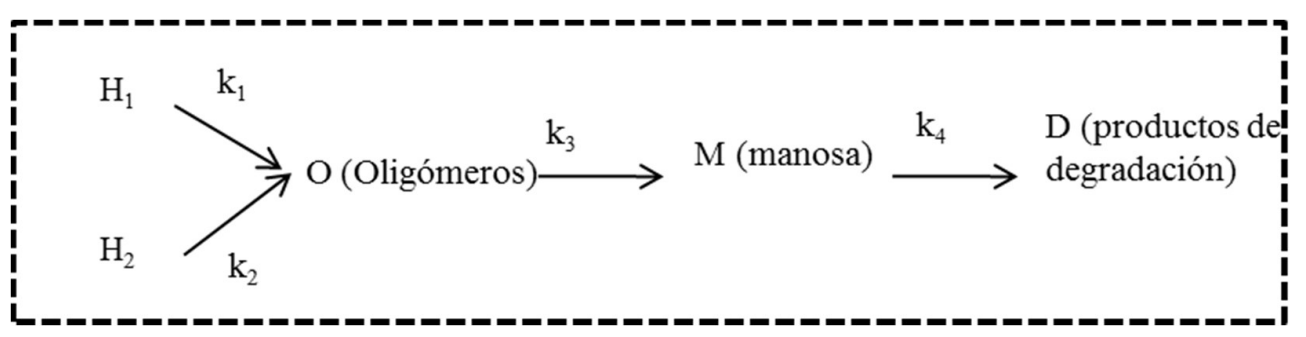

Figura I.20. Patrón cinético de la hidrólisis de las hemicelulosas: H1 es la fracción de hemicelulosas fácil de extraer, $\mathrm{H} 2$ refiere a la fracción difícil de hidrolizar. (Adaptado de Lee et al., 1999)

Durante la fase inicial de la reacción, un ataque aleatorio del ácido en las cadenas de hemicelulosas produce oligómeros con diferentes grados de polimerización. Los oligómeros son hidrolizados a monómeros, los cuales luego son degradados a productos de descomposición (Lee et al., 1999).

La deshidratación catalizada por ácido en condiciones suaves lleva a la formación de azúcares anhidros con enlaces glucosídicos intramoleculares, resultado de la eliminación de una molécula de agua de dos grupos hidroxilos. Como estos enlaces glucosídicos pueden ser fácilmente hidrolizables, se generan una serie de productos de degradación aromáticos y productos condensados. Los productos de degradación más importantes (considerando rendimiento y potencial utilización) son los compuestos cíclicos furfural (2-furaldehído) proveniente de pentosas y el hidroximetilfurfural (5-(hidroximetil)-2-furaldehído), HMF, procedente de hexosas. Se consiguen altos rendimientos de éstos productos con alta concentración de ácido, a elevada temperatura. Si se incrementa adicionalmente la temperatura la molécula de HMF es convertida a ácido levulínico y fórmico (Figura I.21) (Fengel, 1989). 


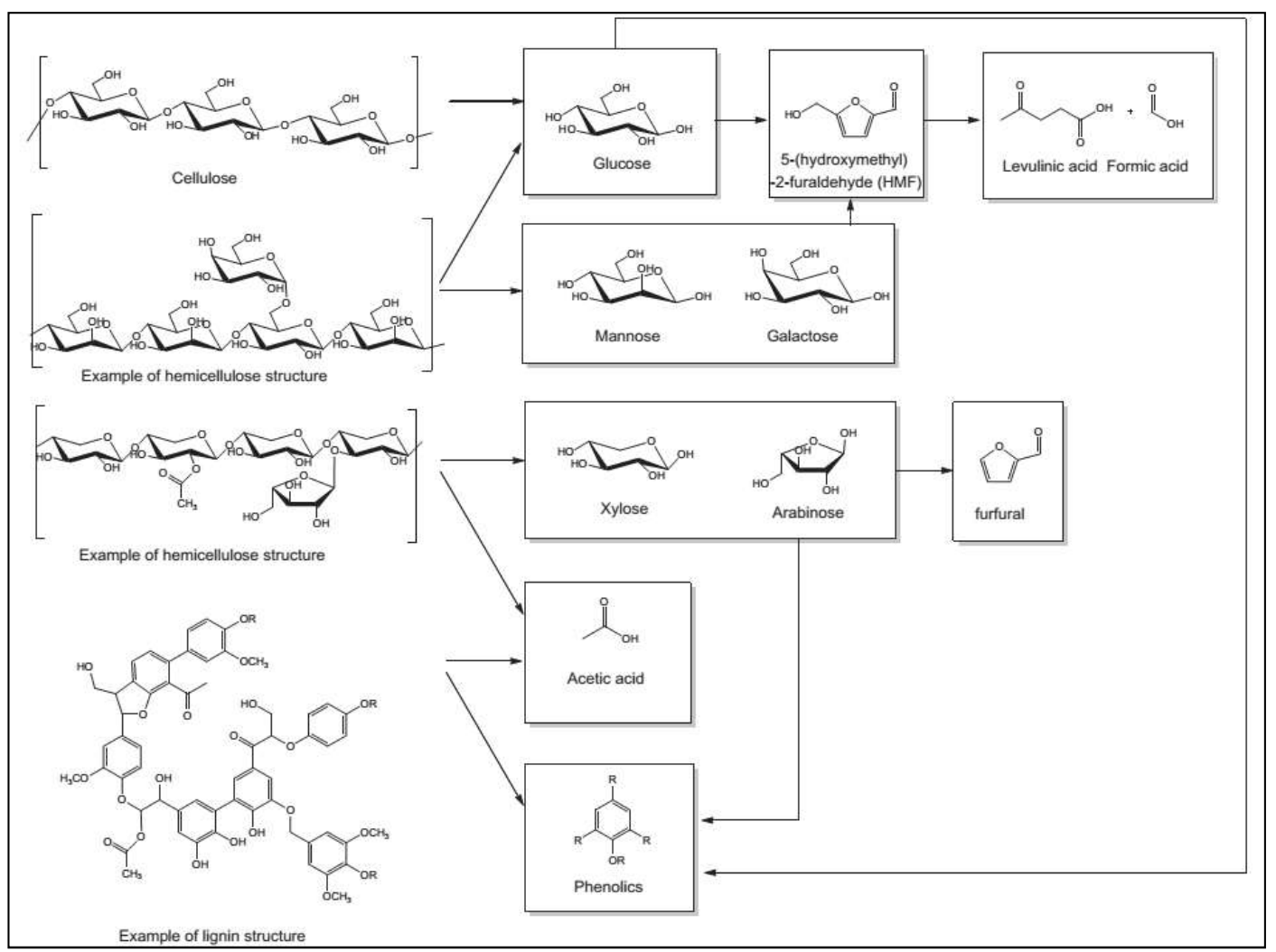

Figura I.21. Productos de degradación de celulosa, hemicelulosas y lignina en medio ácido (Rasmussen et al., 2014).

A su vez, como resultado de reacciones de polimerización y/o condensación de los intermediarios 3,8-dihidroxi-2-metilcromona y 1,2,4-bencenotriol que derivan del furfural y $\mathrm{HMF}$, respectivamente se puede formar un compuesto aromático denominado pseudolignina. Se ha demostrado mediante microscopía electrónica de barrido (SEM) que la pseudolignina se deposita en forma de gotitas en la superficie de las fibras, lo que puede retardar la hidrólisis enzimática por la inhibición de la enzima y/o reducción de la accesibilidad del sustrato (Rasmussen et al., 2014) (Sannigrahi et al., 2011) (Hu et al., 2012). Por lo tanto, uno de los objetivos de los tratamientos ácidos consiste en la minimización de la formación de productos de degradación.

En condiciones ácidas, las hemicelulosas son degradadas mucho más rápido que la celulosa. Los xilanos o arabinoxilanos y los galactanos de los galactoglucomananos son degradados más rápidamente que los glucomananos (Figura I.22). Las uniones arabinofuranosídicas son más rápidamente hidrolizados en medio ácido que las uniones glucopiranosídicas (Sixta, 2006). 


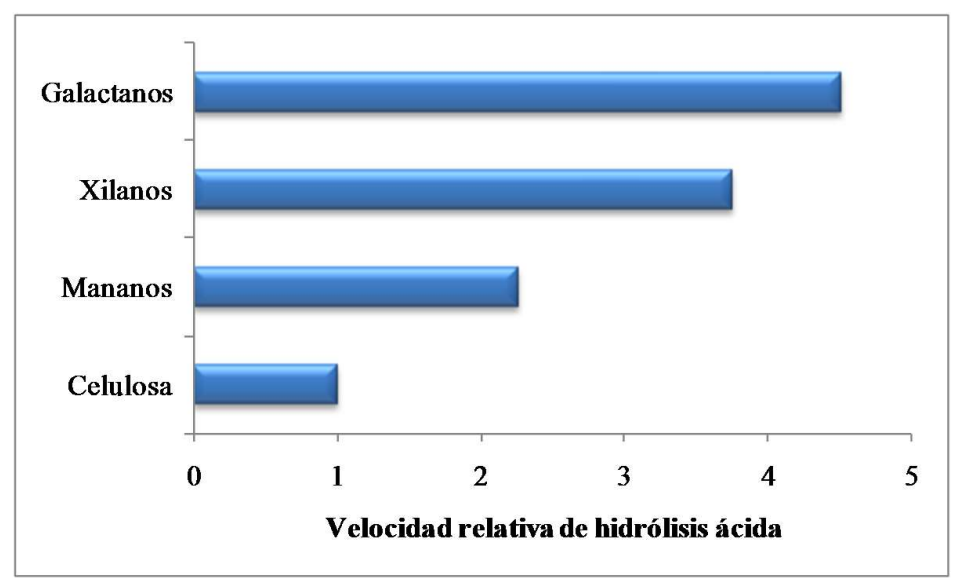

Figura I.22. Comparación de las velocidades relativas de hidrólisis de los polímeros de la madera (Sixta et al., 2006)

La hidrólisis ácida concentrada permite obtener altos rendimientos de extracción de hemicelulosas (cercanos al 100\%) y celulosa a moderadas temperaturas con baja degradación de azúcares. Este proceso ha sido ampliamente utilizado para el tratamiento de materiales lignocelulósicos ya que los ácidos concentrados son agentes poderosos para la hidrólisis de la celulosa y por lo tanto, no es necesaria la implementación de una etapa enzimática posterior a la hidrólisis ácida (Harmsem et al., 2010). El uso de altas concentraciones de ácidos (por ejemplo: $\left.30-80 \% \mathrm{H}_{2} \mathrm{SO}_{4}\right)$ permite reducir la temperatura del proceso $\left(40-60^{\circ} \mathrm{C}\right)$. Las desventajas de la hidrólisis ácida concentrada son la mayor toxicidad debido a la degradación de los componentes del material y el requerimiento de reactores resistentes a la corrosión o construcciones no metálicas especializadas y la necesidad indispensable de recuperación del ácido para hacer el proceso económicamente factible. El factor fundamental de este proceso es lograr una impregnación eficiente de la biomasa con el ácido para minimizar el consumo de ácido (Yoon et al., 2014) (Wijaya et al., 2014) (Galbe \& Zacchi, 2002) (Zheng et al., 2009) (Kumar et al., 2009) (Harmsem et al., 2010). A su vez, cuando se utiliza ácido sulfúrico el proceso de neutralización produce grandes cantidades de yeso (sulfato de calcio hidratado). A pesar de estas desventajas es ampliamente utilizado en la actualidad para la producción de etanol celulósico, como es el caso de las empresas Arkenol Inc., Massada Resource Group, Weyland y Biosulfurol en Estados Unidos (Taherzadeh \& Karimi, 2007). La empresa Weyland utiliza ácido concentrado para la hidrólisis de diferentes materias primas (caña de azúcar, rastrojos y mazorcas de maíz, paja de arroz, latifoliadas, coníferas, residuos de madera y papeles) recirculando el 98,5\% del ácido sulfúrico (Bacovsky et al., 2010). 
A diferencia de los procesos concentrados, en la hidrólisis con ácido diluido (HAD) se utilizan concentraciones más bajas de ácidos a temperatura y tiempo mayores. Generalmente el proceso es llevado a cabo a temperaturas altas $\left(\mathrm{T}>160^{\circ}\right)$ y tiempos cortos, o a temperaturas más bajas y tiempos más largos (Jung \& Kim, 2015). El rendimiento de extracción de las hemicelulosas de coníferas en la hidrólisis ácida diluida $\left(150^{\circ} \mathrm{C}-180^{\circ} \mathrm{C}, 1-5 \mathrm{~g} / \mathrm{L} \mathrm{H}_{2} \mathrm{SO}_{4}, 60 \mathrm{~min}\right)$ es de aproximadamente 60\% (Shuai et al., 2010) (Marzialetti et al., 2008). Debido a su simplicidad, bajo costo y eficiencia es considerado como uno de los procesos más cercanos a la comercialización (Jung \& Kim, 2015), (Galbe \& Zacchi, 2002).

En la HAD, el material lignocelulósico es mezclado con ácido diluido (típicamente ácido sulfúrico) y agua formando un sistema heterogéneo sólido líquido. La HAD puede ser realizada en reactores batch, reactores de flujo pistón, reactores continuos en contracorriente y corrientes paralelas y en percoladores (Jørgensen et al., 2007) (Lee et al., 1999). La HAD ha sido utilizada con distintos materiales (residuos forestales, agrícolas y gramíneas) y varios ácidos (nítrico, hidroclorhídrico, peracético, oxálico, sulfúrico). Sin embargo, el ácido sulfúrico es el más utilizado debido a que es altamente activo, de bajo costo y es un químico disponible para aplicaciones industriales a pesar de no ser seguro y contaminante (Singh et al., 2015).

Un pretratamiento típicamente utilizados es el proceso de autohidrólisis o hidrotérmico, que es una reacción que se produce en condiciones ácidas diluidas pero sin adicionar ningún catalizador. El material lignocelulósico es tratado en agua líquida a altas temperaturas y presión. Durante el tratamiento las reacciones hidrolíticas son catalizadas por los iones hidronios generados in situ, por la ionización del agua en la primer etapa y por autoionizción de los ácidos orgánicos (ácido acético) de las hemicelulosas en reacciones posteriores (Garrote, 2009), (Hu \& Ragauskas, 2012). La autohidrólisis presenta varias ventajas con respecto a la hidrólisis ácida diluida: no requiere catalizador, minimiza la formación de compuestos de degradación, elimina la etapa de lavado o neutralización y tiene bajo costo de solvente para aplicaciones de gran escala (Hu \& Ragauskas, 2012) (Mosier et al., 2005) (Behera et al., 2014). Mediante la aplicación de este proceso a pino taeda a $180^{\circ} \mathrm{C}$ por 15 min se obtuvo un rendimiento máximo de extracción $11,9 \%$ de las hemicelulosas totales (Yoon et al, 2008).

Las especies de coníferas usualmente requieren para su fraccionamiento un tratamiento químico combinado con un tratamiento mecánico como en el proceso de explosión de vapor (Overend et al., 1987). La explosión de vapor es el método más estudiado para fraccionar y aumentar la accesibilidad de coníferas, ya que es uno de los procesos más prometedores para el fraccionamiento de la madera en sus tres componentes mientras que mejora la accesibilidad de la celulosa al ataque enzimático. 
Este método involucra el calentamiento de la biomasa a alta temperatura y presión seguida por una descarga violenta (explosión) que provoca una ruptura mecánica del material tratado con vapor. Uno de los factores más importantes en la explosión de vapor es el reactor que debe resistir altas presiones durante el pretratamiento. El proceso puede ser continuo o discontinuo, y en caso de ser continuo debe poseer equipamiento especial para la alimentación y descarga (Kokta \& Ahmed, 1998).

El principal efecto de este tratamiento es la descompresión que provoca una reducción en el tamaño y longitud de la fibra. A su vez, la fuerza de corte causa fracturas en el interior de la capa S2 de la pared celular incrementando el área superficial. Un beneficio secundario es la hidrólisis química y subsecuente liberación de las hemicelulosas que causa un incremento substancial de la porosidad (Cullis, 2003).

La explosión de vapor se puede llevar a cabo con o sin adición de un catalizador ácido. Si no se adiciona ácido el proceso se lleva a cabo en condiciones de autohidrólisis. La adición de un catalizador, generalmente $\mathrm{SO}_{2}$ o $\mathrm{H}_{2} \mathrm{SO}_{4}$ (típicamente 0,3 a $3 \%$ sobre base seca (bs)), es un requisito en el tratamiento de coníferas, ya que el proceso de autohidrólisises es efectivo para latifoliadas y residuos agrícolas pero no para coníferas (Negro et al., 2003) (Jørgensen et al., 2007). El catalizador que ha sido probado como el más efectivo es el $\mathrm{SO}_{2}$ (Nguyen et al., 1998) (Mackie et al., 1985). Si se usa $\mathrm{SO}_{2}$ el vapor en el proceso podría reaccionar con $\mathrm{el}_{\mathrm{SO}_{2}}$ formando $\mathrm{H}_{2} \mathrm{SO}_{4}$, el cual rompe efectivamente los enlaces glicosídicos de las hemicelulosas y de las celulosas durante el proceso de explosión de vapor (Nguyen et al., 1998) (Tengborg et al., 1998) (Schwald et al., 1989). Luego de la EV la mayor parte de la lignina queda retenida en la fracción insoluble. Los tratamientos posteriores de remoción de lignina son más eficientes para los materiales impregnados con $\mathrm{SO}_{2}$ debido a la sulfonación y al menor grado de condensación que cuando se impregna con ácido sulfúrico (Mackie et al., 1985). El dióxido de azufre es un excelente catalizador, más fácil y rápido de introducir en el material que el ácido sulfúrico diluido pero la principal desventaja es que es altamente tóxico y puede causar un impacto negativo en la salud y el medioambiente (Zhang \& Shahbazi, 2011), (Schwald et al., 1989).

El rango de concentración típicamente empleado de $\mathrm{SO}_{2}$ es $2 \%$ a $4,5 \% \mathrm{SO}_{2}$ (bs) con temperaturas que varían de $190^{\circ}$ a $225^{\circ} \mathrm{C}$ y tiempo entre 2 y 5 min se alcanzan rendimientos de entre 80 y $90 \%$ de remoción de hemicelulosas (Kumar et al., 2010), (Cullis, 2003), (Stenberg et al., 1998), (Clark $\&$ Mackie, 1987), (Chacha et al., 2011). Las condiciones de temperatura y tiempo utilizadas en la $\mathrm{EV}$ con $\mathrm{H}_{2} \mathrm{SO}_{4}$ son similares a las utilizadas con $\mathrm{SO}_{2}$ mientras que las concentraciones de $\mathrm{H}_{2} \mathrm{SO}_{4}$ son algo inferiores. Por ejemplo, con la aplicación de la EV a chips de coníferas tratados a $212^{\circ} \mathrm{C}$ y 105 s con una concentración de ácido sulfúrico de $0,35 \%$ bs se obtuvo una remoción del $90 \%$ de las hemicelulosas (Nguyen et al., 1998). Con el tratamiento de Picea abies a $180^{\circ} \mathrm{C}$, por $10 \mathrm{~min}$ 
con una concentración de $1,5 \% \mathrm{H}_{2} \mathrm{SO}_{4} \mathrm{p} / \mathrm{p}$ se obtuvo un rendimiento en la extracción de hemicelulosas del 88\% (Söderström et al., 2002). El rendimiento de extracción de azúcares es similar utilizando ambos catalizadores $\left(\mathrm{H}_{2} \mathrm{SO}_{4} \mathrm{O}_{\mathrm{SO}_{2}}\right)$ pero la fermentación de estos azúcares hidrolizados es menor cuando se utiliza $\mathrm{H}_{2} \mathrm{SO}_{4}$ probablemente por la mayor formación de productos de degradación. A su vez, la hidrólisis enzimática de la biomasa pretratada resulta con menores rendimientos de glucosa cuando se impregna con $\mathrm{H}_{2} \mathrm{SO}_{4}$ (Tengborg et al., 1998).

La hidrólisis ácida y la explosión de vapor son tratamientos similares ya que en ambos se produce la hidrólisis ácida de los enlaces glicosídicos de las hemicelulosas y de la celulosa. Una de las diferencias es que en la HAD se utilizan relaciones líquido a sólido más altas que en la EV, por lo tanto con la EV se consigue una fracción soluble de azúcares más concentrada. Además, las temperaturas utilizadas en la EV son mayores mientras que los tiempos de residencia en el reactor son menores que en la HAD (Jørgensen et al., 2007) (Singh et al., 2015). Las hemicelulosas pueden ser hidrolizadas a temperaturas de $160^{\circ} \mathrm{C}$ aproximadamente para formar azúcares con rendimientos razonables ( $>$ a $60 \%$ de extracción de hemicelulosas). Mientras que la hidrólisis de la celulosa requiere temperaturas del orden de $\operatorname{los} 200-240^{\circ} \mathrm{C}$ (Wyman, 1994). Por lo tanto, como en la EV se utilizan temperaturas más altas que en la HAD la degradación de celulosa puede ser mayor. Carrasco et al. compararon ambos procesos y concluyeron que la EV es más eficiente en cuanto a la remoción de hemicelulosas aunque la degradación de azúcares es mayor. A su vez, debido a la degradación de celulosa amorfa el índice de cristalinidad aumenta (Carrasco et al., 1994).

La HAD también ha sido utilizada como pretratamiento para hidrolizar la celulosa mediante un proceso en dos etapas. La primera etapa en condiciones más suaves para hidrolizar las hemicelulosas evitando la formación de productos de degradación y la segunda etapa en condiciones más severas para hidrolizar la celulosa (Janga et al., 2012), (Kim, 2005), (Nguyen et al., 1998). A su vez, Söderström et al. han estudiado el proceso con ácido diluido como pretratamiento de la hidrólisis enzimática. La primera etapa se realizó bajo condiciones suaves $\left(180{ }^{\circ} \mathrm{C}, 10 \mathrm{~min}, 0.5 \% \mathrm{H} 2 \mathrm{SO} 4\right)$ en la cual se extrayeron la mayor parte de las hemicelulosas y en la segunda etapa en condiciones más severas para hidrolizar parte de la celulosa y hacer la celulosa más accesible al ataque enzimático (Söderström et al., 2003).

Una de las principales desventajas del tratamiento ácido es que la lignina sufre reacciones de condensación dando como resultado del proceso una lignina menos reactiva. La elucidación de la estructura de lignina de pino pretratado con ácido sulfúrico reveló un incremento en el grado de condensación de la lignina y una disminución de los enlaces $\beta$-O-4 los cuales fueron fragmentados y luego recondensados (Sannigrahi, Ragauskas, \& Miller, 2008). 
Bajo condiciones ácidas, las reacciones predominantes en la lignina son la fragmentación de los enlaces $\beta$-O-4 y la polimerización mediante condensación catalizada con ácido entre los carbonos aromáticos $\mathrm{C} 6$ o $\mathrm{C} 5$ y un ion carbonio, normalmente localizado en el $\mathrm{C} \alpha$ de la cadena lateral. Ambas reacciones se forman a partir de un intermediario común, el cual es formado de un alcohol bencílico de la lignina. En la depolimerización, el intermediario rompe el enlace éter y la lignina es fragmentada. Sin embargo, cualquier anillo aromático adyacente con un carbono rico en electrones puede competir por el ion carbonio y se forman uniones carbono-carbono estables resultando en la repolimerización de la lignina (Figura I.23). Sólo bajo condiciones muy suaves puede suprimirse esta última reacción (Li et al., 2007) (Pu et al., 2015).

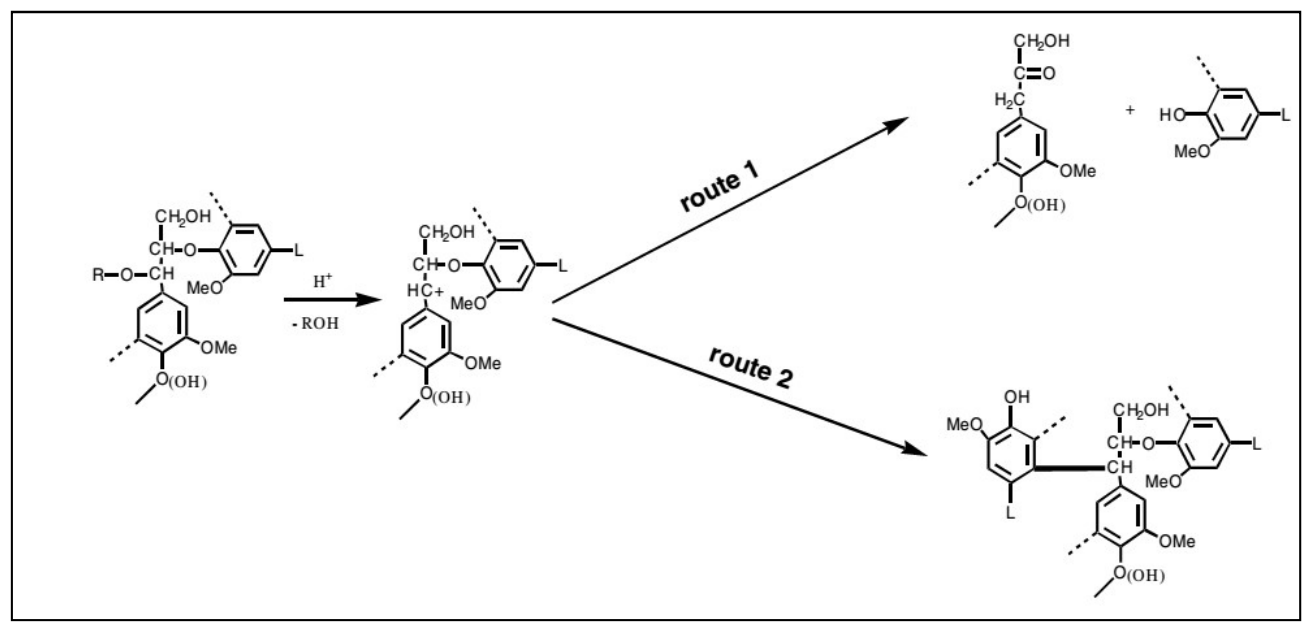

Figura I.23. Esquema de las reacciones de competencia entre la depolimerización $\beta-O-4$ (Ruta 1) y la repolimerización (Ruta2) (Li, 2007)

La proporción de rupturas de enlaces $\beta$-O- 4 es dependiente del tipo de base conjugada utilizada en el siguiente orden: $\mathrm{HBr}>\mathrm{HCl}>\mathrm{H}_{2} \mathrm{SO}_{4}$ (Santos et al., 2013). La formación de enlaces intermoleculares entre fragmentos de lignina es obviamente un proceso contraproductivo si la lignina debe ser depolimerizada para ser extraída de la pared celular. Considerando que la condensación se produce por competencia del ion carbonio (o protonación del oxígeno bencílico), es más probable que ocurra cuando se incrementa la acidez del sistema. Por lo tanto, los tipos de reacciones que se producen en la lignina durante los tratamiento hidrotérmicos son similares a aquellas que ocurren durante la hidrólisis con ácido diluido pero en una menor extensión (Pu et al., 2013). A su vez, la reactividad de los carbocationes guayacilos de las coníferas es mayor que la de los carbocationes siringilos de las latifoliadas, por lo tanto, la lignina de coníferas es más propensa a las reacciones de condensación (Mcdonough, 1992). 


\section{I.4.2.2 Hidrólisis alcalina}

El pretratamiento alcalino consiste en la impregnación de la biomasa con una solución alcalina mezclando a la temperatura de proceso predeterminada por un cierto período de tiempo. Las condiciones utilizadas en las etapas de pretratamiento alcalino son generalmente menos severas que las de otros procesos (menor temperatura y presión), y los tiempos utilizados son de horas o días (Brodeur et al., 2011) (Mosier et al., 2005) (Zheng et al., 2009). Posteriormente, las hemicelulosas extraídas pueden ser recuperadas mediante precipitación por neutralización ácida o por la adición de un solvente, como acetona o etanol (Peng et al., 2012).

Los principales reactivos utilizados en los pretratamientos alcalinos son hidróxido de sodio, amoníaco, calcio, potasio, bario, litio aunque las soluciones acuosas de hidróxido de potasio y sodio son las más utilizadas debido a que permiten obtener un alto rendimiento de hemicelulosas (Gupta, 2008) (Brodeur et al., 2011) (Peng et al., 2012). Varios autores han demostrado que a iguales concentraciones, el hidróxido de sodio es ligeramente más efectivo que el hidróxido de potasio en cuanto a la recuperación de hemicelulosas. Además, el agregado de ácido bórico minimiza la degradación de los grupos reductores terminales facilitando la disolución de los glucomananos en medio alcalino (Peng et al., 2012). El proceso de extracción de hemicelulosas de pino taeda en medio alcalino suave $\left(90^{\circ} \mathrm{C}, 4\right.$ horas y $6 \%$ bs de $\left.\mathrm{NaOH}\right)$ con el agregado de ácido bórico ( $5 \%$ bs) permitió recuperar el $44 \%$ de la manosa presente en el material original, ya que los grupos vecinos cis-hidroxi de la manosa forman un complejo con el borato que es más ácido que las hemicelulosas que se solubiliza en medio alcalino (Huang \& Ragauskas (b), 2013).

Los pretratamientos alcalinos son conocidos por su habilidad de alterar la composición de la lignina y por lo tanto aumentar la digestibilidad de la celulosa (Pedersen \& Meyer, 2010). A su vez, consiguen remover la mayoría de los extractivos presentes en los residuos forestales, resultando en una fracción insoluble rica en carbohidratos (Burkhardt, 2010). En general, las siguientes reacciones son producidas en medio alcalino:

- Deacetilación $\left(\mathrm{T}<70^{\circ} \mathrm{C}\right)$

- Reacciones de peeling y stopping $\left(\mathrm{T}>80^{\circ} \mathrm{C}\right)$

- Hidrolisis alcalina aleatoria de enlaces glucosídicos $\left(T>140^{\circ}\right)$

- Fragmentaciones

- Disolución de hemicelulosas

- Eliminación de metanol de los ácidos 4-O-metilglucurónico

- Re adsorción de hemicelulosas en la superficie de las fibras

- Formación de cromóforos (Sixta et al., 2006). 
La reactividad de los carbohidratos en medio alcalino depende altamente de las características estructurales como la morfología, cristalinidad y el grado de polimerización (GP). Por lo tanto, la celulosa es más resistente en medio alcalino y sufre menos degradación que las hemicelulosas. El hinchamiento promueve la penetración de los licores en la madera. El elevado $\mathrm{pH}$ ioniza parte de los grupos hidroxilos y produce la deacetilación $\left(\mathrm{T}>70^{\circ} \mathrm{c}\right)$ de los acetilos de las hemicelulosas (Sixta et al., 2006).

La degradación de los carbohidratos puede ser divida en tres reacciones básicas. El peeling que lentamente disminuye el GP desde el grupo final reductor de la cadena, mientras que el peeling oxidativo rompe la cadena polimérica aleatoriamente y la hidrólisis alcalina que se produce a temperaturas más altas (Sixta et al., 2006).

La degradación de los polisacáridos empieza en los grupos terminales reductores (peeling primario). Posterior a la hidrólisis alcalina nuevos grupos reductores son generados dando lugar al peeling secundario. La reacción de stopping resulta en la formación de grupos terminales ácidos estables en álcali. Prácticamente todos los carbohidratos perdidos son degradados a una mezcla complicada de hidroxiácidos no volátiles, y cantidades considerables de ácido acético y fórmico son generados. Los hexosanos son principalmente degradados a ácidos glucoisosacarínicos y 25-dihidroxivalérico mientras que los pentosanos son la fuente de producción de ácido xiloisosacarìnico y 2-hidroxibutanoico. En ambos casos, se forman grandes cantidades de ácido láctico (Sjöström, 1977).

La presencia de enlaces ester intramoleculares entre las hemicelulosas y la lignina previenen la solubilización selectiva y remoción de los componentes de la madera durante los procesos de biorrefinería. El mecanismo de tratamiento alcalino involucra la saponificación de estos enlaces causando hinchamiento, incremento de área interna superficial, disminución del grado de polimerización y mayor exposición de la celulosa. Además, la remoción de grupos acetilos y ácidos urónicos de las hemicelulosas incrementa su accesibilidad. En adición, durante los pretratamientos alcalinos se extraen más hemicelulosas que lignina y celulosa (Fan et al., 1982) (Behera et al., 2014) (Hu \& Ragauskas, 2012). Los pretratamientos alcalinos para extracción de hemicelulosas generalmente no alcanzan las altas temperaturas utilizadas en los procesos de pulpado, por lo tanto, a temperaturas menores a $160^{\circ} \mathrm{C}$ unidades fenólicas reactivas de la lignina, tal como $\alpha$-O-4 éteres, se fragmentan y disuelven en el licor. A estas temperaturas las reacciones de condensación de la lignina no son significativas (Sixta et al., 2006) (Sarkanen, 1971). Por lo tanto, en condiciones suaves la deslignificación no es significativa ya que la ruptura de los enlaces $\beta-\mathrm{O}-4$ que son los más abundantes en coníferas (45-60\%) es más importante a temperaturas elevadas. 
Las pérdidas de glucomananos son especialmente altas mientras que los xilanos son más resistentes en medio alcalino. Una de las razones para esta mayor reactividad es la falta de sustituyentes (Sjöström, 1977) (Sixta et al., 2006). A su vez, en vistas a el aprovechamiento de las hemicelulosas, la extracción alcalina es solamente adecuada para latifoliadas o residuos agrícolas ya que los xilanos son disueltos en forma oligomérica mientras que los galactoglucomananos de las coníferas son rápidamente degradadas por la reacción de peeling y por lo tanto pierden su valor de uso (Schild et al., 2010) (Fišerová \& Opalená, 2012).

La efectividad de los tratamientos alcalinos depende del contenido de lignina de la biomasa (Kumar et al., 2009). En general es más efectivo en latifoliadas, cultivos herbáceos y residuos agrícolas con bajo contenido de lignina que para coníferas con alto contenido de lignina. La digestibilidad de latifoliadas tratadas con $\mathrm{NaOH}$ aumentó de $14 \%$ a $55 \%$ con una disminución del contenido de lignina desde $24 \%$ a $20 \%$. Sin embargo, no se observaron efectos al tratar coníferas con un contenido de lignina superior al 26\% (Kumar et al., 2009) (Zheng et al., 2009) (Hu \& Ragauskas, 2012).

A su vez, el medio alcalino es generalmente menos eficiente en cuanto a la solubilización de las hemicelulosas comparado con los tratamientos ácidos (Burkhardt, 2010). Una desventaja significativa del tratamiento alcalino es que el álcali se convierte a sales que pueden ser incorporadas a la biomasa (Behera et al., 2014). Una limitación es el costo de capital del reciclado del álcali (Hu \& Ragauskas, 2012).

\section{I.4.2.3 Deslignificación}

Después de la celulosa, la lignina es el componente más importante de los materiales lignocelulósicos. A pesar de esto, el desarrollo de productos de alto valor a partir de la lignina ha sido considerablemente menos estudiada que el de la celulosa y actualmente se utiliza principalmente como combustible.

La lignina restringe el hinchamiento de la celulosa, se redeposita en las superficie de las fibras y se une covalentemente a las enzimas disminuyendo su efectividad. Por este motivo, para disminuir la recalcitrancia de los materiales lignocelulósicos y aumentar la digestibilidad enzimática para obtener celulosa de alta pureza con gran potencial para la producción de bioetanol, se han aplicado procesos deslignificantes (Kumar et al., 2012). A su vez, la lignina puede ser separada de las corrientes líquidas de los procesos y utilizada como materia prima para la producción de productos de alto valor, como la vainillina. La producción de etanol no es económicamente competitiva sin una aplicación efectiva de la lignina (Li et al., 2009). 
Actualmente, uno de los mayores desafíos en la biorrefinería es obtener estructuras de lignina que permitan su valorización y no sólo para reducir la recalcitrancia de la biomasa (Ragauskas, 2014). Otro desafío consiste en aumentar la selectividad del proceso, es decir conservar la fracción de carbohidratos tanto como sea posible (Kumar, 2013).

Los pretratamientos que tienen como objetivo la extracción de lignina tienen sus orígenes técnicos en la industria química de pulpado (Ragauskas, 2014). Pero a pesar de que la remoción de lignina es técnicamente posible mediante los procesos de pulpados utilizados actualmente, estos procesos no son económicamente factibles para su aplicación en la bioconversión de materiales lignocelulósicos. El valor relativamente alto de la pulpa (US 800 por tonelada de pulpa blanqueada kraft en Estados Unidos $^{3}$ ) puede justificar el alto costo de capital y los costos operativos del pulpado químico, mientras que los biocombustibles que son de bajo valor comercial deben buscar alternativas de tratamientos más baratos (Nakagame, 2010) (Chandra et al., 2007).

Las alternativas de deslignificación más estudiadas como parte de secuencias de fraccionamiento, son los procesos alcalinos más atranquinona (Reguant et al., 1997), (Anglés Neus et al., 2003), oxidativos (Maekawa, 1996) (Schwald et al., 1989) (Yang et al., 2002) (Palonen et al., 2004) (Kumar, 2013) (Pan et al., 2004) (Draude et al., 2001) y el proceso organosolv (Sannigrahi, Miller \& Ragauskas, 2010) (Park et al., 2010) (Pan et al., 2007).

En los procesos de explosión de vapor, las altas presiones modifican químicamente la lignina la cual puede ser posteriormente extraída aplicando un lavado alcalino suave o con procesos oxidativos. Para las latifoliadas o residuos agro-industriales se obtienen altos rendimientos de extracción en cambio en coníferas es necesario utilizar otros tratamientos más severos (Pereira Ramos, 2003).

Los tratamientos alcalinos de la materia prima lignocelulósica se encuentran ampliamente difundidos y utilizados en la industria de transformación química de dicho material en pulpa celulósica. El proceso de pulpado Kraft, que utiliza $\mathrm{NaOH}$ y $\mathrm{Na}_{2} \mathrm{~S}$, es el más popular entre los tratamientos alcalinos a nivel mundial. Los problemas ambientales derivados de los tratamientos que involucran dichos compuestos alentaron la búsqueda de alternativas libres de sulfurados, como el pulpado alcalino a la Soda con Atraquinona (AQ). La utilización de AQ como aditivo presenta el beneficio de incrementar el rendimiento al preservar los carbohidratos, a la vez que aumenta el grado de deslignificación, lo cual se ve fundamentado en el mecanismo de acción de la misma (Grace \& Malcolm, 1989).Además, este proceso permite la obtención de ligninas libre

\footnotetext{
${ }^{3}$ De acuerdo al PIX (Pulp Bencmark Index). http://www.foex.fi/PIX/pulp-paper/
} 
de azufre que es una ventaja en algunas aplicaciones futuras de productos de alto valor de la lignina, como la fibras de carbono (von Schenck et al., 2013).

Reguant et al. estudiaron la deslignificación soda/antraquinona en aserrín de pino y spruce pretratado con vapor para la producción de pulpa blanqueada. Este proceso en condiciones optimizadas $\left(170^{\circ} \mathrm{C}, 40 \%\right.$ de $\mathrm{NaOH}, 150$ min y $0,1 \%$ bs de $\left.\mathrm{AQ}\right)$ produjo pulpas con un número de Kappa de 16.6 (el número de Kappa es un parámetro que indica el contenido de lignina residual en pulpas). Además, concluyeron que la deslignificación aumenta cuando la severidad del pretratamiento aplicado se incrementa (Reguant et al., 1997). Por el contrario, el rendimiento de recuperación de lignina posterior del licor es menor debido a que en condiciones más severas de pretratamiento las lignina sufre reacciones de condensación produciendo moléculas con enlaces C-C muy estables difíciles de extraer o transformar (Anglés Neus et al., 2003)

La aplicación de una secuencia ácida-deslignificación alcalina de pino no resultó interesante debido al bajo rendimiento de carbohidratos ( $8 \%$ menor comparado a la aplicación de solo una etapa alcalina con soda/AQ) (von Schenck et al., 2013).

La química de los procesos alcalino se basa en tres grupos de reacciones: fragmentación, degradación y disolución y condensación de la lignina (Fengel, 1989) (Sixta et al., 2006) (Gupta Kumar \& Tuohy, 2013) siendo los iones hidroxilo los responsables de la deslignificación. Las reacciones de degradación producen la liberación de fragmentos de lignina y su posterior disolución. Las reacciones de condensación generan enlaces estables incrementando el peso molecular de los fragmentos de la lignina y pueden resultar en su reprecipitación.

Las siguientes reacciones son la base de la degradación/disolución de las porciones fenólicas de la lignina: ionización de grupos fenólicos, ruptura de enlaces $\alpha$ aril éter y el enlace más abundante $\beta$-O-4 éter y liberación de grupos fenólicos libres. En la figura I.24 se muestra la ruptura alcalina del enlace $\alpha$-aril éter en unidades fenólicas fenilpropano. A partir de la ruptura de estos enlaces, se forma de manera reversible un intermediario denominado quinonametídica. En una reacción subsecuente se produce la adición nucleofílica del $\mathrm{OH}$ al $\mathrm{C} \alpha$ de la quinonametídica resultando en rupturas de uniones internas de la lignina y una mayor hidrofilicidad de los fragmentos con una mejor disolución en el licor. La adición del ión hidrosulfuro en el pulpado Kraft representa una ventaja con respecto al pulpado a la soda, ya que este ión presenta mayor nucleofilicidad que el ion $\mathrm{OH}$. A su vez la adición de sulfuro reduce la extensión de las reacciones indeseadas de condensación (Sarkanen, 1971) (Sixta et al., 2006) (Santos et al., 2013). 


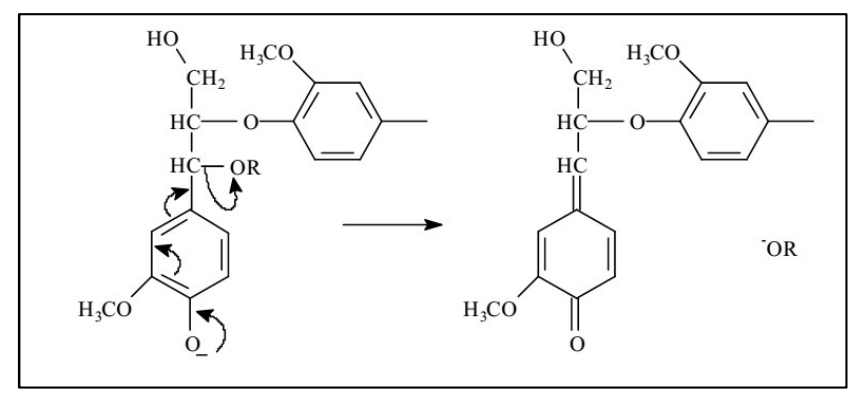

Figura I.24 Ruptura alcalina del enlace $\alpha$-aril éter en unidades fenólicas fenilpropano

(Ragauskas, 2015)

Las reacciones sufridas por la lignina en los procesos de deslignificación alcalinos convierten al polímero parcialmente hidrofílico permitiendo su solubilización en el licor alcalino (Ragauskas, 2015).

El proceso organosolv se puede llevar a cabo en condiciones alcalinas o ácidas, dependiendo del catalizador utilizado. Este proceso consiste en el tratamiento de la biomasa con una mezcla de agua y solventes orgánicos junto con la adición de un catalizador a $140-200^{\circ} \mathrm{C}$. La celulosa puede ser recuperada en la fase sólida y la lignina y hemicelulosas pueden ser obtenidas después de la extracción o destilación de la fase líquida. Los solventes más utilizados son el etanol y metanol debido a su bajo costo, bajo punto de ebullición y fácil recuperación (Xu et al., 2013) (Sannigrahi \& Ragauskas, 2013). Diferentes catalizadores han sido evaluados para biomasa lignocelulósica, siendo los más estudiados el ácido sulfúrico y el hidróxido de sodio. Park et al. aplicaron este proceso a pino evaluando el uso de tres catalizadores (ácido sulfúrico, hidróxido de sodio y magnesio) con etanol y concluyeron que el ácido sulfúrico es el más eficiente en cuanto a la digestibilidad enzimática del material (93\% a las 72 horas) aunque la deslignificación no fue significativa. Por el contrario, el proceso en medio alcalino dio el menor rendimiento de hidrólisis enzimática (73\% a las 72 horas) y mayor rendimiento de deslignificación (Park et al., 2010). El tratamiento de aserrín de pino con etanol sin la adición de catalizador consigue un rendimiento de hidrólisis enzimática considerablemente más bajo ( $30 \%$ a las 50 horas con una carga enzimática de 12 FPU) a pesar de la elevada eficiencia en la deslignificación (76,5\%) (Xu et al., 2013).

El tratamiento organosolv típicamente resulta en una remoción de lignina del $50 \%$ a través de la ruptura de uniones lignina-carbohidrato y enlaces $\beta$-O-4 con la subsecuente solubilización en el solvente orgánico (Ragauskas, 2014). Por ejemplo, la aplicación de este proceso con etanol y ácido sulfúrico $\left(65 \%\right.$ de etanol, $170^{\circ} \mathrm{C}, 70 \mathrm{~min}$ y $\left.1,1 \% \mathrm{H}_{2} \mathrm{SO}_{4}\right)$ a pino permite obtener una recuperación de celulosa del 75-80\% con una deslignificación de 60\% aproximadamente (Pan et 
al., 2007), (Sannigrahi, Miller \& Ragauskas, 2010). Pan et al. obtuvieron un rendimiento de conversión de celulosa a glucosa de 93-97\%.

La deslignificación parcial de la biomasa lignocelulósica puede alcanzarse con un agente oxidante como el peróxido de hidrógeno, ozono, oxígeno o aire (Kumar Gupta \& Tuohy, 2013). Estos procesos son comúnmente aplicados como parte de las secuencias de blanqueo utilizadas en las industrias de fabricación de pulpa. Por lo tanto, generalmente se aplica a pulpas con contenido relativamente bajo de lignina (por ejemplo: pulpas kraft), siendo un desafío su aplicación a materiales con alto contenido de lignina ( $>40 \%$ ) (Kumar, 2013). A su vez, en un marco de biorrefinería son generalmente utilizados como post tratamientos para aumentar la digestibilidad enzimática de la biomasa pretratada (Pan et al., 2005).

El tratamiento con peróxido alcalino ha sido reportado como un proceso altamente efectivo en la remoción de lignina y mejoramiento de la hidrólisis enzimática de varias coníferas pretratadas con vapor (Maekawa, 1996), (Yang et al., 2002), (Schwald et al., 1989). Por ejemplo, el tratamiento con peróxido alcalino de Douglas Fir pretratado (impregnado con $\mathrm{SO}_{2}$ y explosión de vapor) con una carga de peróxido de hidrógeno de $1 \% \mathrm{p} / \mathrm{p}$ a $80^{\circ} \mathrm{C}$ por $45 \mathrm{~min}$ a $\mathrm{pH} 11,5$ permitió solubililizar más del 90\% de la lignina residual e hidrolizar la fracción celulósica obtenida completamente a las 48 horas con una carga enzimática de 20 FPU/g de celulosa (Yang et al., 2002).

El mecanismo de reacción no está completamente establecido pero se cree que los productos de la descomposición del peróxido de hidrógeno en medio alcalino (radicales hidroxilos y aniones superoxidos) causan la oxidación de la estructuras de la lignina formando grupos hidrofílicos (carboxilos), la ruptura de algunas uniones y eventualmente la disolución de la lignina. Al mismo tiempo los radicales libres pueden depolimerizar la celulosa. La descomposición del peróxido está influenciada por la presencia de metales que actúan como estabilizantes del mismo, por lo cual generalmente, se agregan agentes quelantes que forman un complejo con los mismos eliminando su efecto. A su vez, los pretratamientos ácidos mejoran la deslignificación con peróxido ya que eliminan los metales del material (Lachenal, 1996).

El proceso de peróxido alcalino requiere la aplicación de altas cargas de peróxido que hace impráctica su aplicación industrial. Por lo tanto, una alternativa es la oxidación húmeda que consiste en la aplicación de oxígeno o aire en medio alcalino que es un proceso ampliamente utilizado en pulpado y blanqueo. Pan et al. aplicaron este proceso a abeto Douglas exploído (impregnado con $\mathrm{SO}_{2}$ y explosión de vapor) bajo condiciones optimizadas (presión de oxígeno de $0,5 \mathrm{MPa}, 15 \% \mathrm{NaOH}, 110^{\circ} \mathrm{C}$ y $3 \mathrm{~h}$ ) y obtuvieron un $84 \%$ de deslignificación con una posterior 
conversión de celulosa a glucosa de $90 \%$ a las 48 h con una carga enzimática de $20 \mathrm{FPU} / \mathrm{g}$ de celulosa (Pan et al., 2004).

La oxidación húmeda es un método oxidativo que emplea aire u oxígeno como catalizador a bajas temperaturas que ha sido probado como un método eficiente para la solubilización de hemicelulosa y lignina mientras incrementa la digestibilidad enzimática de la biomasa (Huang \& Ragauskas (a), 2013). Este tratamiento aplicado a Picea abies a $200^{\circ} \mathrm{C}, 10 \mathrm{~min}$ y $\mathrm{pH}$ neutro permitió obtener una conversión del $79 \%$ de celulosa a glucosa a las 72 h con $30 \mathrm{FPU} / \mathrm{g}$ de celulosa. Aunque este aumento del rendimiento de la hidrólisis enzimática fue atribuido a la extracción de hemicelulosas ya que no hubo deslignificación significativa (Palonen et al., 2004).

El ozono es un potente agente oxidante que reacciona con los grupos fenólicos de la lignina formando un gran número de ácido carboxílicos que hacen a la lignina más hidrofílica. La susceptibilidad de los carbohidratos de reaccionar con los productos de degradación del ozono restringe la capacidad de utilización del ozono en los procesos de blanqueo (van Lierop et al., 1996). La aplicación de ozono en coníferas no ha permitido obtener una deslignificación significativa y en consecuencia, los rendimientos de la hidrólisis enzimática son bajos (Sannigrahi et al., 2012), (Yu et al., 2011). Yu et al. atribuyen este resultado a que debido a la alta reactividad del ozono éste reacciona mayormente en la superficie de la biomasa antes de penetrar en la estructura más interna dando lugar a una deslignificación poco uniforme. La principal ventaja de este proceso es que no genera ningún producto de degradación que interfiera en los procesos biológicos mientras que su principal desventaja es la gran cantidad de ozono utilizada, tornando al proceso muy costoso (Huang \& Ragauskas (a), 2013).

La deslignificación con oxígeno es ampliamente utilizada en la industria de pulpa y papel. Este proceso ha sido definido como un método en el cual una fracción de lignina residual de pulpa sin blanquear puede ser removida usando oxígeno y álcali. En general, la química de la deslignificación con oxígeno involucra hidrólisis alcalina de la cadena de celulosa y ruptura de la molécula de lignina mediante reacciones con radicales libres y en condiciones más severas condensación de la lignina (Pan et al., 2004).

Las condiciones típicamente utilizadas en las fábricas de pulpa son: media consistencia (10-14\%), temperaturas de $85-105^{\circ} \mathrm{C}$ por 60 min. y bajo presión (700-800 $\mathrm{kPa}$ de presión interna). En estas condiciones se consigue disolver el $50 \%$ de la lignina presente en una pulpa Kraft sin impacto significativo en el rendimiento y resistencia de la pulpa. La aplicación de este proceso a sustratos con alto contenido de lignina ha sido escasamente estudiado (Pan et al., 2004), (Draude et al., 2001), (Charles et al., 1998). 
Pan et al. han encontrado que la biomasa con alto contenido de lignina se comporta de manera diferente durante la deslignificación con oxígeno ya que las reacciones de condensación de la lignina y destrucción de la celulosa fueron más importantes que la deslignificación. Sin embargo, en condiciones más suaves consiguieron remover el $84 \%$ de la lignina siendo la pérdida de carbohidratos del 10\% aumentando la digestibilidad enzimática a $90 \%$ en 48 h con 20 FPU/g de celulosa (Pan et al., 2004).

\section{I.4.3 Cambios estructurales producidos durante el pretratamiento y su relación con la hidrólisis enzimática}

La hidrólisis enzimática (HE) es una reacción heterogénea multietapa en la cual la celulosa se rompe inicialmente en la interfase sólido-líquido a través de la acción sinérgica de endoglucanasas y exoglucanasas/celobiohidrolasa, como se observa en la Figura I.25. Esta reacción inicial es acompañada por una posterior hidrólisis de los compuestos solubles en la fase líquida, como los oligosacáridos y la celobiosa, para producir glucosa por la acción de la $\beta$-glucosidasas (Yang et al, 2011). La acción de las enzimas está influenciada por las características estructurales de los materiales lignocelulósicos. El principal objetivo de la etapa de pretratamiento en la producción de bioetanol de segunda generación consiste en modificar esta estructura disminuyendo la recalcitrancia de la celulosa para aumentar el rendimiento de la HE (Sannigrahi \& Ragauskas, 2008).

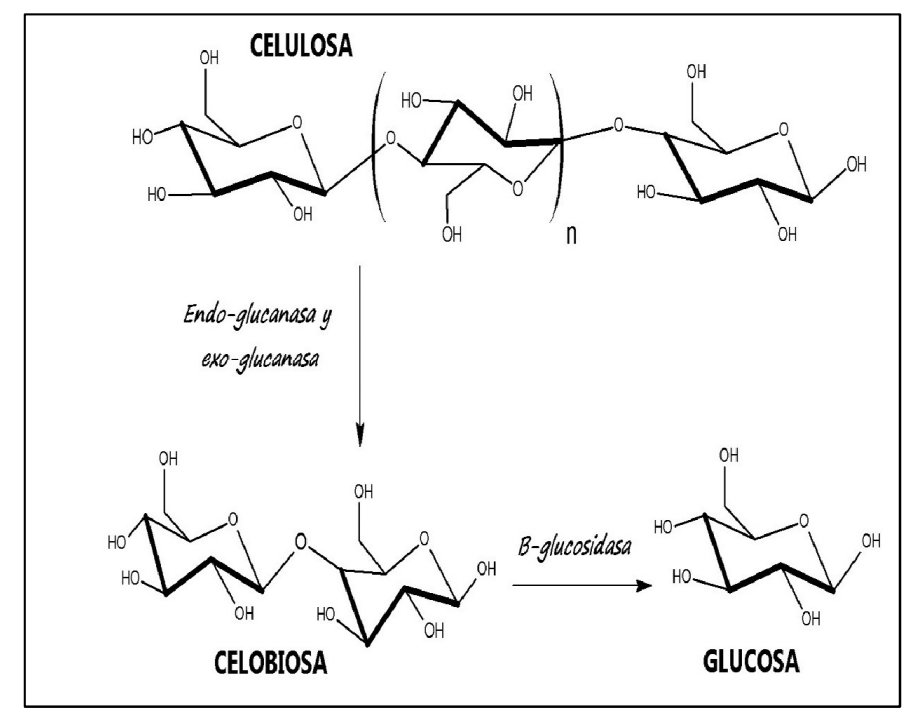

Figura I.25. Hidrólisis enzimática de la celulosa (Sánchez Ramírez et al., 2014) 
La microestructura compleja de los materiales lignocelulósicos está compuesta por lignina y una matriz de hemicelulosas, que encapsulan y sostienen las fibrilas de celulosa. Durante los procesos de fraccionamiento/pretratamiento la estructura de los materiales lignocelulósicas es alterada como resultado de las altas temperaturas utilizadas y de la solubilización de las hemicelulosas causando cambios estructurales en la lignina y la celulosa (Yang et al., 2011) (Pu et al., 2013).

\section{I.4.3.1 Cambios estructurales de la celulosa}

Las características físicas de la celulosa que se modifican durante los pretratamientos son el grado de cristalinidad, el grado de polimerización y el área superficial accesible (Yang et al., 2011).

Como ya se ha mencionado anteriormente, las fibrillas de celulosa son una mezcla de regiones más ordenada y otras desordenadas. La cristalinidad de la celulosa aumenta durante los pretratamientos a causa de la degradación de las regiones más accesibles que son menos estables. A su vez, la celulosa está formada por una región ordenada que es una mezcla de dos alomorfos cristalinos, la celulosa $\mathrm{I}_{\alpha}$ y la celulosa $\mathrm{I}_{\beta}$. La primera es meta estable y puede ser convertida termodinámicamente al alomorfo estable $\mathrm{I}_{\beta}$ que es más resistente al ataque enzimático (Debzi et al., 1991). Se ha reportado que durante los pretratamientos la celulosa $I_{\alpha}$ es convertida a celulosa para-cristalina que luego se transforma a celulosa $I_{\beta}$. (Sannigrahi \& Ragauskas, 2008) (Foston \& Ragauskas, 2010). Esta transformación puede provocar un rendimiento más bajo de la HE.

La longitud de la cadena de la celulosa expresada como grado de polimerización (GP) puede afectar las propiedades mecánicas de materiales compuestos y del papel, la solubilidad de la celulosa en un determinado solvente y la eficiencia de la hidrólisis enzimática. Por lo tanto, el GP es una de las propiedades estructurales de la celulosa más importantes. Un menor GP favorece la hidrólisis enzimática porque las cadenas de celulosa más cortas forman menos enlaces hidrógenos que contribuyan a la estructura cristalina incrementando así la accesibilidad de las enzimas a la celulosa y a su vez, el número de grupos finales reductores permitiendo una actividad más efectiva de las exoglucanasas (Pu et al., 2013).

Los pretratamientos producen una parcial hidrólisis de la celulosa que resulta en una disminución del GP, que es aún mayor a severidades más altas de pretratamiento. El GP de la celulosa decrece gradualmente hasta alcanzar un valor nominal llamado grado de polimerización estabilizado. La disminución inicial del GP representa la hidrólisis de la región amorfa, mientras que la meseta corresponde a la hidrólisis lenta de la región cristalina de la celulosa (Pu et al., 2013). Huang et 
al. comprobaron que el GP de pino tratado con ácido sulfúrico diluido a $180^{\circ} \mathrm{C}$ durante $30 \mathrm{~min}$ disminuyó entre 60-64\% en comparación con el material inicial (Huang \& Ragauskas (b), 2012).

El área superficial puede ser dividida como el área superficial interior que es esencialmente reflejada por la porosidad de la biomasa, y el área superficial exterior que es determinada por el tamaño de partícula (Meng \& Ragauskas, 2014). El área específica superficial y el tamaño medio de poro influencian la adsorción de las enzimas en la superficie de la celulosa y la subsecuente desconstrucción enzimática. Los pretratamientos provocan un incremento del área superficial, del volumen y tamaño de poro a causa de la descomposición y desprendimiento de la estructura lignocelulósica (Pu et al., 2013). El incremento de la accesibilidad de la celulosa en la explosión de vapor, autohidrólisis e hidrólisis con ácido diluido es debido a la remoción de hemicelulosas mientras que en los procesos de deslignificación, como el proceso organosolv este aumento es provocado tanto por la remoción de la lignina como de las hemicelulosas (Meng \& Ragauskas, 2014). Meng et al. demostraron que los tratamientos ácidos son más efectivos que los procesos alcalinos en términos de incremento de la accesibilidad de la celulosa (Meng et al., 2015).

Meng et al compararon los efectos producidos en la accesibilidad de madera de álamo durante dos pretratamientos llevados a cabo a $150^{\circ} \mathrm{C}$ : ácido sulfúrico diluido y explosión de vapor (EV) con agua. El pretratamiento con ácido diluido fue más efectivo en términos de área superficial accesible a pesar de la descompresión explosiva en el tratamiento EV. Sin embargo, el tratamiento EV fue más efectivo en cuanto al aumento de la porosidad (Meng et al., 2013). Muzamal et al han concluido que durante los procesos de explosión de vapor la descompresión final no es la responsable de la desintegración de la madera, si no que esto ocurre por el ablandamiento de las fibras a alta temperatura. Durante el tratamiento de explosión de vapor se produce un aumento de la porosidad de las traqueidas (Muzamal et al., 2015).

\section{I.4.3.2 Cambios estructurales de la lignina}

La lignina es considerada el componente que provoca más recalcitrancia a la pared celular de la madera ya que actua como un pegamento de los componentes de la pared celular restringiendo la accesibilidad de la celulosa. A su vez, la lignina es negativa para la HE porque las enzimas se adsorben a esta molécula disminuyendo la efectividad de las mismas. En general, a mayor contenido de lignina menor rendimiento de la hidrólisis enzimática (Yang et al., 2011) (Pu et al., 2013). Este es una de las causas por las cuales las coníferas suelen ser más refractarias al ataque enzimático. Los procesos que extraen lignina contribuyen en la mejora de la digestibilidad de la celulosa. Por ejemplo, Kruyeniski et al. concluyeron que existe una correlación negativa entre el rendimiento de la HE y el contenido de lignina de aserrín de pino tratado con etanol e hidróxido 
de sodio (Kruyeniski et al, 2015). Yu et al. demostraron que la remoción de lignina no solamente expone más a la celulosa sino también incrementa la porosidad del material y rompe el complejo lignina-carbohidrato (Yu et al., 2011).

Durante los pretratamientos en medio ácido las reacciones predominantes que se producen en la lignina son reacciones de fragmentación por ruptura de enlaces $\beta-\mathrm{O}-4$ y reacciones de condensación. Los cambios producidos en el peso molecular de la lignina indican el grado de ocurrencia de estas reacciones, ya que la ruptura de los enlaces $\beta-\mathrm{O}-4$ genera una disminución en el peso molecular y las reacciones de condensación un incremento del mismo (Pu et al., 2013). El peso molecular es una propiedad fundamental que influye en la recalcitrancia de la biomasa y en la valorización de la lignina (Tolbert et al., 2014). Estudios demostraron que a medida que se incrementa el tiempo de pretratamiento las reacciones de recondensación son dominantes, resultando en un incremento del peso molecular (Pu et al., 2013) (Sun et al., 2015). Sin embargo, el comportamiento del peso molecular de la lignina en condiciones ácidas depende del tipo de pretratamiento, severidad aplicada y tipo de biomasa (Pu et al., 2015).

Además, la lignina se relocaliza y redistribuye durante los pretratamientos, formando burbujas de lignina o aglomerados con varias morfologías (Pu et al., 2015). Las altas temperaturas provocan la licuefacción de la lignina lo cual permite que esta se vuelva más elástica. Cuando la temperatura y la presión se reducen, la lignina liberada se aglomera en la pared celular (debido a su naturaleza hidrofóbica) y se condensa formando enlaces bifeniles 5-5' y nuevos enlaces C-C. Esta lignina condensada es mucho más difícil de remover que la lignina nativa y como tiende a acumularse en el lúmen y en las áreas que han sido abiertas durante el pretratamiento, se observa una disminución de la porosidad y por ende de la eficacia de los procesos químicos o biológicos que son aplicados posteriormente (Cullis, 2003). Kobayashi et al. observaron que la lignina de álamo pretratado con ácido sulfúrico diluido a temperaturas $\geq 140^{\circ} \mathrm{C}$ se vuelve más rígida como resultado de la ruptura de enlaces éter y subsecuente formación de nuevos enlaces, es decir recondensación de la lignina (Kobayashi et al, 2011).

\section{I.4.3.3 Cambios estructurales de las hemicelulosas}

Las hemicelulosas envuelven y protegen a la celulosa influenciando la recalcitrancia de la biomasa al ataque enzimático (Pu et al., 2013) (Yang et al., 2011). Por lo tanto, la extracción de las hemicelulosas podría incrementar la accesibilidad de la celulosa durante la hidrólisis enzimática. Varios autores han demostrado que la disolución de las hemicelulosas durante el pretratamiento incrementa la porosidad del material y en consecuencia la digestibilidad enzimática de la biomasa (Singh et al., 2015) (Chandra et al., 2007) (Grethlein \& Converse, 1991). 
Las cadenas de hemicelulosas son extensamente acetiladas, y los grupos acetilos incrementan la recalcitrancia de los materiales lignocelulósicos ya que restringen la accesibilidad de la celulosa. Por lo tanto, la deacetilación provee más sitios para la unión de las enzimas favoreciendo la digestibilidad enzimática de materiales pretratados (Pu et al., 2013) (Yang et al., 2011).

La degradación de las hemicelulosas en medio ácido contribuye a la formación de pseudolignina que es incluso más negativo al proceso enzimático que la lignina pretratada (Pu et al., 2013). Este material aromático es producido por la condensación de los productos de degradación de los polisacáridos (Sannigrahi, Ragauskas y Miller, 2008). 


\section{CAPÍTULO II.}

OBJETIVOS 


\section{CAPITULO II. OBJETIVOS}

\section{II.1 OBJETIVO GENERAL}

El objetivo general de esta tesis doctoral consiste en aplicar el concepto de biorrefinería al aserrín generado en la industrialización primaria de pino, mediante el diseño y optimización de secuencias de fraccionamiento, rentables y amigables con el medioambiente, combinando procesos fisicoquímicos de separación, para lograr su aprovechamiento integral mediante el desarrollo de productos de alto valor agregado (productos intermedios, bioetanol y biomateriales).

\section{II.2 OBJETIVOS PARTICULARES}

Para lograr el objetivo general es necesario alcanzar distintos objetivos específicos, entre los que se incluyen los siguientes:

$\checkmark$ Caracterización físico-química de aserrines generados en aserraderos seleccionados de la provincia de Misiones a fines de conocer la variabilidad que puede existir dependiendo del proceso de aserrado y la especie de la cual provengan.

$\checkmark$ Diseño y optimización de una etapa de desresinación alcalina del residuo.

$\checkmark$ Diseño y optimización de la extracción de hemicelulosas a través de dos tecnologías: hidrólisis ácida diluida y explosión de vapor.

$\checkmark$ Evaluación de diferentes alternativas de deslignificación: soda/antraquinona, organosolv alcalino, peróxido de hidrógeno alcalino, oxígeno alcalino.

$\checkmark$ Caracterización química de las fracciones líquidas y sólidas obtenidas durante los diferentes fraccionamientos.

$\checkmark$ Evaluación de los cambios estructurales producidos en el aserrín de pino durante el proceso de fraccionamiento.

$\checkmark$ Comparación de los procesos considerando los rendimientos y características químicas y fisicoquímicas de los materiales obtenidos.

$\checkmark$ Evaluación de la fracción celulósica obtenida para su posterior conversión a bioetanol. 


\section{CAPÍTULO III.}

MATERIALES $\gamma$

MÉTODOS 


\section{CAPITULO III. MATERIALES Y MÉTODOS}

\section{III.1 MATERIALES}

\section{III.1.1 Materias primas}

Se utilizaron como materia prima los residuos lignocelulósicos generados por la industrialización primaria de pino de la provincia de Misiones. Con el objetivo de obtener una muestra representativa de los residuos que se generan se recolectaron muestras de pilas de aserrín de dos aserraderos ubicados en distintas zonas de la provincia (norte y sur), que procesan principalmente pino elliottii (Tabla III.1). Se determinó la humedad inicial del material y luego se secó al aire hasta alcanzar una humedad de equilibrio de entre 10 y $12 \%$.

Tabla III.3. Aserraderos muestreados, ubicación y especie procesada.

\begin{tabular}{|l|c|c|}
\hline \multicolumn{1}{|c|}{ Aserradero } & Zona & \multicolumn{1}{c|}{$\begin{array}{c}\text { Materia } \\
\text { prima }\end{array}$} \\
\hline Aserradero Forestal Eldorado & Norte & pino elliottii \\
\hline Aserradero Forestal AM & Sur & pino elliotti \\
\hline
\end{tabular}

Para la caracterización física se tomó una muestra de $700 \mathrm{~g}$ aproximadamente utilizando el método de cuarteo sucesivo y se determinó la granulometría por medio de tamizado con tamices normalizados de 8, 10, 18, 40 y 60 mesh según normas ASTM E11 (ASTM 1995). Se determinaron los pesos y los porcentajes de cada fracción.

Posteriormente, se realizó un fraccionamiento grueso de todo el material para lo cual se utilizaron tamices con aberturas cuadradas de tres tamaños diferentes (Tabla III.2).

Tabla III.2. Fraccionamiento grueso de la materia prima

\begin{tabular}{|l|c|c|c|c|}
\hline & \multicolumn{2}{|c|}{ Forestal Eldorado } & \multicolumn{2}{c|}{ Fores tal AM } \\
\hline Fracciones & Peso (g) & \% & Peso (g) & \% \\
\hline R 12,5 mm & 228 & 2,0 & 251 & 2,3 \\
\hline R 5 mm & 1682 & 14,9 & 459 & 4,2 \\
\hline R 3 $\mathbf{~ m m}$ & 2947 & 26,0 & 3049 & 27,7 \\
\hline P 3 mm & 6469 & $\mathbf{5 7 , 1}$ & 7251 & $\mathbf{6 5 , 9}$ \\
\hline Total & 11326 & 100 & 11010 & 100 \\
\hline
\end{tabular}


En ambos casos, la fracción P3 (pasa aberturas de $3 \mathrm{~mm}$ ) resultó en mayor proporción. La hidrólisis ácida diluida se realizó con esta fracción mientras que la explosión de vapor se realizó con el aserrín R3 (aserrín que pasa aberturas de $5 \mathrm{~mm}$ y queda retenido en aberturas de $3 \mathrm{~mm}$ ), debido al mayor volumen del reactor, para evitar la compactación del aserrín dentro del mismo y facilitar su manipulación.

\section{III.1.2 Reactivos y Enzimas}

Los reactivos utilizados fueron $\mathrm{NaOH}, \mathrm{H}_{2} \mathrm{SO}_{4}$, Etanol y $\mathrm{H}_{2} \mathrm{O}_{2}$ (Anedra) y Antraquinona (Aldrich) todos de grado analítico. El $\mathrm{O}_{2}$ (La Oxigena) utilizado fue de grado medicinal. Los patrones utilizados para las curvas de calibración de azúcares (celobiosa, glucosa, xilosa, arabinosa, manosa y galactosa), del standard interno (manitol) y productos de degradación (furfural, HMF y ácido acético) utilizados para la cuantificación cromatográfica fueron de Sigma Aldrich.

Las enzimas utilizadas fueron enzimas comerciales celulasas de Trichoderma Reesei (actividad $51 \mathrm{FPU} / \mathrm{mL}$ de celulasa) y celobiasa de Aspergillus niger (339 IU celobiosa) adquiridas a través de Sigma Adrich.

\section{III.2 MÉTODOS DE CARACTERIZACIÓN}

En esta sección se describen los métodos utilizados para la caracterización de muestras sólidas (materias primas y sólidos pretratados) y líquidas (líquidos de pretratamiento, hidrolizados).

\section{III.2.1 Caracterización química de muestras sólidas}

La caracterización química del aserrín utilizado como materia prima, y de la fracción sólida resultante de los diferentes pretratamientos se llevó a cabo según normas estándares del Laboratory Analytical Procedure, Technical Reports (NREL/TP). La mayoría de estos procedimientos provienen de normas de organismos internacionales como ASTM (American Society for Testing and Materials) y la IUPAC (International Union of Pure and Applied Chemistry). Un esquema del procedimiento de caracterización del material puede observarse en la Figura III.1. Las determinaciones se realizaron a cada muestra por duplicado. 


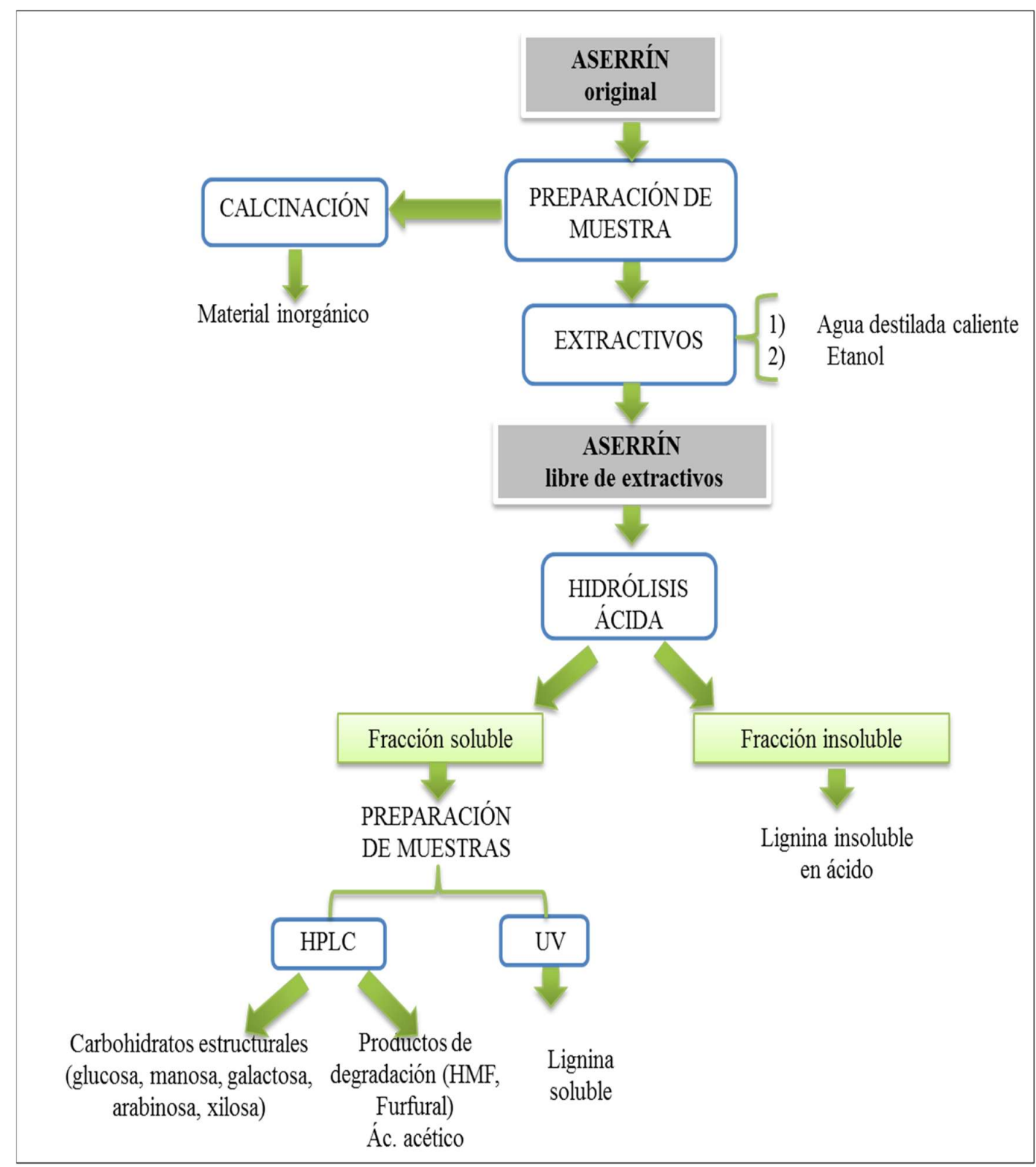

Figura III.1 Esquema de caracterización del aserrín, antes y después de los tratamientos.

\section{III.2.1.1 Toma y Preparación de muestras}

La toma y preparación de las muestras antes del análisis de cenizas, extractivos, carbohidratos y lignina soluble e insoluble en ácido se llevó a cabo siguiendo el procedimiento "Preparación de muestras para análisis de composición”, NREL/TP-510-42620 (Hames et al., 2005). Se utilizó el método de preparación de muestra A (secado al aire). Se tomó una muestra de aserrín de la fracción R3 proveniente del tamizado grueso. La muestra seca al aire se pesó en balanza analítica con $0,1 \mathrm{mg}$ de precisión y luego fue mantenida en la estufa hasta que la variación en peso de biomasa fue inferior a 1\%. Luego se molió la muestra, se tamizó y la fracción retenida en un tamiz 
de malla 80 mesh se utilizó para el análisis composicional. Finalmente, la muestra se almacenó en un recipiente hermético hasta su utilización. Se determinó la composición, expresado en porcentaje como base seca.

\section{III.2.1.2. Determinación de sólidos totales y humedad}

La determinación de sólidos totales y humedad se realizó según el método NREL/TP-510-42621 (Sluiter et al. (a), 2008), que utiliza horno a convección para la determinación de humedad. Para ello, se colocó la muestra en una cápsula previamente tarada en estufa a $105 \pm 3^{\circ} \mathrm{C}$ durante $1 \mathrm{~h}$. Se enfrió en desecador hasta temperatura ambiente y se pesó con precisión de 0,1 mg en balanza analítica. Se repitió el procedimiento hasta que la variación de dos pesadas sucesivas fue inferior a $0,1 \%$. El resultado obtenido se expresó en porcentaje, relacionando la masa de sólido seco con la masa del sólido inicial (Ec.III.1).

Sequedad $(\%)=\frac{\text { Peso seco }}{\text { Peso húmedo }} * 100$

Ec.III.1

\section{III.2.1.3. Componentes extraíbles en agua y alcohol etílico}

Se evaluaron los componentes extraíbles en agua y alcohol etílico. Para ello se utilizó un equipo Soxhlet (Figura III.2), según lo especificado en NREL/TP-510-42619 (Sluiter et al., 2005). La muestra sólida se colocó en un cartucho de extracción, se pesó y se realizaron dos extracciones consecutivas. La primera de ellas con agua destilada y la segunda con alcohol etílico. Cada extracción se llevó a cabo durante 6 horas. Posteriormente, se destiló el solvente y se pesó el residuo. El contenido de extraíbles se expresa en porcentaje en base seca (Ec.III.2).

$\%$ Extractivos $=\frac{\text { Peso seco extracto }}{\text { Peso seco muestra }} * 100$

Ec.III.2 


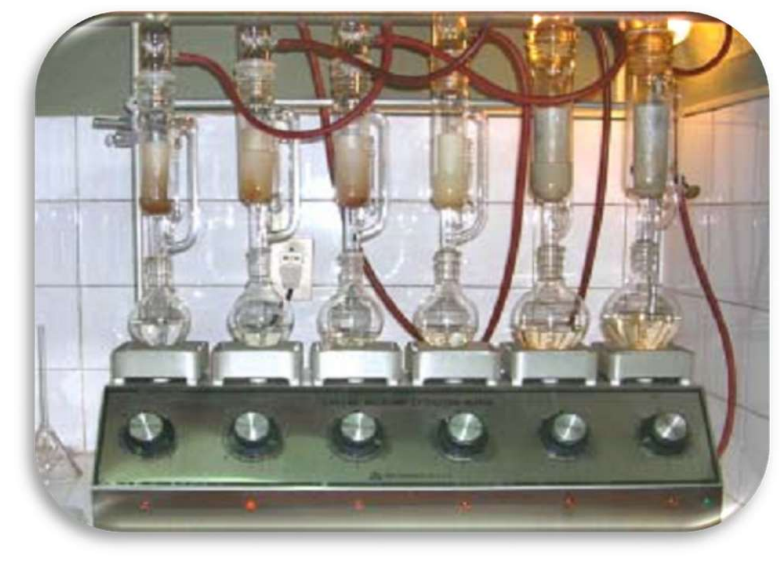

Figura III.2. Calentador múltiple para extracción con Soxhlet.

\section{III.2.1.4. Contenido de cenizas}

A partir de la muestra sólida libre de extractivos se determinó la composición de cenizas (material inorgánico). Para ello, se colocaron crisoles con la muestra en mufla a $575 \pm 25^{\circ} \mathrm{C}$ durante $3 \mathrm{~h}$, hasta calcinación. Luego se enfriaron hasta temperatura ambiente, y se pesaron los crisoles con el residuo. Se repitió el procedimiento hasta peso constante. Este procedimiento es el especificado por NREL/TP-510-42622 (Sluiter et al., 2005). Se determinó el contenido de cenizas, expresado como porcentaje en base seca.

\section{III.2.1.5. Determinación de carbohidratos estructurales y lignina}

La determinación de carbohidratos estructurales y lignina en biomasa se llevó a cabo según el procedimiento NREL/TP-510-42618 (Sluiter et al. (b), 2008). Para ello, se hidrolizó la muestra sólida con solución de ácido sulfúrico al $72 \%$, durante $1 \mathrm{~h}$ a $30^{\circ} \mathrm{C}$. Luego, se diluyó al $4 \%$ y se colocó en autoclave a $121^{\circ} \mathrm{C}$ durante $1 \mathrm{~h}$. Posteriormente se separó el sólido del líquido con filtración al vacío. Para la cuantificación del contenido de lignina insoluble en ácido se tomó el residuo retenido en el filtro, se secó en estufa y se pesó. El contenido de lignina soluble en ácido se determinó sobre la fase líquida, mediante espectrofotometría a $320 \mathrm{~nm}$. Las ligninas de coníferas son insolubles en ácido sulfúrico al $72 \%$ por lo tanto la cuantificación de lignina insoluble provee una medición bastante exacta del contenido total de lignina (Pettersen, 1984).

Los productos de degradación (Furfural y HMF) y el ácido acético se determinaron por HPLC (Waters Corp. Massachusetts, USA) equipado con un inyector automático y una columna AMINEX-HPX87H, bajo las siguientes condiciones: $4 \mathrm{mM}$ de $\mathrm{H}_{2} \mathrm{SO}_{4}$ como eluyente, caudal de 
$0,6 \mathrm{~mL} / \mathrm{min}, 35^{\circ} \mathrm{C}$, y detector de Arreglo de Diodos (ácidos orgánicos a $210 \mathrm{~nm}$ y furfural e $\mathrm{HMF}$ a $254 \mathrm{~nm})$.

Los carbohidratos fueron analizados utilizando HPLC usando una columna SHODEX SP810 conectada en serie a una pre-columna deionizadora BIORAD. Las condiciones cromatográficas utilizadas fueron: agua como eluyente, caudal de $0,6 \mathrm{~mL} / \mathrm{min}, 85^{\circ} \mathrm{C}$, y detector de Índice de Refracción (IR). Las muestras se prepararon neutralizando los hidrolizados con hidróxido de bario y agregando manitol como estándar interno para cuantificar la disolución producida en el transcurso de la neutralización de la muestra. El procedimiento consistió en la toma de $20 \mathrm{~mL}$ de hidrolizado y $3 \mathrm{~mL}$ de manitol de una solución de concentración conocida $(2 \mathrm{~g} / \mathrm{L})$. Esta solución fue ajustada a un $\mathrm{pH}$ de 5,3 con $\mathrm{Ba}(\mathrm{OH})_{2}$ sólido manteniendo la mezcla en perfecta agitación con un agitador magnético. Una vez neutralizada la muestra se centrifugó durante 10 minutos con el objetivo de separar el $\mathrm{BaSO}_{4}$ precipitado durante la reacción de neutralización de la fase líquida. El líquido sobrenadante $(30 \mathrm{~mL})$ se concentró hasta cuatro veces usando un evaporador rotativo hasta un volumen final de $5 \mathrm{~mL}$ aproximadamente. La muestra se colocó en un vial y se congeló hasta el momento de realización del análisis. La figura III.3 muestra un ejemplo de los cromatogramas obtenidos. Como se observa en la figura III.3 la manosa no se resuelve bien de la arabinosa por lo tanto, la concentración de arabinosa se verificó inyectando la muestra en la columna AMINEX-HPX87H la cual permite una buena resolución de este carbohidrato. Con esta metodología no se encontraron diferencias significativas en la concentración cuantificada de arabinosa entre ambas columnas.

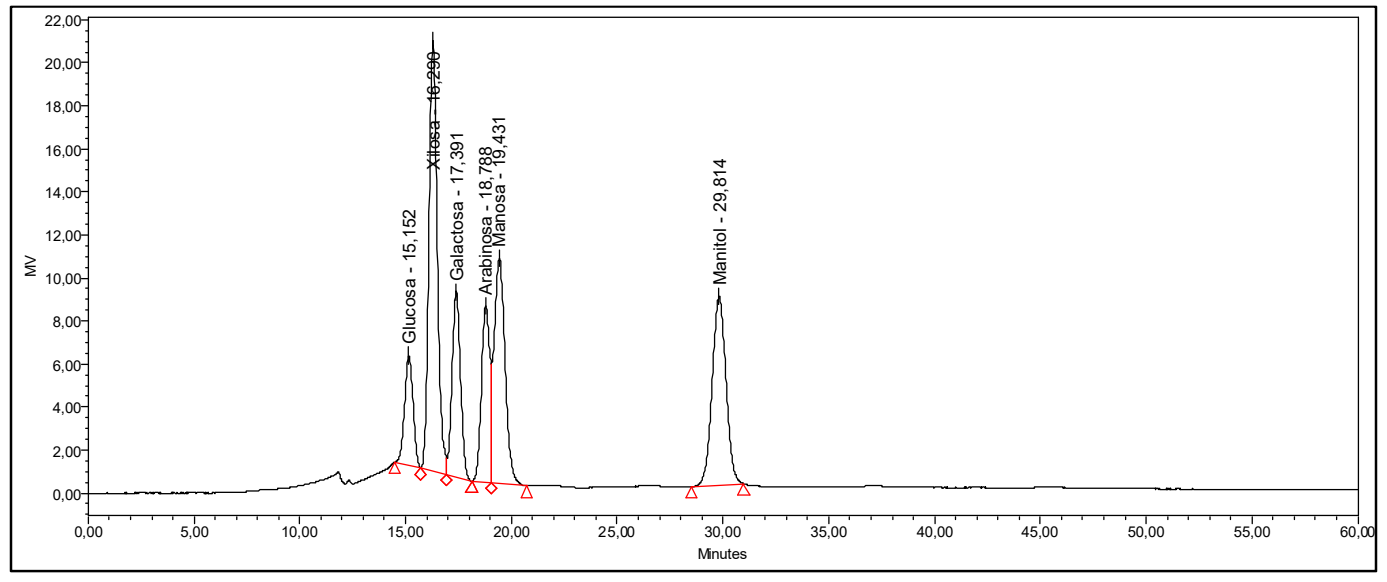

Figura III.3. Análisis cromatográfico de un hidrolizado de pino para la cuantificación de azúcares con columna Shodex SP810. 
Para la cuantificación de los azúcares se calcula un Factor de dilución según la siguiente expresión:

Factor de dilución $=\frac{\text { Vpi*Cpi inicial }}{\text { Valicuota } * \text { Cpi } H P L C}=\frac{3 * 2}{20 * C p i H P L C}$

Donde:

Vpi: volumen inicial del patrón interno, $3 \mathrm{~mL}$.

Cpi inicial: concentración inicial del patrón interno, 2 g/L

V alícuota: es el volumen de muestra tomado para la neutralización, $20 \mathrm{~mL}$.

Cpi HPLC: es la concentración del patrón interno calculada por el sistema cromatográfico expresada en $\mathrm{g} / \mathrm{L}$.

Los límites de detección se estimaron a partir de la curva de calibración para concnetraciones bajas aplicando la siguiente ecuación (Quattrocchi et al, 1992):

$L D=\frac{Y_{b l}+3 S_{b l}}{b} * \frac{1}{\sqrt{n}}$

Donde:

$\mathbf{b}=$ pendiente de la curva de calibración en el rango de estudio

Ybl = respuesta obtenida por extrapolación a concentración cero de la curva de calibración para concentraciones bajas

$\mathbf{S b} \mathbf{l}=$ desviación estándar a concentración cero de la curva de calibración a concentraciones bajas

$\mathbf{n}=$ número de medidas individuales

Las hexosas degradadas se cuantificaron como el producto de la concentración de HMF por el factor estequiométrico de 1,4286, y las pentosas degradadas como el producto de la concentración de furfural por una factor estequiométrico de 1,5625 (Mr glucosa/Mr HMF y $\mathrm{Mr}$ xilosa/Mr furfural respectivamente siendo $\mathrm{Mr}$ la masa molar del componente). Los carbohidratos se multiplican por un factor de corrección anhidro para expresarlos como polímero (Kaar,1991).

El contenido de celulosa en la materia prima se determinó midiendo el contenido total de glucosa en el aserrín y descontando la glucosa proveniente de los glucomananos. Se asume que el valor 
medio de unidades de manosa por unidad de glucosa en hemicelulosas de pino es 4,15 (Yoon et al., 2008).

La glucosa proveniente de la celulosa (C) y los azúcares hemicelulósicos (H) en el aserrín original se calcularon utilizando las siguientes ecuaciones:

$$
\begin{aligned}
& C=\text { glucosa } * 0,9-\frac{\text { manosa }}{4,15} * 0,9 \\
& H=(\text { arabinos } a+x i l o s a) * 0,88+(\text { galactos } a+\text { III.5 } 5
\end{aligned}
$$

La hidrólisis de las cadenas de hemicelulosas implica la adición de una molécula de agua al residuo glucosídico, por lo tanto, es necesario considerar un factor estequiométrico para expresar el peso del componente como polímero en la madera. Los coeficientes de las ecuaciones representan la relación: (Mr componente - Mr agua)/(Mr componente) para expresar los carbohidratos como homopolímeros (glucanos, mananos, xilanos, arabinanos y galactanos). Por lo tanto, en el caso de las hexosas, la relación es (180-18)/180 = 0,9 y para las pentosas, $(150-$ $18) / 150=0,88($ Kaar, 1991).

\section{III.2.1.6 Cristalinidad}

La cristalinidad del aserrín original y pretratado fue determinada mediante difracción de Rayos $\mathrm{X}$. El aserrín fue molido y la fracción que pasa un tamiz de 80 mesh fue utilizado para el análisis. Para la obtención de los espectros correspondientes se utilizó un equipo de Difracción Philips X' Pert con radiación de $\mathrm{Cu}$. La cantidad de muestra utilizada fue la necesaria para llenar el portamuestra. Los datos de difracción se obtuvieron por un modo de escaneado por pasos con una

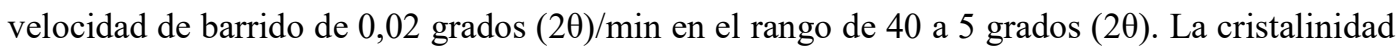
se determinó mediante el método de Segal que permite determinar la cristalinidad relativa de la celulosa. El supuesto de este método es que hay dos componentes del material celulósico: cristalino y no cristalino o amorfo. La cantidad de material cristalino está representada por la altura del pico más alto de difracción $\left(\mathrm{I}_{002}\right)$ y la región amorfa está representada por la altura del pico de la menor intensidad $\left(\mathrm{I}_{\mathrm{am}}\right)$ entre los picos principales. El índice de cristalinidad (CrI) es 
simplemente la diferencia entre estos dos picos, dividido por la intensidad del pico más alto (French et al., 2013), según la siguiente ecuación:

$\operatorname{CrI}=\left(\frac{I_{002}-I_{a m}}{I_{002}}\right) * 100$

Donde $\mathrm{I}_{002}$ es la intensidad del pico cristalino correspondiente al plano de reflexión hkl=002, en el máximo $2 \theta$ entre $22^{\circ}$ y $23^{\circ}$ para celulosa I (entre $21^{\circ}$ y $22^{\circ}$ para celulosa II), $I_{a m}$ es la altura de la zona desordenada de la celulosa a $2 \theta$ entre $18^{\circ}$ y $19^{\circ}$ para celulosa I (entre $15^{\circ}$ y $16^{\circ}$ para celulosa II) (Kamide, 2005).

\section{III.2.1.7 Microscopía electrónica de barrido}

El aserrín original y los materiales pretratados se caracterizaron mediante microscopía electrónica de barrido. El análisis microscópico fue realizado utilizando un microscopio de barrido JEOL JSM 6360-LV perteneciente al Centro de Microscopía Electrónica (CME) de la Universidad Federal do Paraná (UFPR) y un microscopio electrónico FE-SEM Ligma perteneciente al Laboratorio de Microscopía Electrónica y Análisis por Rayos X (LAMARX) de la Universidad Nacional de Córdoba (UNC). Para el análisis, las muestras de aserrín se molieron y posteriormente se secaron al aire. Luego se colocaron en un "stub" o disco porta muestra con un adhesivo termoplástico conductor. Posteriormente las muestras fueron metalizadas con oro por el método de sputtering en un metalizador Balzers SCD 030 (Figura III.4). Las imágenes fueron tomadas utilizando detectores de electrones secundarios.

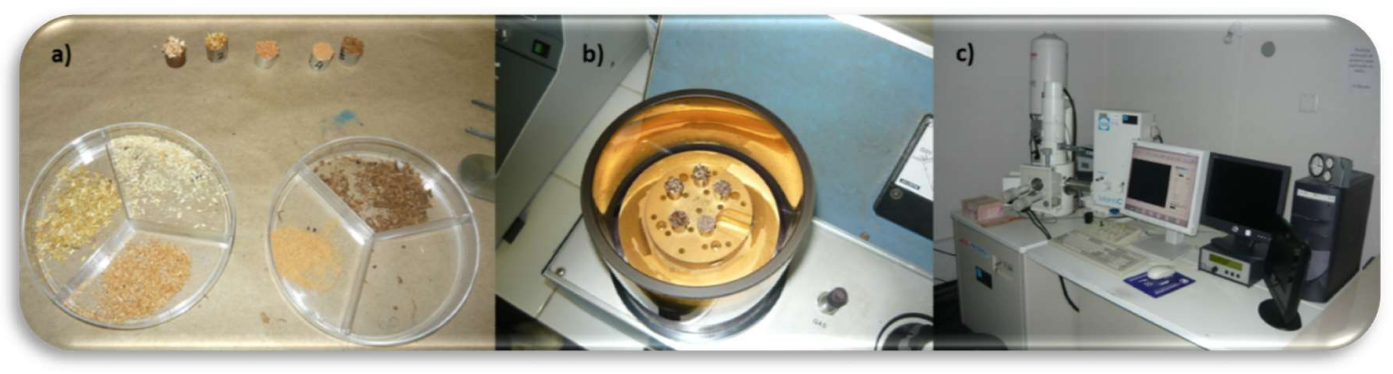

Figura III.4. Análisis microscópico. a) Preparación de muestras (colocación en stub). b) Metalizado con oro. c) Microscopio electrónico de barrido del CME, UFPR. 


\section{III.2.1.8 Hidrólisis enzimática}

Los materiales sin tratamiento y pretratados fueron sacarificados por hidrólisis enzimática (HE), siguiendo la norma NREL-LAP (NREL/TP-510-42629) (Selig et al., 2008). Este procedimiento permite determinar la máxima extensión de digestibilidad. La actividad de la celulasa es expresada en términos de unidades de papel de filtro (Filter Paper Units, FPU) por mililitro de solución enzimática sin diluir. La determinación de la actividad enzimática expresada como FPU consiste en cuantificar la concentración de enzima que libera $2 \mathrm{mg}$ de azúcar reductor como glucosa de una muestra de $50 \mathrm{mg}$ de papel (4\% de conversión) en 60 minutos. La actividad de la $\beta$-glucosidasa se expresa en IU (International Units) que se define como la cantidad de enzima requerida para liberar un $\mu \mathrm{mol}$ de azúcar reductor por minuto en condiciones estándares (Selig et al., 2008).

Los ensayos de $\mathrm{HE}$ se realizaron a $2 \%$ de consistencia (porcentaje de materia seca), $\mathrm{pH} 4,8$ y $50^{\circ} \mathrm{C}$; con una carga enzimática de $20 \mathrm{FPU} / \mathrm{g}$ glucanos (celulasas) y $40 \mathrm{IU} / \mathrm{g}$ glucanos $(\beta-$ glucosidasas). Las hidrólisis se llevaron a cabo en Erlenmeyers de vidrio de $50 \mathrm{~mL}$ manteniendo la temperatura y agitación en un baño térmico con agitación. Se pesó $1 \mathrm{~g}$ seco de material y se llevó a un peso final de $50 \mathrm{~g}$ con la solución buffer citrato de sodio $0,1 \mathrm{M}, \mathrm{pH}$ 4,8 (ácido cítrico más citrato de potasio). Luego se agregó el volumen apropiado de enzimas con micropipeta. Se monitoreó la reacción cada 24 horas hasta las 72 horas. Se realizaron las experiencias por duplicado.

Los rendimientos de la hidrólisis se calcularon diferentes tiempos (24, 48 y 72 horas) como indica la Ecuación III.8.

Rendimiento $H E(\%)=\frac{\text { glucosa } * 0,9}{\text { glucanos en biomasa inicial }} * 100$

Ec.III.8

Para expresar la concentración de glucosa como glucanos se multiplica por el factor estequiométrico 0,9 . 


\section{III.2.2. Caracterización de muestras líquidas}

Se analizaron las fases líquidas provenientes de las etapas de fraccionamiento e hidrólisis para determinar la composición de carbohidratos, sus productos de degradación (furfural y 5hidroximetilfurfural) y ácidos orgánicos (ácido acético).

\section{III.2.2.1. Cuantificación de azúcares, productos de degradación y ácidos orgánicos}

Los azúcares, productos de degradación y ácidos orgánicos se cuantificaron mediante HPLC, en el mismo equipo y con iguales condiciones que en el caso de carbohidratos estructurales en muestras sólidas. Los hexosanos degradados se calcularon como el producto de la concentración de HMF por el factor estequiométrico 1,2857, y los pentosanos degradados por el factor estequiométrico, 1,375 (Mr glucanos/Mr HMF y Mr xilanos/Mr furfural respectivamente siendo Mr la masa molar del componente)

Considerando que una fracción de los carbohidratos extraídos en las soluciones líquidas puede estar en forma de oligómeros, las mismas fueron sometidas a una post hidrólisis $\left(3 \% \mathrm{H}_{2} \mathrm{SO}_{4}\right.$ a $121^{\circ} \mathrm{C}$ por una hora en autoclave). La determinación de azúcares se realizó antes y después de la post hidrólisis de los licores. Para la cuantificación de la degradación de azúcares durante la post hidrólisis se determina un factor corrector (factor de recuperación) como la variación en peso que experimentan los azúcares por efecto de la solvatación durante la hidrólisis. El procedimiento consiste en la preparación de soluciones de concentración conocida a partir de los estándares, que luego son sometidas a las condiciones de post-hidrólisis. Estas soluciones hidrolizadas fueron analizadas por cromatografía líquida determinando el porcentaje de monosacárido degradado. En la Tabla III.3 se indican los factores de recuperación que tienen en cuenta la degradación de cada azúcar durante la post-hidrólisis: 
Tabla III.3. Factores de recuperación de azúcares durante la post hidrólisis $\left(3 \% \mathrm{H}_{2} \mathrm{SO}_{4}-121^{\circ} \mathrm{C}\right.$ $60 \mathrm{~min})$

\begin{tabular}{|l|c|}
\hline Componente & Factor de recuperación \\
\hline Glucosa & 0,967 \\
\hline Xilosa & 0,920 \\
\hline Galactosa & 0,965 \\
\hline Arabinosa & 0,960 \\
\hline Manosa & 0,955 \\
\hline
\end{tabular}

El grado se solubilización o pérdida de peso (expresado como \% en base seca) en los pretratamientos fue determinado por diferencia de peso (W) antes y después del tratamiento con la siguiente ecuación:

$\%$ Solubilización $=\frac{W_{\text {inicial de biomasa }}-W_{\text {biomasa tratada }}}{W_{\text {inicial }}} * 100$

El porcentaje de remoción de carbohidratos de la biomasa sólida fue calculado a partir del análisis químico de composición del sólido (biomasa inicial y tratada) y de acuerdo a la siguiente ecuación:

$\%$ Remoción $=\frac{W_{\text {carbohidratos en biomasa inicial }}-W_{\text {carbohidratos en biomasa tratada }}}{W_{\text {carbohidra }} \text { en biomasa inicial }} 100 \quad$ Ec.III.10

El porcentaje de recuperación de carbohidratos en la fracción líquida fue calculado a partir del contenido de los respectivos azúcares en el líquido y fue calculado con la Ecuación:

$\%$ Recuperación $=\frac{W_{\text {carbohidratos en el líquido despues del tratamiento }}}{W_{\text {carbohidratos en biomasa inicial }}} * 100$

Los rendimientos de extracción (Ye) de los componentes de la madera fueron calculados según la siguiente ecuación:

$Y e=\frac{\text { masa disuelta }}{\text { masa inici }} * 100$ 


\section{III.2.3 FRACCIONAMIENTOS}

La propuesta de fraccionamiento del aserrín de pino consiste en una secuencia de tres etapas: desresinación alcalina-hidrolisis ácida-deslignificación alcalina como se muestra en la Figura III.5. La hidrólisis ácida se realizó utilizando dos tecnologías diferentes: hidrólisis ácida diluida (HAD) y explosión de vapor (EV). Las experiencias fueron realizadas siguiendo diseños experimentales de cada etapa para evaluar la influencia de las principales variables de proceso (temperatura, tiempo y concentración) y encontrar las condiciones que optimizan el mismo.

\section{III.2.3.1. Diseños Experimentales}

Los experimentos de la etapa alcalina y la HAD se realizaron de acuerdo a un Diseño Central Compuesto (Barker, 1985) en cada caso. Las variables estudiadas para la etapa alcalina fueron carga alcalina y tiempo, y para el tratamiento ácido concentración de ácido sulfúrico, tiempo y temperatura. Los niveles de estos factores fueron seleccionados mediante pruebas preliminares y datos bibliográficos. El método utiliza valores codificados de los niveles (+1 y -1$)$, los cuales surgen de transformar los valores verdaderos, utilizando la siguiente ecuación:

Valor codificado $=\frac{x-\bar{x}}{\frac{\left(x_{S}-x_{i}\right)}{2}}$

Donde $x$ es el valor del nivel, $x_{s}$ es el nivel superior, $x_{i}$ es el nivel inferior y $\bar{x}$ es el promedio entre $x_{i}$ y $x_{s}$ 


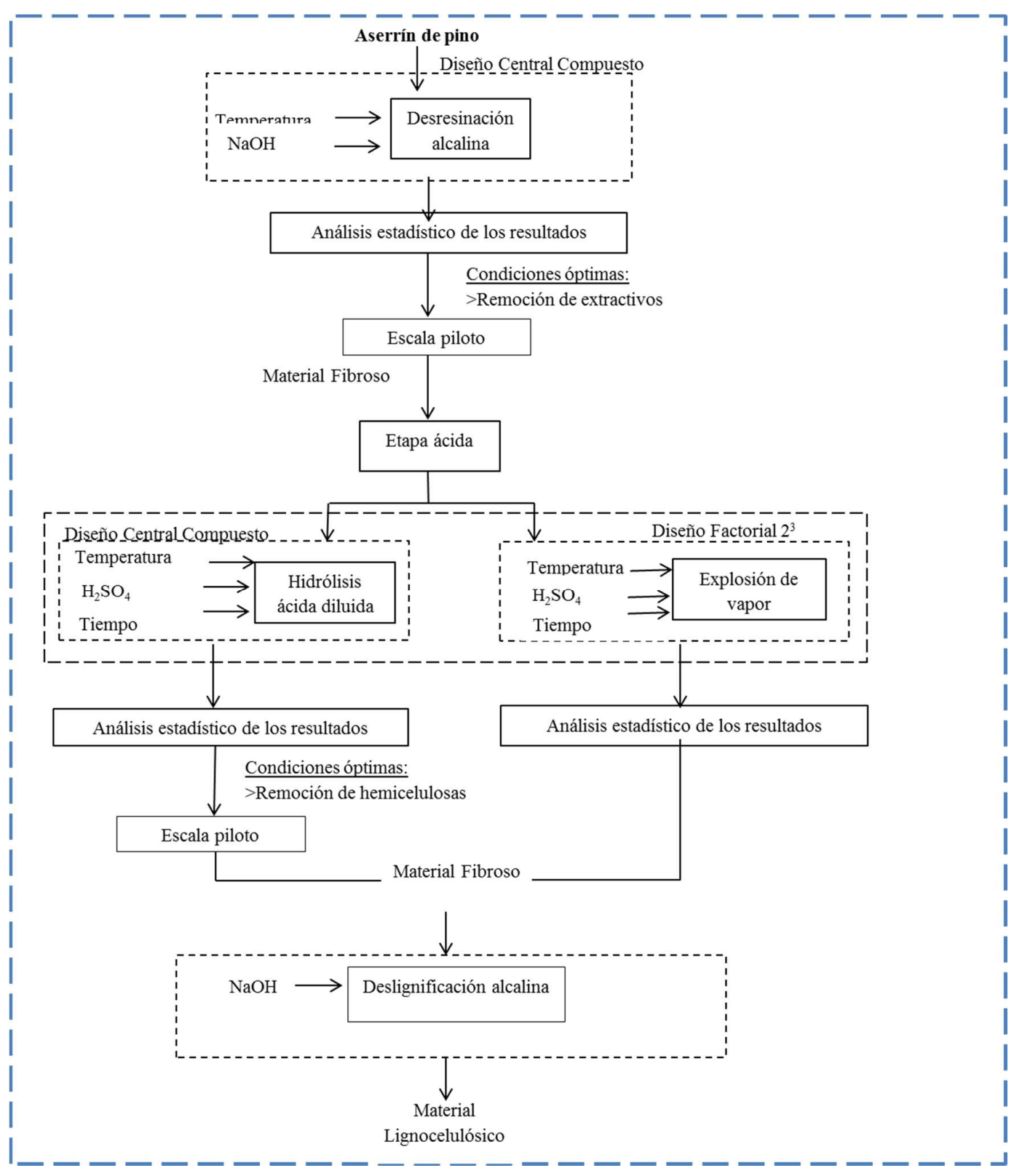

Figura III.5. Propuesta de fraccionamiento a evaluar para aserrín de pino

Los diseños experimentales para la etapa alcalina y ácida se muestran las Figuras III.6 y III.7, respectivamente. Cada eje corresponde a un factor y cada punto en el cubo representa una combinación experimental de condiciones (como variables codificadas). El diseño Central Compuesto consiste en $2^{\mathrm{k}}+2 \mathrm{k}+\mathrm{m}$ corridas experimentales, donde $\mathrm{k}$ es el número de factores, $2^{\mathrm{k}}$ es el número de puntos factoriales en el cetro del cubo o el cuadrado, $2 \mathrm{k}$ es el número de puntos axiales en los ejes de cada diseño factorial a una distancia de $\pm \alpha\left(\alpha=2^{\mathrm{k} / 4}\right)$ desde el centro del cuadrado o del cubo. En este estudio se realizaron tres réplicas del punto central para estimar el 
error experimental. En consecuencia, en la etapa alcalina el número de experimentos fue de $4+4+3=11$ y para la etapa ácida de $8+6+3=17$. Los experimentos fueron realizados aleatoriamente. Los factores y niveles de cada tratamiento como variables codificadas y no codificadas se muestran en las Figuras III.6.b y III.7.b.

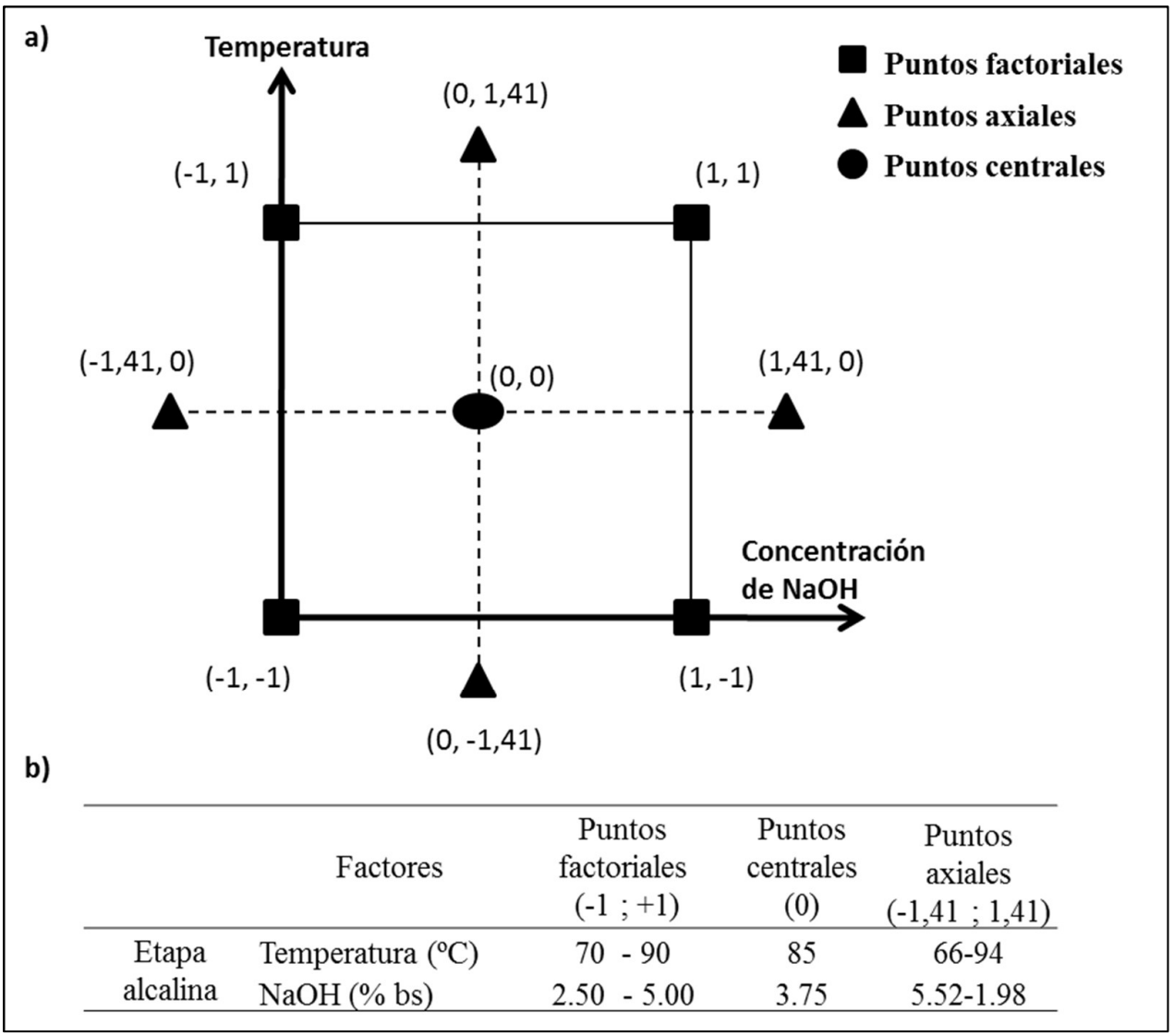

Figura III.6 (a) Diseño Factorial de dos factores a cinco niveles para la etapa alcalina. (b) Factores y niveles en variables codificadas y no codificadas. 


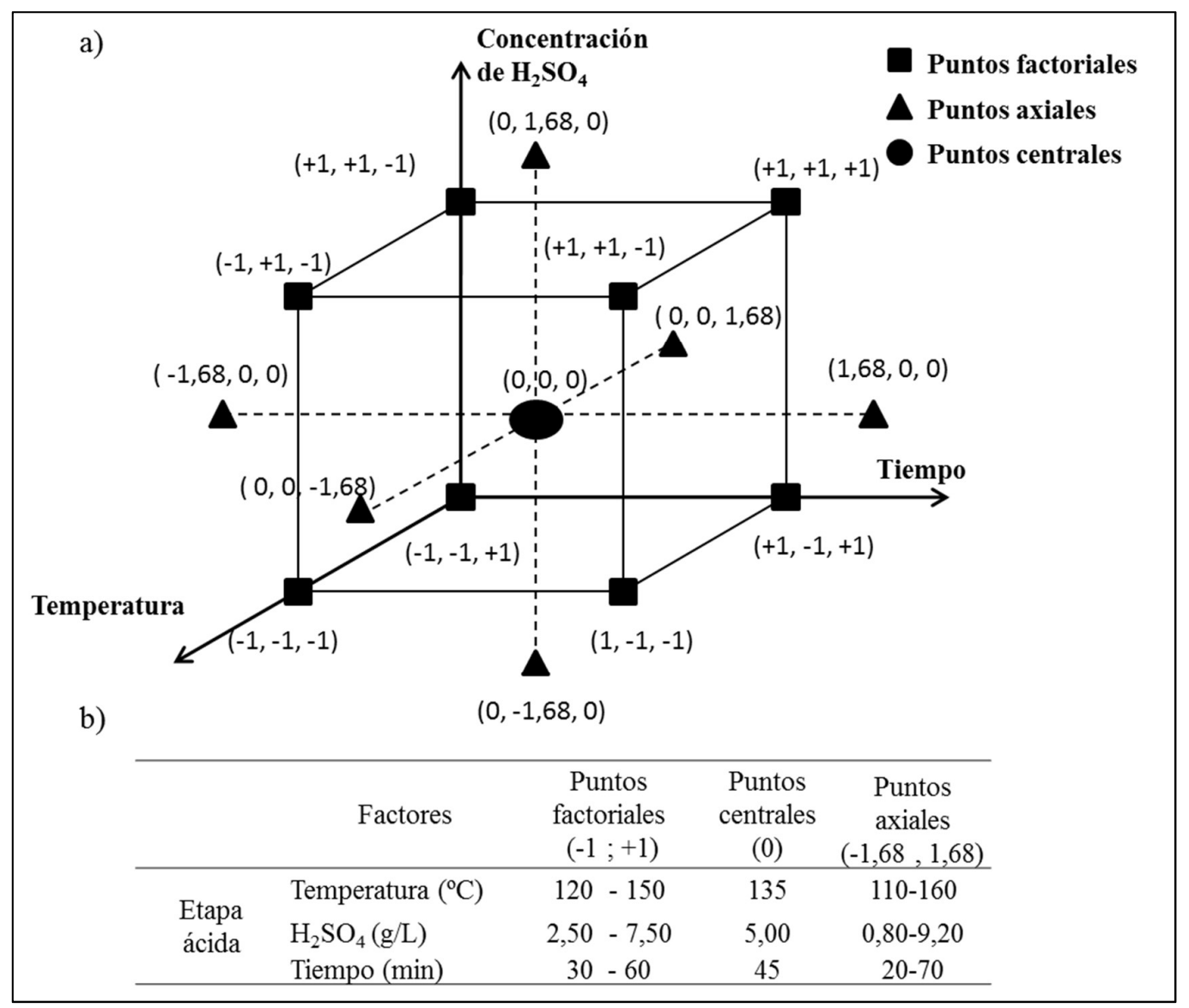

Figura III.7 (a) Diseño Factorial de tres factores a cinco niveles para la etapa ácida. (b) Factores y niveles en variables codificadas y no codificadas.

Para la evaluación de la EV se planteó un Diseño Factorial $2^{\mathrm{n}}$. Las variables estudiadas fueron concentración de ácido sulfúrico, tiempo y temperatura. Por lo tanto, el número de tratamientos está dado por $2^{3}=8$ combinaciones de tratamientos. Para esta etapa se realizaron 2 réplicas del punto central (Figura III.8.a). Los factores y niveles del tratamiento como variables codificadas y no codificadas se muestran en la Figura III.8.b. 


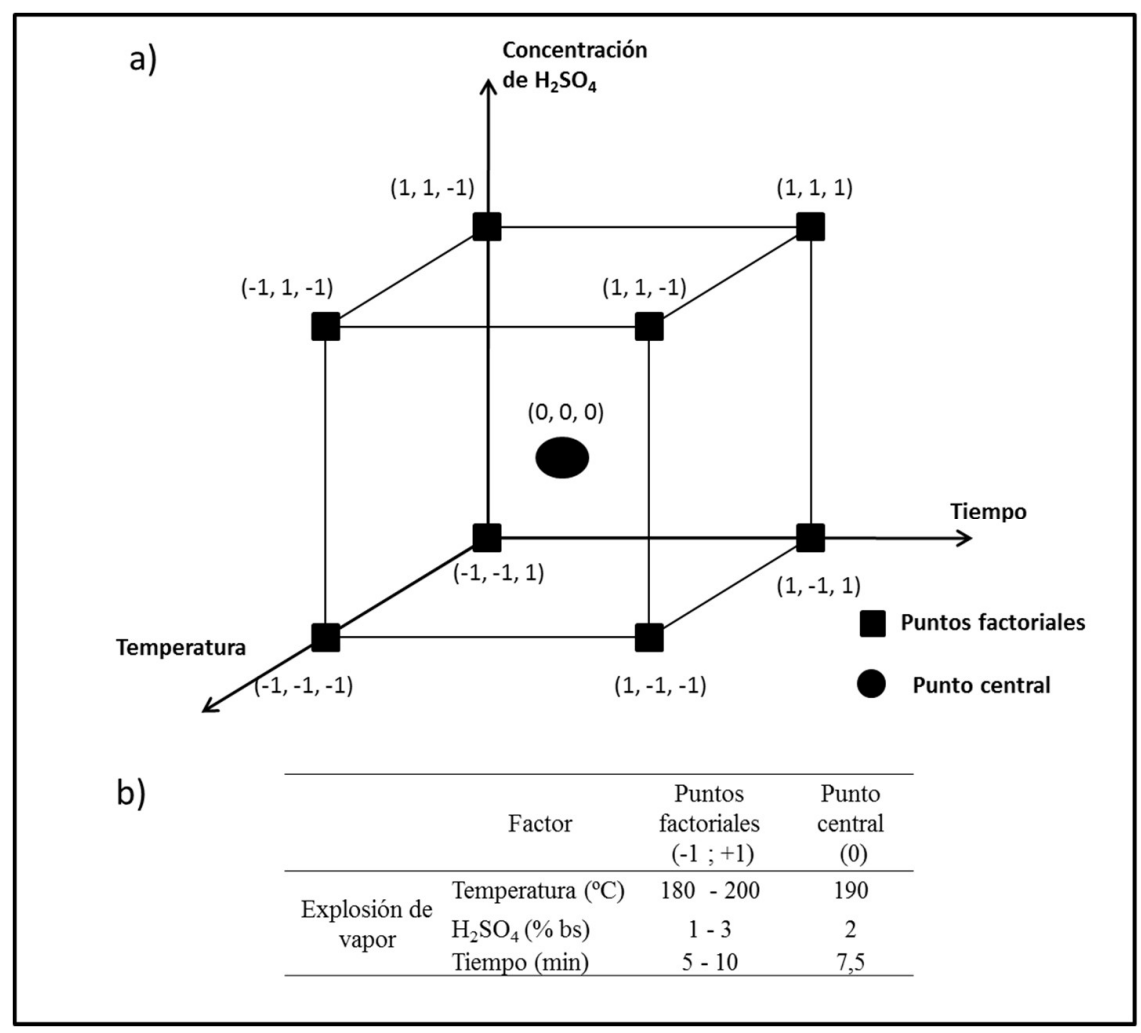

Figura III.8 (a) Diseño Factorial de tres factores a dos niveles para la EV. (b) Factores y niveles de cada tratamiento en variables codificadas y no codificadas.

Estos diseños de optimización permiten obtener datos experimentales que luego son ajustados a un modelo polinomial de regresión lineal múltiple con el propósito de caracterizar la superficie de respuesta. Los datos son examinados mediante un análisis de varianza (ANOVA) y dejando solo las variables significativas del modelo inicial (Vera Candioti et al., 2014). Los análisis estadísticos se realizaron con el programa Stagraphics considerando un nivel de confianza de $95 \%$.

\section{III.2.3.1.2 Optimización}

Debido a que la optimización involucra a más de una respuesta se utilizó el método de optimización de múltiples respuestas para encontrar las condiciones experimentales que simultáneamente alcanzan la respuesta óptima. La función deseabilidad (di) es una función que permite optimizar simultáneamente múltiple ecuaciones. La misma siempre toma valores entre 0 y 1 , donde di $=0$ para un respuesta indeseable y di $=1$ representa un valor completamente deseable, 
es decir, una respuesta ideal. La función deseabilidad combina las respuestas individuales en una función compuesta que posteriormente se optimiza (Vera Candioti et al., 2014)

\section{III.2.3.2 Remoción de Extractivos}

El aserrín fue sometido a una etapa alcalina con el objetivo de extraer los ácidos grasos y resínicos. Los distintos tratamientos realizados según el DCC se muestran en la Tabla III.4.

Tabla III.4. Ensayos de la etapa alcalina (Concentración de $\mathrm{NaOH}$ expresado como \% en base seca, bs)

\begin{tabular}{|c|c|c|}
\hline Ensayo & $\begin{array}{c}\text { Temperatura } \\
\left({ }^{\mathbf{}} \mathbf{C}\right)\end{array}$ & $\begin{array}{c}\text { Concentración } \\
\mathbf{N a O H}(\% \mathbf{b s})\end{array}$ \\
\hline 1 & 70 & 2,50 \\
\hline 2 & 90 & 2,50 \\
\hline 3 & 70 & 5,00 \\
\hline 4 & 90 & 5,00 \\
\hline 5 & 66 & 3,75 \\
\hline 6 & 94 & 3,75 \\
\hline 7 & 80 & 1,98 \\
\hline 8 & 80 & 5,52 \\
\hline 9 & 80 & 3,75 \\
\hline 10 & 80 & 3,75 \\
\hline 11 & 80 & 3,75 \\
\hline
\end{tabular}

Todas las reacciones fueron realizadas en recipientes de vidrio de $250 \mathrm{~mL}$ calentados en un baño de agua caliente (Figura III.9.a) con control de temperatura. En cada ensayo se utilizaron $10 \mathrm{~g}$ secos de aserrín, manteniendo una relación licor/madera $(\mathrm{L} / \mathrm{M})$ de 10 (volumen de solución agregada sobre peso de aserrín seco). Los recipientes fueron cerrados con un film de plástico, colocados en el baño a la temperatura deseada y mantenidos en esas condiciones por una hora. Los recipientes conteniendo el aserrín con el licor fueron agitados manualmente antes de cerrarlos. Durante la reacción no se requirió agitación dado que la relación licor madera fue alta y el calentamiento promueve el movimiento del sólido en el líquido. Pasado el tiempo de reacción, los recipientes fueron instantáneamente enfriados con hielo, y el licor fue separado del sólido por 
filtración a presión reducida. Posteriormente, el aserrín fue lavado con abundante agua, secado al aire y almacenado en bolsas plásticas para su posterior caracterización. Los licores fueron conservados para determinación de $\mathrm{NaOH}$ residual.

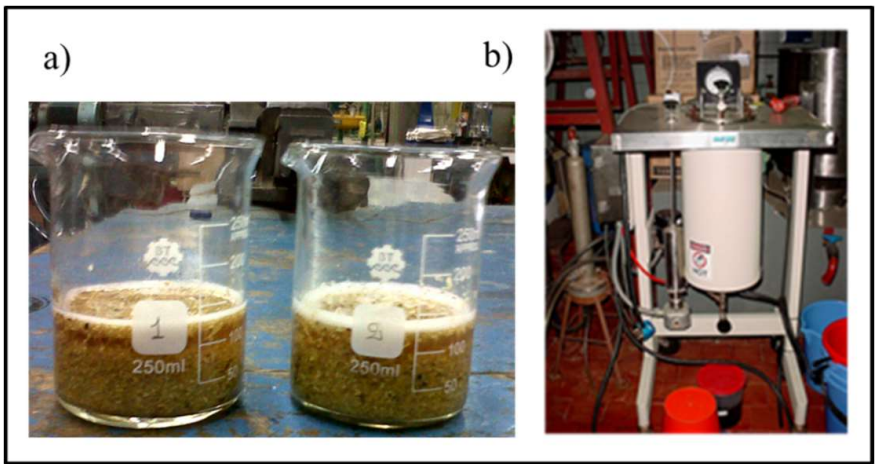

Figura III.9. Desresinación alcalina a) A escala laboratorio. b) En escala piloto.

Luego, un ensayo en condiciones cercanas a las óptimas fue realizado a escala piloto, con el objetivo de verificar la representatividad de los datos obtenidos a escala laboratorio. El ensayo se llevó a cabo en un reactor (M/K Systems, Inc., Maryland) de 7 L con recirculación del licor (Figura III.9.b), utilizando $500 \mathrm{~g}$ de aserrín seco con $5 \mathrm{~L}$ de solución alcalina (relación L/M de 10). Una vez transcurrido el tiempo de reacción, el licor fue separado del sólido mediante centrifugación hasta aproximadamente un $40 \%$ de contenido de sólidos. Subsecuentemente, el residuo fue exhaustivamente lavado con agua, filtrado y secado al aire para la determinación de pérdida de peso, tomando una muestra para el análisis químico.

\section{III.2.3.2.1 Determinación de álcali residual en el licor}

La determinación del contenido de álcali fue realizada mediante titulación con una solución estándar de ácido clorhídrico siguiendo la norma T625 cm-85 de TAPPI (1994-1995), “Analysis Of Soda And Sulfate Black Liquor".

\section{III.2.3.3 Extracción de hemicelulosas}

El aserrín de pino fue sometido a una etapa ácida con el objetivo de extraer las hemicelulosas. Los tratamientos fueron aplicados al aserrín pre-extraído en álcali y al aserrín original, como 
control. El aserrín pre-extraído en álcali fue secado al aire previo a la etapa ácida. Se evaluaron dos tecnologías diferentes utilizando ácido sulfúrico diluido como catalizador: hidrólisis ácida diluida (HAD) y explosión de vapor (EV).

Para la comparación de los procesos en términos de la severidad del tratamiento se determinó el factor de severidad. El concepto de severidad fue desarrollado por Overend et al. a partir de conceptos previos similares utilizados en la industria del pulpado, tales como el Factor $\mathrm{H}$ y el Factor P, los cuales son utilizados para controlar la extensión del pulpado y la prehidrólisis en la industria del pulpado. El factor de severidad combina en un solo parámetro la temperatura y el tiempo de reacción. Aunque el concepto de severidad es una descripción fenomenológica permite la comparación de varios procesos (Chum et al, 1990). El factor de severidad es una variante del Factor $\mathrm{H}$ que resulta de la integración del período de reacción a cierta temperatura:

$R_{0}=\int_{a}^{b} \exp \left(\frac{T(t)-T_{r e f}}{R * T_{r e f} * \frac{T}{E_{a}}}\right) * d t$

Donde $\mathrm{t}$ es el tiempo de residencia (min), $\mathrm{T}$ es la temperatura del tratamiento $\left({ }^{\circ} \mathrm{C}\right)$, Tref es la temperatura de referencia $\left(100^{\circ} \mathrm{C}\right)$, y Ea es la energía de activación. Si se aproxima:

$T e \approx R * \operatorname{Tr} e f *\left(\frac{T}{E a}\right)$

En la extracción de biomasa lignocelulósica con agua caliente, Te equivale a $14,75^{\circ} \mathrm{C}$, asumiendo que la reacción es hidrolítica y la conversión global es de primer orden (Liu, 2010). El factor de severidad se define como el logaritmo del resultado de la integración de la Ec.III.14:

$\log \left(R_{0}\right)=\log \left(t * \exp \left(\frac{T-100}{14,75}\right)\right)$

Cuando el pretratamiento es realizado en condiciones acidas, el efecto del $\mathrm{pH}$ puede ser tomado en consideración mediante la severidad combinada (SC), definida como:

Severidad combinada $(S C)=\log (R 0)-p H$

Ec.III.17

El pH se calculó a partir de la concentración de la solución de ácido sulfúrico adicionado a la muestra. El pH se corrigió por el cambio de concentración del ácido debido a la neutralización parcial del mismo por parte de los carboxilatos de sodio (principalmente ácidos resinicos y grasos residuales) y álcali residual (remanentes del lavado) que están en la madera como consecuencia del tratamiento alcalino y consumen hidrogeniones al ser llevados a forma ácida. Para el cálculo del pH del licor se determinó la cantidad de ácido sulfúrico que se consume en la neutralización del álcali residual. Para ello, una muestra de $24 \mathrm{~g}$ de aserrín pre-extraído en álcali se mantuvo con 
agua en agitación por una hora y se tituló con $\mathrm{HCl}$ de concentración $0,1 \mathrm{~N}$ hasta alcanzar un pH de 4. La cantidad de $\mathrm{H}_{2} \mathrm{SO}_{4}$ consumido se calculó según la Ec. III.18:

$\mathrm{g} \mathrm{H}_{2} \mathrm{SO}_{4}$ consumidos $=$ Volumen $\mathrm{HCl}$ gastado $(\mathrm{mL}) *[\mathrm{HCl}] \mathrm{N} * \mathrm{meqH}_{2} \mathrm{SO}_{4} \mathrm{~g} / \mathrm{eq}$

Los meq $\mathrm{H}_{2} \mathrm{SO}_{4}$ es la masa de un equivalente de ácido sulfúrico expresada en g/ equivalente.

\section{III.2.3.3.1 Hidrólisis ácida diluida}

La hidrólisis ácida diluida se llevó a cabo en reactores de acero inoxidable de $200 \mathrm{~mL}$ calefaccionados en un baño de glicerina (Figura III.10) con control de temperatura.

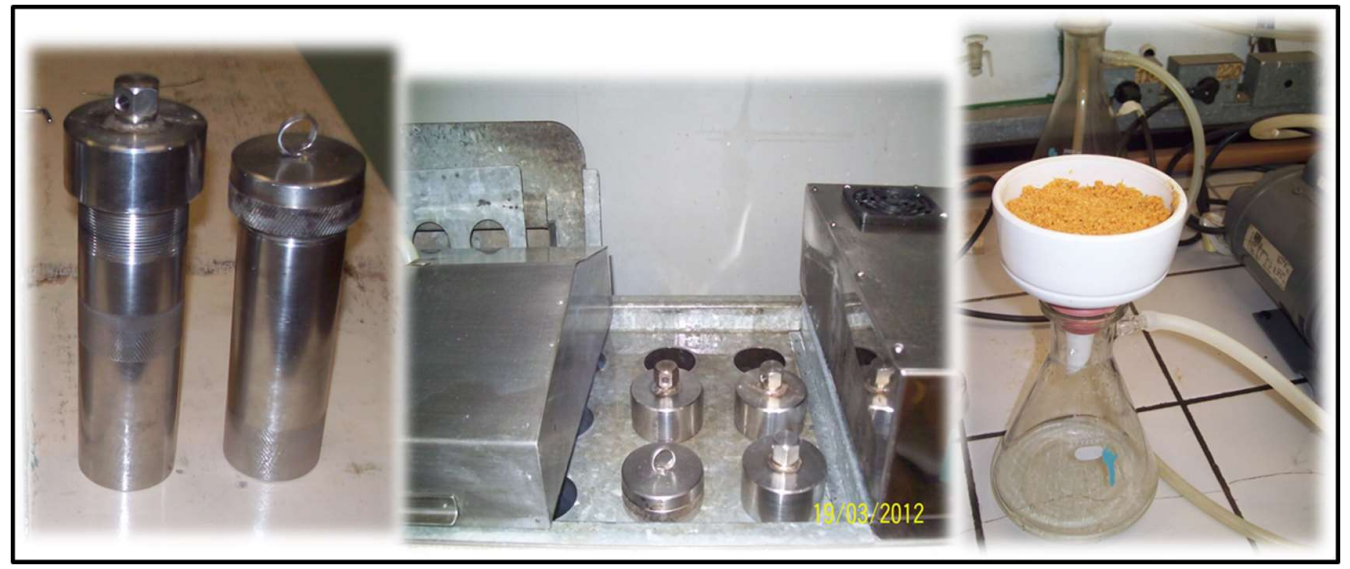

Figura III.10. Reactores de acero inoxidable, baño de glicerina y filtración

Los reactores fueron cargados con $15 \mathrm{~g}$ secos de aserrín y $150 \mathrm{~mL}$ de la solución ácida a la concentración establecida por el diseño manteniendo una relación $\mathrm{L} / \mathrm{M}$ de 10 . El aserrín y el licor fueron mezclados manualmente previamente al cerrado de los reactores. Durante la reacción no se requirió agitación dado que la relación licor madera fue alta y el calentamiento promueve el movimiento del sólido en el líquido. Transcurrido el tiempo de reacción, el reactor fue instantáneamente enfriado con hielo. Este sistema de reacción previene rampas de calentamiento y enfriamiento ya que los mismos son casi instantáneos. El sólido fue filtrado a presión reducida para separar el licor. Luego, este material sólido fue lavado con agua. Todas las muestras liquidas fueron guardadas en viales cerrados herméticamente y almacenadas en heladera para su posterior caracterización. Se secaron al aire muestras de los sólidos para determinar la pérdida de peso producida durante el tratamiento. 
Los ensayos realizados de acuerdo a los niveles establecidos por el DCC se muestran en la Tabla III.5.

Tabla III.5. Ensayos realizados en la HAD.

\begin{tabular}{|c|c|c|c|c|c|}
\hline Ensayo & $\begin{array}{c}\text { Temperatura } \\
\left({ }^{\mathbf{C}} \mathbf{C}\right)\end{array}$ & $\begin{array}{c}\text { Tiempo } \\
(\mathbf{m i n})\end{array}$ & $\begin{array}{c}\text { Concentración } \\
\mathbf{H}_{\mathbf{2}} \mathbf{S O}_{\mathbf{4}(\mathbf{g} / \mathbf{L})}\end{array}$ & $\begin{array}{c}\text { SC aserrín } \\
\text { original }\end{array}$ & $\begin{array}{c}\text { SC } \\
\text { aserrín } \\
\text { pre- } \\
\text { extraído } \\
\text { en álcali }\end{array}$ \\
\hline 1 & 120 & 30 & 2,50 & 0,78 & 0,62 \\
\hline 2 & 150 & 30 & 7,50 & 1,25 & 1,21 \\
\hline 3 & 120 & 60 & 2,50 & 1,08 & 0,93 \\
\hline 4 & 150 & 60 & 7,50 & 1,55 & 1,51 \\
\hline 5 & 120 & 30 & 2,50 & 1,66 & 1,51 \\
\hline 6 & 150 & 30 & 7,50 & 2,14 & 2,09 \\
\hline 7 & 120 & 60 & 2,50 & 1,96 & 1,81 \\
\hline 8 & 150 & 60 & 7,50 & 2,44 & 2,40 \\
\hline 9 & 110 & 45 & 5,00 & 0,96 & 0,89 \\
\hline 10 & 160 & 45 & 5,00 & 2,43 & 2,37 \\
\hline 11 & 135 & 20 & 5,00 & 1,34 & 1,27 \\
\hline 12 & 135 & 70 & 5,00 & 1,89 & 1,82 \\
\hline 13 & 135 & 45 & 0,80 & 0,90 & $-0,18$ \\
\hline 14 & 135 & 45 & 9,20 & 1,96 & 1,92 \\
\hline 15 & 135 & 45 & 5,00 & 1,70 & 1,63 \\
\hline 16 & 135 & 45 & 5,00 & 1,70 & 1,63 \\
\hline 17 & 135 & 45 & 5,00 & 1,70 & 1,63 \\
\hline
\end{tabular}

\section{III.2.3.3.2 Explosión de vapor}

La etapa de EV fue realizada en un reactor de acero inoxidable con una capacidad de $10 \mathrm{~L}$ (Figura III.11.a) perteneciente a la Usina Piloto del Sector Tecnológico de la Universidad Federal do Paraná. 


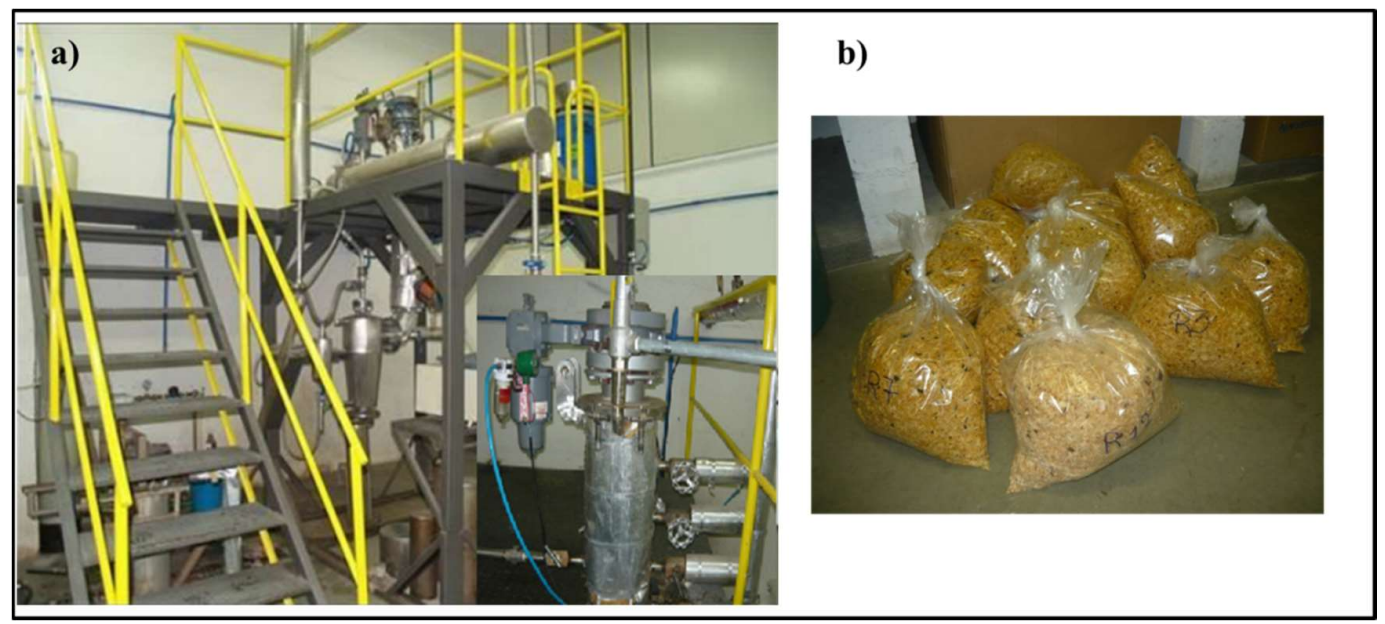

Figura III.11. a) Reactor de explosión de vapor b) Impregnación de aserrín con $\mathrm{H}_{2} \mathrm{SO}_{4}$.

Los ensayos, realizados de acuerdo a los niveles establecidos por el diseño factorial, se muestran en la Tabla III.6. Para esta secuencia de fraccionamiento se utilizó el aserrín proveniente del aserradero Forestal AM. Dada las características del reactor y con el objetivo de facilitar el proceso se seleccionó la fracción retenida en aberturas cuadradas de $3 \mathrm{~mm}$.

El reactor cuenta con sensores para el control de la temperatura. La inyección de vapor al reactor es dividida en 3 vías y la presión es controlada en la entrada principal de vapor. Todas las entradas cuentan con válvulas de alta presión lo que proporciona una mejor distribución del vapor y mayor eficiencia térmica, y por lo tanto una mayor homogeneidad durante el proceso. El reactor esta acoplado a una caldera de alta presión Weco, modelo GVO 10/30, un compresor de aire y un ciclón, que es empleado para la descarga del material y escape de vapores. 
Tabla III.6 Ensayos realizados en la EV

\begin{tabular}{|c|c|c|c|c|}
\hline & Ensayo & \begin{tabular}{|c} 
Temperatura \\
$\left({ }^{\circ} \mathrm{C}\right)$
\end{tabular} & $\begin{array}{c}\text { Tiempo } \\
(\mathrm{min})\end{array}$ & $\begin{array}{c}\text { Concentración } \\
\mathrm{H}_{2} \mathrm{SO}_{4}(\% \text { bs }) \\
\end{array}$ \\
\hline \multirow{10}{*}{$B$} & 1 & 180 & 5,0 & 1,00 \\
\hline & 2 & 200 & 5,0 & 1,00 \\
\hline & 3 & 180 & 10,0 & 1,00 \\
\hline & 4 & 200 & 10,0 & 1,00 \\
\hline & 5 & 180 & 5,0 & 3,00 \\
\hline & 6 & 200 & 5,0 & 3,00 \\
\hline & 7 & 180 & 10,0 & 3,00 \\
\hline & 8 & 200 & 10,0 & 3,00 \\
\hline & 9 & 190 & 7,5 & 2,00 \\
\hline & 10 & 190 & 7,5 & 2,00 \\
\hline \multirow{2}{*}{$D$} & 1 & 190 & 7,5 & 0,75 \\
\hline & 2 & 190 & 7,5 & 0,75 \\
\hline
\end{tabular}

APA: aserrín pre-extraído con álcali; A: aserrín original

La impregnación se realizó colocando el aserrín seco al aire (14\% humedad inicial) en bolsas plásticas y rociando una solución de $\mathrm{H}_{2} \mathrm{SO}_{4}$ hasta alcanzar un contenido de humedad de $50 \%$.). Además, se realizaron un ensayo adicional a $200^{\circ} \mathrm{C}, 5 \mathrm{~min}$ y $3 \% \mathrm{H}_{2} \mathrm{SO}_{4}$ con aserrín pretratado con álcali sin secar (56\% humedad inicial). Las bolsas se mantuvieron a temperatura ambiente durante toda la noche (Figura III.11.b). El esquema de trabajo y la nomenclatura utilizado en la EV se representa en la Figura III.12. 


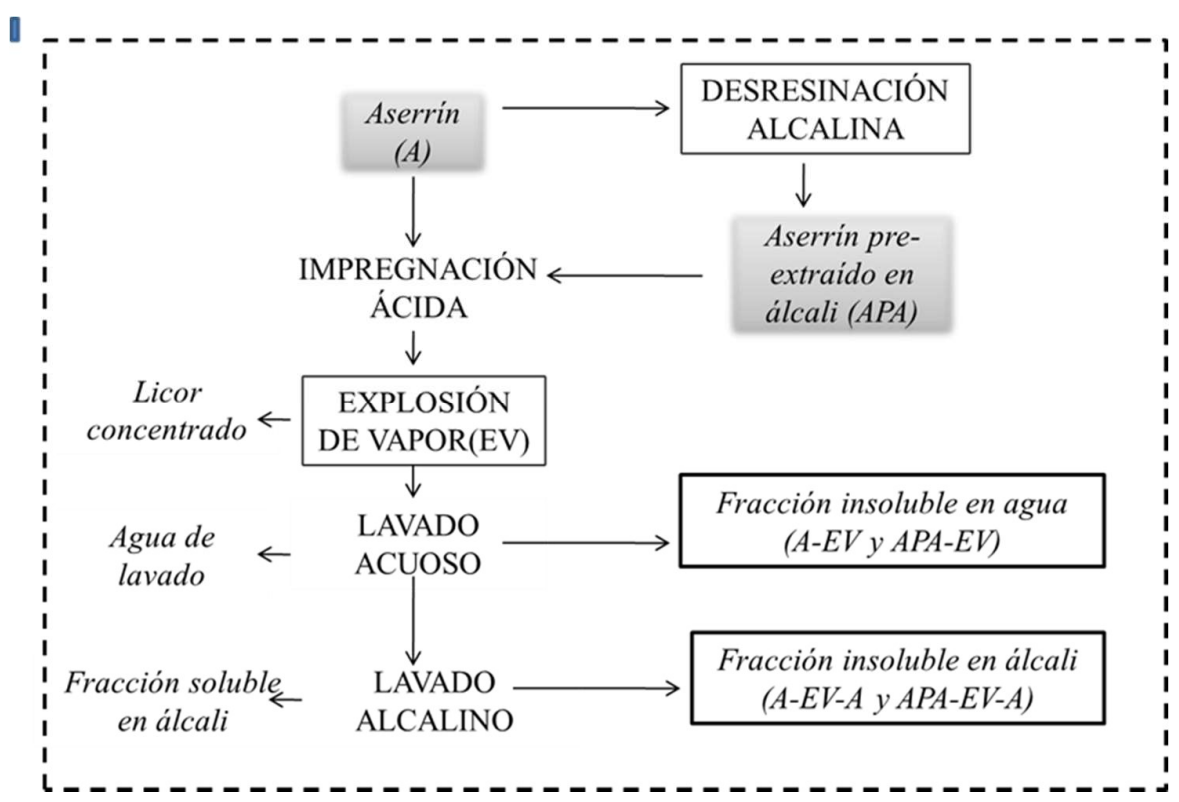

Figura III.12 Esquema de trabajo de la EV.

Las explosiones se realizaron colocando $280 \mathrm{~g}$ secos de aserrín impregnado en el reactor precalentado. Una vez colocado el material a tratar, se cerró la válvula superior del reactor y se abrieron inmediatamente las válvulas de admisión de vapor. Alcanzado el tiempo de residencia, se cerraron las válvulas de entrada de vapor y se abrió inmediatamente la válvula esférica (dispositivo mecánico utilizado para controlar el flujo de material hacia el colector) a través de un actuador neumático para promover la descompresión del material (explosión). El material es arrastrado al interior de un ciclón provisto con un colector. Para garantizar la recuperación total del material, se realizan dos explosiones más, sólo con inyección de vapor.

El material resultante de la EV se filtró con vacío hasta alcanzar un contenido total de sólidos de $30 \%$ aproximadamente, obteniendo así una fracción soluble llamada licor concentrado (LC) y una fracción insoluble. Posteriormente, el aserrín pretratado se lavó con agua para extraer azúcares solubles residuales de las fibras pretratadas. El lavado se realizó a temperatura ambiente durante una hora con agitación y una consistencia de $5 \%$ de sólidos totales $(\mathrm{P} / \mathrm{V})$. La fracción sólida lavada con agua se denominó APA-EV.

El residuo sólido lavado con agua se lavó con álcali a $60^{\circ} \mathrm{C}, 0,4 \% \mathrm{NaOH}$ bs y $1 \mathrm{~h}$ para comprobar la posible influencia del tratamiento sobre la extracción de lignina. Las condiciones del lavado alcalino se seleccionaron de acuerdo a lo encontrado en la bibliografía (Pereira Ramos et al., 
1992), (Donaldson et al., 1988). La fracción resultante de esta etapa fue llamada A-EV-A-y APAEV-A, para el aserrín original y para el aserrín pre-extraído en álcali respectivamente.

\section{III.2.3.3.3 Tratamiento con ácido diluido de holocelulosa para determinación de pseudolignina}

Para comprobar que el aumento de lignina es producto de la condensación de los productos de degradación, se aplicó la técnica desarrollada por Sannigrahi et al. (2011) que consiste en aplicar tratamientos ácidos a la holocelulosa. Se extrajo la holocelulosa de aserrín de pino y luego se sometió a un tratamiento ácido a $150^{\circ} \mathrm{C}, 60 \mathrm{~min}$ y 7,5 g/L H2SO4 (Severidad Combinada=2,44). Se determinó el contenido de lignina en la holocelulosa de aserrín antes y después del tratamiento ácido.

La holocelulosa fue aislada de biomasa libre de extractivos mediante el tratamiento del aserrín con clorito ácido de sodio $\left(\mathrm{NaClO} 240 \%\right.$ bs) y ácido acético $\left(10 \%\right.$ bs ) a $70^{\circ} \mathrm{C}$ por $1 \mathrm{~h}$. El proceso se repitió hasta asegurar la máxima remoción de lignina.

La holocelulosa obtenida fue tratada siguiendo la secuencia de fraccionamiento planteada en este trabajo. Las condiciones ensayadas fueron el punto óptimo determinado en la sección III.2.3.2 Remoción de Extractivos y el punto óptimo de la HAD determinado en la sección III.2.3.3.1 Hidrólisis ácida diluida. Luego se llevó a cabo la caracterización de la holocelulosa pretratada siguiendo la metodología de la sección III.2.1.5. Determinación de carbohidratos estructurales y lignina.

\section{III.2.3.4 Deslignificación alcalina}

El material sólido obtenido de la etapa ácida fue sometido a una etapa de deslignificación con el objetivo de extraer la lignina y mejorar el rendimiento de la hidrólisis enzimática. Se evaluaron cuatro procesos deslignificantes: soda/antraquinona (SODA/AQ), organosolv alcalino, peróxido de hidrógeno alcalino y oxígeno alcalino. Los tratamientos se aplicaron a los puntos óptimos de las etapas anteriores, es decir, los materiales tratados en las siguientes condiciones: APA $\left(90^{\circ}-60\right.$ min-5 g/L NaOH)-HAD $\left(150^{\circ} \mathrm{C}-30\right.$ min-7,5 g/ $\left.\mathrm{L} \mathrm{H}_{2} \mathrm{SO}_{4}\right)$ llamado APA-HAD y APA (90 ${ }^{\circ}-60$ min$5 \mathrm{~g} / \mathrm{L} \mathrm{NaOH})-\mathrm{EV}\left(200^{\circ} \mathrm{C}-5\right.$ min- $\left.3 \% \mathrm{H}_{2} \mathrm{SO}_{4}\right)$ codificado como APA-EV. 


\section{III.2.3.4.1 Deslignificación Soda/AQ}

Los procesos de deslignificación alcalinos dependen de varias variables de operación, como la temperatura máxima de cocción, la carga alcalina, el período de calentamiento, el tiempo de cocción, la relación licor/madera y las características intrínsecas del tipo de pulpado alcalino que se lleve a cabo. En 1957, Vroom desarrolló un método para expresar el tiempo y la temperatura como una variable de operación única llamada Factor H y que representa el área bajo la curva velocidad relativa de reacción-tiempo. Para desarrollar este factor se parte de que la velocidad específica de reacción, k, depende de T, según la ecuación de Arrhenius:

$$
\ln k=B-\frac{A}{T}
$$

La constante $\mathrm{A}$ es igual a $\mathrm{Ea} / \mathrm{R}$, donde $\mathrm{Ea}$ es la energía de activación de la reacción de deslignificación y $\mathrm{R}$ la constante de los gases $(1,987 \mathrm{cal} / \mathrm{g} \mathrm{mol} \mathrm{K})$. La energía de activación ha sido calculada en varias condiciones y para el proceso Kraft se toma como $32000 \mathrm{cal} / \mathrm{mol}$. Por lo tanto, A es igual a 16113. Si la velocidad de reacción, k, es arbitrariamente elegida como la unidad a $100^{\circ} \mathrm{C}$, la ecuación queda:

$0=B-\frac{16113}{373}$

De esta ecuación se determina el valor de B, que en este caso es igual a 43,20. Reemplazando en la Ec. III.19 y tomando logaritmo natural, la velocidad relativa a cualquier otra temperatura, T, es dada por la siguiente ecuación:

$k=\ln ^{-1}\left(43,20-\frac{16113}{T}\right)$

Integrando gráficamente los valores de la constante $\mathrm{k}$ con el tiempo se obtiene el factor $\mathrm{H}$, es decir:

Factor $H=\int k d t$ Ec.III.22

Para el proceso a la soda con cero sulfidez (sin agregado de azufre), como es el caso particular del pulpado soda-antraquinona, la energía de activación que debe utilizarse es $35000 \mathrm{cal} / \mathrm{mol}$ para ajustar la velocidad relativa deslignificación que es más baja (Clayton et al., 1989). Por lo tanto, el factor $\mathrm{H}$ para procesos con cero sulfidez se expresa como:

Factor $H=\int \exp (47,22) \exp \left(-\frac{17614}{T}\right) d t=3,15.10^{20} \int \exp \left(-\frac{17614}{T}\right) d t \quad$ Ec.III.23 
Las cocciones se llevaron a cabo en un digestor sin agitación de acero inoxidable, de $200 \mathrm{~mL}$ de capacidad calefaccionados en un baño de glicerina con control de temperatura (Figura III.13). Las condiciones de cocción se fijaron de acuerdo a un trabajo de optimización de deslignificación SODA/AQ de aserrín de pino (Imlauer et al., 2014) y se muestran en la Tabla III.7. Se ensayaron las fracciones insolubles resultantes de las condiciones APA-HAD y de la APA-EV.

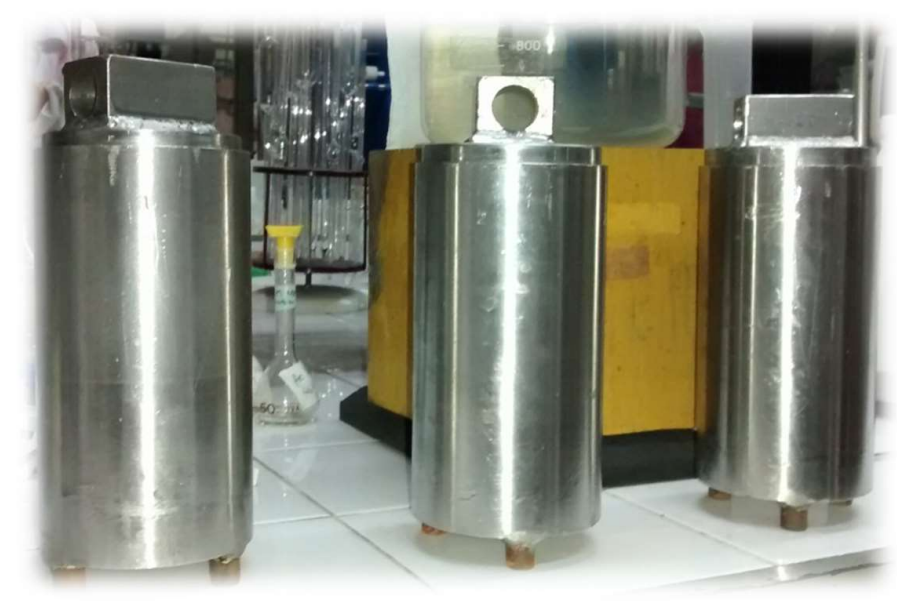

Figura III.13. Reactores utilizados para la etapa deslignificante

Se trataron $20 \mathrm{~g}$ secos de material manteniendo una relación $\mathrm{L} / \mathrm{M}$ de 5 . Las cocciones se realizaron a una temperatura máxima de $170^{\circ} \mathrm{C}$, con tiempo hasta temperatura máxima de $30 \mathrm{~min}$. La carga de antraquinona fue de $0,11 \%$ bs en todos los casos. Pasado el tiempo de reacción los reactores fueron enfriados en un baño de agua. Las pulpas obtenidas se sometieron a etapas de filtración con vacío y lavado exhaustivo con agua. Se tomó una muestra para determinación de rendimiento por pérdida de peso y el material restante húmedo se guardó en bolsas plásticas y se almacenó en heladera.

Tabla III.7. Condiciones experimentales de la etapa deslignificante con Soda-AQ

\begin{tabular}{|l|c|c|c|c|}
\hline Material & Factor $\mathbf{H}$ & $\begin{array}{c}\mathbf{N a O H} \\
(\mathbf{g} / \mathbf{L})\end{array}$ & $\begin{array}{c}\text { Temperatura } \\
\left({ }^{\circ} \mathbf{C}\right)\end{array}$ & $\begin{array}{c}\text { Tiempo a } \\
\text { Tmáx } \\
(\mathbf{m i n})\end{array}$ \\
\hline APA-HAD & 3850 & 55,2 & 170 & 140 \\
\hline APA-EV & 3850 & 55,2 & 170 & 140 \\
\hline
\end{tabular}




\section{III.2.3.4.2 Deslignificación Organosolv alcalino}

Las deslignificaciones organosolv se llevaron a cabo en el mismo digestor que en el proceso anterior (Figura III.13) Las condiciones de cocción se fijaron de acuerdo a un trabajo previo de deslignificación Organosolv de aserrín de pino realizado en nuestro laboratorio (Kruyeniski et al., 2015). Se evaluó la respuesta al tratamiento organosolv de la fracción insoluble resultante de la condición óptima de la APA-EV.

El aserrín fue pretratado (20 g secos de aserrín) en una solución etanol-agua (23/77) con hidróxido de sodio como catalizador ( $28 \% \mathrm{NaOH}$ base seca) con una relación L/M de 6 . El tiempo de calentamiento hasta alcanzar la temperatura de proceso $\left(170^{\circ} \mathrm{C}\right)$ fue de $30 \mathrm{~min}$ que luego se mantuvo por $140 \mathrm{~min}$. Pasado el tiempo de reacción los reactores fueron enfriados en un baño de agua. Las pulpas obtenidas se sometieron a etapas de filtración con vacío y lavado exhaustivo con agua. Se tomó una muestra para determinación de rendimiento por pérdida de peso y el material restante húmedo se guardó en bolas plásticas y se almacenó en heladera.

\section{III.2.3.4.3 Peróxido alcalino}

El tratamiento con peróxido de hidrógeno se aplicó a la fracción insoluble resultante de la secuencia de fraccionamiento alcalina $\left(90^{\circ} \mathrm{C}-60\right.$ min- $\left.5 \mathrm{~g} / \mathrm{L} \mathrm{NaOH}\right)-\mathrm{EV}\left(200^{\circ} \mathrm{C}-5 \mathrm{~min}-3 \%\right.$ $\mathrm{H}_{2} \mathrm{SO}_{4}$ ). Fueron evaluados la concentración de peróxido de hidrógeno y el tiempo. Las condiciones ensayadas fueron seleccionadas de datos bibliográficos, y se indican en la Tabla III.8.

Tabla III.8 Condiciones aplicadas en la etapa de peróxido alcalino al material tratado con EV

\begin{tabular}{|c|c|c|}
\hline Ensayo & $\mathrm{H}_{2} \mathbf{O}_{2}$ (\% bs) & Tiempo (min) \\
\hline 1 & 5 & 60 \\
\hline 2 & 10 & 60 \\
\hline 3 & 5 & 120 \\
\hline 4 & 10 & 120 \\
\hline
\end{tabular}

Los tratamientos con peróxido fueron realizados en recipientes de vidrio calentados a $100^{\circ} \mathrm{C}$ en un baño de agua caliente con agitación (Figura III.14). Las experiencias se llevaron a cabo a una 
consistencia de $10 \%$. Los recipientes se cargaron con $5 \mathrm{~g}$ secos de material y el pH se ajustó a 11,5 con $\mathrm{NaOH}$. Se adicionó $0,1 \%$ bs de un compuesto quelante (DTPMA) para evitar la descomposición del peróxido de hidrógeno.

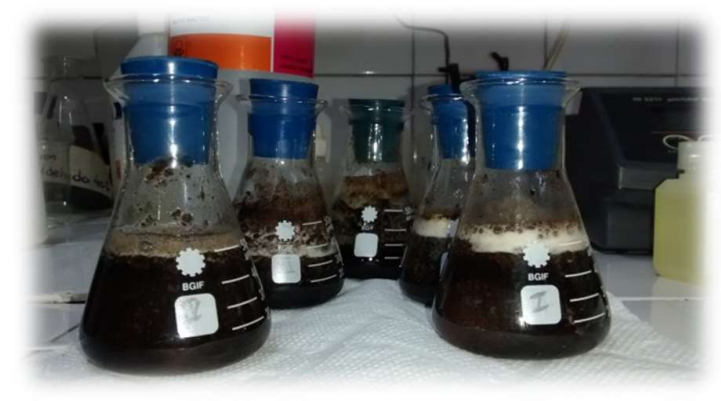

Figura III.14 Tratamientos con peróxido alcalino de aserrín de pino.

Finalizada la reacción, el material sólido es separado del líquido mediante filtración con vacío. Posteriormente, se realizó un lavado exhaustivo del mismo y se determinó el peso total húmedo. Se tomó una muestra para determinación de sequedad y luego se calculó el rendimiento por pérdida de peso y el material restante húmedo se guardó en bolas plásticas y se almacenó en heladera. El licor es almacenado para la determinación del pH final con peachímetro. A su vez se determinó el contenido de $\mathrm{H}_{2} \mathrm{O}_{2}$ residual siguiendo la norma Norma CPPA (Canadian Pulp and Paper Association) Standard J.16P "Analysis of peroxides. En resumen, el peróxido de hidrógeno se determinó por Iodometría basándose en la habilidad del peróxido de reaccionar cuantitativamente con el ioduro en solución ácida con el agregado de molibdato de amonio como catalizador. El iodo libre se valora con solución de tiosulfato de sodio $0,1 \mathrm{~N}$, empleando solución de almidón para la determinación del punto final.

\section{III.2.3.4.4 Oxígeno alcalino}

El tratamiento con oxígeno fue aplicado a la fracción insoluble resultante de la secuencia de fraccionamiento alcalina $\left(90^{\circ} \mathrm{C}-60\right.$ min- $\left.5 \mathrm{~g} / \mathrm{L} \mathrm{NaOH}\right)-\mathrm{EV}\left(200^{\circ} \mathrm{C}-5\right.$ min- $\left.3 \% \mathrm{H}_{2} \mathrm{SO}_{4}\right)$. Las condiciones ensayadas fueron seleccionadas de datos bibliográficos (Pan et al., 2004). El tratamiento se llevó a cabo en un reactor multipropósito que cuenta con un agitador motorizado y que es calefaccionado con una camisa de glicerina (Figura III.15). 


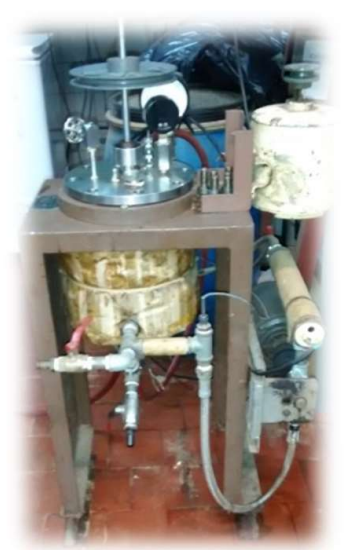

Figura III.15. Reactor multipropósito utilizado en la etapa de oxígeno alcalino

Se pesaron $80 \mathrm{~g}$ secos de material APA-EV y se colocaron en el reactor junto con el $\mathrm{NaOH}$ y el agua. Se trabajó con una carga alcalina de $15 \%$ de $\mathrm{NaOH}$ bs, consistencia de $10 \%$ y se agregó $0,1 \%$ de $\mathrm{MgSO}_{4}$ para evitar la degradación de la celulosa durante la oxidación. El tiempo de residencia fue de 2 horas y la temperatura $100^{\circ} \mathrm{C}$. La presión de $\mathrm{O}_{2}$ mantenida dentro del reactor fue de $6 \mathrm{Kg} / \mathrm{cm}^{2}$.

Pasado el tiempo de reacción, el material se sometió a una etapa de filtración con vacío y lavado exhaustivo con agua. Se tomó una muestra para determinación de rendimiento por pérdida de peso y el material restante húmedo se guardó en bolsas plásticas y se almacenó en heladera. El licor se almacenó y se determinó el álcali residual en el mismo. 


\section{CAPÍTULO IV.}

RESULTADOS $Y$

DISCUSIÓN 


\section{CAPÍTULO IV. RESULTADOS Y DISCUSIÓN}

\section{IV.I. MATERIAS PRIMAS}

La materia prima utilizada fue aserrín de pino generado en la industrialización primaria de la madera de Misiones. En la tabla IV.1 se especifica la procedencia de las muestras obtenidas, la especie y el contenido de humedad inicial.

Tabla IV.1. Aserraderos muestreados, ubicación, especie procesada y contenido de humedad de la muestra.

\begin{tabular}{|l|c|c|c|}
\hline \multicolumn{1}{|c|}{ As e rrade ro } & Zona & $\begin{array}{c}\text { Mate ria } \\
\text { prima }\end{array}$ & $\begin{array}{c}\text { Hume dad } \\
\text { inicial }\end{array}$ \\
\hline Aserradero Forestal Eldorado & Norte & pino elliottii & $53,1 \%$ \\
\hline Aserradero Forestal AM & Sur & pino elliotti & $49,9 \%$ \\
\hline
\end{tabular}

\section{IV.1.1 Caracterización física}

Se determinó la granulometría de las distintas muestras recolectadas de los aserraderos. La tabla IV.2 muestra los resultados obtenidos de la tamización.

Tabla IV.2. Determinación de granulometría

\begin{tabular}{|l|c|c|c|c|}
\hline & \multicolumn{2}{|c|}{$\begin{array}{c}\text { Forestal } \\
\text { Eldorado }\end{array}$} & \multicolumn{2}{c|}{ Fores tal AM } \\
\hline Fracciones & Peso (g) & \% & Peso (g) & \% \\
\hline R 6 & 108 & 13,8 & 27 & 3,7 \\
\hline R 10 & 121 & 15,5 & 85 & 11,7 \\
\hline R 18 & 210 & 26,9 & 235 & 32,4 \\
\hline R 40 & 224 & 28,6 & 258 & 35,5 \\
\hline R 60 & 59 & 7,5 & 64 & 8,8 \\
\hline P 60 & 60 & 7,7 & 57 & 7,9 \\
\hline Total & 782 & 100 & 726 & 100 \\
\hline
\end{tabular}

La fracción P18 - R40 es la que se encuentra en mayor proporción con respecto a las otras fracciones en todas las muestras. Los datos de granulometría denotan que cada muestra posee 
características distintas debido a la diversidad de las máquinas utilizadas en los aserraderos. Esto genera variabilidad tanto en el tamaño de partículas así también como en el contenido de corteza. La fracción más gruesa (R6) estuvo compuesta principalmente por fragmentos de corteza.

La importancia del tamaño inicial de la partícula de biomasa radica en que frecuentemente, se requiere una reducción mecánica del tamaño de partícula para hacer el material más manejable e incrementar la relación superficie/volumen previo a un procesamiento químico, ya que el menor tamaño de partícula permite una mejor penetración de los licores de cocción y disolución de los componentes de la madera. La reducción de tamaño se suele realizar mediante molienda, chipeado o extrusión. Los costos de capital, costos operativos, posibilidades de ampliación y la depreciación de los equipos son muy importantes para este tipo de pretratamientos (Harmsem et al., 2010). Estudios sobre el efecto del tamaño de los chips en la hidrólisis ácida de conífera concluyeron que existe un compromiso entre el consumo de energía y el rendimiento del pretratamiento para garantizar la economía del proceso (Monavari et al., 2009). En el caso del aserrín, puede considerarse que el material ya ha pasado por una molienda con costo nulo, dado que es un residuo.

\section{IV.1.2 Caracterización química}

La composición química del aserrín de pino, determinada por HPLC, UV, calcinación y extracción Soxlhet, se muestra en la Tabla IV.3. Es importante resaltar que a pesar de la heterogeneidad que presenta este residuo se obtuvo un balance de materia cercano al $100 \%$ ( \pm $5 \%$ ) teniendo en cuenta que la mayoría de los métodos de caracterización están desarrollados para materiales limpios (libre de corteza).

El porcentaje de celulosa y hemicelulosas se calculó a partir de las ecuaciones III.5 y III.6. De la Tabla IV.3 se puede observar que existen ciertas diferencias en la composición química de la biomasa proveniente de los diferentes aserraderos. El aserrín generado por Forestal AM tiene una menor cantidad de celulosa y más de lignina. Esto puede estar asociado con el contenido de corteza de ambos materiales, ya que la composición química de la corteza generalmente se caracteriza por un mayor contenido de lignina y menor contenido de celulosa (Alvarez Vasco et al., 2015). El porcentaje de extractivos presentes en al aserrín Forestal Eldorado resulto mayor que para el aserrín de Forestal AM. Esta diferencia puede ser causada tanto por la cantidad de corteza como el periodo de almacenamiento del material ya que a mayor tiempo de almacenamiento pueden ocurrir perdidas de extractivos por crecimiento microbiológico en la madera (Burkhardt, 2010). 
En coníferas una cantidad considerable de glucosa está asociada a los glucomananos. En maderas de pino el valor medio de unidades de manosa por unidad de glucosa en hemicelulosas es 4,15 (Yoon et al., 2008). Por lo tanto la glucosa asociada a los glucomananos en estas muestras sería de 2,45\% para el aserrín de Forestal Eldorado y de 2,57\% para el de Forestal AM.

Tabla IV.3 Composición química del aserrín de pino generado en industrias de Misiones (\% base seca, \%bs)

\begin{tabular}{|c|c|c|}
\hline Componente & $\begin{array}{l}\text { Fores tal } \\
\text { Eldorado }\end{array}$ & $\begin{array}{c}\text { Forestal } \\
\text { AM }\end{array}$ \\
\hline \multicolumn{3}{|c|}{ Carbohidratos Estructurales Totales } \\
\hline Glucanos & 46,62 & 39,85 \\
\hline Xilanos & 7,30 & 6,50 \\
\hline Galactanos & 2,24 & 1,99 \\
\hline Arabinanos & 1,13 & 1,34 \\
\hline Mananos & 10,18 & 10,68 \\
\hline Acetilos & 1,13 & 1,81 \\
\hline Celulosa & 44,17 & 37,28 \\
\hline He mice lulos as & 24,43 & 24,89 \\
\hline Lignina Total & 27,67 & 31,41 \\
\hline Lignina Insoluble en ácido & 27,22 & 30,48 \\
\hline Lignina Soluble en ácido & 0,45 & 0,93 \\
\hline Extractivos Totales & 4,71 & 3,52 \\
\hline Extractivos en alcohol & 3,47 & 2,28 \\
\hline Extractivos en agua & 1,24 & 1,24 \\
\hline Cenizas & 0,26 & 0,26 \\
\hline Total & 101,24 & 97,36 \\
\hline
\end{tabular}

El aserrín de pino presentó la composición típica de una conífera, con un alto contenido de lignina insoluble y de hexosas. La caracterización química es similar a la obtenida para diferentes coníferas por otros autores (Tabla IV.4).

Tabla IV.4. Composición química de coníferas

\begin{tabular}{|c|c|c|c|c|c|c|c|c|c|c|}
\hline Material & Glucanos & Xilanos & s Galactanos & Arabinanos & sMananos & Acetilos & $\begin{array}{c}\text { Lignina } \\
\text { ins oluble }\end{array}$ & $\begin{array}{l}\text { Lignina } \\
\text { soluble }\end{array}$ & $\begin{array}{l}\text { Extrac- } \\
\text { tivos }\end{array}$ & Referencia \\
\hline Picea & 42,03 & 4,84 & 2,34 & 1,06 & 9,72 & - & 29,00 & 1,10 & - & Shuai et al, 2010 \\
\hline Cicuta & 40,23 & 3,70 & 2,61 & 1,23 & 12,51 & 1,29 & 28,30 & 0,50 & 6,00 & Kim, 2005 \\
\hline Picea & 49,90 & 5,30 & 2,30 & 1,70 & 12,30 & - & 28,70 & - & - & Söderström et al, 2003 \\
\hline Pinus contorta & 45,40 & 6,20 & 3,20 & 1,70 & 11,50 & - & 28,50 & 0,50 & 3,40 & Kumar et al, 2010 \\
\hline Douglas fir & 44,70 & 4,90 & 2,80 & 1,60 & 12,90 & - & 28,00 & 0,40 & 2,20 & Kumar et al, 2011 \\
\hline Mezcla de coníferas & 40,00 & 4,90 & 2,10 & 2,00 & 10,10 & 1,30 & 27,90 & 0,35 & 2,50 & Boucher et al, 2014 \\
\hline Pino & 48,00 & 8,20 & 3,70 & 1,90 & 12,10 & - & 26,10 & - & - & Shahbazi et al, 2005 \\
\hline Mezcla de coníferas & 44,10 & 6,00 & 3,70 & 3,00 & 13,20 & - & - & - & - & Nguyen et al, 1998 \\
\hline
\end{tabular}




\section{IV.2 FRACCIONAMIENTO}

En esta sección se exponen los resultados obtenidos en las diferentes etapas de fraccionamiento aplicado al aserrín de pino así como los resultados de la optimización.

\section{IV.2.1 Fraccionamiento alcalino: remoción de extractivos}

El aserrín proveniente del aserradero Forestal Eldorado fue sometido a una etapa alcalina con el objetivo de extraer los ácidos resínicos y grasos. El análisis de los resultados de esta etapa se basó en la caracterización de la composición química del sólido pretratado. En la Tabla IV.5 se exponen las condiciones experimentales de extracción y la composición del sólido pretratado, expresado en base seca como porcentaje sobre madera tratada (\%bs). Además se incluye el porcentaje de álcali consumido durante el pretratamiento.

Tabla IV.5. Condiciones experimentales de la etapa alcalina, composición química del sólido tratado y porcentaje de $\mathrm{NaOH}$ consumido

\begin{tabular}{|c|c|c|c|c|c|c|c|c|c|c|c|c|}
\hline \multirow[b]{2}{*}{ Ensayo } & \multirow{2}{*}{\multicolumn{2}{|c|}{$\begin{array}{l}\text { Tempera- } \mathrm{NaOH} \\
\text { tura }\left({ }^{\circ} \mathrm{C}\right)(\% \text { bs })\end{array}$}} & \multicolumn{9}{|c|}{ Composición del material sólido (\% bs) } & \multirow{2}{*}{$\begin{array}{c}\% \\
\mathrm{NaOH} \\
\text { consumido } \\
\end{array}$} \\
\hline & & & $\mathbf{G l}^{\mathbf{a}}$ & $\mathbf{X} \mathbf{i}^{\mathbf{a}}$ & $\mathbf{G a}^{\mathbf{a}}$ & $\mathbf{A r} \mathbf{r}^{\mathbf{a}}$ & $\mathbf{M a}^{\mathrm{a}}$ & $\mathbf{A c}^{\mathrm{a}}$ & $\mathbf{E x} \mathbf{x}^{\mathbf{a}}$ & Lig $^{\mathbf{a}}$ & $\begin{array}{c}\text { Pérdida } \\
\text { de peso }\end{array}$ & \\
\hline 1 & 70 & 2,5 & 42,3 & 6,91 & 1,99 & 0,92 & 10,3 & N.d. & 0,72 & 28,7 & 5,34 & 95,2 \\
\hline 2 & 90 & 2,5 & 43,2 & 6,52 & 1,92 & 0,96 & 10,3 & N.d. & 0,62 & 28,7 & 6,50 & 97,6 \\
\hline 3 & 70 & 5,0 & 42,3 & 6,38 & 1,82 & 0,94 & 10,3 & N.d. & 0,57 & 28,6 & 6,81 & 86,0 \\
\hline 4 & 90 & 5,0 & 43,8 & 6,70 & 1,74 & 0,86 & 10,1 & N.d. & 0,44 & 28,7 & 8,59 & 88,8 \\
\hline 5 & 66 & 3,8 & 43,1 & 6,33 & 1,89 & 0,92 & 10,5 & N.d. & 0,95 & 28,7 & 6,21 & 92,6 \\
\hline 6 & 94 & 3,8 & 43,0 & 6,47 & 1,60 & 0,68 & 10,6 & N.d. & 0,55 & 28,6 & 7,78 & 95,0 \\
\hline 7 & 80 & 2,0 & 44,5 & 6,92 & 2,25 & 1,09 & 10,6 & N.d. & 0,87 & 29,1 & 7,06 & 100,0 \\
\hline 8 & 80 & 5,5 & 43,9 & 6,76 & 1,76 & 0,93 & 10,3 & N.d. & 0,35 & 29,6 & 4,07 & 87,7 \\
\hline 9 & 80 & 3,8 & 44,0 & 6,70 & 2,11 & 1,07 & 10,4 & N.d. & 0,45 & 29,8 & 7,14 & 93,6 \\
\hline 10 & 80 & 3,8 & 44,3 & 6,81 & 2,10 & 1,03 & 10,4 & N.d. & 0,38 & 29,2 & 6,64 & 94,2 \\
\hline 11 & 80 & 3,8 & 43,3 & 6,82 & 2,11 & 1,02 & 10,3 & N.d. & 0,44 & 29,1 & 6,25 & 94,2 \\
\hline
\end{tabular}

N.d.: No detectado (Límite de detección ácido acético UV $210 \mathrm{~nm}=0,02 \%$ bs)

a Gl:glucanos; Xi: xilanos; Ga:galactanos; Ar:arabinanos; Ma:mananos; Ac:acetilos; Ex: extractivos; Lig: lignina

En general, durante el tratamiento alcalino se consumió aproximadamente el $90 \%$ del $\mathrm{NaOH}$ adicionado.

Los grupos acetilos fueron completamente removidos del aserrín en estas condiciones. Esto puede resultar beneficioso en la producción de bioetanol ya que la deacetilación mejora los rendimientos 
de extracción de glucosa y xilosa durante el tratamiento ácido diluido y la hidrólisis enzimática, debido a que estos grupos aumentan la recalcitrancia de los materiales lignocelulósicos. A su vez, se reduce la toxicidad de los pretratamientos ácidos posteriores mejorando el rendimiento de etanol en la fermentación (Chen et al., 2012). Adicionalmente, el ácido acético puede ser recuperado mediante electrodiálisis, filtración por membranas de adsorción y resinas de intercambio aniónico para su valorización ya que es un producto económicamente atractivo ampliamente utilizado en la industria química y alimenticia (Kundu et al., 2014).

La pérdida de peso aumentó tanto con un incremento de la carga alcalina como de la temperatura. Las variaciones en el contenido de lignina y carbohidratos fueron mínimas en todos los casos, pero el tratamiento aplicado produce diferencias significativas en el contenido de extractivos. La máxima remoción de extractivos $(90,5 \% \mathrm{sbi})$ se produce en el ensayo 8 a $80^{\circ} \mathrm{C}$ con $5,5 \mathrm{~g} / \mathrm{L}$ de $\mathrm{NaOH}$.

El modelo empírico derivado de la aplicación del diseño experimental que explica el contenido residual de extractivos en el material tratado se indica en la Tabla IV.6.

Tabla IV.6 Modelo de regresión para los extractivos residuales en la fracción sólida posterior a la extracción alcalina (en variables codificadas).

\begin{tabular}{|l|c|c|}
\hline Componente & \multicolumn{1}{|c|}{ Ecuación de regresión } & $\mathbf{R}^{\mathbf{2}}$ \\
\hline Extractivos & $0,42-0,10 * \mathrm{~T}-0,13 * \mathrm{C}+0,14 \mathrm{~T}^{2}+0,07 \mathrm{C}^{2}$ & $86 \%$ \\
\hline
\end{tabular}

De acuerdo con este modelo, tanto la temperatura como la concentración tienen una influencia significativa en la desresinación ( $p$-valor $<0,05$ ). Según los coeficientes de la ecuación y considerando los efectos simples, la concentración es el factor con mayor influencia en la remoción de extractivos. El contenido residual de extractivos en la muestra disminuye con el aumento de la temperatura y la concentración, pero los términos cuadráticos indican la presencia de un límite (Figura IV.1). Es decir que hay un límite en la extracción alcalina, una cantidad de extractivos remanentes en la madera que no pueden ser removidos con álcali, siendo probablemente la fracción de insaponificables.

La combinación de factores que permiten obtener la respuesta óptima, es decir, el mínimo contenido de extractivos remanente en el material corresponden a una temperatura de $84^{\circ} \mathrm{C}$ y una concentración de $5 \%$ bs $\mathrm{NaOH}$. De acuerdo al modelo, en estas condiciones se obtendría un contenido de extractivos de $0,35 \%$ bs. 


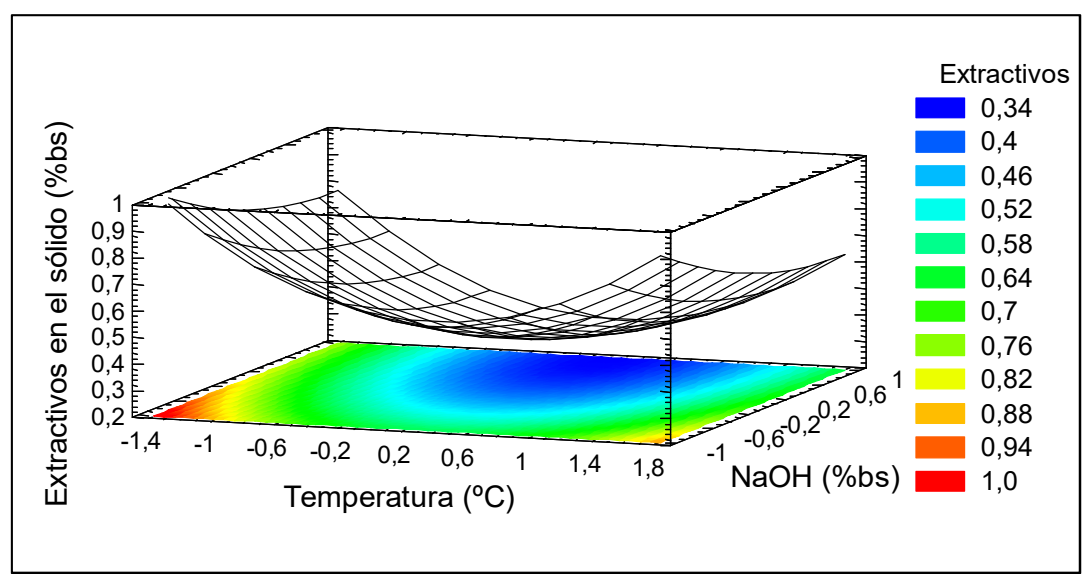

Figura IV.1. Superficie de respuesta de la remoción de extractivos (temperatura y concentración como variables codificadas)

La condiciones correspondientes al ensayo $4\left(90^{\circ} \mathrm{C}\right.$ y $5 \%$ bs $\left.\mathrm{NaOH}\right)$ fueron seleccionadas para realizar el escalado de la etapa en un reactor de 7 L. En la Figura IV.2 se expone la composición química del aserrín original y del aserrín pre-extraído con álcali en estas condiciones, expresado cómo \% sobre madera inicial.

El rendimiento de este ensayo fue de $91,8 \%$ y se extrajo 90,7 \% de los extractivos. En esta etapa se extrajeron en total $22,6 \%$ de los carbohidratos, probablemente en la forma de ácidos orgánicos (hidroxiácidos) (Mänttäri et al., 2015), (Hellstén et al., 2013). La remoción de lignina, xilanos, galactanos y arabinanos fue despreciable (inferior al 1\%). Sin embargo, la pérdida de glucanos y mananos fue mayor, aunque pueden ser consideradas bajas con respecto a los valores originales del aserrín (12\% en ambos casos). Los galactoglucomanos son fácilmente disueltos en condiciones alcalina suaves a diferencia de lo que ocurre con los arabinoglucuroxilanos que son más estables (Schild et al., 2010) (Sjöström, 1977). 


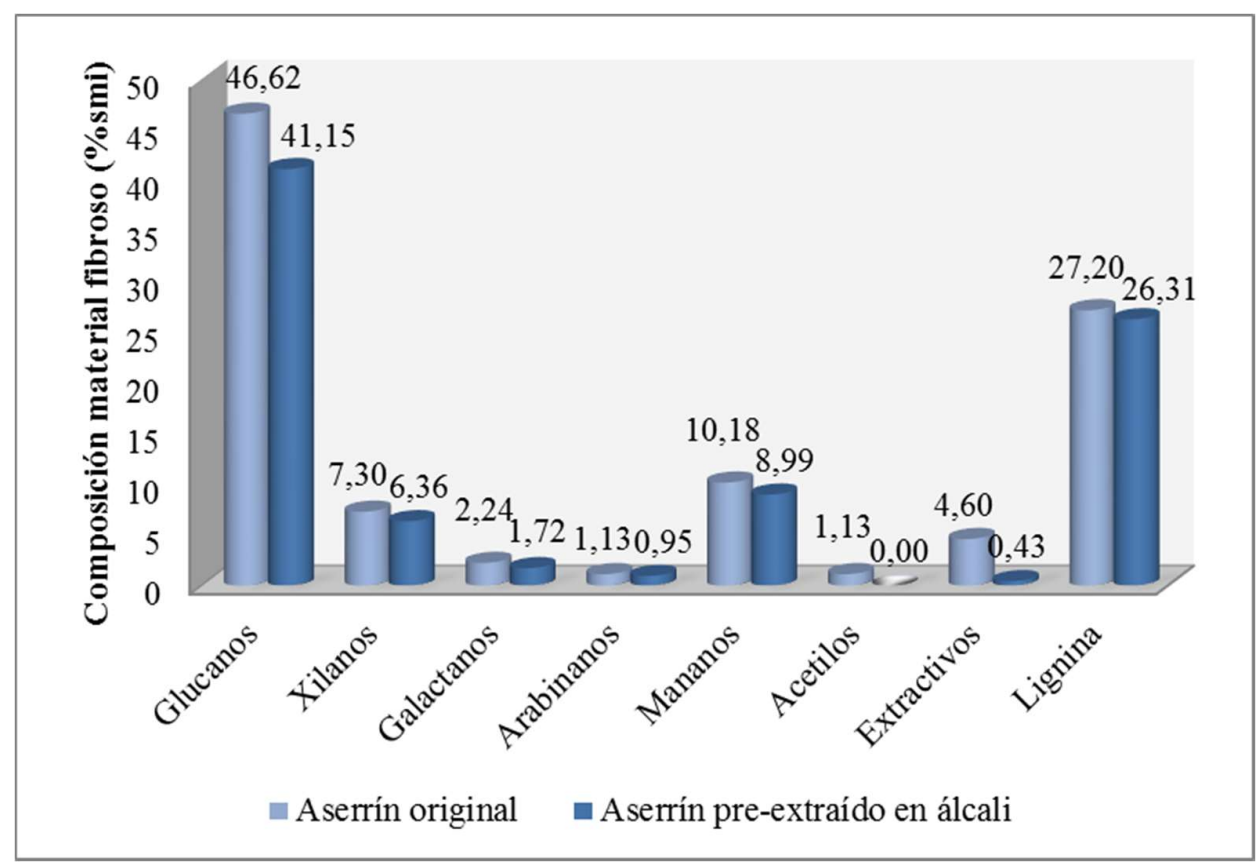

Figura IV.2 Composición química del aserrín original y del aserrín posterior al tratamiento alcalino a escala piloto (expresado como porcentaje con respecto al material inicial, \%sobre madera inicial)

A su vez, el índice de cristalinidad (IC) del aserrín sin tratamiento calculado a partir de la ecuación III.7 resultó de 61,0 mientras que el IC del aserrín pretratado con álcali fue de 66,9. En la Figura IV.3 se muestran a modo de ejemplo los difractogramas correspondientes a la materia prima y al aserrín pre-extraído en álcali. La cristalinidad del aserrín original es similar a la cristalinidad de pino determinada por otros autores (IC igual a 62,5 para pino taeda) (Pu et al., 2013). Durante los pretratamientos el incremento del grado de cristalinidad de la biomasa está relacionado con la degradación de celulosa menos cristalina durante el tratamiento pero en este caso no sería una causa de la mayor cristalinidad ya que la pérdida de glucanos puede ser adjudicada a la pérdida de galactoglucomananos. 


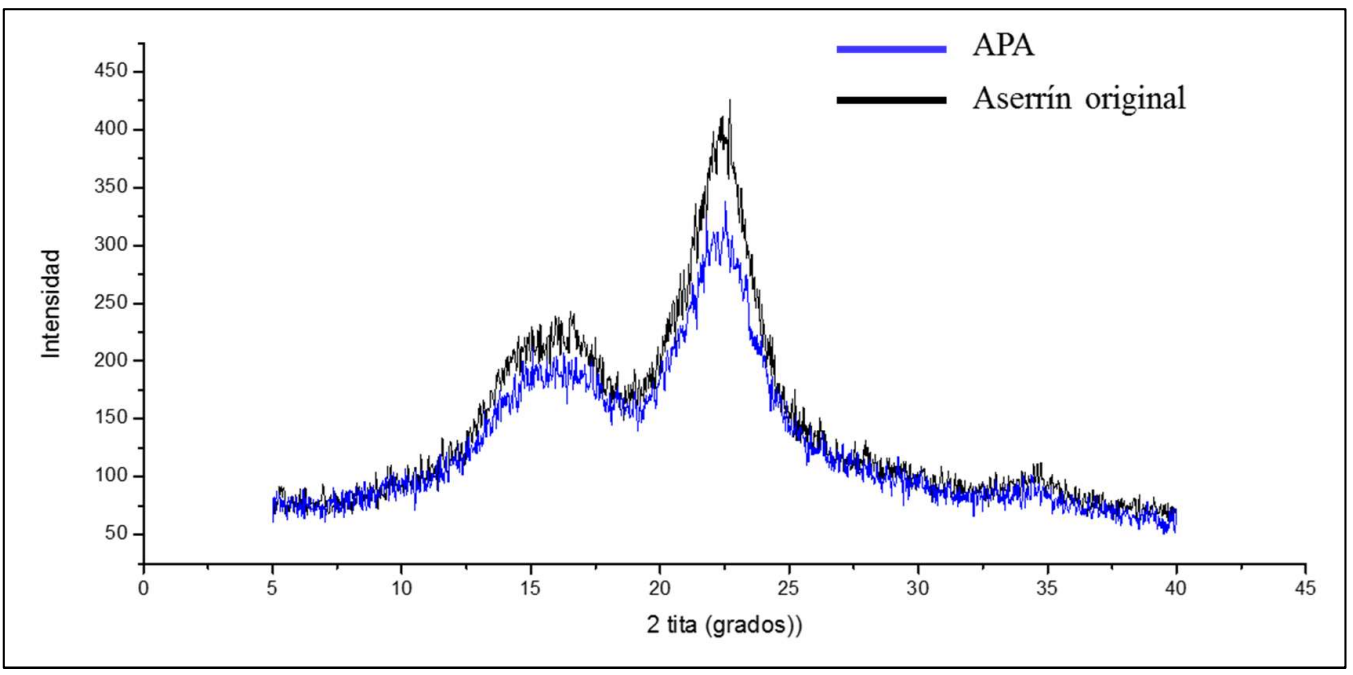

Figura IV.III. Difractogramas del aserrín original y del aserrín pre-extraído en álcali (APA).

Debido a la similitud en los resultados de la extracción alcalina a escala piloto con respecto a los obtenidos a escala laboratorio, se estableció que existe una buena capacidad de predicción de estas experiencias. A pesar del alto rendimiento de remoción de extractivos obtenidos, esta etapa es susceptible de optimización. Por ejemplo, se deberían realizar estudios para disminuir la relación licor:madera para facilitar la recuperación de los ácidos resínicos y grasos, disminuyendo a su vez el consumo de agua y energía.

Por lo tanto, como resultado del tratamiento alcalino se obtuvo aserrín con bajo contenido de extractivos y una corriente líquida compuesta principalmente por extractivos y ácidos orgánicos. Estos compuestos pueden ser separados mediante técnicas como ultrafiltración, nanofiltración, electrodiálisis, destilación entre otros. Los extractivos (ácidos resínicos y grasos) tienen potencial para la producción de productos químicos como surfactantes, adhesivos, insumos de la industria farmacéutica, de pinturas, cosmética e incluso los ácidos grasos pueden ser utilizados para biodiesel (Arshadi et al., 2013) (Burkhardt, 2010). Los potenciales usos de los hidroxiácidos son la producción de ácido láctico, detergentes, cosméticos, polímeros y resinas, plastificantes y surfactantes, furanos, etc. (Alén, 2015). 


\section{IV.2.2 FRACCIONAMIENTO ÁCIDO: EXTRACCIÓN DE HEMICELULOSAS}

El aserrín de pino fue sometido a una etapa ácida con el objetivo de hidrolizar las hemicelulosas. Se evaluaron y optimizaron dos tecnologías diferentes utilizando ácido sulfúrico como catalizador: hidrólisis ácida diluida (HAD) y explosión de vapor (EV).

\section{IV.2.2.1 Hidrólisis con ácido diluido}

\section{IV.2.2.1.1 Resultados Experimentales}

La biomasa fue sometida a una etapa ácida con el fin de encontrar las condiciones que optimizan la remoción de hemicelulosas. El tratamiento fue aplicado al aserrín pre-extraído en álcali (APA) a $90^{\circ} \mathrm{C}, 5 \% \mathrm{NaOH}$ bs, 60 min en un reactor $\mathrm{M} / \mathrm{K}$ de $7 \mathrm{~L}$ y al aserrín original como control. En la Figura IV.4 se indica el contenido de hexosanos, pentosanos y lignina de ambos materiales. El contenido de hexosanos y pentosanos es mayor en el aserrín control (sin tratamiento) mientras que el porcentaje de lignina es ligeramente mayor para APA. Es decir, que el aserrín original tiene más carbohidratos susceptibles a extracción en esta etapa.

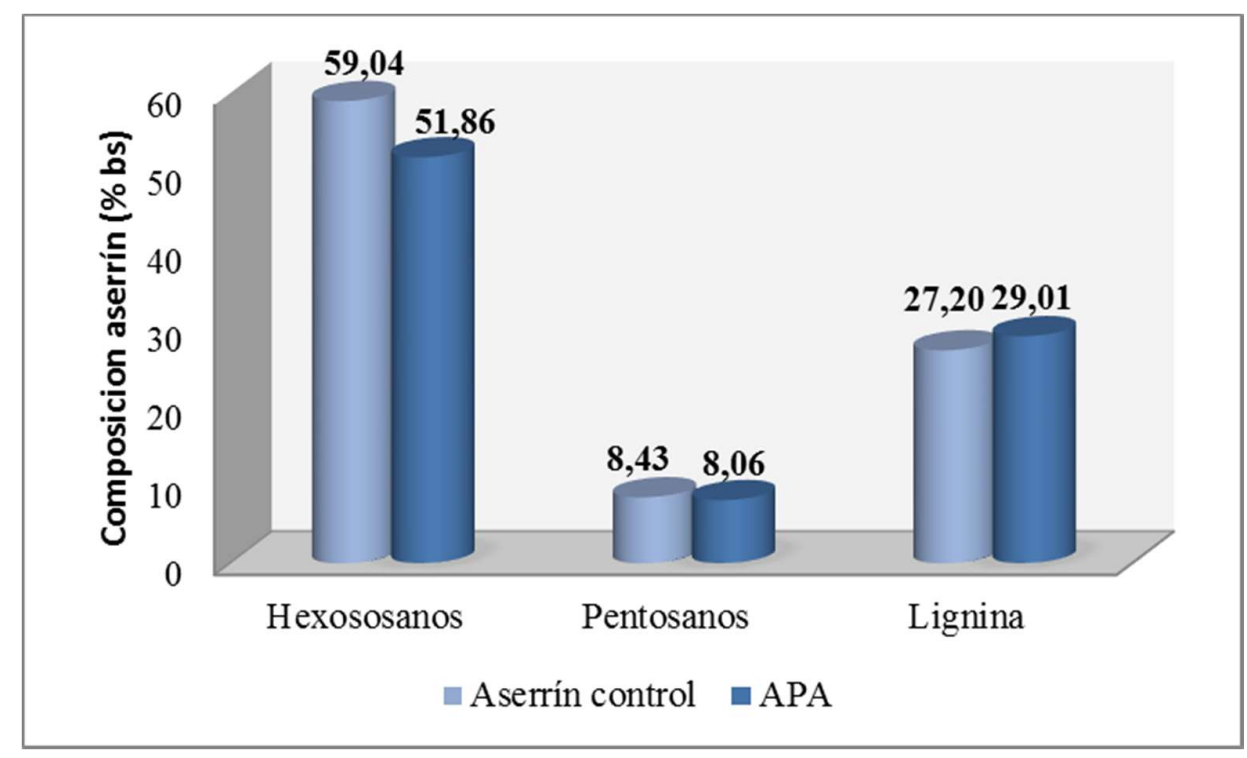

Figura IV.4. Composición química del aserrín control (sin tratamiento) y del aserrín preextraído en álcali (APA) (hexosanos=glucanos + mananos + galacatanos; pentosanos $=$ xilanos + arabinanos) 
En la Tabla IV.7 se muestran las combinaciones de factores utilizadas, la severidad combinada de cada tratamiento y los rendimientos obtenidos correspondientes a cada ensayo experimental del diseño para el aserrín original (control) y el aserrín pre-extraído con álcali. La severidad combinada se calculó a partir de la expresión III.17.

Dado que se requería $0,73 \mathrm{~g} / \mathrm{L}$ de la carga inicial de $\mathrm{H}_{2} \mathrm{SO}_{4}$ (Ecuación III.18) para la neutralización de los carboxilatos de sodio y el álcali remanente del lavado se determinó el pH considerando la concentración corregida para el cálculo de la severidad combinada (SC). Por lo tanto, la SC del tratamiento aplicado al aserrín pre-extraído con álcali es menor que la correspondiente al aserrín sin tratamiento, debido al consumo de ácido para la neutralización del álcali residual.

Tabla IV.7. Condiciones experimentales y rendimientos de la HAD.

\begin{tabular}{|c|c|c|c|c|c|c|c|c|}
\hline & & & & Ase & rrín original & & & $\mathbf{A P A}^{\mathbf{a}}$ \\
\hline Ensayo & Temp. $\left({ }^{\circ} \mathrm{C}\right)$ & Tiempo(min) & $\begin{array}{c}\mathrm{H}_{2} \mathrm{SO}_{4} \\
(\mathrm{~g} / \mathrm{L})\end{array}$ & $\mathbf{S C}^{\mathbf{b}}$ & Rendimiento & $\begin{array}{c}\mathrm{H}_{2} \mathrm{SO}_{4}(\mathrm{~g} / \mathrm{L}) \\
\text { corregido }^{\mathrm{c}}\end{array}$ & $\mathbf{S C}^{\mathbf{b}}$ & Rendimiento \\
\hline 1 & 120 & 30 & 2,50 & 0,78 & 94,90 & 1,77 & 0,62 & 95,85 \\
\hline 2 & 150 & 30 & 2,50 & 1,66 & 91,10 & 1,77 & 1,51 & 91,70 \\
\hline 3 & 120 & 60 & 2,50 & 1,08 & 92,30 & 1,77 & 0,92 & 91,70 \\
\hline 4 & 150 & 60 & 2,50 & 1,96 & 85,20 & 1,77 & 1,81 & 89,30 \\
\hline 5 & 120 & 30 & 7,50 & 1,25 & 79,90 & 6,77 & 1,21 & 87,55 \\
\hline 6 & 150 & 30 & 7,50 & 2,14 & 74,90 & 6,77 & 2,09 & 80,02 \\
\hline 7 & 120 & 60 & 7,50 & 1,55 & 76,20 & 6,77 & 1,51 & 83,19 \\
\hline 8 & 150 & 60 & 7,50 & 2,44 & 70,70 & 6,77 & 2,39 & 76,31 \\
\hline 9 & 110 & 45 & 5,00 & 0,96 & 94,20 & 4,27 & 0,89 & 94,00 \\
\hline 10 & 160 & 45 & 5,00 & 2,43 & 70,20 & 4,27 & 2,36 & 76,42 \\
\hline 11 & 135 & 20 & 5,00 & 1,34 & 90,30 & 4,27 & 1,27 & 91,05 \\
\hline 12 & 135 & 70 & 5,00 & 1,89 & 81,90 & 4,27 & 1,82 & 77,95 \\
\hline 13 & 135 & 45 & 0,80 & 0,90 & 90,50 & 0,07 & 0,00 & 95,63 \\
\hline 14 & 135 & 45 & 9,20 & 1,96 & 78,00 & 8,47 & 1,92 & 83,95 \\
\hline 15 & 135 & 45 & 5,00 & 1,70 & 80,00 & 4,27 & 1,62 & 86,24 \\
\hline 16 & 135 & 45 & 5,00 & 1,70 & 80,50 & 4,27 & 1,62 & 87,23 \\
\hline 17 & 135 & 45 & 5,00 & 1,70 & 80,90 & 4,27 & 1,62 & 86,46 \\
\hline
\end{tabular}

a APA: Aserrín pre-extraído en álcali

${ }^{\mathrm{b}} \mathrm{SC}$ : Severidad Combinada

${ }^{\mathrm{c}}$ Concentración corregida $=$ Carga inicial-Carga consumida

Los rendimientos del aserrín original resultaron menores que los obtenidos para el aserrín preextraído en álcali. Esta mayor solubilización de material del aserrín original puede ser debido a que la severidad aplicada durante su procesamiento fue levemente mayor. A su vez, los 
componentes más lábiles del material ya fueron extraídos en la etapa alcalina previa. Estudios del comportamiento de los carbohidratos durante tratamientos alcalinos demostraron en condiciones alcalinas suaves, la reacción de peeling se inicia a temperaturas menores a $100^{\circ} \mathrm{C}$, produciéndose disolución de materia que es especialmente alta para los glucomananos (Sjostrom, 1977) (Sixta et al., 2006).

Es importante resaltar que el aserrín pre-extraído en álcali fue más fácilmente impregnado por la solución de ácido diluido que el aserrín original, en la Figura IV.5 se puede observar este efecto. Montagna et al. demostraron que la deacetilación y la pérdida de glucomananos en el pino están relacionados con el aumento de la capilaridad de la madera. A su vez, la remoción de extractivos hace más hidrofílico al material o a su superficie (Montagna et al., 2012).

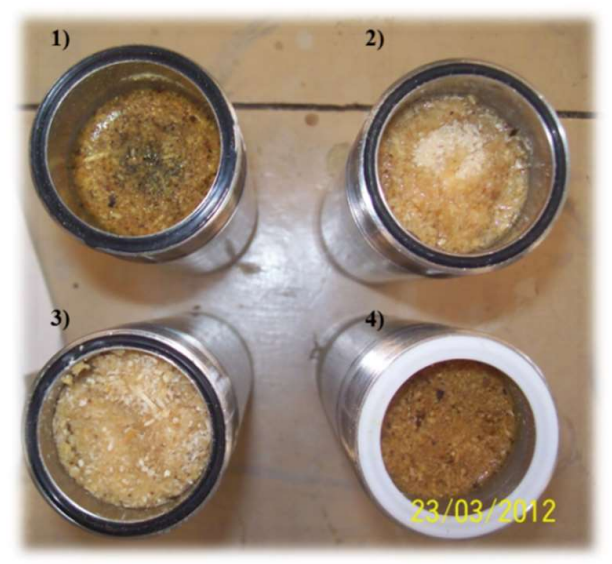

Figura IV.5 Reactores 1 y 4 corresponden a APA y reactores 2 y 3 al aserrín original.

Los arabinoglucuroxilanos y los galactoglucomananos se disuelven en el medio de reacción primero como oligómeros seguido por la ruptura de más uniones glicosídicas que se disuelven como mosacáridos. La presencia de oligosacáridos solubles después de la HAD fue confirmada aplicando una hidrólisis ácida secundaria a los líquidos de pretratamiento. En la Figura IV.6 se muestra a modo de ejemplo una comparación de cromatogramas antes y después de la posthidrólisis. Como se observa en la figura, la concentración de carbohidratos es mayor en el licor hidrolizado, indicando la presencia de oligómeros previo a la hidrólisis secundaria. A su vez, en el cromatograma del licor sin hidrolizar se observan picos no identificados previos al pico de la glucosa que son atribuidos a la presencia de oligómeros. 


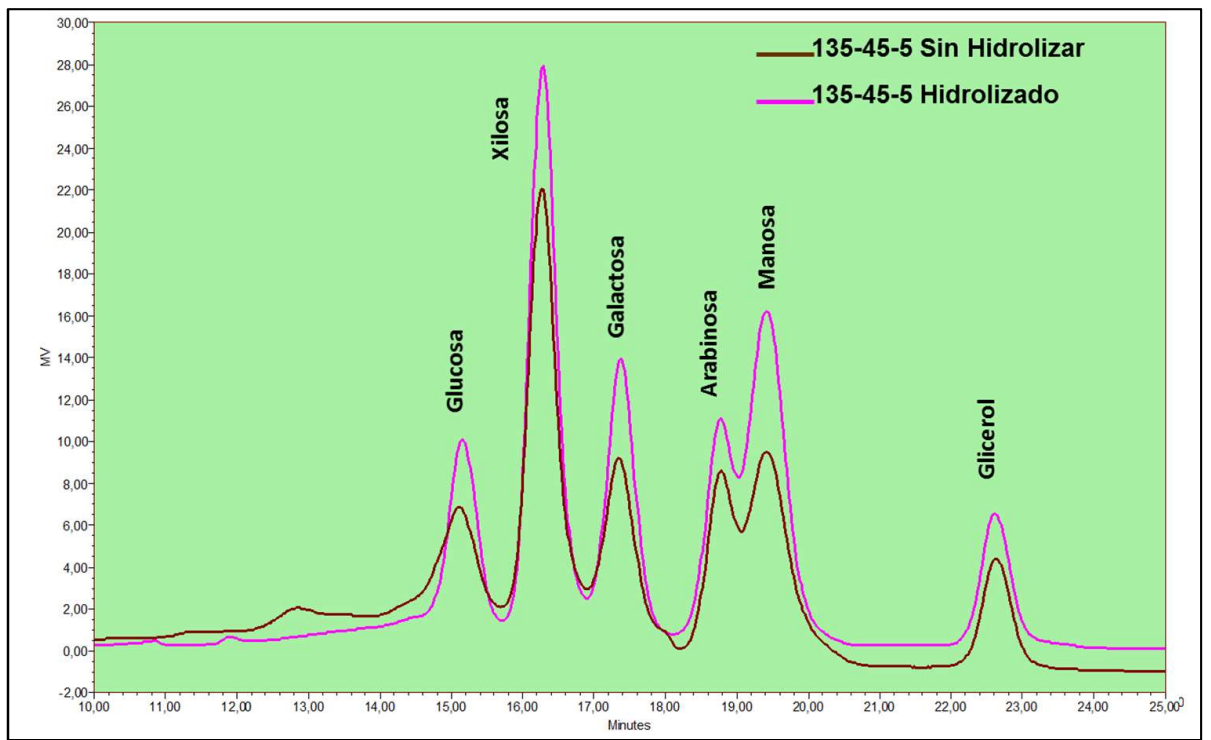

Figura IV.6. Comparación de cromatogromas de licores posteriores a la HAD (ensayo APA$\mathrm{HAD}$ a $135^{\circ} \mathrm{C}, 45$ min y $5 \mathrm{~g} / \mathrm{L}$ de $\mathrm{H}_{2} \mathrm{SO}_{4}$ ) con y sin post-hidrólisis obtenidos con la columna Shodex SP810.

El porcentaje de azúcares hemicelulósicos extraídos como oligómeros en cada uno de los ensayos se exponen en la Figura IV.7.a y b. Para ambos materiales, el porcentaje de oligómeros extraídos en cada ensayo es similar. Los arabinanos se extraen principalmente como monómero en todas las condiciones. En general, en las condiciones más suaves de temperatura, tiempo y concentración de ácido sulfúrico, la glucosa, xilosa, manosa y galactosa se extraen principalmente como polímeros. En los puntos más severos las hemicelulosas se extraen principalmente como azucares mientras que en las condiciones menos severas como oligómeros (Figura IV.7). Es decir, que en los puntos menos severos de tratamiento se consigue extraer las hemicelulosas en forma polimérica pero a costas de un menor rendimiento de extracción. Esto difiere de lo que ocurre en la autohidrólisis, donde incluso en las condiciones más severas los glucomananos son extraídos principalmente como polímeros (Yoon et al., 2008). Por lo tanto, se puede concluir que este proceso no es adecuado para la obtención de hemicelulosas como oligómeros dado los bajos rendimientos que se obtendrían. 

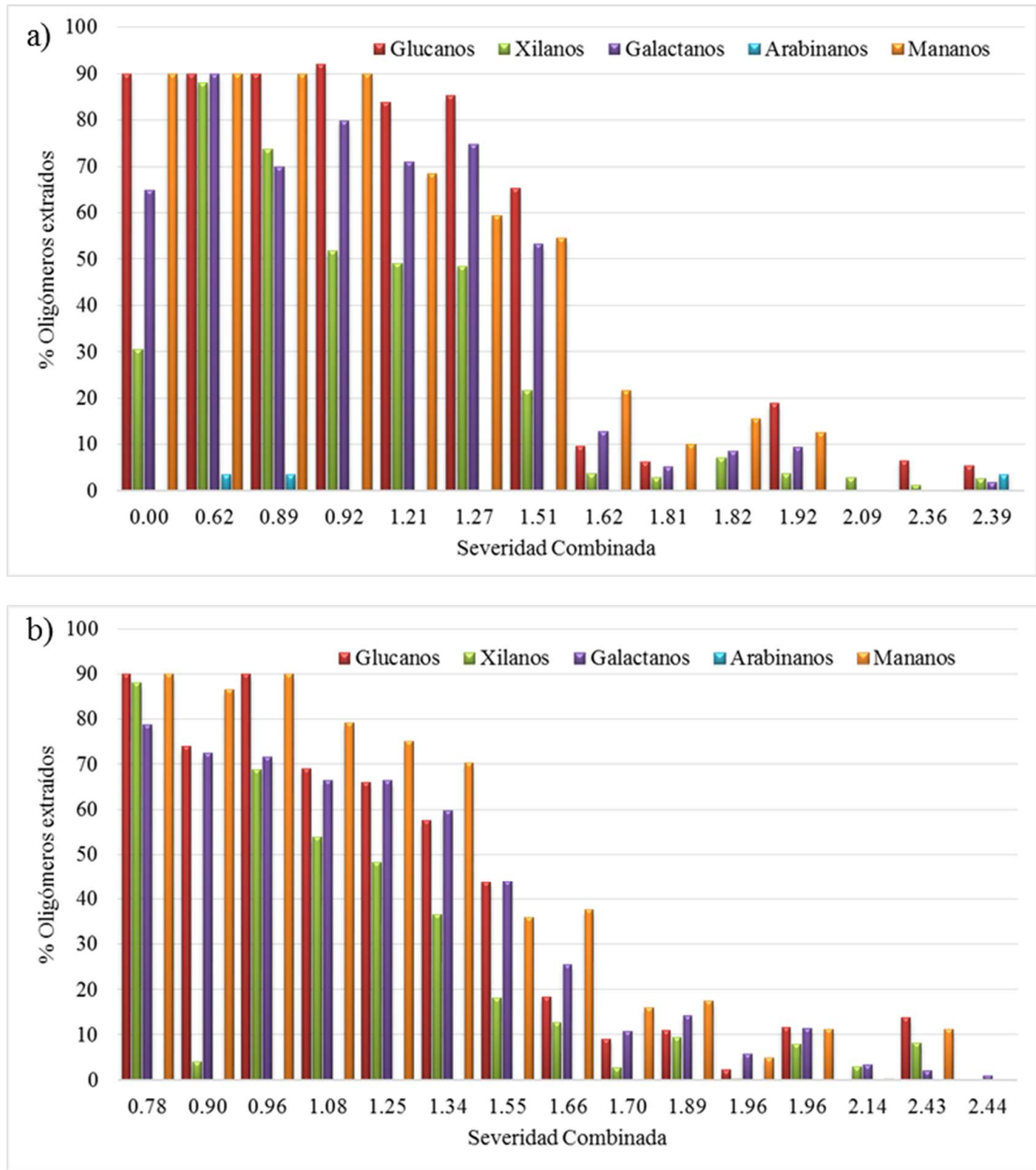

Figura IV.7 Oligómeros extraídos (como \% de azúcares totales removidos), a) en la HAD del aserrín pre-extraído en álcali; b) en la HAD del aserrín original.

La composición de azúcares totales (composición de carbohidratos después de la pos hidrolisis) y productos de degradación en los licores del aserrín pre-extraído se exponen en la Tabla IV.8, y del aserrín original en la Tabla IV.9. 
Tabla IV.8. Composición química de la fracción líquida de la etapa ácida de APA (expresado como porcentaje sobre aserrín inicial)

\begin{tabular}{|c|c|c|c|c|c|c|c|c|c|c|c|}
\hline & & & & úcares tota & & & & $\begin{array}{l}\text { Prod } \\
\text { degI }\end{array}$ & $\begin{array}{l}\text { tos de } \\
\text { ación }\end{array}$ & & \\
\hline Ensayo & $\mathrm{SC}^{\mathrm{a}}$ & Glucosa & Xilosa & Galactosa & Arabinosa & Manosa & Ac.Acético & HMF & Furfural & Hexosas $^{b}$ & Pentosas $^{\mathrm{c}}$ \\
\hline 1 & 0,62 & 0,03 & 0,84 & 0,20 & 0,90 & 0,13 & N.d. & 0,02 & N.d. & 0,35 & 1,74 \\
\hline 2 & 1,51 & 1,00 & 3,03 & 1,30 & 1,34 & 1,92 & N.d. & 0,04 & N.d. & 4,22 & 4,37 \\
\hline 3 & 0,92 & 0,21 & 1,39 & 0,48 & 1,08 & 0,22 & N.d. & 0,04 & N.d. & 0,91 & 2,47 \\
\hline 4 & 1,81 & 1,42 & 4,30 & 1,74 & 1,30 & 3,81 & N.d. & 0,05 & 0,15 & 6,97 & 5,60 \\
\hline 5 & 1,21 & 0,31 & 2,22 & 0,81 & 1,28 & 0,60 & N.d. & 0,03 & 0,00 & 1,72 & 3,49 \\
\hline 6 & 2,09 & 1,94 & 4,47 & 2,12 & 1,23 & 5,06 & N.d. & 0,13 & 0,27 & 9,12 & 5,71 \\
\hline 7 & 1,51 & 0,65 & 2,71 & 1,32 & 1,31 & 1,42 & N.d. & 0,04 & 0,01 & 3,40 & 4,02 \\
\hline 8 & 2,39 & 2,95 & 3,85 & 1,48 & 1,28 & 4,52 & N.d. & 0,62 & 0,99 & 8,96 & 5,13 \\
\hline 9 & 0,89 & 0,13 & 1,53 & 0,45 & 1,18 & 0,09 & N.d. & 0,03 & N.d. & 0,67 & 2,71 \\
\hline 10 & 2,36 & 2,60 & 4,09 & 1,50 & 1,10 & 5,35 & N.d. & 0,55 & 0,82 & 9,45 & 5,18 \\
\hline 11 & 1,27 & 0,48 & 2,36 & 1,26 & 1,26 & 0,74 & N.d. & 0,04 & 0,01 & 2,48 & 3,63 \\
\hline 12 & 1,82 & 1,06 & 3,57 & 1,81 & 1,27 & 3,13 & N.d. & 0,03 & 0,08 & 6,00 & 4,84 \\
\hline 13 & $-0,18$ & 0,05 & 0,87 & 0,16 & 0,62 & 0,19 & N.d. & 0,04 & N.d. & 0,40 & 1,49 \\
\hline 14 & 1,92 & 1,25 & 3,61 & 1,80 & 1,29 & 3,26 & N.d. & 0,03 & 0,08 & 6,32 & 4,91 \\
\hline 15 & 1,62 & 0,96 & 3,24 & 1,78 & 1,37 & 2,49 & N.d. & 0,01 & 0,04 & 5,23 & 4,61 \\
\hline 16 & 1,62 & 0,84 & 3,01 & 1,58 & 1,39 & 2,10 & N.d. & 0,05 & 0,03 & 4,52 & 4,40 \\
\hline 17 & 1,62 & 0,91 & 3,20 & 1,54 & 1,37 & 2,38 & N.d. & 0,04 & 0,03 & 4,83 & 4,57 \\
\hline
\end{tabular}

N.d: No detectado (Límite de detección (LD) ácido acético UV $210 \mathrm{~nm}=0,02 \%$ bs; LD Furfural UV $254 \mathrm{~nm}=0,004 \%)$

${ }^{\text {a }} \mathrm{SC}$ : Severidad Combinada

${ }^{\mathrm{b}}$ Hexosas $=$ glucosa + galactosa + manosa

${ }^{c}$ Pentosas $=$ xilosa + arabinosa

La cantidad de azúcares hemicelulósicos en el licor fue más alta que la cantidad de glucosa. Este resultado se debe a que las hemicelulosas tienen mayor reactividad (estructura amorfa y mayor accesibilidad) en comparación con la celulosa (estructura cristalina empaquetada en un arreglo fibrilar). La composición química del licor resultante del tratamiento ácido diluido del aserrín original es similar a la del aserrín pre-extraído con álcali. A diferencia del líquido de pretratamiento del aserrín pre-extraído con álcali, en este último caso se observa la presencia de ácido acético en la composición del licor. 
Tabla IV.9. Composición química de la fracción líquida de la etapa ácida aplicada al aserrín original (expresado como porcentaje sobre aserrín inicial)

\begin{tabular}{|c|c|c|c|c|c|c|c|c|c|c|c|}
\hline \multirow[b]{2}{*}{ Ensayo } & \multicolumn{7}{|c|}{ Azúcares totales } & \multicolumn{2}{|c|}{ Productos de } & \multicolumn{2}{|c|}{ Total } \\
\hline & SC & Glucosa & Xilosa & Galactosa & Arabinosa & Manosa & Ac.Acético & HMF & Furfural & Hexosas & Pentosas \\
\hline 1 & 0,78 & 0,33 & 0,24 & 0,50 & 0,98 & 0,55 & 0,13 & N.d. & N.d. & 1,39 & 1,22 \\
\hline 2 & 1,25 & 2,22 & 3,75 & 2,00 & 1,17 & 7,00 & 0,85 & 0,02 & 0,05 & 11,23 & 4,92 \\
\hline 3 & 1,08 & 0,72 & 1,00 & 0,98 & 1,26 & 1,93 & 0,33 & N.d.. & N.d. & 3,63 & 2,25 \\
\hline 4 & 1,55 & 2,87 & 4,73 & 2,31 & 1,19 & 8,10 & 1,23 & 0,14 & 0,23 & 13,28 & 5,92 \\
\hline 5 & 1,66 & 0,58 & 0,80 & 0,81 & 1,01 & 1,38 & 0,37 & N.d. & N.d. & 2,77 & 1,81 \\
\hline 6 & 2,14 & 3,07 & 5,01 & 2,34 & 1,01 & 7,93 & 1,31 & 0,16 & 0,26 & 13,34 & 6,01 \\
\hline 7 & 1,96 & 1,52 & 2,57 & 1,66 & 1,12 & 3,84 & 0,86 & N.d. & 0,01 & 7,03 & 3,69 \\
\hline 8 & 2,44 & 3,60 & 4,46 & 1,99 & 0,96 & 7,57 & 1,55 & 0,97 & 1,26 & 13,16 & 5,42 \\
\hline 9 & 0,96 & 0,31 & 0,30 & 0,47 & 1,09 & 0,59 & 0,21 & N.d. & N.d. & 1,37 & 1,40 \\
\hline 10 & 2,43 & 3,68 & 3,87 & 1,69 & 0,98 & 6,06 & 1,57 & 1,41 & 1,53 & 11,43 & 4,85 \\
\hline 11 & 1,34 & 0,86 & 1,22 & 1,03 & 1,18 & 2,31 & 0,38 & N.d. & N.d. & 4,19 & 2,40 \\
\hline 12 & 1,89 & 1,99 & 3,70 & 2,08 & 1,19 & 6,21 & 1,08 & 0,03 & 0,06 & 10,28 & 4,89 \\
\hline 13 & 0,90 & 0,73 & 0,62 & 0,92 & 1,19 & 2,00 & 0,11 & N.d. & N.d. & 3,66 & 1,81 \\
\hline 14 & 1,96 & 2,64 & 4,29 & 2,32 & 1,11 & 7,00 & 1,21 & 0,04 & 0,09 & 11,96 & 5,40 \\
\hline 15 & 1,70 & 2,59 & 4,25 & 2,44 & 1,16 & 6,90 & 1,09 & 0,02 & 0,05 & 11,92 & 5,41 \\
\hline 16 & 1,70 & 2,27 & 3,82 & 2,22 & 1,29 & 6,51 & 1,07 & 0,02 & 0,04 & 10,99 & 5,11 \\
\hline
\end{tabular}

N.d: No detectado (LD Furfural UV $254 \mathrm{~nm}=0,004 \%$; LD HMF UV $254 \mathrm{~nm}=0,003 \%$ )

${ }^{a}$ SC: Severidad Combinada

${ }^{\mathrm{b}}$ Hexosas $=$ glucosa + galactosa + manosa

${ }^{\mathrm{c}}$ Pentosas $=$ xilosa + arabinosa

Debido a las altas temperaturas y las condiciones ácidas, parte de los azúcares liberados son degradados, generando furfural (degradación de pentosas) y 5-hidroximetilfurfural o HMF (degradación de hexosas). A partir de una SC igual a 2 la cantidad de estos compuestos aumenta significativamente mientras que a SC menores es casi despreciable (Figura IV.8). La máxima concentración de HMF $(0,55 \%)$ y furfural $(0,82 \%)$ se produce en la experiencia 8 que corresponde a la SC más alta del diseño mientras que en los niveles más suaves de pretratamiento no se detectaron estos compuestos en el licor. A su vez, la mayor concentración de furfural que de HMF indica que la degradación de pentosas es mayor que la de hexosas. En condiciones más severas la concentración de HMF y furfural pueden disminuir debido a la formación de otros ácidos a partir de estos, como ácido fórmico y ácido levulínico. Estudios sobre pretratamientos ácidos han demostrado que en condiciones más severas (SC mayor a 3,4) la concentración de estos subproductos disminuyó (Larsson et al., 1999). A su vez, la severidad combinada utilizada en este trabajo es menor que la utilizada por otros autores, por lo tanto la degradación de azúcares es menor. Por ejemplo, con el tratamiento de biomasa de abeto Douglas a $200^{\circ} \mathrm{C}$, por $30 \mathrm{~min}$, con una concentración de $1 \%$ de $\mathrm{H}_{2} \mathrm{SO}_{4}$ ( $\mathrm{SC}$ de 2.9 aproximadamente), se degradó el $6 \%$ de los carbohidratos como HMF y furfural (Alvarez Vasco et al., 2015). 


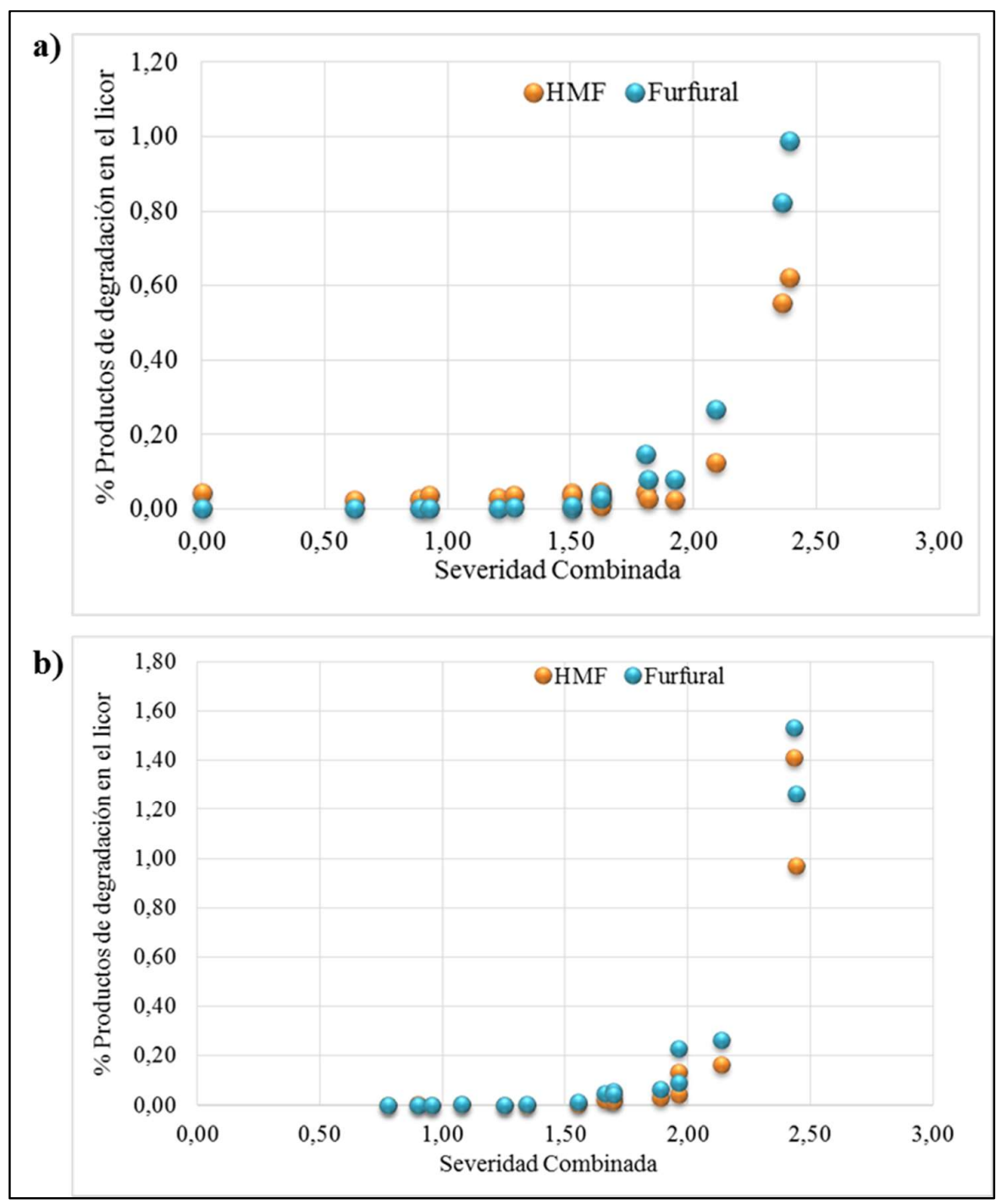

Figura IV.8. Variación del \% de productos de degradación (HMF y furfural) con la severidad del tratamiento con ácido diluido (expresado como \% sobre madera inicial)

La figura IV.9 representa la variación del contenido de azúcares en los licores con la SC para el aserrín pre-extraído en álcali y para el aserrín control. La tendencia del contenido de azúcares hemicelulósicos es similar para ambos materiales, es decir, aumentan con la SC hasta un valor máximo de concentración ( $\mathrm{SC} \sim 2$ ) y luego empiezan a disminuir. Este comportamiento se debe a que los azúcares en los licores se degradan formando HMF y Furfural a SC más altas y coincide con lo observado en la Figura IV.8. A diferencia, el contenido de glucosa aumenta a medida que se incrementa la SC del tratamiento (Figura IV.9.a). A pesar de la degradación a HMF de la glucosa, a SC más altas se hidroliza celulosa aumentando la concentración en el licor. 
A su vez, en la fracción soluble del aserrín sin pretratar se observa la presencia de ácido acético. Como se observa en la Figura IV.9.f, la concentración de ácido acético aumenta cuando se incrementa la SC indicando que la desacetilación es mayor a SC más altas. En los licores, del aserrín pre-extraído no se detectó ácido acético debido a la desacetilación completa en la etapa alcalina.
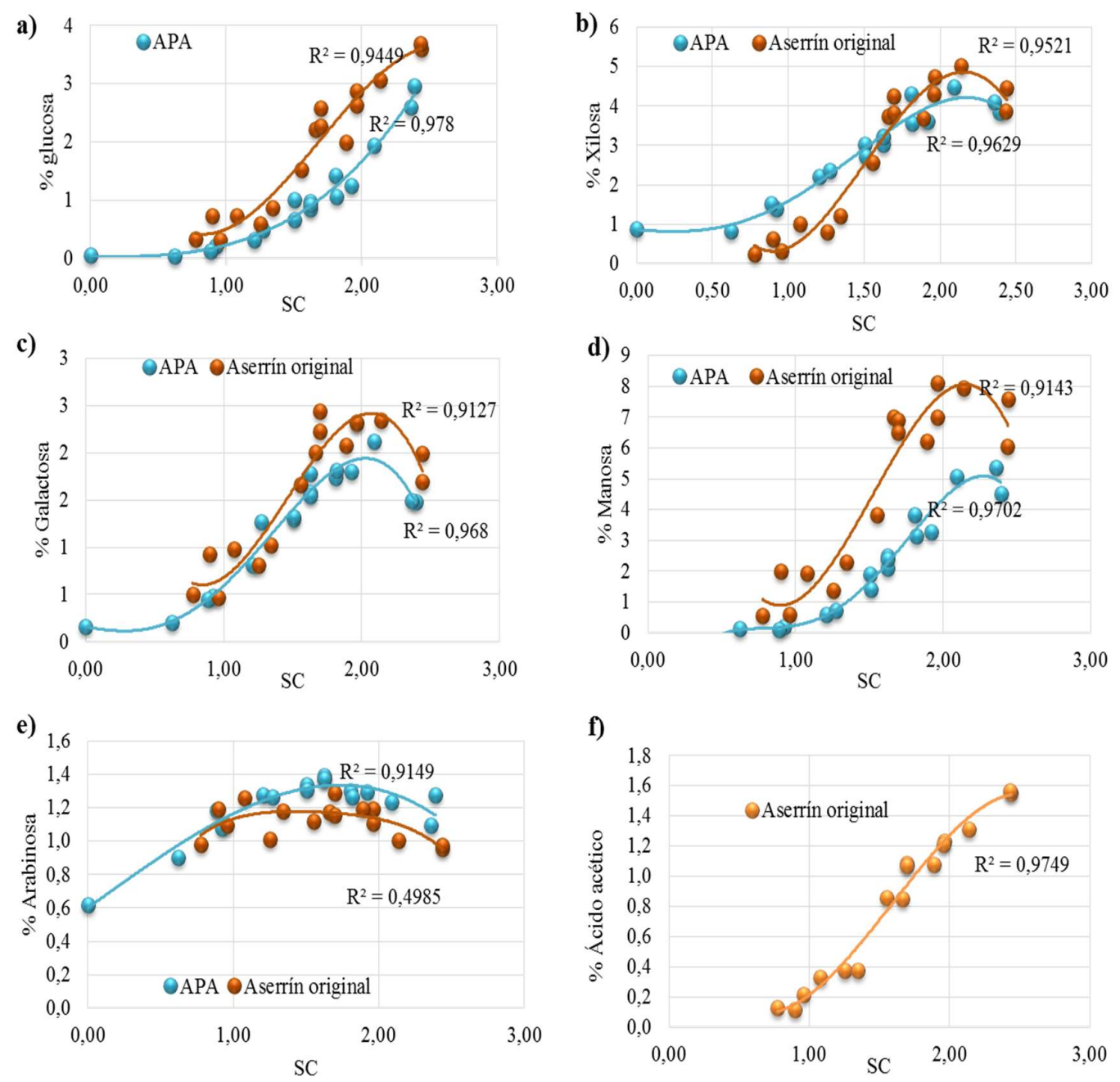

Figura IV.9. Variación del contenido de a) glucosa, b) xilosa, c) galactosa, d) manosa, e) arabinosa y f) ácido acético en los líquidos de pretratamiento del aserrín pre-extraído en álcali (APA) y del aserrín original (expresados como \% sobre aserrín inicial). 
Los rendimientos de extracción de hemicelulosas se calcularon a partir de la ecuación III.12. En la Figura IV.10 se observa que la mayor extracción de carbohidratos se produce en las mismas condiciones para ambos materiales (Ensayo $6: 150^{\circ} \mathrm{C}, 30 \mathrm{~min}$ y $5 \% \mathrm{H}_{2} \mathrm{SO}_{4}$ ) que corresponde a una SC de 2,14 para el aserrín original y de 2,09 para el aserrín pre-extraído en álcali. Por lo tanto, la máxima extracción coincide con la máxima concentración de azúcares presente en el licor. A pesar de la pequeña diferencia en la severidad en este punto, el rendimiento de extracción (hexosas más pentosas) fue significativamente diferente para ambos materiales siendo del $57 \%$ con respecto al contenido de hemicelulosas inicial para el aserrín pre-extraído en álcali y de $74 \%$ para el aserrín original. Esta diferencia en la extracción se atribuye a que durante la etapa alcalina parte de los carbohidratos del aserrín ya son extraídos, como los glucomananos que son muy reactivos en medio alcalino y parte de la celulosa menos cristalina.

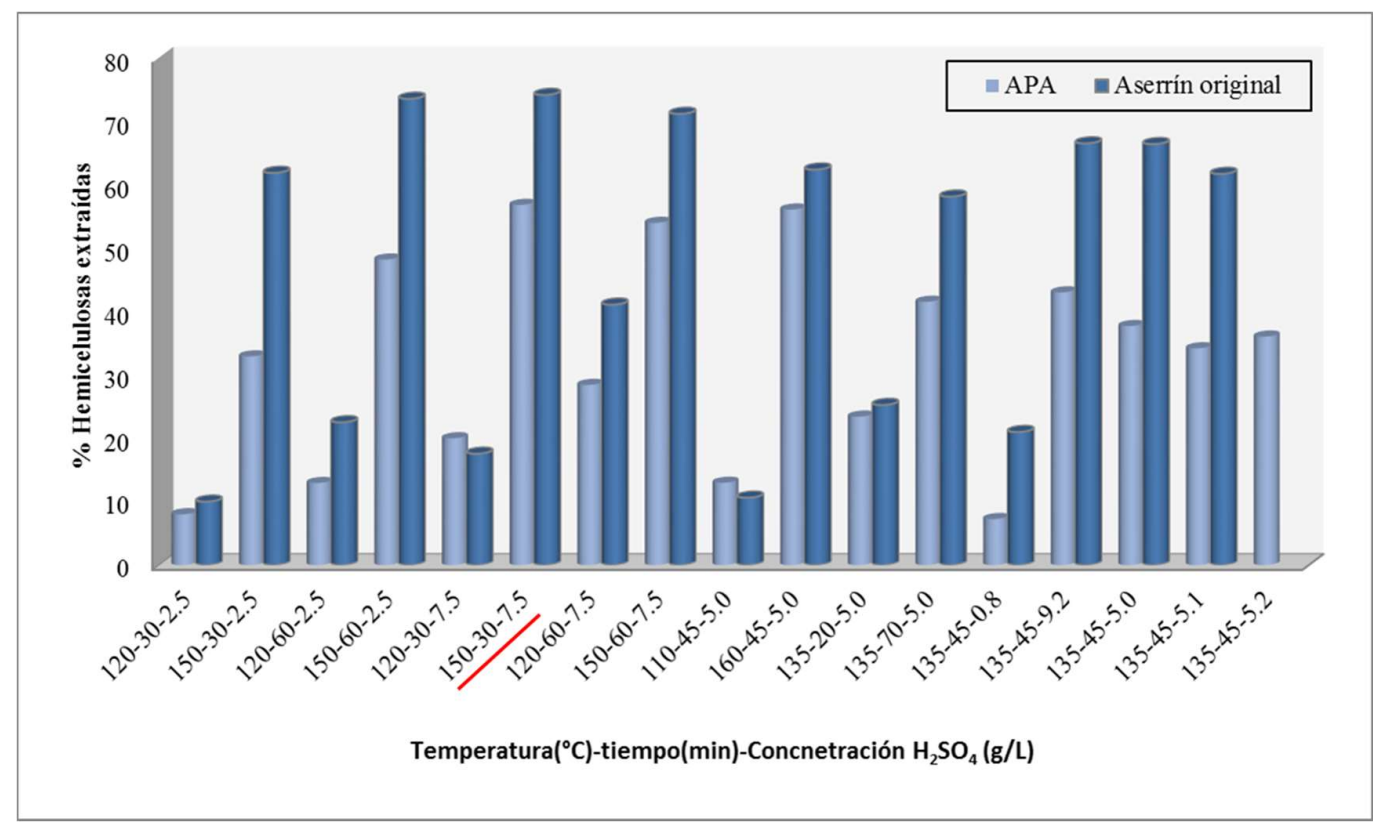

Figura IV.10. Rendimiento de extracción de hemicelulosas del aserrín original y del aserrín pre-extraído en álcali (APA)

En la Tabla IV.10 se muestra un resumen de las condiciones utilizadas y los resultados obtenidos por otros autores. En general, a mayor coeficiente de severidad se extraen más hemicelulosas, pero al mismo tiempo más celulosa. Es importante notar que cuando la temperatura utilizada es $180^{\circ} \mathrm{C}$ o superior la extracción de celulosa es significativa (30\% aproximadamente), a diferencia de lo que ocurre en los procesos a temperaturas inferiores (extracción de celulosa inferior a 5\%). 
Además, condiciones más severas implican mayor degradación de azucares en la fase líquida. Es decir, algunos autores consiguen rendimientos casi del 100\% de extracción de hemicelulosas con factores de severidad combinada cercanos a 3, pero la recuperación de las hemicelulosas en el licor es baja debido a la degradación de estos azúcares (Alvarez Vasco et al., 2015) (Lim \& Lee, 2013) (Huang \& Ragauskas, 2012). Los resultados de la tabla IV.10 son comparables con los resultados obtenidos en este trabajo para el aserrín original, ya que el aserrín con tratamiento alcalino es un material diferente en cuanto a su composición química. El rendimiento de extracción de hemicelulosas fue del 75\% para el aserrín original en condiciones menos severas (SC: 2,14). Por ejemplo, Bouchert el al consiguió un rendimiento de extracción $80 \%$ a una SC superior $(2,95)$ que resultó en mayor degradación de azucares que en este trabajo (Boucher et al., 2015).

Marzialetti el al. obtuvieron un rendimiento de extracción de hemicelulosas similar pero con un factor de severidad menor (Marzialetti et al., 2008). Este resultado más favorable puede atribuirse al hecho de que utilizaron madera de tronco y no biomasa proveniente de la industrialización de la madera. Alvarez Vazco et al. estudiaron el comportamiento en la HAD de chips recolectados de pilas de residuos de aserraderos versus chips limpios destinados a procesos de pulpado y concluyó que los primeros son más recalcitrantes hacia el pretratamiento y a la posterior hidrólisis enzimática debido a la presencia de mayor cantidad de corteza, lignina y restos de suelo (Alvarez Vasco et al., 2015). A su vez, los chips destinados al pulpado son de menor edad ya que provienen de raleos mientras que la madera utilizada es aserraderos es de mayor edad y en consecuencia son más lignificados.

Los rendimientos obtenidos en los tratamientos catalizados con ácido fueron considerablemente mayores que los reportados por Yoon et al. aplicando un proceso de autohidrólisis a chips de pino taeda (Yoon et al., 2008) (Tabla IV.10). 
Tabla IV.10. Condiciones y resultados obtenidos del tratamiento ácido diluido de coníferas.

\begin{tabular}{|c|c|c|c|c|c|}
\hline Materia prima & Condiciones & SC & Rendimiento & $\begin{array}{c}\text { Productos de } \\
\text { degradación }\end{array}$ & Referencias \\
\hline Mezcla de coníferas (Pino) & $\begin{array}{l}4,4 \mathrm{~g} / \mathrm{L} \mathrm{H}_{2} \mathrm{SO}_{4} ; 30 \mathrm{~min} ; \\
170^{\circ} \mathrm{C}\end{array}$ & 2.49 & $\begin{array}{l}100 \% \text { de manosa y } \\
\text { xilosa; } 5 \% \text { de } \\
\text { celulosa }\end{array}$ & $\begin{array}{l}1.49 \mathrm{~g} / \mathrm{L} \text { furfural } \\
5.57 \mathrm{~g} / \mathrm{L} \mathrm{HMF}\end{array}$ & $\begin{array}{l}\text { Lim, W., Lee,J. } \\
2013\end{array}$ \\
\hline Chips de abeto & $\begin{array}{l}5 \mathrm{~g} / \mathrm{L} \mathrm{H}_{2} \mathrm{SO}_{4} ; 60 \mathrm{~min}, \\
180^{\circ} \mathrm{C}\end{array}$ & 3,15 & $\begin{array}{l}100 \% \text { de } \\
\text { hemicelulosas; } 30 \% \\
\text { de celulosa }\end{array}$ & $\begin{array}{l}2.7 \text { g/L furfural; } \\
4.7 \text { g/L HMF; } \\
11,4 \text { g/L Ác. } \\
\text { levulínico; } 7,4 \\
\text { g/L ác. fórmico }\end{array}$ & $\begin{array}{l}\text { Shuai et al., } \\
2010\end{array}$ \\
\hline Aserrín de pino taeda & $\begin{array}{l}1 \mathrm{~g} / \mathrm{L} \mathrm{H}_{2} \mathrm{SO}_{4} ; 60 \mathrm{~min}, \\
150^{\circ} \mathrm{C}\end{array}$ & 1,57 & $\begin{array}{l}60 \% \text { de } \\
\text { hemicelulosas; } 2.1 \\
\% \text { de celulosa }\end{array}$ & $\begin{array}{l}2.9 \% \mathrm{HMF}+ \\
\text { furfural }\end{array}$ & $\begin{array}{l}\text { Marzialetti et } \\
\text { al., } 2008\end{array}$ \\
\hline $\begin{array}{l}\text { Mezcla de chips de conífera } \\
\text { (pino, abeto, picea) }\end{array}$ & $\begin{array}{l}2,5 \mathrm{~g} / \mathrm{L} \mathrm{H}_{2} \mathrm{SO}_{4} ; 120 \\
\min , 160^{\circ} \mathrm{C}\end{array}$ & 2,95 & $80 \%$ hemicelulosas & $\begin{array}{l}2.8 \mathrm{~g} / \mathrm{L} \text { furfural; } \\
3 \mathrm{~g} / \mathrm{L} \mathrm{HMF}\end{array}$ & $\begin{array}{l}\text { Boucher et al, } \\
2014\end{array}$ \\
\hline Chips de abeto Douglas & $\begin{array}{l}2,5 \mathrm{~g} / \mathrm{L} \mathrm{H}_{2} \mathrm{SO}_{4}, 30 \mathrm{~min}, \\
200^{\circ} \mathrm{C}\end{array}$ & 2,89 & $\begin{array}{l}100 \% \text { de } \\
\text { hemicelulosas; } 30 \% \\
\text { de glucanos }\end{array}$ & $\begin{array}{l}\text { 4,8\% furfural; } \\
\text { 3,9\% HMF; 0,6 } \\
\% \text { Ác. Fórmico; } \\
0,9 \% \text { Ác. } \\
\text { Levulínico }\end{array}$ & $\begin{array}{l}\text { Alvarez Vasco } \\
\text { et al, } 2015\end{array}$ \\
\hline Chips de pino taeda & $\begin{array}{l}1,25 \mathrm{~g} / \mathrm{L} \mathrm{H}_{2} \mathrm{SO}_{4}, 30 \\
\min , 180^{\circ} \mathrm{C}\end{array}$ & 2,25 & $\begin{array}{l}100 \% \text { de } \\
\text { hemicelulosas; } 37 \% \\
\text { de celulosa }\end{array}$ & & $\begin{array}{l}\text { Huang,F., } \\
\text { Ragauskas,A., } \\
2012\end{array}$ \\
\hline Chips de pino taeda & $\begin{array}{l}\mathrm{H} \text {-factor } 1500\left(170^{\circ} \mathrm{C} \text {; }\right. \\
90 \text { min time at Tmáx) } \\
\text { (autohydrolysis) }\end{array}$ & - & $\begin{array}{l}11.9 \% \text { de } \\
\text { hemicelulosas; } 0.54 \\
\% \text { de celulosa }\end{array}$ & No reportado & $\begin{array}{l}\text { Yoon et al., } \\
2008\end{array}$ \\
\hline Aserrín de pino elliottii & $\begin{array}{l}7.5 \mathrm{~g} / \mathrm{L} \mathrm{H}_{2} \mathrm{SO}_{4} ; 30 \mathrm{~min}, \\
150^{\circ} \mathrm{C}\end{array}$ & 2,14 & $\begin{array}{l}57 \% \text { de } \\
\text { hemicelulosas; } 4 \% \\
\text { de glucanos }\end{array}$ & $\begin{array}{l}0.11 \% \mathrm{HMF} ; \\
0.22 \% \text { furfural }\end{array}$ & Este trabajo \\
\hline
\end{tabular}

\section{IV.2.2.1.2 Análisis Estadístico}

El análisis de varianza (ANOVA) de la composición química de la fracción soluble del aserrín pre-extraído en álcali (APA) indicó que la temperatura (T), la concentración de ácido (C) y el tiempo ( $\mathrm{t}$ ) resultaron significativos $(\mathrm{p}$-valor $<0,05)$ en la extracción de azúcares en el proceso ácido. Las ecuaciones de regresión (en variables codificadas) que representan la influencia de estos factores sobre la extracción de azúcares totales en el tratamiento ácido del aserrín pretratado con álcali se presentan en la Tabla IV.11

Tabla IV.11. Ecuaciones de regresión de los componentes en el licor de la hidrólisis ácida diluida de APA (en variables codificadas).

\begin{tabular}{|l|l|c|}
\hline Componente & \multicolumn{1}{|c|}{ Ecuación de regresión } & $\mathbf{R}^{\mathbf{2}}$ \\
\hline Glucosa & $0,82+0,75 * \mathrm{~T}+0,21 * \mathrm{t}+0,38 * \mathrm{C}+0,21 * \mathrm{~T}^{2}+0,11 * \mathrm{~T} * \mathrm{t}+0,22 * \mathrm{C} * \mathrm{~T}+0,09 * \mathrm{t} * \mathrm{C}$ & $99 \%$ \\
\hline Xilosa & $3,04+0,94 * \mathrm{~T}+0,27 * \mathrm{t}+0,61 * \mathrm{C}-0,21 * \mathrm{~T} * \mathrm{C}-0,24 * \mathrm{t} * \mathrm{C}-0,25 * \mathrm{C} \mathrm{C}^{2}$ & $93 \%$ \\
\hline Galactosa & $1,60+0,41 * \mathrm{~T}+0,35 * \mathrm{C}-0,22 * \mathrm{~T}^{2}-0,21 * \mathrm{C}$ & $82 \%$ \\
\hline Manosa & $2,01+1,60 * \mathrm{~T}+0,46 * \mathrm{t}+0,78 * \mathrm{C}+0,23 * \mathrm{~T}^{2}$ & $93 \%$ \\
\hline
\end{tabular}


Las ecuaciones muestran ajustes significativos a un $95 \%$ de significancia ( $p$-valor $<0,05$ ). En el caso de la arabinosa, HMF y furfural, la falta de ajuste del modelo planteado es significativa debido a que su cantidad es demasiado pequeña con relación al error experimental. De igual manera, se puede concluir del análisis estadístico que la temperatura es el factor con mayor influencia en la formación de estos compuestos de degradación (Figura IV.11).
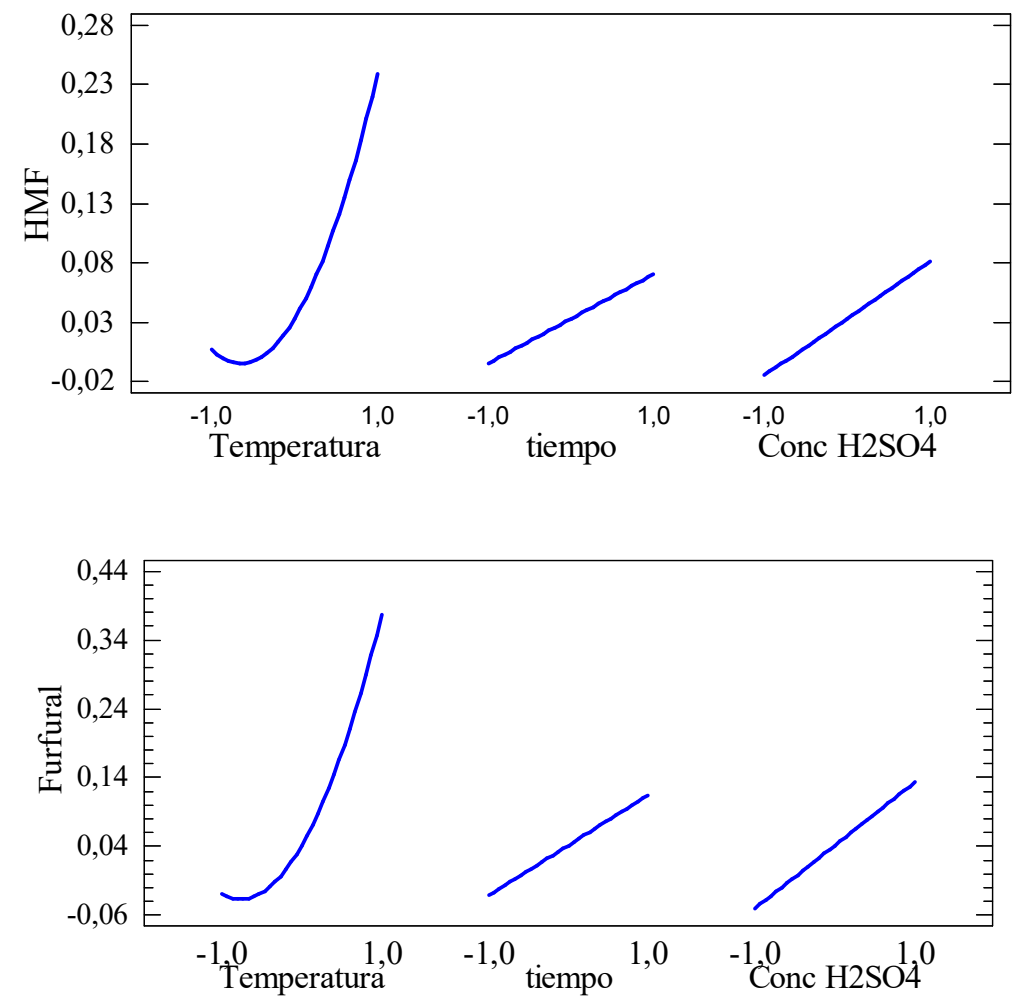

Figura IV.11. Gráfico de los efectos principales para el HMF y el Furfural del APA

De acuerdo con los coeficientes de las ecuaciones y como se observa en la Figura IV.12, la temperatura es el factor que más influye, seguido por la concentración de ácido y el tiempo. El mismo resultado fue hallado por Janga et al en condiciones de hidrólisis ácida concentrada (Janga et al., 2012). En todos los casos, cuando el nivel del factor aumenta la extracción se incrementa. La cantidad de manosa y glucosa es afectada por un leve efecto cuadrático positivo de la temperatura, lo que indica que la extracción se acelera a valores mayores de este factor. 

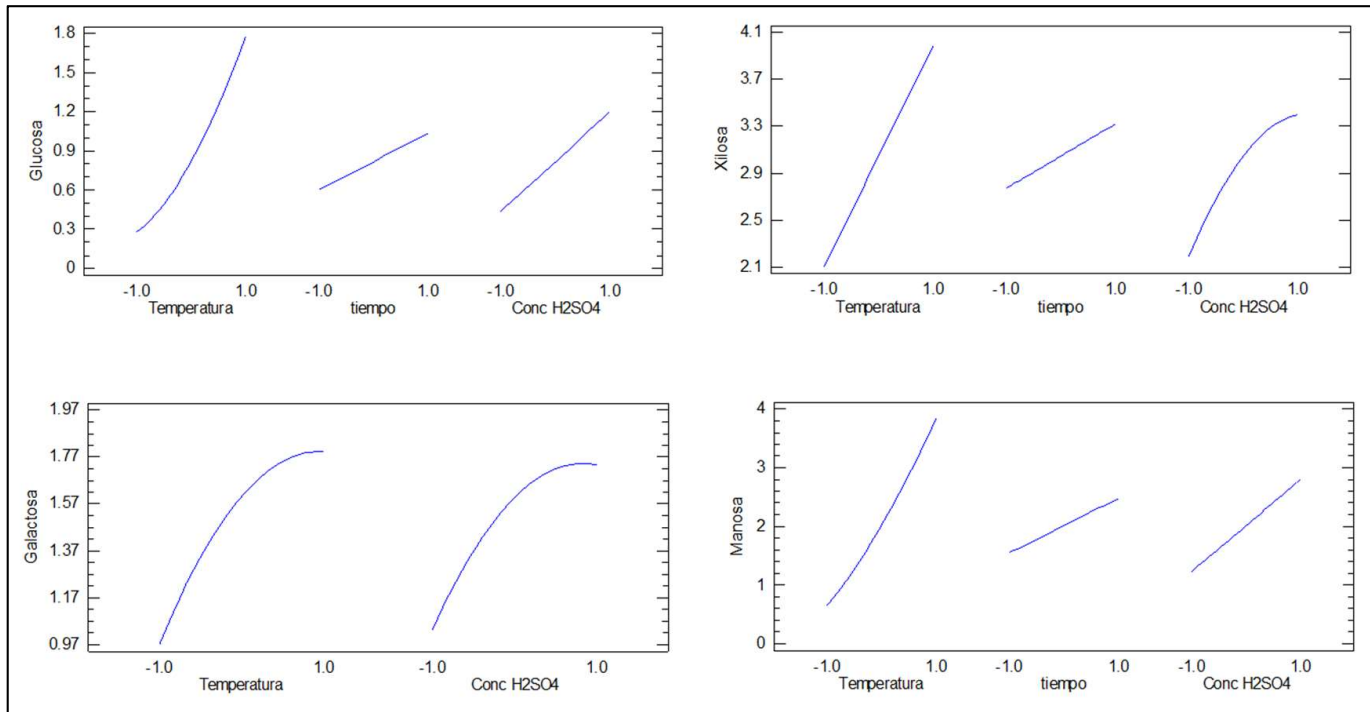

Figura IV.12. Gráfico de los efectos principales de la glucosa, xilosa, galactosa y manosa presentes en los licores del tratamiento HAD de APA.

El efecto positivo de las interacciones: temperatura-tiempo y temperatura-concentración sobre la extracción de glucosa indican que la influencia de estos factores se vuelve más importante a temperaturas altas (Figura IV.13). La interacción positiva entre el tiempo y la concentración indica que a tiempos mayores el efecto de la concentración es más pronunciado. El aumento de la glucosa puede atribuirse a que en condiciones más severas la celulosa menos cristalina empieza a disolverse. En el caso de la xilosa, el efecto cuadrático negativo de la concentración representa un máximo en la extracción debido a la degradación de la xilosa. Esta tendencia de la glucosa y la xilosa a medida que aumenta la severidad del pretratamiento concuerda con lo hallado por otros autores (Marzialetti et al., 2008) (Jensen et al., 2010). La galactosa está afectada por un efecto cuadrático negativo de la temperatura y la concentración, indicando que existe un valor máximo posible de galactosa, ya que luego empieza a disminuir debido a su degradación. 


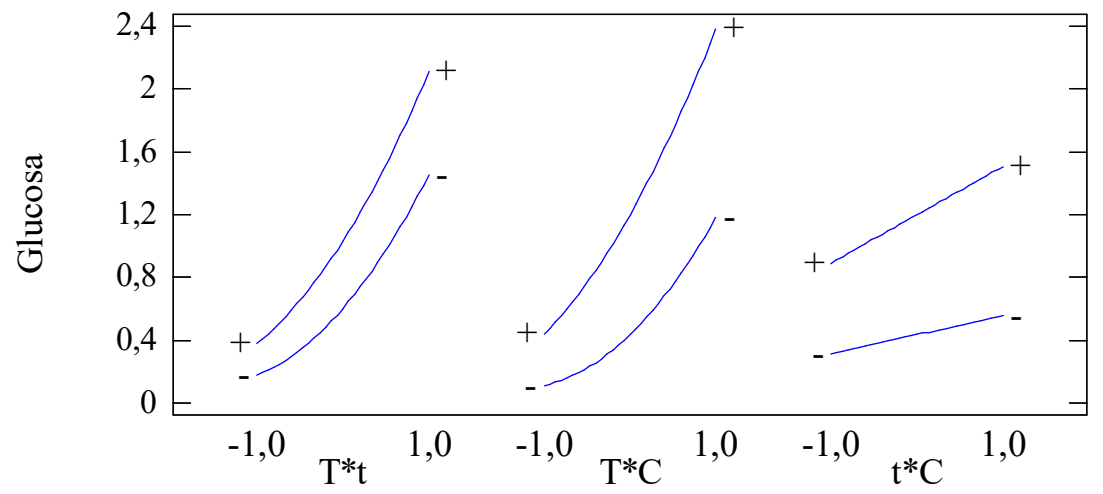

Figura IV.13. Gráfico de las interacciones de la glucosa de la HAD del APA (T: temperatura, t: tiempo, C: concentración de $\mathrm{H}_{2} \mathrm{SO}_{4}$ )

Las ecuaciones de regresión (en variables codificadas) que representan la influencia de los factores sobre la extracción de azúcares totales en el tratamiento ácido del aserrín original se muestran en la Tabla IV.12.

Tabla IV.12. Ecuaciones de regresión de los componentes en el licor de la hidrólisis ácida diluida del aserrín original (en variables codificadas).

\begin{tabular}{|l|l|c|}
\hline Componente & \multicolumn{1}{|c|}{ Ecuación de regresión } & $\mathbf{R}^{\mathbf{2}}$ \\
\hline Glucosa & $1,95+1,05 * \mathrm{~T}+0,21 * \mathrm{t}+0,32 * \mathrm{C}$ & $86 \%$ \\
\hline Xilosa & $2,79+1,42 * \mathrm{~T}+0,21 * \mathrm{t}+0,68 * \mathrm{C}$ & $72 \%$ \\
\hline Manosa & $4,97+2,79 * \mathrm{~T}$ & $71 \%$ \\
\hline Ac. acético & $0,99+0,41 * \mathrm{~T}+0,18 * \mathrm{t}+0,25 * \mathrm{C}-0,08 * \mathrm{t}^{2}-0,11 * \mathrm{C}$ & $96 \%$ \\
\hline Furfural & $0,01+0,32 * \mathrm{~T}+0,09 * \mathrm{t}+0,10 * \mathrm{C}+0,25 * \mathrm{~T}^{2}+0,15 * \mathrm{~T} * \mathrm{t}+0,15 * \mathrm{C} * \mathrm{~T}+0,10 * \mathrm{t} * \mathrm{C}$ & $88 \%$ \\
\hline
\end{tabular}

Las ecuaciones muestran ajustes significativos al 95\% de significancia ( $p$-valor $<0,05$ ). En el caso de la arabinosa, galactosa e HMF la falta de ajuste del modelo planteado fue significativa. Al igual que en el caso anterior, la temperatura es el factor que más influye en la formación de estos productos de degradación como se indica en la figura IV.14. La formación de HMF y furfural es influenciada por un efecto cuadrático positivo de la temperatura que indica la presencia de un mínimo en la formación de furfural a una dada temperatura. 

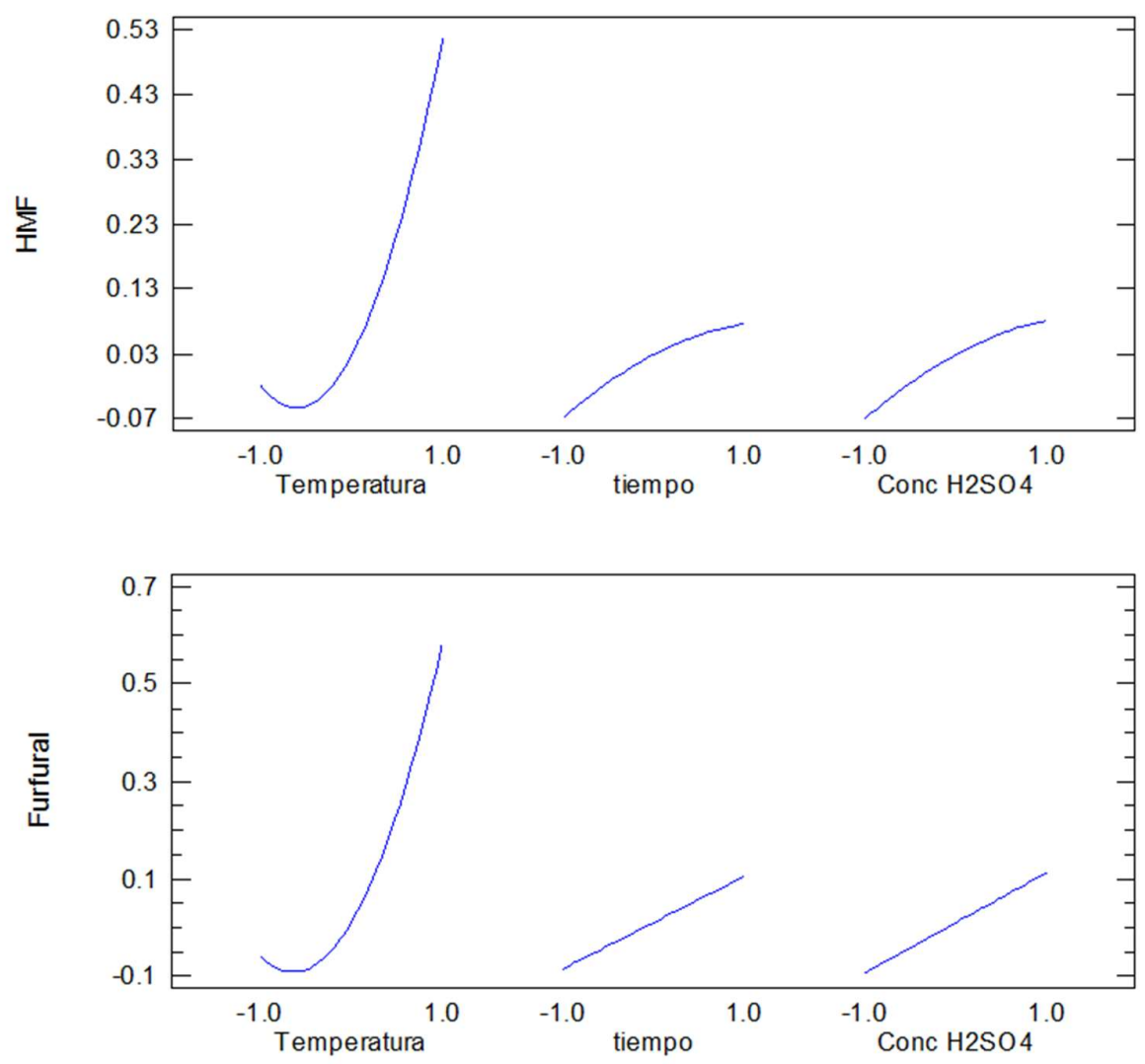

Figura IV.14. Gráfico de los efectos principales en el contenido de Furfural e HMF en el licor del aserrín original tratado con HAD.

De acuerdo con los modelos de regresión, la temperatura es un factor estadísticamente significativo ( $\mathrm{p}$-valor $<0,05$ ) con un efecto positivo en la extracción de glucosa, xilosa, manosa y ácido acético. Es decir, que ante un aumento de temperatura, la extracción de estos componentes es mayor. La extracción de glucosa y xilosa es afectada positivamente por la concentración de ácido y el tiempo. Por lo tanto, a tiempo y concentraciones más elevadas se extrae más glucosa y xilosa. En el caso del ácido acético, el efecto cuadrático negativo de la concentración de ácido y el tiempo indican que existe un máximo en la extracción para un dado nivel de estos factores. El efecto de los factores en las variables estudiadas pude observarse en la figura IV.15. 


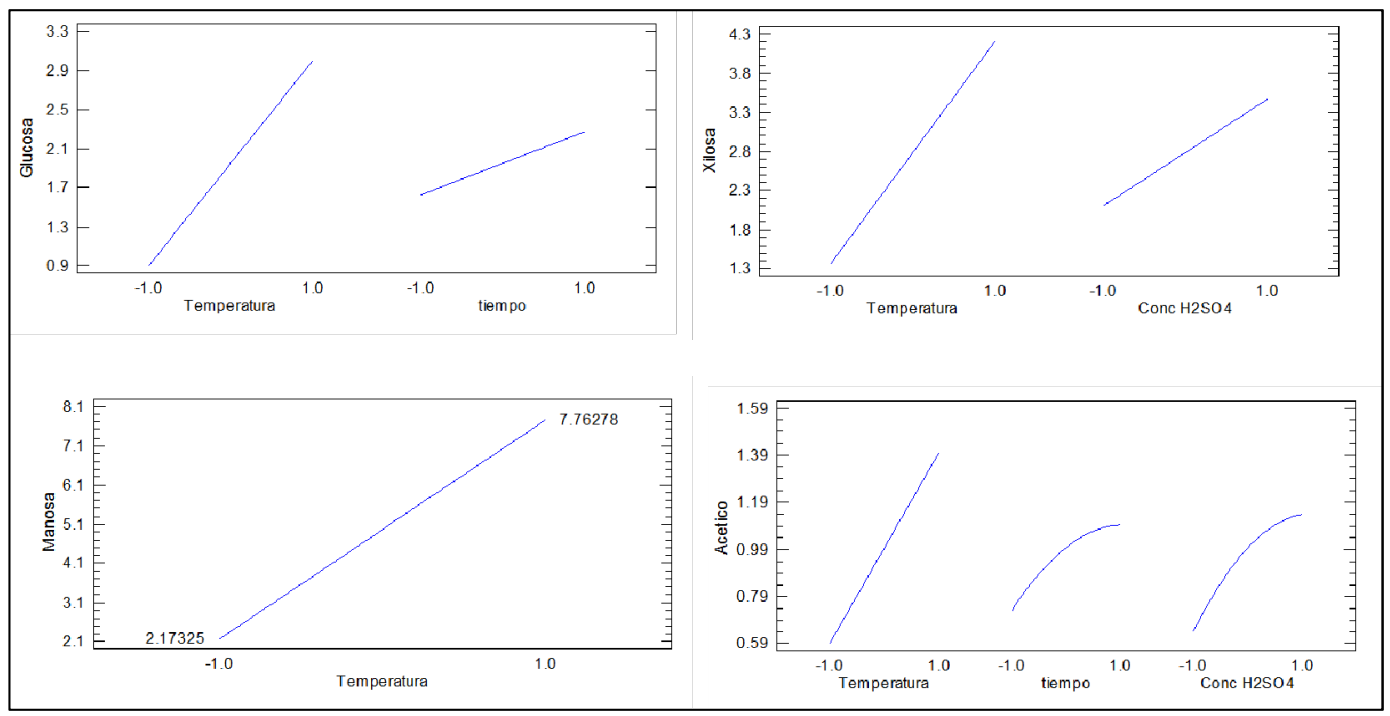

Figura IV.15. Gráfico de los efectos principales de la glucosa, xilosa, galactosa y manosa presentes en los licores del tratamiento HAD del aserrín original.

El efecto positivo de las interacciones temperatura-tiempo y temperatura-concentración sobre el furfural indican que la influencia de estos factores se vuelve más importante a temperaturas altas. De igual manera, el efecto positivo de la interacción tiempo-concentración indica que a tiempos más altos el efecto de la concentración es más importante (Figura IV.16).

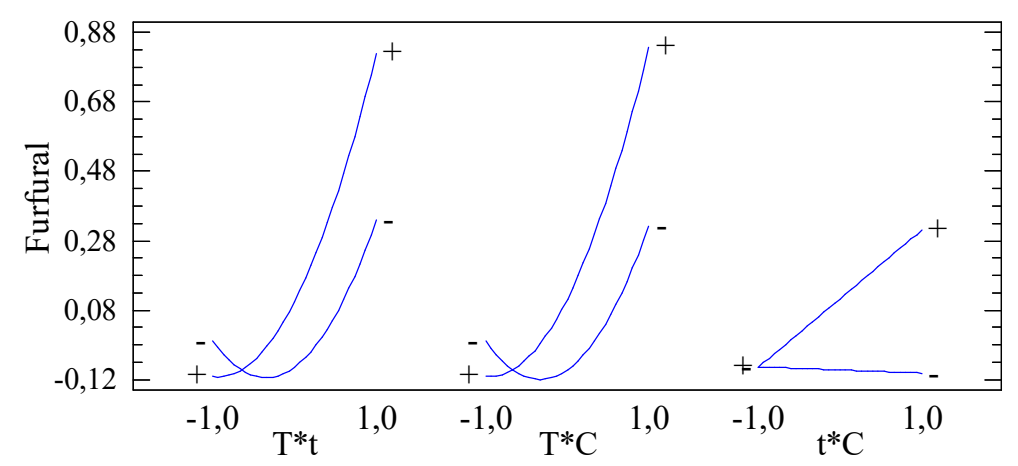

Figura IV.16. Gráfico de las interacciones del furfural de la HAD del aserrín original (T: temperatura, t: tiempo, C: concentración de $\mathrm{H}_{2} \mathrm{SO}_{4}$ ) 


\section{IV.2.2.1.3 Optimización estadística}

Se optimizó la función de deseabilidad con el objetivo de encontrar las condiciones que maximizan la extracción de azúcares hemicelulósicos minimizando la disolución de la celulosa y la formación de compuestos de degradación.

La Figura IV.17 muestra el gráfico de contorno de la función de deseabilidad que maximiza el porcentaje de galactosa, manosa y xilosa en el licor del aserrín pre-extraído en álcali mientras se establece como objetivo de la optimización mantener la glucosa en $2,00 \%$.

Como ya se ha mencionado, la función de deseabilidad se conforma a partir de la combinación de las ecuaciones de regresión individuales de los factores. Se puede observar en la Figura IV.17 que esta función alcanza un valor máximo de 0,85 y luego disminuye a cero a valores más altos de temperatura y concentración. Este comportamiento es consecuencia a que en condiciones más severas la degradación de carbohidratos es alta y en paralelo, la extracción de celulosa aumenta. Estos resultados concuerdan con el trabajo de Marzialetti et al., quienes encontraron que el rendimiento de hemicelulosas cae dramáticamente con un incremento de la temperatura $\left(150^{\circ} \mathrm{C}\right.$ vs. $200^{\circ} \mathrm{C}$ ), reflejado en un importante aumento de los productos de degradación en el licor. El incremento en el rendimiento de extracción de la glucosa puede deberse a la mejor accesibilidad del ácido a los enlaces $\beta(1-4)$ glucosídicos de la celulosa a altas temperaturas y a una menor tasa de descomposición de la glucosa en comparación con la xilosa, galactosa, manosa y arabinosa (Marzialetti 2008). La hidrólisis de la celulosa requiere temperaturas del orden de los $200-240^{\circ} \mathrm{C}$ (Wyman, 1994).

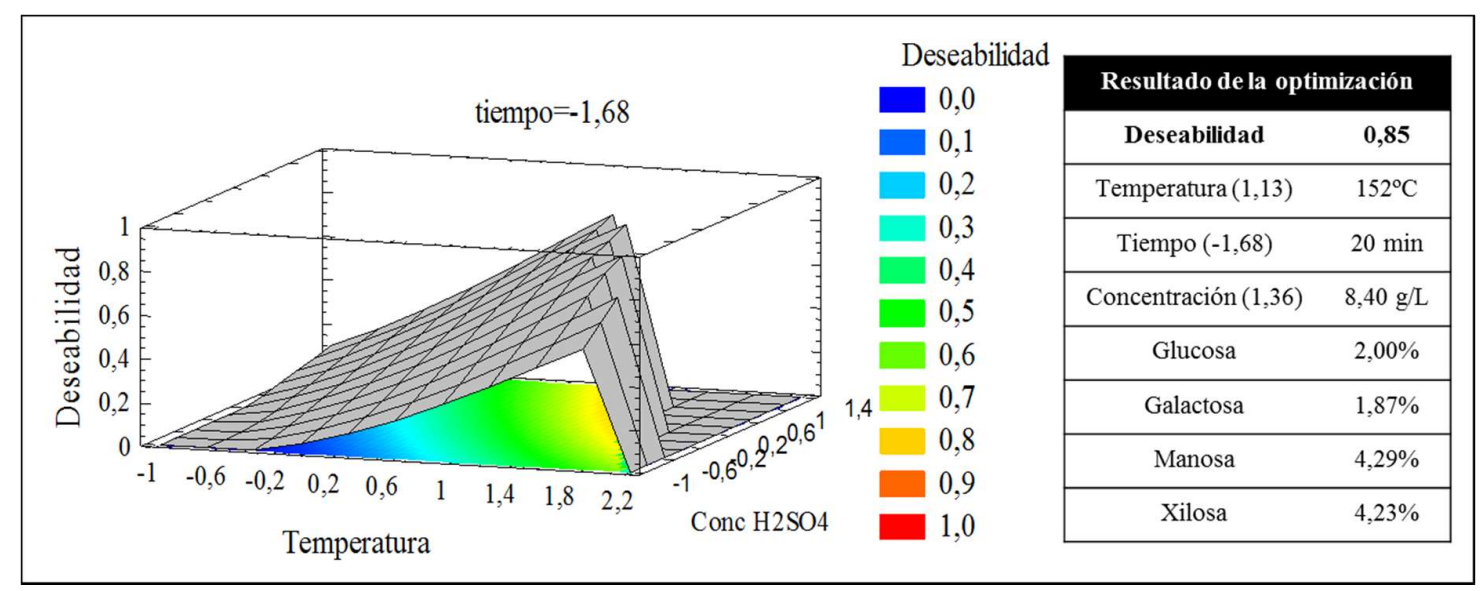

Figura IV.17 Superficie de respuesta de la función de deseabilidad (temperatura, tiempo y concentración de ácido como variables codificadas) y resultado de la optimización que maximiza extracción de azúcares hemicelulósicos manteniendo el contenido de glucanos en 2\%. 
El programa estadístico a su vez indica la deseabilidad alcanzada en cada punto del diseño, considerando las condiciones establecidas en cada una de las respuestas. Entre los puntos del diseño, la deseabilidad máxima se alcanza en la experiencia 6 (Tabla IV.13).

La deseabilidad de la experiencia $6(0,82)$ es inferior al valor de la deseabilidad optimizada $(0,84)$, pero se seleccionaron como óptimas estas condiciones $\left(150^{\circ}, 30 \mathrm{~min}\right.$ y $\left.7,5 \mathrm{~g} / \mathrm{L}\right)$ ya que la remoción de manosa y xilosa es superior.

Tabla IV.13 Deseabilidad de cada punto del diseño (carbohidratos expresados cómo \% sobre aserrín inicial) que maximiza extracción de azúcares hemicelulósicos manteniendo el contenido de glucanos en $2 \%$.

\begin{tabular}{|c|c|c|c|c|c|}
\hline Fila & Galactos a & Glucosa & Manosa & Xilosa & Deseabilidad \\
\hline 1 & 0,20 & 0,03 & 0,13 & 0,84 & 0,00 \\
\hline 2 & 1,30 & 1,00 & 1,92 & 3,03 & 0,35 \\
\hline 3 & 0,48 & 0,21 & 0,22 & 1,39 & 0,02 \\
\hline 4 & 1,74 & 1,42 & 3,81 & 4,30 & 0,58 \\
\hline 5 & 0,81 & 0,31 & 0,60 & 2,22 & 0,12 \\
\hline 6 & 2,12 & 1,94 & 5,06 & 4,47 & 0,82 \\
\hline 7 & 1,32 & 0,65 & 1,42 & 2,71 & 0,24 \\
\hline 8 & 1,48 & 2,95 & 4,52 & 3,85 & 0,00 \\
\hline 9 & 0,45 & 0,13 & 0,09 & 1,53 & 0,00 \\
\hline 10 & 1,50 & 2,60 & 5,35 & 4,09 & 0,00 \\
\hline 11 & 1,26 & 0,48 & 0,74 & 2,36 & 0,20 \\
\hline 12 & 1,81 & 1,06 & 3,13 & 3,57 & 0,51 \\
\hline 13 & 0,16 & 0,05 & 0,19 & 0,87 & 0,05 \\
\hline 14 & 1,80 & 1,25 & 3,26 & 3,61 & 0,59 \\
\hline 15 & 1,78 & 0,96 & 2,49 & 3,24 & 0,34 \\
\hline 16 & 1,58 & 0,84 & 2,10 & 3,01 & 0,34 \\
\hline 17 & 1,54 & 0,91 & 2,38 & 3,20 & 0,34 \\
\hline
\end{tabular}

En conclusión, las condiciones óptimas de extracción de hemicelulosas de la hidrólisis ácida diluida del aserrín pre-extraído en álcali corresponden a $150^{\circ} \mathrm{C}, 30$ min y $7,5 \mathrm{~g} / \mathrm{L}$ de ácido sulfúrico $(\mathrm{SC}=2,09)$. En estas condiciones el rendimiento de la extracción es de 57\%, principalmente como azúcares. En la Figura IV.18 se observa la zona de trabajo en la superficie de contorno de la función de deseabilidad. 


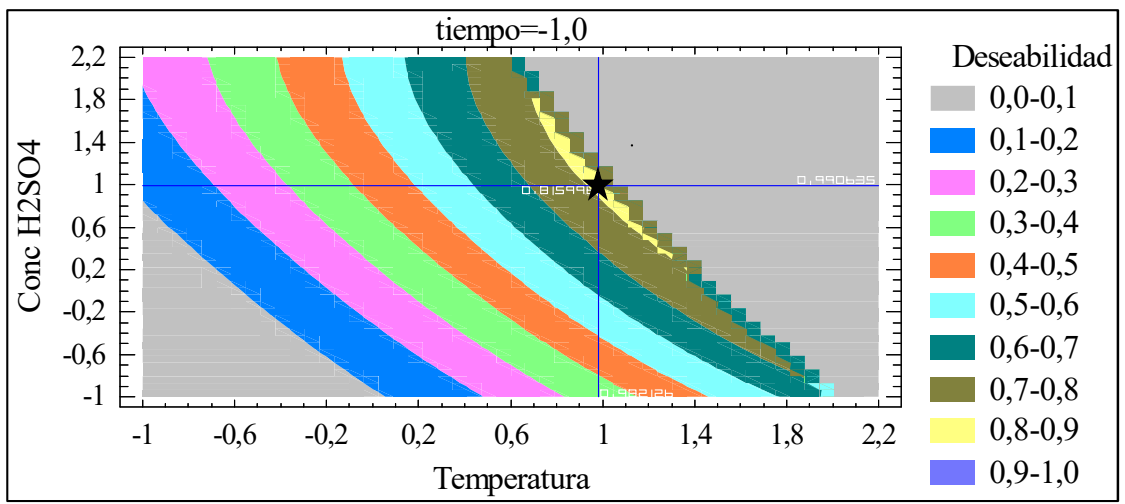

Figura IV.18. Superficie de contorno de la función de deseabilidad del aserrín pre-extraído en álcali (la estrella representa la deseabilidad del proceso a $150^{\circ} \mathrm{C}(+1), 30 \min (-1) \mathrm{Y} 7,5 \mathrm{~g} / \mathrm{L}(+1)$ que maximiza la extracción de azúcares hemicelulósicos minimizando la disolución de la celulosa

La Figura IV.19 muestra el gráfico de contorno de la función de deseabilidad que maximiza el porcentaje de manosa y xilosa en el licor del aserrín original mientras se minimiza el furfural manteniendo el contenido de glucosa en $2,7 \%$.

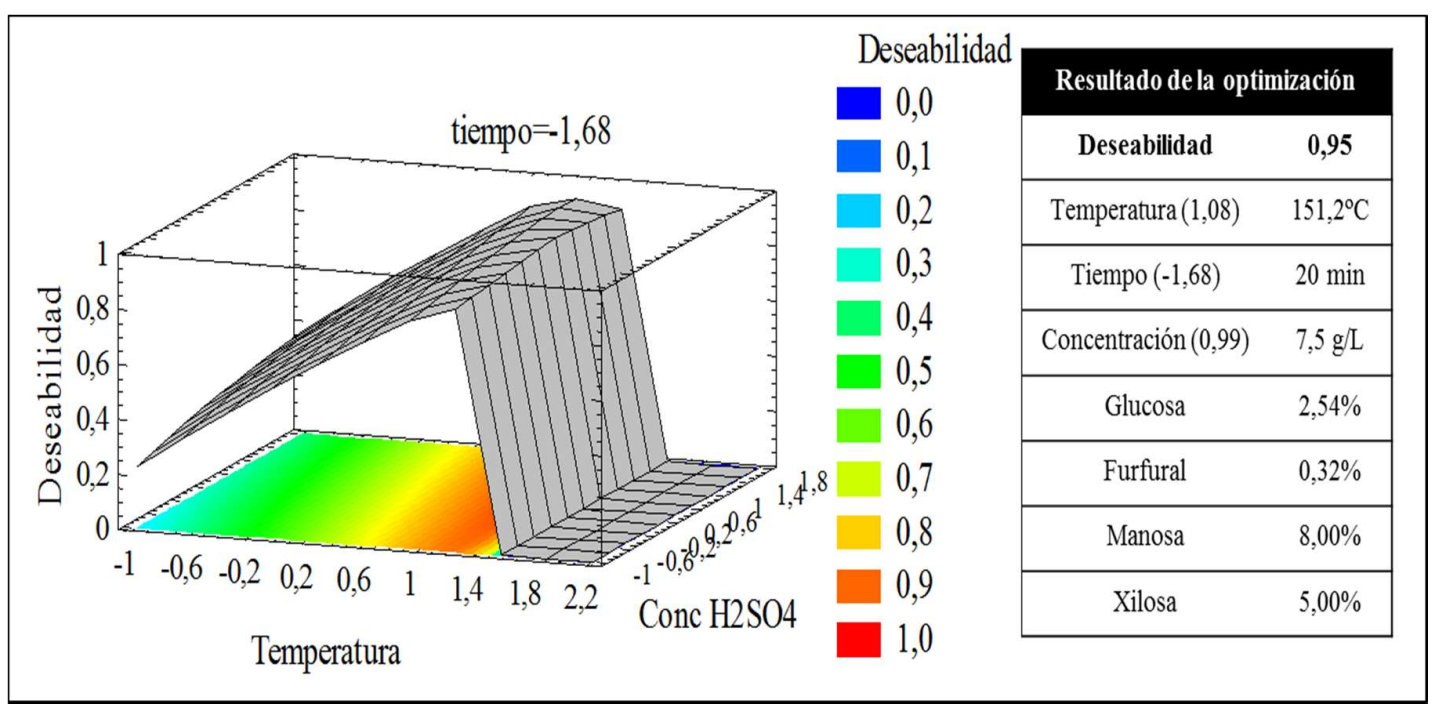

Figura IV.19 Superficie de respuesta de la función de deseabilidad (temperatura, tiempo y concentración de ácido como variables codificadas) y resultado de la optimización que maximiza el porcentaje de manosa y xilosa en el licor del aserrín original mientras minimiza el furfural manteniendo el contenido de glucosa en $2,7 \%$ 
De igual manera que para el aserrín pre-extraído en álcali, la función de deseabilidad global óptima alcanza un valor máximo de 0,95 y luego disminuye abruptamente a cero. Es decir, que el contenido de manosa y xilosa aumenta en el líquido de pretratamiento mientras que aumenta la degradación y se empieza a extraer celulosa cristalina.

La tabla IV.14 muestra la función de deseabilidad evaluada para cada punto del diseño. Entre los puntos del diseño se alcanza la máxima deseabilidad en el ensayo 6.

En conclusión, las mejores condiciones de extracción de hemicelulosas son las mismas para ambos materiales. La HAD del aserrín original permite obtener un licor con mayor porcentaje de azúcares y de productos de degradación. Cuando se trata aserrín previamente extraído en álcali el material posee menor contenido de hemicelulosas, y el rendimiento de extracción es menor.

Tabla IV.14 Deseabilidad de cada punto del diseño (carbohidratos expresados cómo \% sobre aserrín inicial) que maximiza el porcentaje de manosa y xilosa en el licor del aserrín original mientras minimiza el furfural manteniendo el contenido de glucosa en $2,7 \%$

\begin{tabular}{|c|c|c|c|c|c|}
\hline Fila & Furfural & Glucosa & Xilosa & Manosa & Deseabilidad \\
\hline 1 & 0,00 & 0,33 & 0,24 & 0,55 & 0,24 \\
\hline 2 & 0,05 & 2,22 & 3,75 & 7,00 & 0,84 \\
\hline 3 & 0,00 & 0,72 & 1,00 & 1,93 & 0,26 \\
\hline 4 & 0,23 & 2,87 & 4,73 & 8,10 & 0,00 \\
\hline 5 & 0,00 & 0,58 & 0,80 & 1,38 & 0,36 \\
\hline 6 & 0,26 & 3,07 & 5,01 & 7,93 & 0,90 \\
\hline 7 & 0,01 & 1,52 & 2,57 & 3,84 & 0,40 \\
\hline 8 & 1,26 & 3,60 & 4,46 & 7,57 & 0,00 \\
\hline 9 & 0,00 & 0,31 & 0,30 & 0,59 & 0,08 \\
\hline 10 & 1,53 & 3,68 & 3,87 & 6,06 & 0,00 \\
\hline 11 & 0,00 & 0,86 & 1,22 & 2,31 & 0,62 \\
\hline 12 & 0,06 & 1,99 & 3,70 & 6,21 & 0,65 \\
\hline 13 & 0,00 & & 0,62 & 2,00 & 0,53 \\
\hline 14 & 0,09 & 2,64 & 4,29 & 7,00 & 0,72 \\
\hline 15 & 0,05 & 2,59 & 4,25 & 6,90 & 0,64 \\
\hline 16 & 0,04 & 2,27 & 3,82 & 6,51 & 0,64 \\
\hline & & & & & \\
\hline
\end{tabular}

\section{IV.2.2.1.4 Composición química del material solido pretratado}

En la Tabla IV.15 se muestra el contenido de carbohidratos del material fibroso resultante de la HAD. En todos los ensayos, el material fibroso resultante está compuesto principalmente por hexosanos (glucanos y mananos) siendo mucho menor el contenido de xilanos y no detectables los demás azúcares (arabinanos y galactanos). En condiciones ácidas, las hemicelulosas son 
degradadas mucho más rápido que la celulosa. Los xilanos y galactanos son degradados más rápidamente que los mananos. Los arabinanos son rápidamente hidrolizados en medio ácido (Sixta et al., 2006)

El contenido de azúcares hemicelulósicos es mayor para el aserrín pre-extraído con álcali, aunque el contenido de glucanos es menor en la mayoría de los ensayos, es decir que en la hidrólisis ácida diluida del aserrín original se extraen más hemicelulosas. Esto indicaría que durante la etapa alcalina se producen cambios físicos o químicos en el aserrín que hacen al material más recalcitrante hacia la extracción de hemicelulosas.

Tabla IV.15. Contenido de carbohidratos de la fracción sólida resultante de la HAD (como \%

bs)

\begin{tabular}{|c|c|c|c|c|c|c|c|c|c|c|c|}
\hline \multirow[b]{2}{*}{ Ensayo } & \multirow[b]{2}{*}{$\mathrm{T}, \mathrm{t}, \mathrm{C} .^{\mathrm{a}}$} & \multicolumn{5}{|c|}{ As errin original } & \multicolumn{5}{|c|}{$\mathbf{A P A}$} \\
\hline & & $\mathrm{Gl}^{\mathbf{b}}$ & $\mathbf{X i}^{\mathbf{b}}$ & $\mathrm{Ga}^{\mathrm{b}}$ & $\mathrm{Ara}^{\mathrm{b}}$ & $\mathrm{Ma}^{\mathrm{b}}$ & $\mathrm{Gl}^{\mathbf{b}}$ & $\mathbf{X i}^{\mathbf{b}}$ & $\mathrm{Ga}^{\mathrm{b}}$ & $\operatorname{Ara}^{\mathrm{b}}$ & $\mathbf{M a}^{\mathrm{b}}$ \\
\hline 6 & $150-30-7,5$ & 52,1 & 2,75 & $\mathrm{Nd}$ & $\mathrm{Nd}$ & 2,63 & 44,1 & 2,23 & $\mathrm{Nd}$ & $\mathrm{Nd}$ & 4,67 \\
\hline 8 & $150-60-7,5$ & 46,0 & 1,56 & $\mathrm{Nd}$ & $\mathrm{Nd}$ & 1,16 & 42,0 & 1,49 & $\mathrm{Nd}$ & $\mathrm{Nd}$ & 3,26 \\
\hline 9 & $110-45-5$ & 42,8 & 5,95 & 1,78 & $\mathrm{Nd}$ & 8,15 & 44,8 & 4,63 & 1,46 & $\mathrm{Nd}$ & 8,13 \\
\hline 10 & $160-45-5$ & 49,9 & 1,36 & $\mathrm{Nd}$ & $\mathrm{Nd}$ & 0,78 & 44,7 & 1,60 & $\mathrm{Nd}$ & $\mathrm{Nd}$ & 3,46 \\
\hline 12 & $135-70-5$ & 51,7 & 5,38 & 0,54 & $\mathrm{Nd}$ & 5,22 & 41,0 & 3,05 & $\mathrm{Nd}$ & $\mathrm{Nd}$ & 6,49 \\
\hline 13 & $135-45-0,8$ & 47,7 & 5,9 & 1,6 & $\mathrm{Nd}$ & 8,0 & 45,2 & 5,3 & 1,7 & $\mathrm{Nd}$ & 8,2 \\
\hline 14 & $135-45-9,2$ & 46,0 & 2,2 & $\mathrm{Nd}$ & $\mathrm{Nd}$ & 2,9 & 49,1 & 2,4 & $\mathrm{Nd}$ & $\mathrm{Nd}$ & 5,6 \\
\hline
\end{tabular}

N.d.: No detectado (LD galactosa IR $0,1 \%$ bs; LD arabinosa IR $0,1 \%$ bs)

${ }^{\mathrm{a}} \mathrm{T}$ : Temperatura $\left({ }^{\circ} \mathrm{C}\right)$, t: tiempo (min), C: Concentración de $\mathrm{H}_{2} \mathrm{SO}_{4}(\mathrm{~g} / \mathrm{L})$

${ }^{\mathrm{b}}$ Gl:glucanos; Xi: xilanos; Ga:galactanos; Ar:arabinanos; Ma:mananos

Con el objetivo de determinar si se produce extracción de lignina en la HAD, se seleccionaron los puntos de mayor y menor SC para la determinación del contenido de lignina insoluble posterior al tratamiento ácido (Tabla IV.16).

Considerando el contenido de lignina inicial del aserrín original $(27,2 \%$ bs $)$ y del APA $(29,0 \%$ bs), se concluye que en la etapa ácida no ocurre una deslignificación significativa. Por el contrario, en algunos puntos se observa un incremento en el contenido de lignina que es más significativo para el aserrín original. A su vez, el contenido de lignina aumentó progresivamente con el aumento en la severidad del pretratamiento. Este fenómeno ha sido previamente informado por varios autores, y se cree que es consecuencia de la formación de un material denominado pseudolignina. Este material aromático es formado por la condensación de los productos de degradación de los polisacáridos y su formación se intensifica cuando las condiciones aplicadas son más severas (Sannigrahi et al., 2011) (Sannigrahi, Ragauskas \& Miller, 2008). 
Tabla IV. 16 Contenido de lignina insoluble en la fracción sólida del aserrín original y preextraído en álcali (APA) (expresado cómo \% sobre madera inicial)

\begin{tabular}{|c|c|c|c|c|c|}
\hline \multirow[b]{2}{*}{ Ensayo } & \multirow[b]{2}{*}{$\mathbf{T}, \mathbf{t}, \mathbf{C} .^{\mathrm{a}}$} & \multicolumn{2}{|c|}{ Aserrín Original $(27,2 \% \text { bs })^{b}$} & \multicolumn{2}{|c|}{$\operatorname{APA}(29,0 \% \text { bs })^{c}$} \\
\hline & & $S^{d}{ }^{d}$ & $\begin{array}{c}\text { Lignina } \\
\text { Insoluble (\%) } \\
\end{array}$ & $\mathrm{SC}^{\mathrm{d}}$ & $\begin{array}{c}\text { Lignina } \\
\text { Insoluble (\%) }\end{array}$ \\
\hline 6 & $150-30-7,5$ & 2,14 & 29,26 & 2,09 & 28,25 \\
\hline 8 & $150-60-7,5$ & 2,44 & 35,16 & 2,40 & 29,69 \\
\hline 9 & $110-45-5,0$ & 0,96 & 29,43 & 0,89 & 28,66 \\
\hline 10 & $160-45-5,0$ & 2,43 & 32,00 & 2,37 & 27,87 \\
\hline 12 & $135-70-5,0$ & 1,89 & 29,38 & 1,82 & 26,77 \\
\hline 13 & $135-45-0,8$ & 0,90 & 29,39 & 0,00 & 29,08 \\
\hline 14 & $135-45-9,2$ & 1,96 & 29,36 & 1,92 & 28,55 \\
\hline
\end{tabular}

${ }^{\mathrm{a}} \mathrm{T}$ : Temperatura $\left({ }^{\circ} \mathrm{C}\right), \mathrm{t}$ : tiempo (min), C: Concentración de $\mathrm{H}_{2} \mathrm{SO}_{4}(\mathrm{~g} / \mathrm{L})$

${ }^{\mathrm{b}}$ Aserrín original (\% Lignina del aserrín antes de la HAD)

'APA: Aserrín pre-extraído en álcali (\% Lignina antes de la HAD)

${ }^{\mathrm{d}} \mathrm{SC}$ : Severidad Combinada

Para comprobar que el aumento de lignina es producto de la condensación de los productos de degradación, se aplicó la técnica desarrollada por Sannigrahi et al. (2011) que consiste en aplicar tratamientos ácidos a la holocelulosa. Se extrajo la holocelulosa de aserrín de pino y luego se sometió a un tratamiento ácido a $150^{\circ} \mathrm{C}, 60 \mathrm{~min}$ y 7,5 g/ $\mathrm{L} \mathrm{H}_{2} \mathrm{SO}_{4}$ (Severidad Combinada=2,44). Se determinó el contenido de lignina en la holocelulosa de aserrín antes y después del tratamiento ácido (Tabla IV.17).

Tabla IV.17. Contenido de lignina de la holocelulosa tratada y sin tratar en medio ácido.

\begin{tabular}{|l|c|}
\hline Holocelulosa & $\begin{array}{c}\text { Lignina Insoluble } \\
(\mathbf{\%})\end{array}$ \\
\hline Aserrín original & 0,19 \\
\hline Aserrín con tratamiento ácido $^{\text {a }}$ & 9,13 \\
\hline Aserrín pre-extraído en álcali y con tratamiento ácido $^{\text {b }}$ & 2,33 \\
\hline
\end{tabular}

${ }^{a}$ Tratamiento ácido a $150^{\circ} \mathrm{C}-60 \mathrm{~min}-7,5 \mathrm{~g} / 1 \mathrm{H}_{2} \mathrm{SO}_{4}$ )

${ }^{\text {b }}$ Tratamiento alcalino a $90^{\circ} \mathrm{C}, 60 \mathrm{~min}$ y $5 \% \mathrm{NaOH}$ seguido de etapa ácida a $150^{\circ} \mathrm{C}-60 \mathrm{~min}-7,5$ $\mathrm{g} / 1 \mathrm{H}_{2} \mathrm{SO}_{4}$

El contenido de lignina resultó mayor luego de los tratamientos ácidos. Dado que la holocelulosa está prácticamente libre de lignina, se comprueba que el incremento puede ser debido a la 
formación de pseudolignina. A su vez, la formación de este material aromático es inferior para el aserrín pre-extraído en álcali, lo cual es una ventaja ya que la presencia de pseudolignina es negativa para la hidrólisis enzimática (Hu \& Ragauskas, 2012).

\section{IV.2.2.1.5. Hidrólisis enzimática}

La aplicación de la hidrólisis enzimática (HE) tiene como objetivo romper las cadenas de celulosa en la biomasa mediante la utilización de enzimas, para obtener glucosa fermentable. Los factores que afectan la efectividad de este proceso son las características físicas y químicas del material, como ser el contenido de lignina, hemicelulosas, la cristalinidad, el grado de polimerización, la porosidad y el área superficial del material. El objetivo de los pretratamientos consiste en modificar estas características fisicoquímicas para aumentar la digestibilidad enzimática del material (Zhao et al., 2012). Por lo tanto, la evaluación de los rendimientos obtenidos en la hidrólisis enzimática permite concluir con respecto a la accesibilidad y la ultraestructura del material.

En la Figura IV.20 se muestran los perfiles de la HE para el aserrín original, APA, APA seguido de hidrólisis ácida diluida y de la hidrólisis ácida diluida (HAD) del aserrín original tratado en las condiciones óptimas. El rendimiento de la HE se calcula a partir de la ecuación III.8. El rendimiento de glucosa del aserrín original fue de 3,76\% a las 72 horas. A pesar de haber pasado por un tratamiento mecánico de molienda el rendimiento es bajo. Según se ha reportado, la digestibilidad enzimática de coníferas utilizando enzimas comerciales varía de 0 a $4 \%$ mientras que la de latifoliadas es de 9\% (Aguilera \& San Martín, 1985). Las coníferas se caracterizan por ser más refractarias a los procesos biológicos debido principalmente a su alto contenido de lignina y su estructura rígida (Galbe \& Zacchi, 2002). A su vez, se ha demostrado que la reducción de tamaño de partícula en un nivel macroscópico no permite mejoras significativas en la hidrolisis enzimática (Da Silva et al., 2013). Kruyeniski et al. hidrolizaron con enzimas pulpa mecánica con refinador (RMP) de pino y obtuvieron un rendimiento a las $72 \mathrm{~h}$ de $15,8 \%$ que supera en más de 50\% al rendimiento del aserrín sin pretratar Kruyeniski et al., 2014).

El rendimiento de glucosa del aserrín pre-extraído en álcali a las $72 \mathrm{~h}(4,52 \%)$ fue ligeramente superior que el obtenido con el aserrín original. Xu et al demostraron que posterior a un tratamiento alcalino suave $\left(90^{\circ} \mathrm{C}-1 \%\right.$ bs $\left.\mathrm{NaOH}\right)$ las microfibrilas de celulosa están más orientadas y la celulosa I se convierte a Celulosa II que es una forma más estable y más resistente a las celulasas (Xu et al., 2012). 
En comparación a lo obtenido por otros autores el rendimiento de la HE del aserrín pretratado con hidrólisis ácida diluida fue considerablemente bajo (7,5\% de glucosa a las $72 \mathrm{~h}$ ) para ambos materiales, es decir, aumento solamente 2 veces con respecto al rendimiento del aserrín sin tratamiento. Por ejemplo, el rendimiento de glucosa de abeto Douglas pretratado mediante hidrólisis ácida diluida $\left(200^{\circ} \mathrm{C}, 30 \mathrm{~min}, 1 \% \mathrm{H}_{2} \mathrm{SO}_{4}\right)$ fue de $55 \%$ utilizando las mismas condiciones en la HE que en este trabajo (Alvarez Vasco et al., 2015). Lim el al. obtuvieron un rendimiento de glucosa en un rango de $36-50 \%$ en la HE de coníferas pretratadas mediante hidrólisis ácida diluida (Lim \& Lee, 2013), mientras que el rendimiento de la hidrólisis enzimática reportado para pino taeda tratado con $\mathrm{H}_{2} \mathrm{SO}_{4}$ fue de $35 \%$ (Huang \& Ragauskas, 2012). La similitud entre los pretratamientos aplicados por estos autores es que las temperaturas estudiadas fueron superiores a $170^{\circ} \mathrm{C}$ y que todos obtuvieron un rendimiento de extracción de hemicelulosas del 100\%. BouderCampbell et al. estudiaron la hidrólisis enzimática de coníferas pretratadas con ácido diluido en diferentes condiciones y concluyeron que la extracción de hemicelulosas es mayor con condiciones más severas de pretratamiento y se incrementa el rendimiento de glucosa en la hidrólisis enzimática (Boudeur-Campbell et al., 2008). Las hemicelulosas actúan como una barrera que limita la accesibilidad de las celulosas (Zhao et al., 2012). Por lo tanto, los menores rendimientos obtenidos en este trabajo pueden estar relacionados con el contenido de hemicelulosas del material resultante del pretratamiento. Por otro lado, la migración de la lignina y su distribución más localizada y concentrada en las paredes celulares exteriores puede abrir la estructura de la matriz de la pared celular y mejorar la accesibilidad de la mayoría de las microfibrillas de celulosa, mejorando la digestibilidad enzimática. La redistribución de la lignina se produce como resultado de su fusión a temperaturas elevadas y posterior coalescencia formando partículas esféricas (Pu et al., 2015) (Donaldson et al., 1988). En consecuencia, la temperatura es un factor clave en la fusión y redistribución de la lignina y por lo tanto las temperaturas más elevadas favorecen este fenómeno.

A su vez, durante los tratamientos ácidos diluidos no se produce deslignificación significativa y la cristalinidad de la celulosa aumenta debido a la disolución de la celulosa menos cristalina (Sannigrahi, Ragauskas \& Miller, 2008) (Sannigrahi et al., 2011). Por lo tanto, el elevado contenido de lignina y la celulosa cristalina podrían estar relacionados con el bajo rendimiento ya que estos dos factores limitan la accesibilidad de las enzimas a la celulosa (Zhao et al., 2012). 


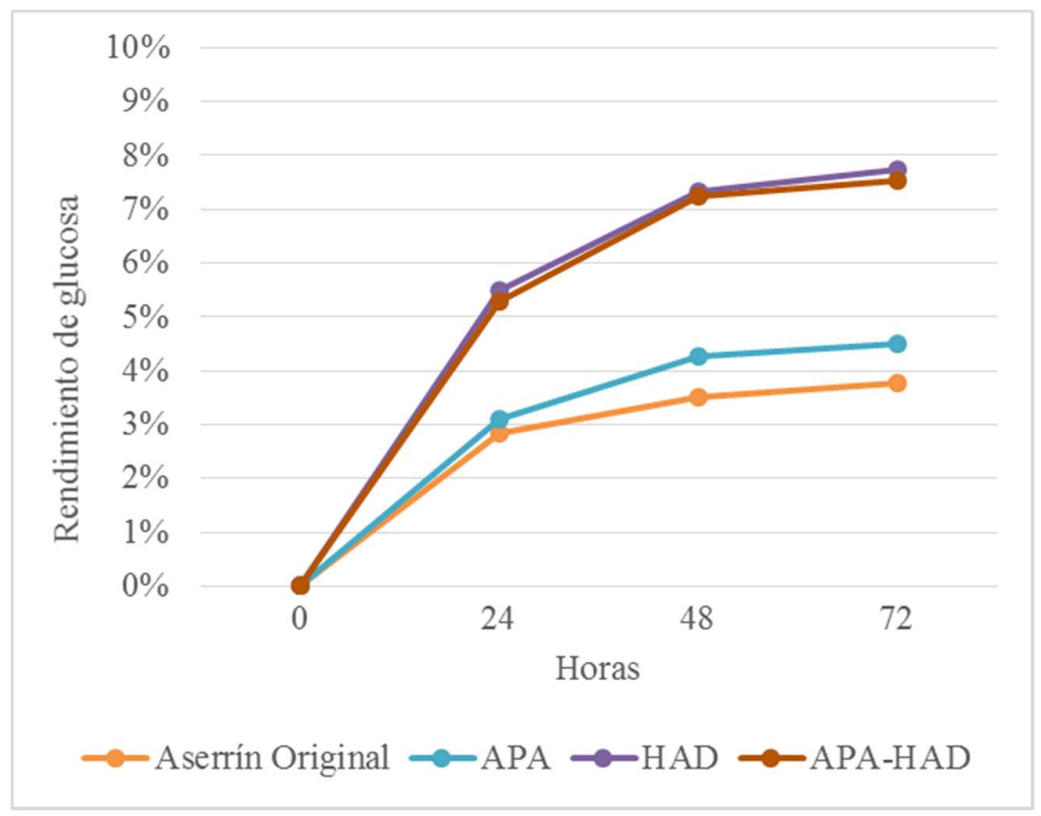

Figura IV.20. Hidrólisis enzimática del aserrín original, pre-extraído con álcali (APA) y con Hidrólisis ácida Diluida (HAD).

Se considera que la cristalinidad de la celulosa juega un rol fundamental en la absorción de enzimas, lo que puede estar correlacionado con la velocidad y rendimiento de la hidrólisis enzimática. En la Tabla IV.18 se indican los índices de cristalinidad del aserrín original y de los materiales pretratados.

Tabla IV.18. Índice de Cristalinidad del aserrín sin tratamiento y de los aserrines pretratados

\begin{tabular}{|c|c|}
\hline Material & Índice de cristalinidad \\
\hline Aserrín original & 61,0 \\
\hline APA & 66,9 \\
\hline APA-HAD & 70,0 \\
\hline HAD & 69,7 \\
\hline
\end{tabular}

La cristalinidad aumentó con todos los tratamientos, pero el principal cambio se produjo en la etapa ácida. Un incremento en el índice de cristalinidad de la celulosa ha sido reportado por otros autores debido a la degradación preferencial de las regiones menos cristalinas durante los tratamientos ácidos (Pu et al., 2013) (Sannigrahi \& Ragauskas, 2008). No existe una correlación clara entre el índice de cristalinidad y la digestibilidad enzimática ya que la accesibilidad de la 
celulosa es además afectada por otros factores, como el contenido de hemicelulosas y lignina y la porosidad y área superficial de la celulosa amorfa (Park et al., 2010). El aumento del IC se atribuye a la solubilización de la celulosa menos ordenada durante los tratamientos aplicados.

Si el objetivo es la producción de bioetanol mediante HE, estos bajos rendimientos obtenidos con este material hacen necesaria la adición de una etapa de deslignificación para aumentar el rendimiento de hidrólisis de celulosa a glucosa.

\section{IV.2.2.2 Explosión de vapor}

\section{IV.2.2.2.1 Resultados experimentales}

Para el estudio de la explosión de vapor se utilizó como materia prima el aserrín proveniente del aserradero Forestal AM. Debido al tamaño y a las características del reactor (reactor batch de 10 L de capacidad) se seleccionó una fracción del aserrín de mayor tamaño (retenido en aberturas de $2 \mathrm{~mm}$ ) a diferencia de la HAD (pasa aberturas de $3 \mathrm{~mm}$ ) para evitar que el material se compacte dentro del reactor y para facilitar la descarga y manipulación del mismo.

El aserrín fue sometido a una etapa alcalina de desresinación aplicando las condiciones óptimas encontradas en este trabajo $\left(90^{\circ} \mathrm{C}, 5 \%\right.$ bs, $60 \mathrm{~min}$ en reactor $\mathrm{M} / \mathrm{K}$ de $\left.7 \mathrm{~L}\right)$. Luego, con el objetivo de optimizar la extracción de hemicelulosas el aserrín pre-extraído en álcali y seco al aire (humedad inicial 14\%) fue sometido a una etapa ácida de explosión de vapor. En la tabla IV.19 se presentan la composición química del aserrín de pino elliotti sin tratamiento (A) y pre-extraído en álcali (APA) expresados cómo \% sobre base seca.

En la desresinación alcalina la pérdida de peso fue de $8 \%$ y se alcanzó una remoción de extractivos del $47 \%$ sobre madera inicial. Este rendimiento de remoción de extractivos resulta menor que el obtenido en la optimización de la etapa alcalina, debido probablemente a que el tamaño de partícula del aserrín utilizado en esta etapa fue mayor. No se produjo una extracción significativa de carbohidratos y lignina. 
Tabla IV.19 Composición química del aserrín original (Forestal AM) y del aserrín pretratado con álcali (\% sobre base seca)

\begin{tabular}{|l|c|c|}
\hline & $\mathbf{A}^{(\mathbf{a})}$ & $\mathbf{A P A}^{(\mathbf{b})}$ \\
\hline Glucanos & 39,4 & 39,7 \\
\hline Xilanos & 6,42 & 6,36 \\
\hline Galactanos & 1,97 & 2,25 \\
\hline Arabinanos & 1,32 & 1,28 \\
\hline Mananos & 10,6 & 11,1 \\
\hline Acetilos & 1,79 & N.d. \\
\hline Extractivos & 2,28 & 1,32 \\
\hline Lignina & 30,1 & 29,8 \\
\hline
\end{tabular}

N.d.: No detectado (LD Acetilo UV $210 \mathrm{~nm}=0,014 \% \mathrm{bs}$ )

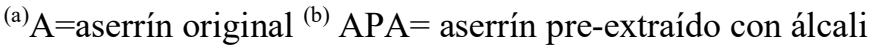

En la Tabla IV.20 se muestran las combinaciones de factores utilizadas, la severidad combinada, el rendimiento de cada ensayo y la composición química del sólido posterior al tratamiento EV.

Al igual que en la $\mathrm{HAD}$, la concentración de $\mathrm{H}_{2} \mathrm{SO}_{4}$ fue corregida debido al consumo de ácido en la neutralización del álcali residual (0,73\% base seca de la carga inicial). Para el cálculo de SC se determinó el pH considerando la concentración corregida. Por ejemplo, en el punto 5 del diseño la concentración corregida es de 2,27\% $\mathrm{H}_{2} \mathrm{SO}_{4}$ base seca.

Tabla IV.20 Composición química del aserrín con explosión de vapor \% sobre base seca (bs)

\begin{tabular}{|c|c|c|c|c|c|c|c|c|c|}
\hline & & & \multicolumn{9}{|c|}{ APA $^{(\mathbf{b})}$} \\
\hline Ensayo & T-t-C $^{(\mathbf{a})}$ & $\mathbf{S C}^{\mathbf{d}}$ & Rendimientd & Glucanos & Xilanos & Galactanos $^{\text {Arabinanos }}$ & Mananos & Lignina \\
\hline 1 & $180-5-1$ & 1,80 & 90,15 & 46,37 & 3,79 & 1,19 & N.d. & 10,17 & 34,18 \\
\hline 2 & $200-5-1$ & 2,39 & 78,43 & 47,96 & 1,94 & 0,59 & N.d. & 7,32 & 38,12 \\
\hline 3 & $180-10-1$ & 2,10 & 91,35 & 45,90 & 3,54 & 1,13 & N.d. & 10,57 & 34,46 \\
\hline 4 & $200-10-1$ & 2,69 & 74,38 & 50,27 & 2,03 & 0,71 & 0,21 & 7,32 & 39,13 \\
\hline 5 & $180-5-3$ & 2,64 & 71,93 & 51,01 & 1,72 & N.d. & N.d. & 3,51 & 39,90 \\
\hline 6 & $200-5-3$ & 3,32 & 59,98 & 52,53 & 0,75 & N.d. & N.d. & 2,07 & 42,48 \\
\hline 7 & $180-10-3$ & 3,03 & 77,08 & 50,94 & 1,95 & 0,73 & N.d. & 5,47 & 37,82 \\
\hline 8 & $200-10-3$ & 3,53 & 58,83 & 44,72 & N.d. & N.d. & N.d. & 1,57 & 48,24 \\
\hline 9 & $190-7.5-2$ & 2,95 & 75,01 & 50,79 & 2,01 & 0,65 & N.d. & 6,45 & 37,49 \\
\hline 10 & $190-7.5-2$ & 2,95 & 67,68 & 50,80 & 2,23 & 0,61 & N.d. & 6,80 & 36,77 \\
\hline & & & & & & $\mathbf{A}^{(\mathbf{c})}$ & & & \\
\hline 1 & $190-7.5-0.75$ & 2,72 & 69,22 & 48,58 & N.d. & N.d. & N.d. & 0,35 & 43,81 \\
\hline 2 & $190-7.5-0.75$ & 2,72 & 69,17 & 49,11 & 1,30 & N.d. & N.d. & 1,28 & 43,30 \\
\hline
\end{tabular}

N.d.: No detectado (LD Arabinanos IR =0,1\%bs; LD Xilanos IR=0,1\% bs; LD Galactanos= $0,1 \%$ bs). ${ }^{(a)} \mathrm{T}=$ temperatura $\left({ }^{\circ} \mathrm{C}\right) ; \mathrm{t}=$ tiempo (min); $\mathrm{C}=$ concentración $\mathrm{H}_{2} \mathrm{SO}_{4} \%$ bs. ${ }^{(b)} \mathrm{APA}=$ aserrín pre-extraído con álcali. ${ }^{\text {(c) }} \mathrm{A}=$ aserrín original; ${ }^{(d)} \mathrm{SC}$ : Severidad Combinada 
El rendimiento del tratamiento varió entre 90 y $60 \%$. A medida que la severidad del pretratamiento aumenta el rendimiento disminuye (Figura IV.21). Esta tendencia ocurre debido a la solubilización de mayor cantidad de material, sumado a cierta pérdida durante el proceso de recuperación del sólido. En las condiciones más severas del tratamiento de explosión las fibras se rompieron y se separaron obteniéndose un material con las características de un polvo. Durante la etapa de separación de la fracción sólida del licor residual, la pérdida de material fue importante debido el pequeño tamaño de partícula. A su vez, parte del material se compacta en el reactor y es posible que queden restos retenidos en las paredes del equipamiento Por lo tanto, dado que la recuperación de sólidos puede ser no completa, el rendimiento calculado será inferior al rendimiento real del proceso. De igual manera estos resultados son consistentes con los obtenidos por otros autores que han estudiado el proceso de explosión de vapor aplicado a coníferas (Nguyen et al., 1998), (Cotana et al., 2014), (Schwald et al., 1989).

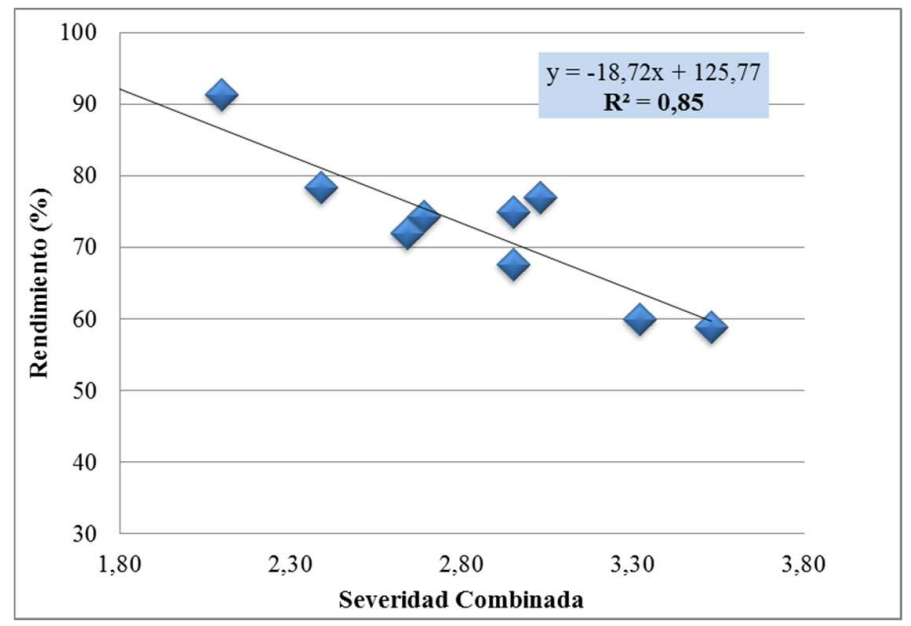

Figura IV.21. Variación del rendimiento del proceso de explosión de vapor con el coeficiente de severidad combinada (SC).

En las condiciones más severas se obtuvo un material constituido principalmente por celulosa y lignina, debido a la remoción de la mayor parte de las hemicelulosas. En los ensayos 6 y 8 , que se llevaron a cabo a $200^{\circ} \mathrm{C}$, la remoción de hemicelulosas fue casi completa. Por ejemplo, en el ensayo 6 a $200^{\circ} \mathrm{C}, 5$ min y $3 \% \mathrm{H}_{2} \mathrm{SO}_{4}$ la mayor parte de la fracción de hemicelulosas fue solubilizada, disminuyendo de $6,36 \%$ bs a $0,75 \%$ bs los xilanos y de $11,08 \%$ bs a $2,07 \%$ bs los mananos. En estas condiciones el material remanente resultó compuesto por 55\% de hexosas, $0,8 \%$ de pentosas y $42 \%$ de lignina. A mayor severidad del proceso, la cantidad de mananos y 
xilanos disminuyó, mientras que la de los glucanos aumentó (Figura IV.22). Además, el comportamiento del aserrín control (sin tratamiento) durante el tratamiento EV fue diferente, ya que a igual factor de severidad combinada, la remoción de hemicelulosas fue mayor. Este comportamiento es similar a lo que ocurría en la HAD donde la remoción de hemicelulosas fue más efectiva en el material de control.

A partir de las pendientes de las rectas que se representan en la Figura IV.22 se puede concluir que la variación en la extracción de mananos es mayor a menor severidad combinada.
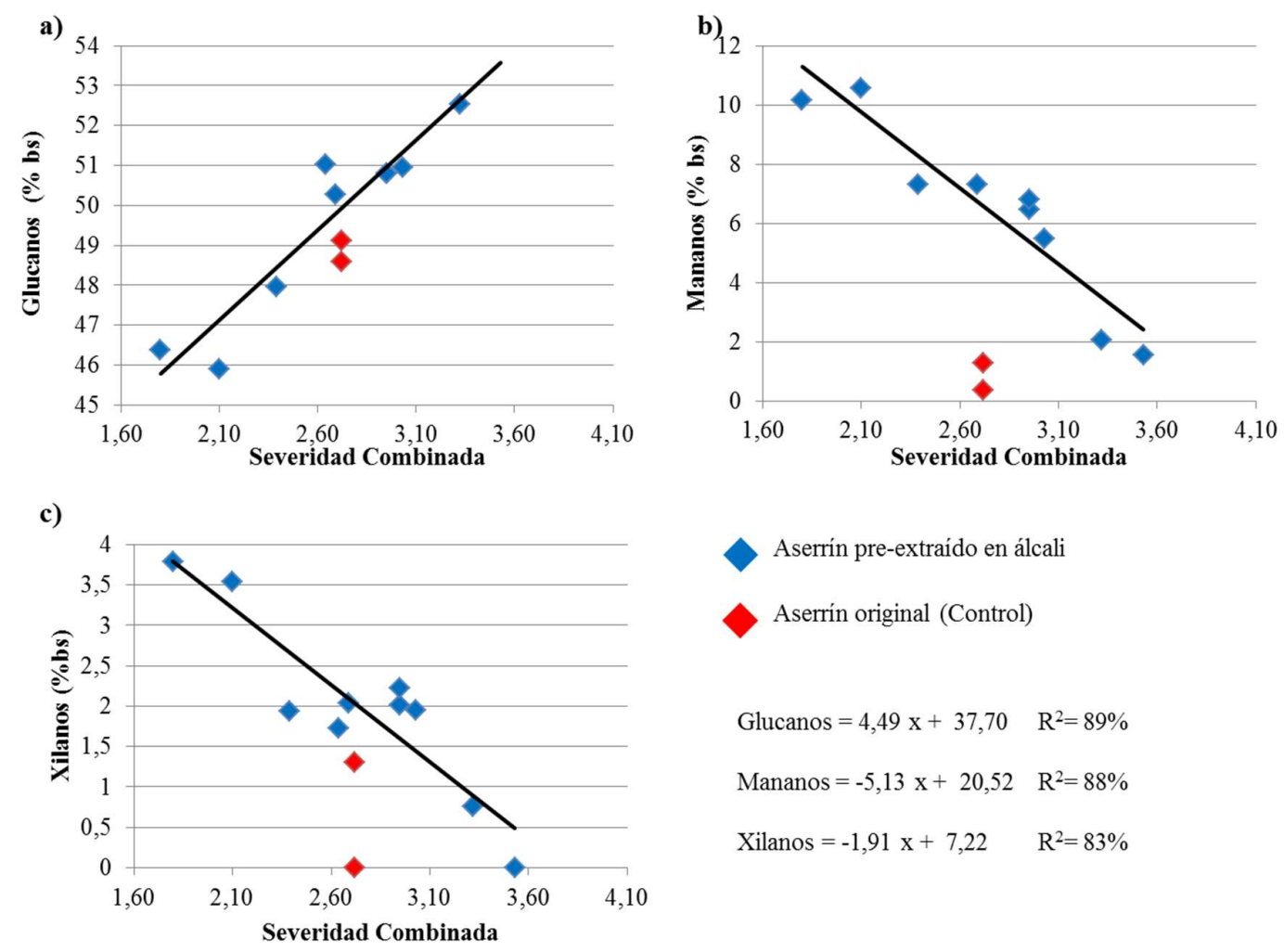

Figura IV.22 Variación del contenido de (a) glucanos, (b) mananos y (c) xilanos en la fracción sólida del aserrín pretratado con álcali y del aserrín original con respecto al factor de severidad combinada.

El rendimiento de la extracción representa el \% del componente que fue extraído del material y se calcula con la ecuación III.10. La tabla IV.21 indica los rendimientos de extracción obtenidos en cada condición experimental en la explosión de vapor basado en la cantidad teórica en el material sólido posterior a la etapa alcalina. El rendimiento de extracción de lignina fue bajo a excepción de los puntos 6 y 10 en que se evidencia una tasa de extracción mayor. El rendimiento 
de extracción de los arabinanos fue del 100\% indicando su carácter lábil ante la hidrólisis ácida. La extracción de hemicelulosas fue casi completa en los ensayos 6 y 8 pero la degradación de glucanos también fue significativa. Estos resultados son consistentes con los de Shahbazi et al., que trataron aserrín de pino mediante explosión de vapor a $190^{\circ} \mathrm{C}$ por 3 min y $1 \%$ bs $\mathrm{H}_{2} \mathrm{SO}_{4} \mathrm{y}$ encontraron que la extracción de celulosa fue de $14 \%$, mientras que cuando incrementaron la temperatura a $215^{\circ} \mathrm{C}$, la disolución de celulosa fue de casi el $70 \%$, concluyendo que condiciones más severas de tratamiento resultan en mayor degradación de celulosa (Shahbazi et al., 2005).

Tabla IV.21. Rendimientos de extracción durante el tratamiento de explosión de vapor (expresado cómo \% referido al material inicial de esta etapa)

\begin{tabular}{|c|c|c|c|c|c|c|c|c|}
\hline & & & \multicolumn{7}{|c|}{ APA $^{(\mathbf{b})}$} \\
\hline Ensayo & T-t-C $^{(\mathbf{a})}$ & $\mathbf{S C}^{\mathbf{c}}$ & Glucanos & Xilanos & Galactanos & Arabinanos & Mananos & Lignina \\
\hline 1 & $180-5-1$ & 1,80 & 0,00 & 46,3 & 52,2 & 100 & 17,2 & 0,00 \\
\hline 2 & $200-5-1$ & 2,39 & 5,28 & 76,1 & 79,3 & 100 & 48,2 & 0,00 \\
\hline 3 & $180-10-1$ & 2,10 & 0,00 & 49,1 & 53,9 & 100 & 12,8 & 0,00 \\
\hline 4 & $200-10-1$ & 2,69 & 5,86 & 76,2 & 76,6 & 87,8 & 50,8 & 2,20 \\
\hline 5 & $180-5-3$ & 2,64 & 7,61 & 80,5 & 100 & 100 & 77,2 & 3,55 \\
\hline 6 & $200-5-3$ & 3,32 & 20,7 & 92,9 & 100 & 100 & 88,8 & 14,4 \\
\hline 7 & $180-10-3$ & 3,03 & 1,15 & 76,4 & 75,1 & 100 & 62,0 & 2,04 \\
\hline 8 & $200-10-3$ & 3,53 & 33,7 & 100 & 100 & 100 & 91,7 & 4,63 \\
\hline 9 & $190-7.5-2$ & 2,95 & 4,08 & 76,3 & 78,2 & 100 & 56,3 & 5,50 \\
\hline 10 & $190-7.5-2$ & 2,95 & 13,4 & 76,3 & 81,8 & 100 & 58,5 & 16,4 \\
\hline & & & \multicolumn{7}{|c|}{ Aserrín original } & & 0,00 \\
\hline 1 & $190-7.5-0.75$ & 2,72 & 24,9 & 100 & 100 & 100 & 92,3 & 0,00 \\
\hline 2 & $190-7.5-0.75$ & 2,72 & 14,5 & 85,8 & 100 & 100 & 92,0 & 1,44 \\
\hline
\end{tabular}

(a) $\mathrm{T}=$ temperatura $\left({ }^{\circ} \mathrm{C}\right)$; $\mathrm{t}=$ tiempo $(\min ) ; \mathrm{C}=$ concentración $\mathrm{H}_{2} \mathrm{SO}_{4} \%$ bs. ${ }^{(b)} \mathrm{APA}=$ aserrín preextraído con álcali. ${ }^{(c)} \mathrm{SC}$ : Severidad Combinada.

La extracción de mananos es inferior a la de xilanos en todos los ensayos. Esto coincide con la velocidad relativa de hidrólisis ácida de los polímeros de la madera, que indica que los xilanos y galactanos son degradados más rápidamente que los mananos (Sixta et al., 2006). A su vez, estudios de extracción de pulpas o de holocelulosa con hidróxido de sodio concentrado en conjunto con acción mecánica e hidrólisis ácida suave demostraron que existe una fracción de glucomananos residual íntimamente asociada a la celulosa, inaccesible o altamente insoluble (Hamilton, 1962).

En la Tabla IV.22 se muestran los resultados obtenidos por otros autores que estudiaron el tratamiento de la explosión de vapor aplicado a coníferas impregnadas con ácido sulfúrico. En general, el comportamiento de los carbohidratos resulta similar, independientemente de las 
condiciones aplicadas. Es decir, cuando se aplican condiciones más severas el rendimiento de extracción de hemicelulosas es mayor, pero la degradación de la celulosa aumenta, al igual que la generación de subproductos.

Además, los procesos autocatalíticos requieren de temperaturas más altas para obtener resultados de extracción similares a los procesos catalizados con ácido como se observa en la Tabla IV.22. Por ejemplo, Cotana et al. obtuvieron un rendimiento de extracción de hemicelulosas del $83 \%$ a $220^{\circ} \mathrm{C}$, que es superior a la utilizada en los procesos catalizados (Cotana et al. 2014) (Tabla IV.22).

Tabla IV.22. Condiciones experimentales y resultados obtenidos por otros autores aplicando el proceso de explosión de vapor a coníferas.

\begin{tabular}{|c|c|c|c|c|c|}
\hline Materia prima & Condiciones & $\mathrm{SC}$ & Rendimiento & $\begin{array}{l}\text { Productos de } \\
\text { degradación }\end{array}$ & Referencias \\
\hline Aserrín de abeto & $\begin{array}{l}0,5 \% \mathrm{H}_{2} \mathrm{SO}_{4} ; 10 \mathrm{~min}, \\
180^{\circ} \mathrm{C}\end{array}$ & 2,36 & $\begin{array}{l}88 \% \text { de manosa; } 12 \\
\% \text { de glucosa }\end{array}$ & $\begin{array}{l}0,6 \% \mathrm{HMF} \\
0,3 \% \text { furfural }\end{array}$ & $\begin{array}{l}\text { Söderström et } \\
\text { al., } 2003\end{array}$ \\
\hline Aserrin de conífera & $\begin{array}{l}1,5 \mathrm{bs} \% \mathrm{H}_{2} \mathrm{SO}_{4 ;}, 190^{\circ} \mathrm{C} ; \\
1,7 \mathrm{~min}\end{array}$ & 2,17 & $\begin{array}{l}60-70 \% \text { de } \\
\text { hemicelulosas; } 17 \% \\
\text { glucosa }\end{array}$ & $\begin{array}{l}0,2 \% \text { HMF; } \\
\text { Furfural not } \\
\text { detected }\end{array}$ & Kim, 2005 \\
\hline $\begin{array}{l}\text { Chips de abeto Douglas y pino } \\
\text { ponderosa }\end{array}$ & $\begin{array}{l}0,4 \% \text { bs } \mathrm{H}_{2} \mathrm{SO}_{4 ;} 201^{\circ} \mathrm{C} ; \\
5,1 \mathrm{~min}\end{array}$ & 3,00 & $\begin{array}{l}62 \% \text { de } \\
\text { hemicelulosas; } 21 \% \\
\text { de celulosa }\end{array}$ & $\begin{array}{l}1,6 \% \mathrm{HMF} \\
7,1 \% \text { furfural }\end{array}$ & $\begin{array}{l}\text { Nguyen et al., } \\
1998\end{array}$ \\
\hline Chips de pino & $\begin{array}{l}1 \% \text { bs } \mathrm{H}_{2} \mathrm{SO}_{4} ; 190^{\circ} \mathrm{C} ; 3 \\
\text { min }\end{array}$ & 2,45 & $\begin{array}{l}82 \% \text { manosa, } 78 \% \\
\text { xilosa, } 14 \% \text { glucosa }\end{array}$ & No reportado & $\begin{array}{l}\text { Shahbazi et al., } \\
2005\end{array}$ \\
\hline Chips de pino & $\begin{array}{l}220^{\circ} \mathrm{C}-10 \mathrm{~min} \\
\text { (Autohidrólisis) }\end{array}$ & & $\begin{array}{l}83 \% \text { de } \\
\text { hemicelulosas, } 10 \% \\
\text { celulosa, }\end{array}$ & $\begin{array}{l}0,25 \% \mathrm{HMF} \\
0,25 \% \text { furfural }\end{array}$ & $\begin{array}{l}\text { Cotana et al., } \\
2014\end{array}$ \\
\hline Aserrín de pino elliottii & $\begin{array}{l}3 \% \mathrm{H}_{2} \mathrm{SO}_{4} ; 200^{\circ} \mathrm{C} ; 5 \\
\min \end{array}$ & 3,32 & $\begin{array}{l}90 \% \text { manosa; } 94 \% \\
\text { xilosa; } 26 \% \text { glucosa }\end{array}$ & $\begin{array}{l}1,2 \% \text { HMF; } \\
0,12 \% \text { Furfural }\end{array}$ & Este trabajo \\
\hline
\end{tabular}

Las hemicelulosas y la celulosa extraídas son recuperadas en la fracción líquida del tratamiento EV. El material obtenido fue lavado con agua para recuperar las hemicelulosas parcialmente hidrolizadas que quedan retenidas en las fibras. La tabla IV.23 muestra la composición de azúcares y productos de degradación en el licor concentrado y en el agua de lavado. A bajas severidades, los balances de masa son cercanos al 100\% sin embargo a severidades más altas los balances presentan diferencias $\pm 10 \%$, debido a la formación de subproductos, gases, etc. que no son analizados y requieren de estudios posteriores para su identificación y cuantificación. Además, la concentración de azúcares obtenida en el licor concentrado fue muy variable debido a la pérdida de calor del reactor, que es mayor a tiempos de residencia más largos y altas temperaturas, resultando en mayor formación de condensado y en consecuencia, mayor dilución 
del licor. La cantidad de azúcares extraídos en el agua de lavado fue muy pequeña, por lo que no se justifica la adición de esta etapa.

La xilosa y la manosa fueron los componentes mayoritarios del licor residual. La concentración de hidroximetilfurfural (HMF) en el licor fue mayor que de furfural, sin embargo, el porcentaje de productos de degradación de hexosas y pentosas (HMF y furfural) formados fue bajo. A $200^{\circ} \mathrm{C}$ la cantidad de HMF y furfural aumentó, indicando que la temperatura tiene un efecto importante en la degradación de azúcares. Taherzadeh et al. aplicaron el tratamiento de explosión de vapor a pino y abeto en un rango de temperaturas de $188^{\circ} \mathrm{C}$ a $234^{\circ} \mathrm{C}$ y concluyeron que la concentración de HMF, ácido acético y furfural aumentan con un incremento de la temperatura (Taherzadeh et al., 1997).

Tabla IV.23 Composición química del licor residual del proceso de explosión de vapor y del agua de lavado del aserrín pre extraído en álcali (APA) y del aserrín original (A) (expresado como porcentaje sobre aserrín inicial)

\begin{tabular}{|c|c|c|c|c|c|c|c|c|c|}
\hline & & \multicolumn{5}{|c|}{ Azucares extraidos } & \multicolumn{2}{|c|}{$\begin{array}{l}\text { Productos de } \\
\text { degradación }\end{array}$} & \multirow{2}{*}{$\begin{array}{c}\text { Agua de } \\
\text { lavado }\end{array}$} \\
\hline & T-t-C ${ }^{(a)}$ & Glucosa & Xilosa & Galactosa & Arabinosa & Manosa & HMF & Furfural & \\
\hline \multirow{10}{*}{$\begin{array}{l}\mathbf{A} \\
\mathbf{P} \\
\mathbf{A}\end{array}$} & $180-5-1$ & 0,27 & 1,07 & 0,34 & 0,22 & 0,54 & N.d. & 0,03 & 1,29 \\
\hline & $200-5-1$ & 0,78 & 1,49 & 0,57 & 0,22 & 1,63 & 0,02 & 0,04 & 0,79 \\
\hline & $180-10-1$ & 0,58 & 2,01 & 0,71 & 0,37 & 1,31 & 0,01 & N.d. & 0,17 \\
\hline & $200-10-1$ & 0,97 & 1,19 & 0,54 & 0,16 & 2,02 & 0,01 & 0,06 & 0,88 \\
\hline & $180-5-3$ & 3,07 & 4,35 & 1,92 & 0,83 & 6,14 & 0,27 & 0,19 & 1,86 \\
\hline & $200-5-3$ & 4,61 & 2,62 & 1,47 & 1,37 & 4,81 & 1,20 & 0,12 & 2,09 \\
\hline & $180-10-3$ & 2,33 & 4,69 & 1,68 & 1,03 & 5,75 & 0,20 & 0,08 & 1,47 \\
\hline & $200-10-3$ & 7,47 & 3,20 & 1,57 & 0,62 & 5,39 & 1,30 & 0,46 & 1,77 \\
\hline & $190-7.5-2$ & 1,49 & 2,71 & 1,17 & 0,51 & 3,70 & 0,34 & 0,06 & 1,38 \\
\hline & $190-7.5-2$ & 1,39 & 3,47 & 1,24 & 0,82 & 3,71 & 0,15 & 0,02 & 1,53 \\
\hline \multirow{2}{*}{$\mathbf{A}$} & $190-7.5-0.75$ & 3,48 & 3,55 & 1,72 & 0,82 & 6,77 & 0,47 & 0,43 & 3,30 \\
\hline & $190-7.5-0.75$ & 3,38 & 3,93 & 2,07 & 0,81 & 7,42 & 1,07 & 0,56 & 2,25 \\
\hline
\end{tabular}

N.d.: No detectado (LD Furfural UV 254 nm = 0,004\%; LD Furfural UV 254 nm = 0,003\%)

(a) $\mathrm{T}=$ temperatura $\left({ }^{\circ} \mathrm{C}\right) ; \mathrm{t}=$ tiempo $(\mathrm{min}) ; \mathrm{C}=$ concentración $\mathrm{H}_{2} \mathrm{SO}_{4} \%$ bs. ${ }^{(b)}$ Azúcares totales: glucosa+xilosa+galactosa+arabinosa+manosa. N.d.: No detectado

La Figura IV.23 muestra la variación de los a) azúcares mayoritarios en el licor (glucosa, manosa y xilosa) y de b) los productos de degradación (HMF y furfural) con la severidad combinada. En general, el tratamiento extrajo más hexosas que pentosas. La extracción de glucosa aumenta a medida que aumenta la severidad del proceso (Figura IV.23). Esta tendencia se debe a que con 
mayor severidad la extracción de celulosa se hace más significativa. La xilosa y la manosa comienzan a disminuir a partir de una SC igual a 3 que coincide con una mayor presencia de productos de degradación en la fracción líquida (Figura IV.23 b). A medida que la severidad de la explosión de vapor aumentó el contenido de productos de degradación en el licor también se incrementó La presencia de HMF es considerablemente mayor que la de furfural, indicando mayor degradación de hexosas.
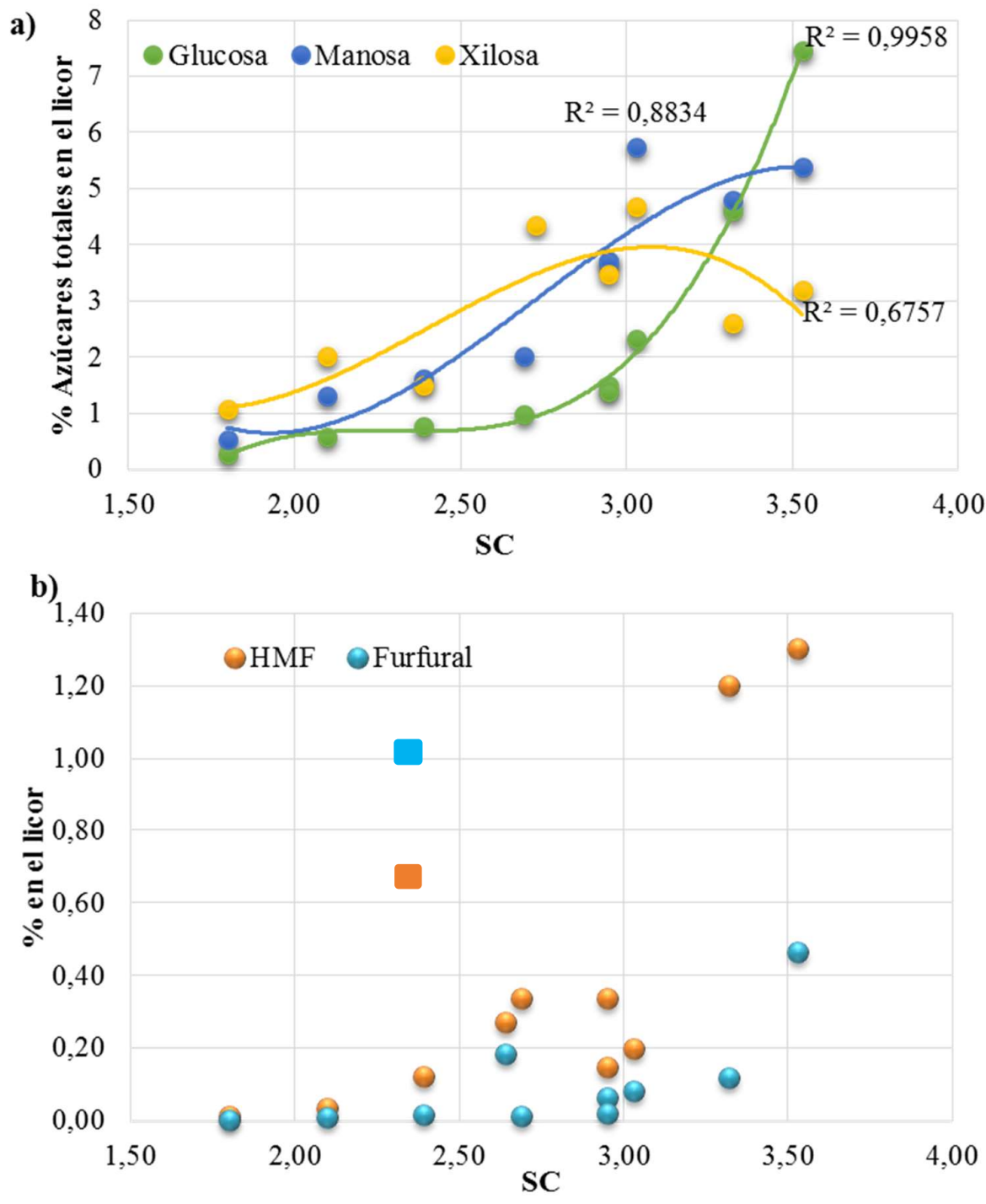

Figura IV.23 Composición química del licor en función de la severidad combinada del tratamiento EV a) azúcares totales y b) productos de degradación: los marcadores cuadrados representan el \% de HMF (anaranjado) y furfural (celeste) del tratamiento HAD a una SC de 2,4 (expresado cómo \% sobre madera inicial) 
En la figura IV.23 b se incluyeron a modo de comparación el contenido de HMF y furfural del tratamiento HAD a la mayor severidad aplicada $(\mathrm{SC}=2,39)$. Se observa que a esta $\mathrm{SC}$ la concentración de estos compuestos es menor en el proceso EV. Este resultado no indicaría que la degradación de azúcares en la EV es menor, sino que debido a las temperaturas más elevadas de este tratamiento, el HMF y furfural han sido degradados a otros compuestos, como ácido fórmico y ácido levulínico. En medio ácido, bajo condiciones más severas tal como tiempo más largos y altas temperaturas y concentración, el HMF es posteriormente degradado a ácido fórmico y ácido levulínico. (Fengel, 1989). El furfural es también inestable en el medio deshidratante y puede ser degradado a ácido fórmico. Estudios sobre pretratamientos ácidos han demostrado que en condiciones más severas (SC mayor a 3,4) la concentración de HMF y furfural disminuyó mientras aumentaba la cantidad de ácido fórmico y levulínico (Larsson et al., 1999).

La presencia de oligosacáridos solubles después del tratamiento EV fue confirmada aplicando una hidrólisis ácida a los líquidos residuales. El porcentaje de azúcares hemicelulósicos extraídos como oligómeros se expone en la Figura IV.24. En condiciones menos severas las hemicelulosas son extraídas principalmente como oligómeros pero a medida que la severidad del tratamiento aumenta, se extraen mayoritariamente como azúcares.

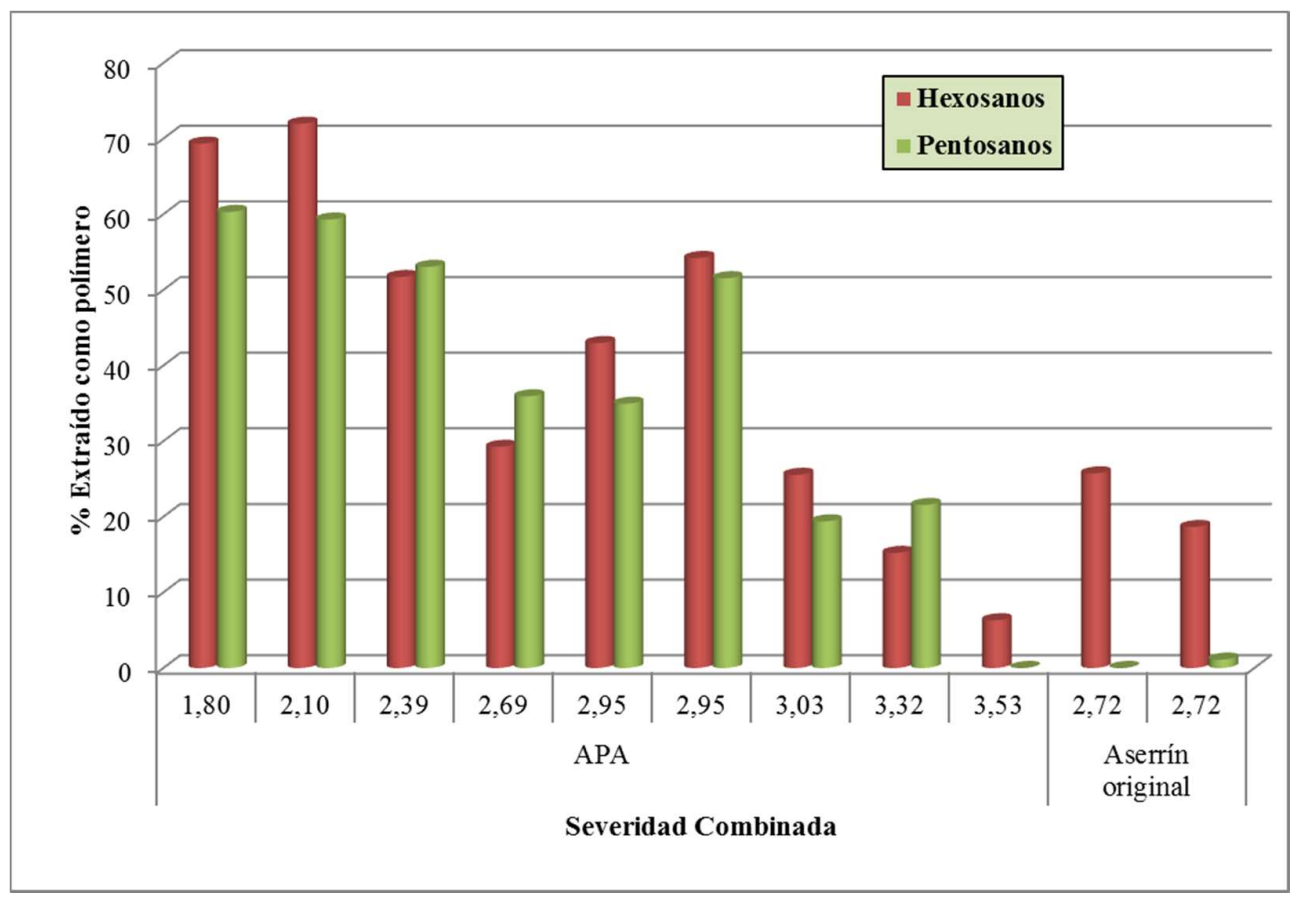

Figura IV.24 Oligómeros extraídos (como \% de azúcares totales removidos) en el proceso EV del aserrín pre-extraído en álcali. 


\section{IV.2.2.2.2 Análisis Estadístico}

El análisis estadístico se realizó a partir de la composición química de la fracción sólida debido a la dificultad en determinar la composición exacta de la fracción soluble. El análisis estadístico indicó que la concentración de ácido ( $\mathrm{p}$-valor $<0,05)$ y la temperatura ( $\mathrm{p}$-valor $<0,05)$ tuvieron influencia en la remoción de hemicelulosas mientras que el efecto del tiempo no resultó estadísticamente significativo ( $p$-valor $>0,05$ ). Las ecuaciones de regresión (en variables codificadas) que representan la influencia de estos factores sobre el contenido de polímeros en el aserrín pretratado con álcali durante el tratamiento EV se presentan en la Tabla IV.24.

Tabla IV.24 Ecuaciones de regresión de los componentes del APA tratado con tratamiento EV (en variables codificadas).

\begin{tabular}{|l|l|c|}
\hline Componente & \multicolumn{1}{|c|}{ Ecuación de regresión } & $\mathbf{R}^{\mathbf{2}} \mathbf{( \% )}$ \\
\hline Glucanos & $50+1,45 * \mathrm{~T}+0,53 * \mathrm{t}+2,38 * \mathrm{C}+0,68 * \mathrm{~T} * \mathrm{t}$ & 100 \\
\hline Xilanos & $2,00-0,79 * \mathrm{~T}-0,86 * \mathrm{C}$ & 96 \\
\hline Galactanos & $0,56-0,22 * \mathrm{~T}-0,36 * \mathrm{C}$ & 83 \\
\hline Mananos & $6,13-1,43 * \mathrm{~T}-2,85 * \mathrm{C}$ & 97 \\
\hline
\end{tabular}

Las ecuaciones muestran ajustes significativos a 95\% de significancia ( $p$-valor $<0,05$ ). De acuerdo con los coeficientes de las ecuaciones y como se observa en la Figura IV.25, la concentración es el factor que más influye, seguido por la temperatura. El efecto del tiempo es únicamente significativo en la extracción de glucanos, pero no afecta la extracción de hemicelulosas. Nguyen et al. obtuvieron el mismo resultado en cuanto al efecto del tiempo en el estudio de la explosión de vapor aplicado a chips de pino y abeto Douglas (Nguyen et al., 1998). Cuando los niveles de la concentración y de la temperatura aumentan, el contenido de hemicelulosas (mananos, xilanos y galactanos) disminuye, es decir que aumenta la extracción. La concentración, temperatura y tiempo tienen un efecto positivo en la extracción de glucanos, es decir que en el nivel superior de estos factores aumenta el contenido de glucanos, debido a una mayor remoción de hemicelulosas. 

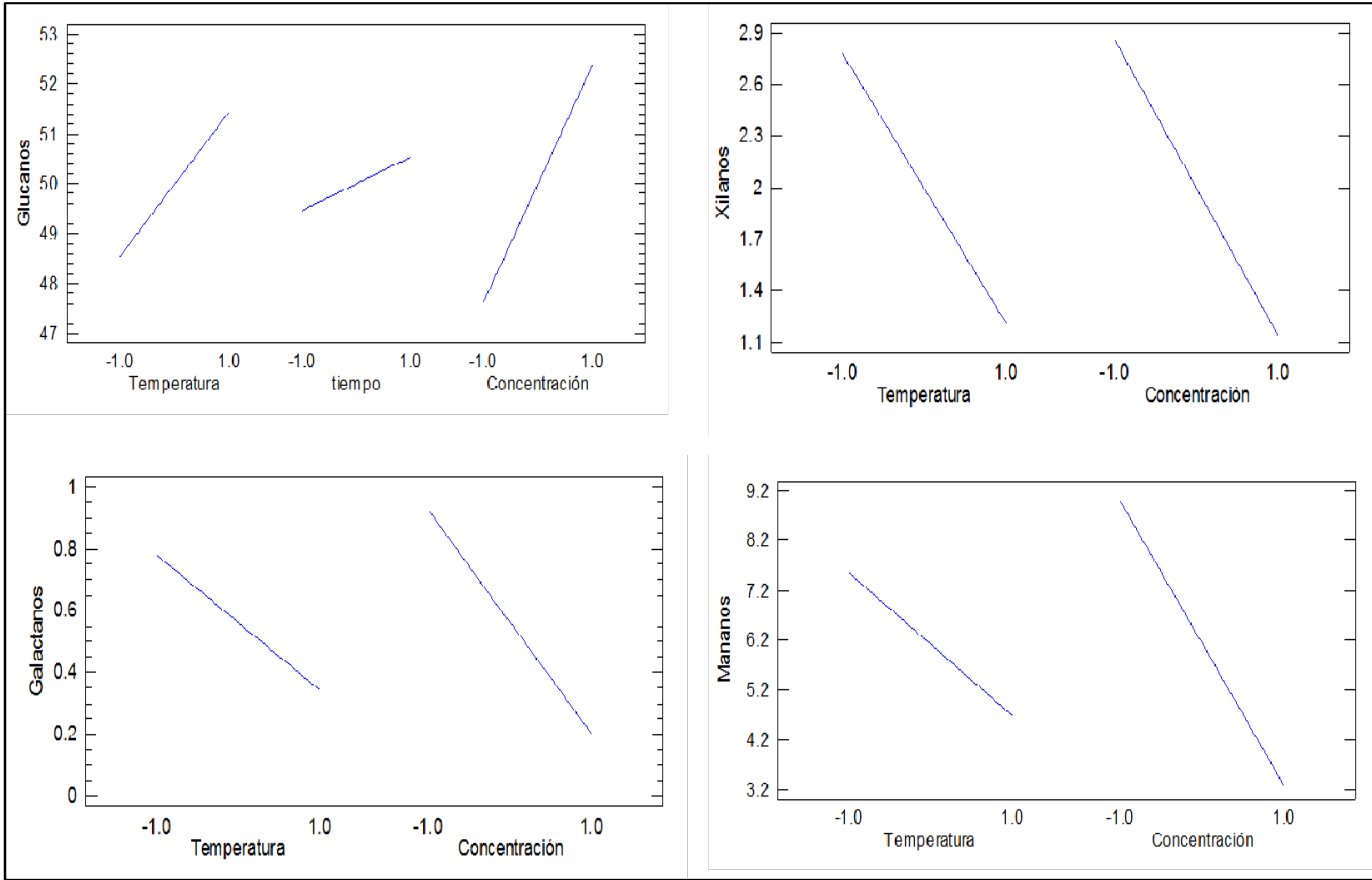

Figura IV.25. Gráfico de los efectos principales sobre glucanos, galactanos, mananos y xilanos del sólido pretratado con EV.

A su vez, el efecto positivo de la interacción temperatura-tiempo sobre los glucanos indica que la influencia del tiempo se vuelve más importante a temperaturas altas (Figura IV.26).

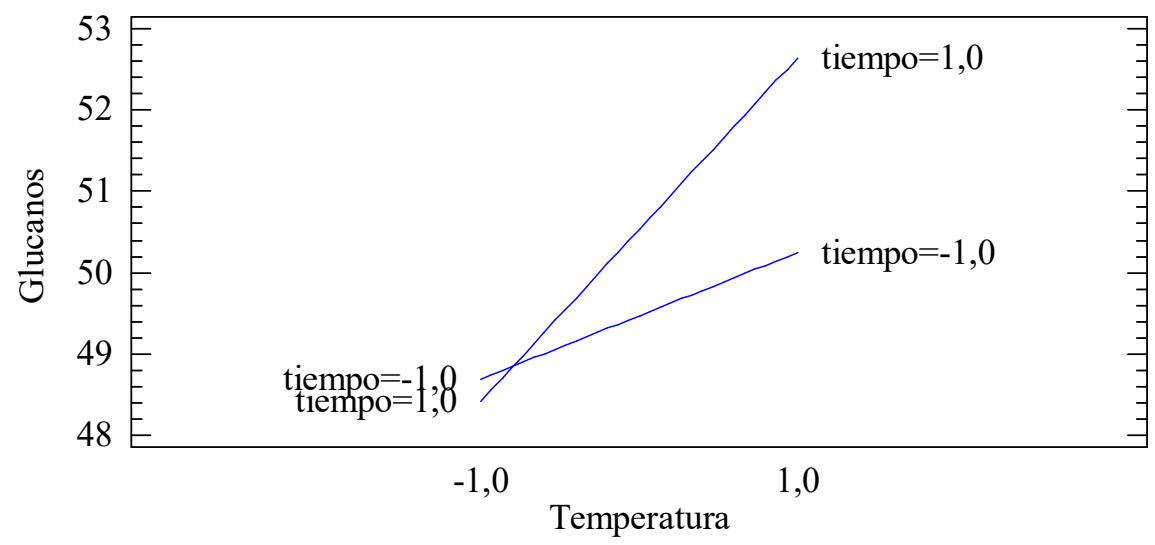

Figura IV.26 Gráfico de la interacción temperatura-tiempo sobre los glucanos del APA y EV.

(T: temperatura, t: tiempo) 
Janzon et al. obtuvieron la misma conclusión acerca del rendimiento de carbohidratos extraídos con el proceso de explosión de vapor aplicado a abeto, pero utilizando $\mathrm{SO}_{2}$ como catalizador en lugar de $\mathrm{H}_{2} \mathrm{SO}_{4}$. En dicho trabajo, el tiempo de reacción mostró una pequeña influencia mientras que la temperatura y la concentración de $\mathrm{SO}_{2}$ resultaron los factores claves (Janzon et al., 2014).

\section{IV.2.2.2.3 Optimización estadística}

La función deseabilidad permite determinar la combinación de factores que optimiza simultáneamente varias respuestas. Esta función, expresada en una escala de 0 a 1 , fue utilizada para maximizar la extracción de mananos, xilanos y galactanos minimizando la de glucanos en el sólido pretratado. La Figura IV.27 muestra la superficie de respuesta de la función deseabilidad para estas condiciones de optimización en variables codificadas.

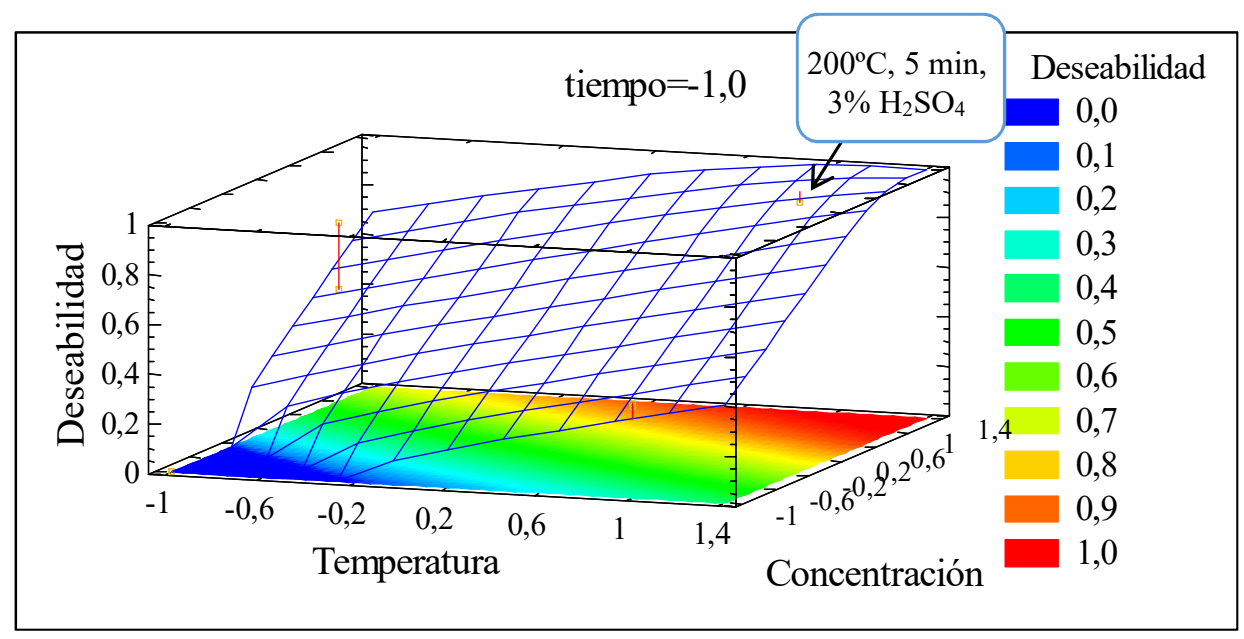

Figura IV.27 Superficie de respuesta de la función deseabilidad (en variables codificadas) para maximizar la extracción de mananos, xilanos y galactanos minimizando la de glucanos en el tratamiento EV (los puntos naranja indican los puntos del diseño).

En la región experimental estudiada, el valor máximo de deseabilidad $(0,96)$ se alcanza a $200^{\circ} \mathrm{C}$ $(+1), 3 \% \mathrm{H}_{2} \mathrm{SO}_{4}$ bs (+1) y $5 \min (-1)$ que corresponde al ensayo 6 del diseño de experimento planteado. En la superficie de respuesta se aprecia que para aumentar la deseabilidad a su máximo valor (1) habría que aumentar ligeramente la concentración de ácido o la temperatura. 
En conclusión, las condiciones que optimizan la extracción de hemicelulosas durante el tratamiento de explosión de vapor dentro del diseño planteado corresponden a $200^{\circ} \mathrm{C}, 3 \% \mathrm{H}_{2} \mathrm{SO}_{4}$ bs y 5 min (ensayo 6). En estas condiciones la extracción de mananos fue $89 \%$, la de xilanos $93 \%$, la de galactanos y arabinanos de $100 \%$ y la de glucanos de $21 \%$. En el licor se recuperaron $11 \%$ de las hexosas y $4 \%$ de pentosas, principalmente como azúcares.

El proceso de explosión de vapor permite extraer casi por completo las hemicelulosas sin afectar significativamente la celulosa y la lignina. La concentración de ácido sulfúrico resultó el factor con mayor influencia en el comportamiento de las hemicelulosas y la penetración del ácido dentro de las fibras resulta crítico para lograr un efecto catalítico uniforme. Por lo tanto, podrían esperarse mejores resultados si se modifica el método de adición de ácido, por ejemplo remojando la biomasa en la solución ácida.

Con el objetivo de aproximarse a lo que sería el proceso a mayor escala y para evaluar el efecto de la etapa de secado al aire del aserrín previo al tratamiento $\mathrm{EV}$, la condición óptima $\left(200^{\circ} \mathrm{C}-5\right.$ min- 3\% $\mathrm{H}_{2} \mathrm{SO}_{4}$ bs) fue reproducida utilizando aserrín pre-extraído con álcali sin secar, con una humedad inicial de 56\%. Debido a que el contenido de agua de este material es mayor, la dilución de ácido durante la impregnación fue más alta, resultando en una severidad combinada menor (2,95 vs 3,32). En la Tabla IV.25 se muestra la composición del líquido y del sólido después del tratamiento. El rendimiento del tratamiento EV fue de 58,83\% muy similar al obtenido para el material con secado previo.

Tabla IV.25. Composición química de la fracción sólida (\% base seca) y líquida (\% base aserrín inicial) del aserrín APA sin secar tratado con EV.

\begin{tabular}{|c|c|c|c|c|c|c|c|c|c|c|}
\hline \multicolumn{3}{|c|}{ Fracción sólida (\% bs) } & \multicolumn{8}{|c|}{ Fracción Líquida (\% bi) } \\
\hline Glucanos & Mananos & Lignina & Glucosa & Xilosa & Galactosa & Arabinosa & Manosa & $\mathrm{HMF}$ & Furfural & $\begin{array}{c}\text { Agua de } \\
\text { lavado }\end{array}$ \\
\hline 42,60 & 1,30 & 49,86 & 8,93 & 3,38 & 1,65 & 0,68 & 5,66 & 1,21 & 0,40 & 2,39 \\
\hline
\end{tabular}

El rendimiento de extracción de xilanos, galactanos y arabinanos fue del 100\%. La extracción de glucanos y mananos para este material fue de 37\% y 93\% respectivamente. En ambos casos el rendimiento de extracción fue mayor que el obtenido para el aserrín seco (21\% de glucanos y $89 \%$ de mananos). La cantidad de azúcares recuperada en la fracción líquida fue mayor, lo que podría indicar que en estas condiciones la degradación fue menor. El contenido de HMF y furfural en el licor fue muy similar en ambos materiales. 


\section{IV.2.2.2.4 Extracción de lignina mediante lavado alcalino}

Posterior al lavado acuoso, el material resultante de algunos de los ensayos realizados se sometió a una etapa de lavado alcalino para extraer la lignina hidrolizada, con el objetivo de mejorar el rendimiento de la hidrólisis enzimática. La Figura IV.28 muestra el contenido de lignina del material tratado mediante explosión de vapor, antes y después del lavado alcalino. La extracción de lignina no fue significativa en ninguno de los casos (entre $2,4 \%$ y $3,3 \%$ ) y tampoco la solubilización de carbohidratos. Se ha reportado que la lignina de latifoliadas tratadas con explosión de vapor puede ser fácilmente recuperada mediante un lavado alcalino suave a temperatura ambiente mientras que la extracción de lignina de coníferas no puede ser removida tan fácilmente (Ramos Pereira et al., 2003). A pesar de la menor eficiencia de extracción mediante lavado alcalino para coníferas cuando el material es impregnado con $\mathrm{SO}_{2}$ en lugar de $\mathrm{H}_{2} \mathrm{SO}_{4} \mathrm{se}$ obtienen resultados más satisfactorios. Schwald et al extrajeron el $25 \%$ de la lignina con un tratamiento alcalino a temperatura ambiente y $0,4 \%$ de $\mathrm{NaOH}$ posterior a la explosión de vapor aplicado a abeto impregnado con $\mathrm{SO}_{2}$ (Schwald et al., 1989). La posible causa del mayor rendimiento de extracción puede ser que la lignina se encuentre sulfonada como resultado del tratamiento con $\mathrm{SO}_{2}$. La sulfonación genera grupos ácidos sulfónicos $\left(-\mathrm{SO}_{3} \mathrm{H}\right)$ en la lignina que incrementan su hidrofilicidad y facilita su solubilidad en agua (Alén, 2015).

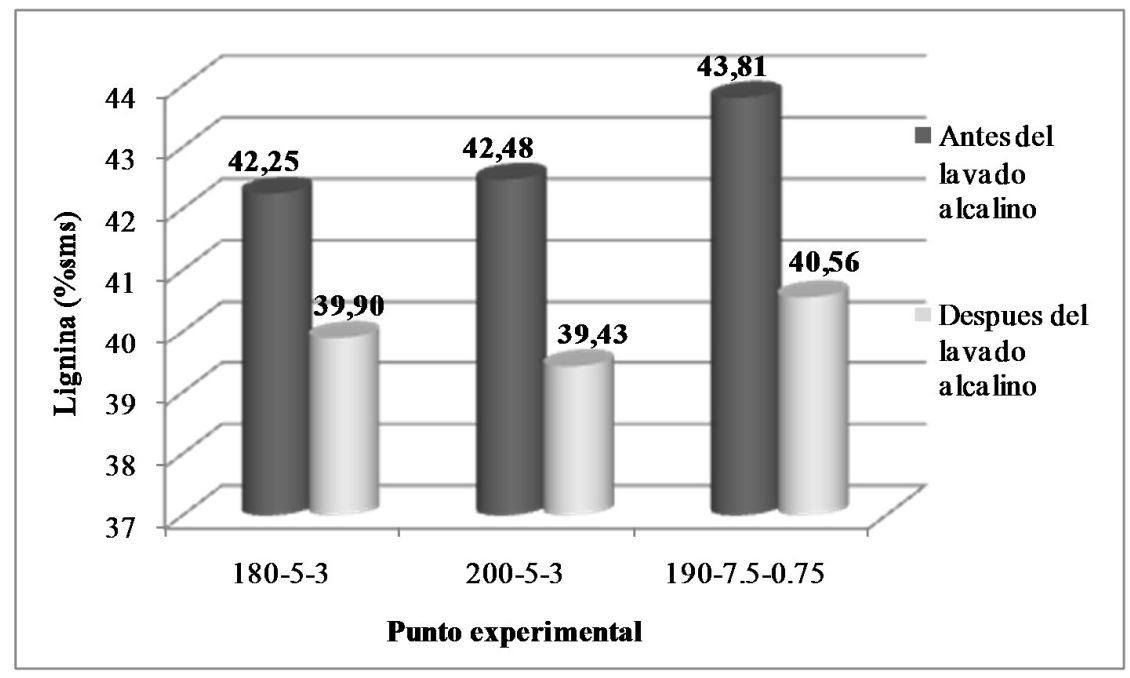

Figura IV.28 Contenido de lignina después del lavado alcalino (\% base seca) del material proveniente del aserrín original sometido a explosión de vapor: ensayo $5\left(180^{\circ} \mathrm{C}, 5 \mathrm{~min}, 3 \%\right.$ $\left.\mathrm{H}_{2} \mathrm{SO}_{4}\right)$, ensayo $6\left(200^{\circ}, 5\right.$ min y $\left.3 \% \mathrm{H}_{2} \mathrm{SO}_{4}\right)$ y ensayo $1\left(190^{\circ} \mathrm{C}, 7,5 \min\right.$ y $\left.0,75 \% \mathrm{H}_{2} \mathrm{SO}_{4}\right)$ 


\section{IV.2.2.2.5 Hidrólisis Enzimática}

El rendimiento de la hidrólisis enzimática (HE) de los materiales lignocelulósicos depende principalmente de la accesibilidad de la celulosa y del contenido de lignina. Se comprobó la digestibilidad enzimática de la fracción sólida resultante de la explosión de vapor y posterior al lavado alcalino utilizando una carga enzimática de $20 \mathrm{FPU} / \mathrm{g}$ de glucano durante 72 horas. En la Figura IV.29 se muestra el rendimiento de la HE a las $72 \mathrm{~h}$ del aserrín tratado mediante explosión de vapor en diferentes condiciones. Aunque el tratamiento EV no extrae lignina, la disrupción de la estructura de las fibras aumenta la susceptibilidad de la celulosa en forma evidente ya que el rendimiento de glucosa en la HE es superior al del aserrín sin tratamiento e incluso superior a los rendimientos obtenidos luego de la HAD. La mejora de la digestibilidad enzimática de los materiales tratados con explosión de vapor es atribuida a tres factores principales: el incremento de área superficial causado por la fragmentación de las fibras, el incremento de la porosidad debido a la hidrólisis y remoción de las hemicelulosas, y el incremento de la porosidad debido a la redistribución de la lignina (Donaldson et al., 1988) (Wong et al., 1988). A pesar de la remoción de las hemicelulosas, la susceptibilidad de la celulosa a la hidrólisis enzimática no aumentó significativamente con el tratamiento EV.

El máximo rendimiento obtenido fue de $24,3 \%$ de glucosa y se alcanzó en la condición óptima $\left(200^{\circ} \mathrm{C}, 5 \mathrm{~min}\right.$ y $\left.3 \% \mathrm{H}_{2} \mathrm{SO}_{4}\right)$ que corresponde a la severidad combinada más alta $(\mathrm{SC}=3,23)$. Este rendimiento es 6 veces mayor que el obtenido para el aserrín sin tratamiento. El rendimiento de glucosa de la hidrólisis enzimática aumentó con una mayor severidad del tratamiento. Estos resultados se encuentran en concordancia con lo obtenido por otros autores. Por ejemplo, Soderstrom et al. obtuvieron un rendimiento de glucosa de 35\% (carga enzimática: $28 \mathrm{FPU} / \mathrm{g}$ de glucanos) de abeto pretratado con una secuencia de explosión de vapor en dos etapa con $\mathrm{H}_{2} \mathrm{SO}_{4}$ (Söderström et al., 2002). A su vez, en condiciones de autohidrólisis se obtienen rendimientos de glucosa en la HE similares pero aplicando temperaturas mucho más elevadas en el pretratamiento. Asada et al. obtuvieron un rendimiento de $24,2 \%$ de conífera pretrada a $245^{\circ} \mathrm{C}$ y 5 min utilizando $40 \mathrm{FPU} / \mathrm{g}$ de glucanos (Asada et al., 2015). Las condiciones severas de pretratamiento resultan en un material que es más accesible al ataque enzimático, aunque también se degrada mayor cantidad de celulosa.

Según se ha reportado, los rendimientos de extracción de hemicelulosas en el tratamiento EV cuando se utiliza $\mathrm{SO}_{2}$ como catalizador en lugar de $\mathrm{H}_{2} \mathrm{SO}_{4}$ son similares, pero los rendimientos de la HE son superiores, por ejemplo, el rendimiento de glucosa durante la HE de coníferas pretratadas con $\mathrm{SO}_{2}$ resultó de 50-60\% o superior a las $72 \mathrm{~h}$ con $20 \mathrm{FPU} /$ glucano (Pereira Ramos et al., 1992), (Kumar et al., 2010) (Clark \& Mackie, 1987) (Stenberg et al., 1998) (Huang \& Ragauskas (b), 2012). 
El rendimiento de HE del aserrín control, es decir sin pre-extracción alcalina previa fue de 17\% con una severidad combinada similar a la del ensayo llevado a cabo a $180^{\circ} \mathrm{C}$, 5 min y $3 \% \mathrm{H}_{2} \mathrm{SO}_{4}$ $(\mathrm{SC}=2,64)$, probablemente debido a que el aserrín control pretratado con EV tiene menor contenido de hemicelulosas (xilanos + mananos $=2,6 \%$ ) que el material con etapa alcalina previa (xilanos + mananos $=5,2 \%$ ). La disolución de hemicelulosas incrementa la porosidad del material y por ende la digestibilidad enzimática de la biomasa (Singh et al., 2015).

No hubo diferencia significativa en el rendimiento de la HE (Figura IV.29) entre el material que fue secado al aire previo al tratamiento de explosión de vapor y el que se mantuvo húmedo. Santi Junior et al encontraron que el secado suave (como el secado al aire) provoca solo el colapso de los poros más pequeños, los cuales ya son inaccesibles para las enzimas, y por lo tanto no afecta la eficiencia de la HE (Santi Junior et al., 2013)

Los materiales tratados con HAD presentaron rendimientos de hidrólisis enzimática inferiores que los tratados con EV. Estos últimos pueden tener mayor área superficial debido al efecto físico que provoca la explosión en las fibras y a su vez poseen menor contenido de hemicelulosas. Estos dos factores pueden influir en el mayor rendimiento de hidrólisis enzimática alcanzado. A su vez, el índice de cristalinidad de los materiales tratados con EV (CrI: 66,04 para el material APA-EV y CrI: 67,23 para el aserrín control con EV) es ligeramente menor que los tratados con HAD (CrI cercano a 70$)$.

Los compuestos solubles generados en los pretratamientos (furfural, ácido acético, HMF, compuestos fenólicos de la degradación de la lignina) inhiben tanto a las enzimas como a las levaduras, aunque el efecto mayor de inhibición fue observado para las levaduras (Pitarelo, 2013). Por lo tanto, debe considerarse que los materiales pretratados en este trabajo fueron exhaustivamente lavados con agua eliminando el furfural del material. En un proceso real esta etapa de lavado no sería posible, por lo tanto, el rendimiento de la HE disminuiría debido a la presencia de furfural. 


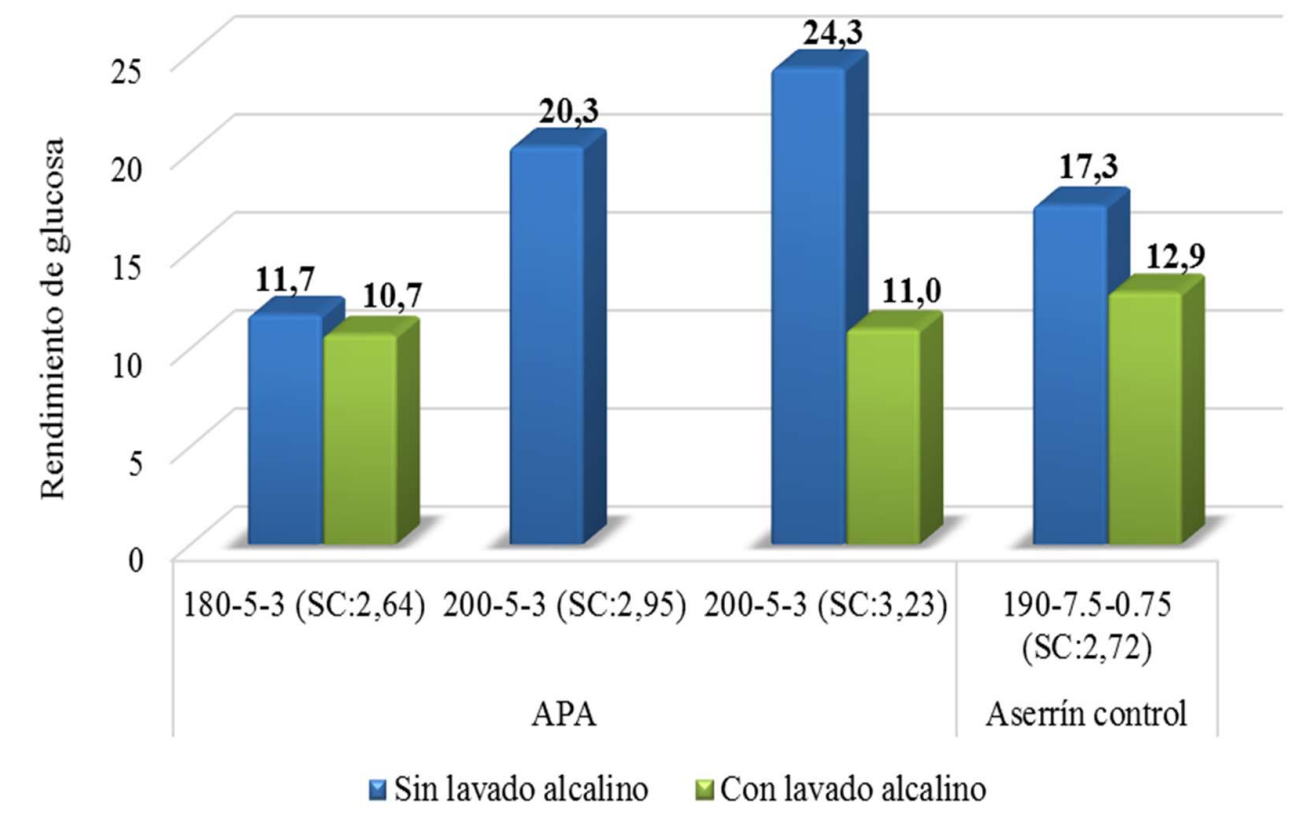

Figura IV.29 Rendimiento de la hidrólisis enzimática a las 72 horas de la explosión de vapor con lavado alcalino y sin lavado alcalino.

El aserrín sometido a lavado alcalino presentó rendimientos de HE más bajos que el material sin lavar (Figura IV.29). El rendimiento máximo alcanzado fue de 13\% para el aserrín control y de $11 \%$ para los ensayos APA-EV. Otros autores encontraron el mismo resultado al someter a biomasa pretratada con explosión de vapor a un lavado alcalino. Es posible que el tratamiento con $\mathrm{NaOH}$ extraiga algo de la lignina disuelta, y que esta se redeposite en las fibras, provocando una disminución de la porosidad y en consecuencia una disminución de la digestibilidad enzimática (Pereira Ramos et al., 1992), (Donaldson et al., 1988).

\section{IV.2.3 CAMBIOS ESTRUCTURALES DE LOS MATERIALES PRETRATADOS}

\section{IV.2.3.1 Condensación de la lignina}

Los beneficios de los tratamientos ácidos son la eficiencia de remoción de hemicelulosas y la apertura de la pared celular, pero un efecto secundario negativo es la condensación de la lignina como consecuencia de la acidez y las altas temperaturas utilizadas en el proceso. 
El grado de condensación de la lignina puede ser determinado indirectamente mediante oxidación con nitrobenceno en medio alcalino, ya que la formación de enlaces carbono-carbono provoca una disminución en el rendimiento total de aldehídos (Lin \& Dence, 1992). Con el objetivo de evaluar la potencialidad de los materiales resultantes de este pretratamiento para la producción de vainillina se realizaron oxidaciones con nitrobenceno de los mismos (Dos Santos, 2014).

La oxidación con nitrobenceno del aserrín de pino elliottii sin tratamiento produce un rendimiento de vainillina de $18 \%$ con respecto a la lignina inicial. En la Tabla IV.26 se indican los rendimientos de vainillina obtenidos a partir de la oxidación con nitrobenceno de los aserrines pretratados siguiendo las secuencias de este trabajo.

El rendimiento de vainillina disminuye en las condiciones más severas de tratamiento, lo que indica una mayor condensación. Según estos resultados, la condensación que produce la HAD es mayor que la producida por el tratamiento $\mathrm{EV}$, ya que la $\mathrm{HAD}$ produce un menor rendimiento de vainillina con una SC menor que el tratamiento EV con una severidad mayor. Este resultado podría atribuirse al factor tiempo, ya que los tiempos utilizados en la HAD son mayores que en la $\mathrm{EV}$, mientras que la temperatura y concentración de ácido son menores. El rendimiento de vainillina es todavía más bajo en los materiales que han sido sometidos a una etapa de extracción alcalina previa. Este resultado indicaría que en la etapa alcalina también se produciría condensación de la lignina. 
Tabla IV.26. Rendimiento de vainillina como \% sobre lignina inicial (sli) producida por oxidación con nitrobenceno de los aserrines pretratados.

\begin{tabular}{|c|c|c|c|}
\hline & Tratamiento & $\mathrm{Sc}^{\mathrm{a}}$ & $\begin{array}{c}\text { Rendimiento } \\
\text { vainillina (\% sli) }\end{array}$ \\
\hline \multirow[t]{2}{*}{ Aserrín original } & & 0 & 18,4 \\
\hline & HAD $^{b}$ & & \\
\hline \multirow{4}{*}{$\begin{array}{c}\text { Con tratamiento alcalino } \\
\text { previo }\end{array}$} & $110^{\circ} \mathrm{C}-45 \mathrm{~min}-5 \mathrm{~g} / \mathrm{L} \mathrm{H}_{2} \mathrm{SO}_{4}$ & 0,89 & 12,6 \\
\hline & $135^{\circ} \mathrm{C}-45 \mathrm{~min}-0,8 \mathrm{~g} / \mathrm{L} \mathrm{H}_{2} \mathrm{SO}_{4}$ & 0,00 & 10,2 \\
\hline & $160^{\circ} \mathrm{C}-45 \mathrm{~min}-5 \mathrm{~g} / \mathrm{L} \mathrm{H}_{2} \mathrm{SO}_{4}$ & 2,36 & 5,7 \\
\hline & $135^{\circ} \mathrm{C}-45 \mathrm{~min}-9,2 \mathrm{~g} / \mathrm{L} \mathrm{H}_{2} \mathrm{SO}_{4}$ & 1,92 & 6,8 \\
\hline \multirow{5}{*}{ Sin tratamiento alcalino } & $110^{\circ} \mathrm{C}-45 \mathrm{~min}-5 \mathrm{~g} / \mathrm{L} \mathrm{H}_{2} \mathrm{SO}_{4}$ & 0,96 & 13,2 \\
\hline & $135^{\circ} \mathrm{C}-45 \mathrm{~min}-0,8 \mathrm{~g} / \mathrm{L} \mathrm{H}_{2} \mathrm{SO}_{4}$ & 0,90 & 14,2 \\
\hline & $160^{\circ} \mathrm{C}-45 \mathrm{~min}-5 \mathrm{~g} / \mathrm{L} \mathrm{H}_{2} \mathrm{SO}_{4}$ & 2,43 & 7,2 \\
\hline & $135^{\circ} \mathrm{C}-45 \mathrm{~min}-9,2 \mathrm{~g} / \mathrm{L} \mathrm{H}_{2} \mathrm{SO}_{4}$ & 1,96 & 7,7 \\
\hline & $\mathbf{E} \mathbf{V}^{\mathbf{c}}$ & & \\
\hline \multirow{3}{*}{$\begin{array}{c}\text { Con tratamiento alcalino } \\
\text { previo }\end{array}$} & $180^{\circ} \mathrm{C}-5 \mathrm{~min}-3 \% \mathrm{H}_{2} \mathrm{SO}_{4}$ & 2,73 & 6,8 \\
\hline & $200^{\circ} \mathrm{C}-5 \mathrm{~min}-3 \% \mathrm{H}_{2} \mathrm{SO}_{4}$ & 3,32 & 5,2 \\
\hline & $190^{\circ} \mathrm{C}-7,5 \mathrm{~min}-2 \% \mathrm{H}_{2} \mathrm{SO}_{4}$ & 2,95 & 8,2 \\
\hline Sin tratamiento alcalino & $190^{\circ} \mathrm{C}-7,5 \mathrm{~min}-0,75 \% \mathrm{H}_{2} \mathrm{SO}_{4}$ & 2,72 & 7,0 \\
\hline
\end{tabular}

${ }^{\mathrm{a}} \mathrm{Sc}=$ severidad combinada del tratamiento ácido

${ }^{\mathrm{b}}$ HAD: Hidrólisis ácida diluida

${ }^{\mathrm{c}} \mathrm{EV}$ : Explosión de vapor.

La figura IV.30 muestra la variación del rendimiento de vainillina con respecto a la severidad del tratamiento aplicado. A medida que aumenta la severidad combinada del tratamiento el rendimiento de vainillina disminuye. A partir de una severidad combinada mayor a 1,5 los cambios que se producen en el rendimiento de vainillina no son tan significativos. Se podría suponer que la condensación de la lignina a severidades mayores no aumenta significativamente. 


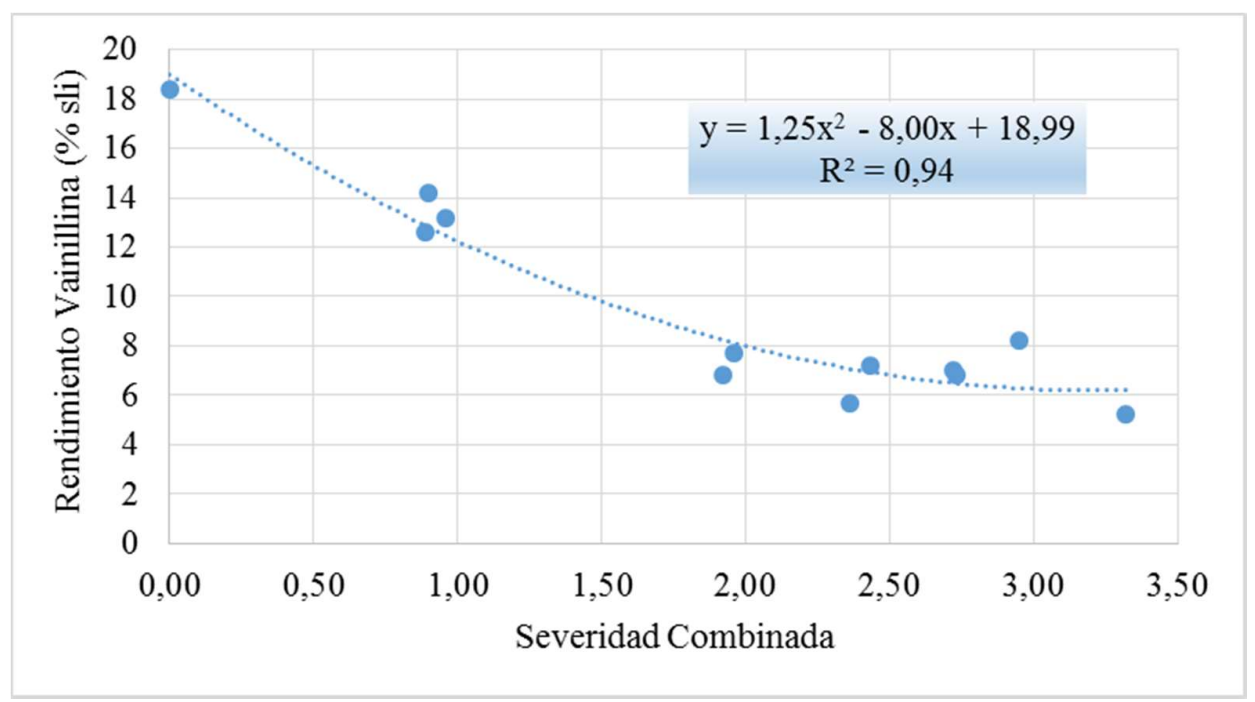

Figura IV.30. Variación del rendimiento de vainillina obtenida por oxidación con nitrobenceno con la severidad combinada del pretratamiento ácido aplicado

\section{IV.2.3.2 Cambios en la estructura del aserrín durante el fraccionamiento}

La microscopía electrónica de barrido permite observar la arquitectura fibrilar de la superficie de las fibras. La secuencia de fraccionamiento aplicada al aserrín puede afectar la estructura de la biomasa debido a que solubiliza o altera las hemicelulosas y la lignina, y modifica el área superficial disponible y la porosidad. La morfología de la biomasa antes y después de los tratamientos aplicados puede ser observada en las imágenes obtenidas mediante microscopía electrónica de barrido en la figura IV.31.

La imagen (a) corresponde al aserrín original y se observa que las células están bien estructuradas y que las fibras están íntimamente conectadas. Posterior al tratamiento alcalino (b) se aprecia que las fibras están en algunas partes separadas y que las puntuaciones están más expuestas. En las fotografías de las muestras tratadas con ácido diluido (c y d) no se aprecian cambios significativos en la estructura de la biomasa. Las muestras que exhiben una mayor diferencia son aquellas que fueron tratadas con explosión de vapor (e y f). En las imágenes se puede observar que el material está más desestructurado. La ruptura de las fibras está relacionado el efecto de la descompresión brusca producida en esta etapa, la alta temperatura utilizada y con la mayor remoción de hemicelulosas. 

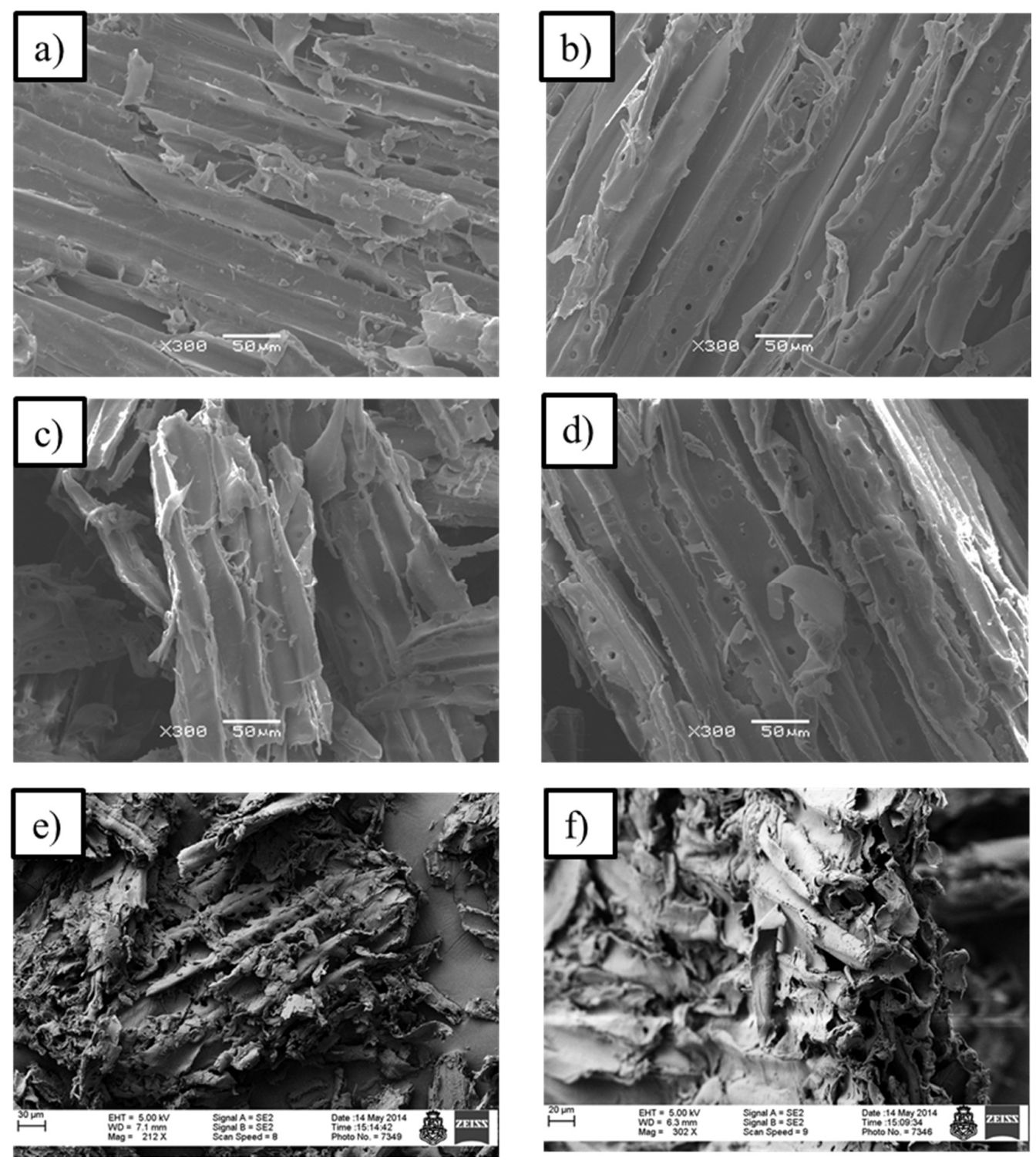

Figura IV.31. Imágenes obtenidas con Microscopio Electrónico de barrido. a) Aserrín Forestal Eldorado sin tratamiento. b) Aserrín pre-extraído con álcali $\left(90^{\circ} \mathrm{C}-60 \mathrm{~min}-5 \% \mathrm{NaOH}\right.$ bs). c) Aserrín tratado con ácido diluido $\left(150^{\circ} \mathrm{C}-7,5 \mathrm{~g} / \mathrm{L} \mathrm{H}_{2} \mathrm{SO}_{4}-30 \mathrm{~min}\right)$. d) Aserrín pre-extraído en álcali $\left(90^{\circ} \mathrm{C}-60 \mathrm{~min}-5 \% \mathrm{NaOH}\right.$ bs $)$ y con ácido diluido $\left(150^{\circ} \mathrm{C}-7,5 \mathrm{~g} / \mathrm{L} \mathrm{H}_{2} \mathrm{SO}_{4}-30 \mathrm{~min}\right)$. e) Aserrín pre-extraído en álcali $\left(90^{\circ} \mathrm{C}-60 \mathrm{~min}-5 \% \mathrm{NaOH}\right.$ bs $)$ y con explosión de vapor $\left(200^{\circ} \mathrm{C}-\right.$ $3 \% \mathrm{H}_{2} \mathrm{SO}_{4}$ bs $\left.-5 \mathrm{~min}\right)$. f) Aserrín con explosión de vapor $\left(190^{\circ} \mathrm{C}-0,75 \% \mathrm{H}_{2} \mathrm{SO}_{4}\right.$ bs $\left.-7.5 \mathrm{~min}\right)$. 


\section{IV.2.4 BALANCE DE MASA DE LA SECUENCIA DE FRACCIONAMIENTO}

En la Figura IV.32 se muestra el balance de masa detallado de la secuencia de fraccionamiento completa con a) hidrólisis ácida diluida y b) explosión de vapor más una etapa de hidrólisis enzimática. Los balances se basaron en $100 \mathrm{~g}$ iniciales de aserrín de pino elliottii seco. La fracción "otros" corresponde a componentes que no han sido cuantificados como productos de degradación y a diferencias correspondientes al error experimental.

La hidrólisis ácida diluida se realizó utilizando aserrín procedente del aserradero Forestal Eldorado mientras que en el tratamiento EV se utilizó el aserrín de Forestal AM, por lo tanto, la composición química de la materia prima es ligeramente diferente.

Posterior a la etapa alcalina, el material está libre de acetilos y muestra un bajo contenido de extractivos. Los carbohidratos que son extraídos en esta etapa no pueden ser aprovechados como azúcares debido a que en medio alcalino se transforman en hidróxiacidos. Estos compuestos podrían ser recuperados para la producción de ácido láctico, detergentes, cosméticos, polímeros y resinas, plastificantes y surfactantes, furanos, etc.

Luego de aplicar la etapa ácida se obtiene una fracción sólida compuesta por celulosa y lignina, y una fracción líquida compuesta principalmente por azúcares y productos de degradación. Las hexosas (glucosa y manosa) son el componente mayoritario de la fracción líquida. La mayor parte de la lignina permanece remanente en la fracción sólida residual de la HE.

La hidrólisis enzimática es más eficiente para el aserrín tratado con EV que en el caso de HAD, sin embargo continúa siendo poco eficiente. Como ya se mencionó anteriormente, la posible causa de este bajo rendimiento es la lignina, indicando la necesidad de una etapa adicional que permita obtener un material más accesible al ataque enzimático. 


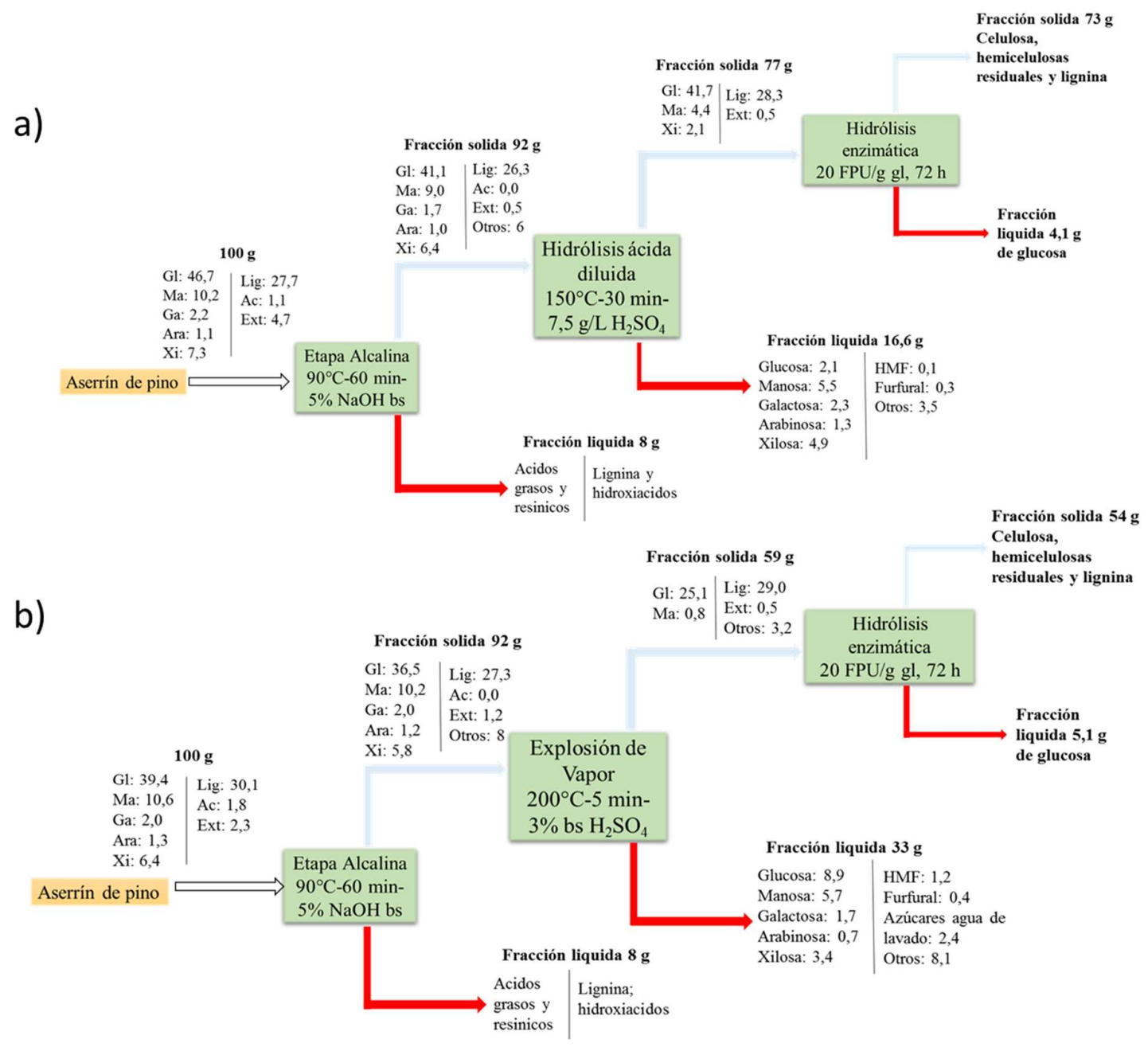

Figura IV.32 Balance de masa de la secuencia de fraccionamiento a) hidrólisis ácida diluida b)

explosión de vapor más una etapa de hidrólisis enzimática. (Gl:glucanos; Ma:mananos;

Ga:galactanos; Ara: arabinanos; Xi: xilanos; Lig: lignina; Ac: acetilos; Ext: extractivos)

La cantidad de hemicelulosas y celulosa en la fracción sólida y líquida, ya sea en forma monómerica u oligomérica, indica la eficiencia global de fraccionamiento del proceso, ya que en los procesos de fraccionamiento se pretende no solo separar los componentes de manera selectiva, sino obtenerlos en una forma utilizable para su posterior aprovechamiento. La recuperación de estos productos implica etapas posteriores de separación y purificación de los mismos. El rendimiento obtenido posterior a estas etapas indicaría el verdadero rendimiento de recuperación de los componentes de la biomasa. En esta sección, el rendimiento de recuperación se refiere a la cantidad de glucanos, xilanos, mananos, galactanos y arabinanos que se obtiene como azúcares u oligómeros en el fraccionamiento y se calcula a partir de la ecuación III.11. Los rendimientos de recuperación de los carbohidratos del aserrín en la fracción líquida y la fracción sólida se indican 
en la Tabla IV.26 expresados como porcentaje de polímero con respecto al contenido en el aserrín inicial. El rendimiento de recuperación de glucanos representa el equivalente a la cantidad de glucosa liberada después de la etapa ácida y en la subsecuente HE. El término no explicado corresponde a los errores experimentales y a los productos de degradación que no han sido cuantificados (ácido levulínico, ácido fórmico, etc).

Tabla IV.26 Rendimientos de recuperación de carbohidratos durante la secuencia de fraccionamiento.

\begin{tabular}{|c|c|c|c|c|c|c|c|c|}
\hline \multirow[b]{2}{*}{ Componente } & \multicolumn{4}{|c|}{ Hidrólisis ácida diluida } & \multicolumn{4}{|c|}{ Explosión de vapor } \\
\hline & $\begin{array}{c}\text { Fracción } \\
\text { líquida }\end{array}$ & $\begin{array}{c}\text { Fracción } \\
\text { sólida } \\
\end{array}$ & Total & $\begin{array}{c}\text { No } \\
\text { explicado }\end{array}$ & $\begin{array}{c}\text { Fracción } \\
\text { líquida }\end{array}$ & $\begin{array}{c}\text { Fracción } \\
\text { sólida }\end{array}$ & Total & $\begin{array}{c}\text { No } \\
\text { explicado }\end{array}$ \\
\hline Glucanos & 12,0 & 82,3 & 94,2 & 5,8 & 32,0 & 63,6 & 95,6 & 4,4 \\
\hline Xilanos & 60,4 & 26,6 & 87,0 & 13,0 & 46,6 & 0,0 & 46,6 & 53,4 \\
\hline Galactanos & 100 & 0,0 & 100 & 0,0 & 77,6 & 0,0 & 77,6 & 22,4 \\
\hline Arabinanos & 100 & 0,0 & 100 & 0,0 & 46,7 & 0,0 & 46,7 & 53,3 \\
\hline Mananos & 48,6 & 39,9 & 88,5 & 11,5 & 48,6 & 7,2 & 55,9 & 44,1 \\
\hline
\end{tabular}

La glucosa es recuperada principalmente en la fracción sólida como celulosa luego de aplicar ambos procesos. Debido a las condiciones más severas utilizadas en el tratamiento EV, la recuperación de glucanos en el licor es mayor (32\%). La hidrólisis de la celulosa cristalina requiere temperaturas del orden de los $200-240^{\circ} \mathrm{C}$ (Wyman, 1994).

La recuperación de arabinanos y galactanos fue completa en la fracción líquida en la HAD. El rendimiento de recuperación de manosa fue del $50 \%$ y el de xilosa del $60 \%$ en el licor posterior a la HAD. Este resultado es similar al obtenido por Alvarez-Vasco que aplicó HAD a chips de abeto Douglas pero en condiciones más agresivas (Alvarez Vasco et al., 2015). Es importante resaltar que este autor alcanzó un rendimiento de extracción de hemicelulosas de $100 \%$, pero el rendimiento de recuperación de las mismas como azúcares es similar al obtenido en este trabajo. Es decir, con severidades más altas se extraen más hemicelulosas pero la recuperación es menor debido a la degradación de azúcares.

La recuperación de mananos en el licor es la misma para ambos materiales. En la EV, el rendimiento de recuperación de manosa fue del 50\% y el de xilosa del $47 \%$. Nguyen et al obtuvo rendimientos de recuperación similares en el tratamiento EV de chips de abeto Douglas y pino con una SC igual a $3\left(0,4 \%\right.$ bs $\left.\mathrm{H}_{2} \mathrm{SO}_{4} ; 201^{\circ} \mathrm{C} ; 5,1 \mathrm{~min}\right)$. El rendimiento de recuperación de mananos fue de $57 \%$, el de xilanos $60 \%$ y el de glucanos fue de $20 \%$ (Nguyen et al., 1998). 
Para el caso de la explosión de vapor, la recuperación global de hemicelulosas es considerablemente menor que en la HAD. Los rendimientos de extracción del tratamiento EV son mayores indicando que la degradación de azúcares es mucho mayor en el tratamiento EV si la recuperación es menor. La fracción no identificada (no explicado) en el licor de la explosión de vapor es mayor sugiriendo que las hemicelulosas y celulosas que han sido extraídas pero que no son cuantificadas en el licor han sido degradadas a otros productos, diferentes a HMF y furfural. A su vez, el error experimental del proceso EV es mayor debido a que se llevó a cabo a escala piloto y la manipulación del material en esta escala fue más complicado.

En general, las condiciones más severas de pretratamiento favorecen la extracción de hemicelulosas y la digestibilidad de la celulosa, pero la recuperación de hemicelulosas en el licor es menor debido a las reacciones de degradación. Por ejemplo en el ensayo llevado a cabo en este trabajo con explosión de vapor a $180^{\circ} \mathrm{C}$, por 5 min y $3 \% \mathrm{H}_{2} \mathrm{SO}_{4}$ (Ensayo 5) la recuperación total fue del $100 \%$ de glucanos, $85 \%$ de xilanos y $77 \%$ de mananos que es considerablemente mayor al obtenido en el punto óptimo pero la extracción de hemicelulosas fue menos eficiente $(10 \%$ menos de glucanos, xilanos y mananos) y el rendimiento de la hidrólisis enzimática fue de $12 \%$. Por lo tanto, existe una relación de compromiso entre la maximización de la recuperación de las hemicelulosas y la maximización de extracción de las mismas y la digestibibilidad enzimática de la celulosa. Estos resultados están en concordancia con lo obtenido por otros autores, tanto en el estudio de la HAD (Marzialetti et al., 2008) (Alvarez Vasco et al., 2015) como en el tratamiento EV (Nguyen et al., 1998). En base a estos resultados muchos autores han evaluado la aplicación de una secuencia de explosión de vapor en dos etapas. La primera etapa en condiciones más severas $\left(170-190^{\circ} \mathrm{C}\right)$ para maximizar la recuperación de las hemicelulosas y una segunda etapa en condiciones más severas $\left(200-230^{\circ} \mathrm{C}\right)$ para atacar la celulosa y aumentar la accesibilidad del material. El rendimiento de extracción de hemicelulosas obtenida en la prime etapa es similar al obtenido en este trabajo y posterior a la segunda etapa el rendimiento de la hidrólisis enzimática es de 34-40\% (Kim, 2005) (Söderström et al., 2002).

La selección del proceso y de las condiciones a utilizarse en un esquema de fraccionamiento estará definida por el tipo de productos que se quieran obtener. Es decir, si el objetivo es la producción de productos a partir de las hemicelulosas sería conveniente utilizar condiciones intermedias para evitar la degradación de las mismas como ocurre con la hidrólisis ácida diluida. Por otro lado si se busca la producción de glucosa, la explosión de vapor resulta más adecuada dado los mayores rendimientos en la hidrólisis enzimática. Sin embargo, se requieren de tratamientos posteriores para aumentar la accesibilidad del material.

La fracción líquida de la hidrólisis ácida diluida tiene gran potencial para la producción de bioetanol mediante fermentación debido al bajo contenido de productos de degradación que son 
inhibitorios de las levaduras. El licor de la explosión podría ser utilizado para la producción de ácidos orgánicos como el ácido levulínico que se produce mediante la degradación controlada de las hexosas (deshidratación).

\section{IV.2.5 DESLIGNIFICACIÓN}

Debido a que la fracción sólida obtenida de la explosión de vapor tuvo una mejor respuesta a la HE y en vistas a la producción de bioetanol se evaluó una etapa de deslignificación con el objetivo de extraer la lignina para verificar si se mejora el rendimiento de la hidrólisis enzimática. Se evaluaron cuatro procesos deslignificantes: soda/antraquinona (Soda/AQ), organosolv alcalino, peróxido de hidrógeno alcalino y oxígeno alcalino. Los tratamientos se aplicaron al sólido tratado en condiciones óptimas, es decir, los materiales tratados en las siguientes condiciones: alcalino $\left(90^{\circ}-60 \mathrm{~min}-5 \mathrm{~g} / \mathrm{L} \mathrm{NaOH}\right)-\mathrm{EV}\left(200^{\circ} \mathrm{C}-5 \mathrm{~min}-3 \% \mathrm{H}_{2} \mathrm{SO}_{4}\right)$ codificado como APA-EV, cuya composición química se indica en la Tabla IV.20 de la sección IV.2.3.2.1. El proceso Soda/AQ también se llevó a cabo sobre el sólido resultante de la secuencia: etapa alcalina ( $90^{\circ}-60 \mathrm{~min}-5$ $\mathrm{g} / \mathrm{L} \mathrm{NaOH})-\mathrm{HAD}\left(150^{\circ} \mathrm{C}-30 \mathrm{~min}-7,5 \mathrm{~g} / \mathrm{L} \mathrm{H}_{2} \mathrm{SO}_{4}\right)$ llamado APA-HAD cuya composición química se indica en la Tabla IV.12 de la sección IV.2.2.1.4.

\section{IV.2.5.1 Deslignificación Soda/AQ}

Los materiales tratados en las siguientes condiciones: alcalino ( $\left.90^{\circ}-60 \mathrm{~min}-5 \mathrm{~g} / \mathrm{L} \mathrm{NaOH}\right)-\mathrm{HAD}$ ( $150^{\circ} \mathrm{C}-30$ min-7,5 g/ $\mathrm{L} \mathrm{H}_{2} \mathrm{SO}_{4}$ ) llamado APA-HAD y alcalino (90 $\left.{ }^{\circ}-60 \mathrm{~min}-5 \mathrm{~g} / \mathrm{L} \mathrm{NaOH}\right)-\mathrm{EV}$ $\left(200^{\circ} \mathrm{C}-5\right.$ min- $\left.3 \% \mathrm{H}_{2} \mathrm{SO}_{4}\right)$ codificado como APA-EV fueron sometidos a una etapa de deslignificación alcalina con $\mathrm{NaOH}$ y antraquinona.

Las condiciones de cocción se establecieron de acuerdo con un trabajo de optimización de deslignificación Soda/AQ de este mismo aserrín de pino (Imlauer et al., 2014) y corresponden a un Factor $\mathrm{H}$ de $3850\left(170^{\circ} \mathrm{C}, 140 \mathrm{~min}\right)$, carga alcalina de $28 \%$ bs $\mathrm{NaOH}$ y $0,11 \%$ bs (sobre base seca) de antraquinona. En la Tabla IV.27 se indican los puntos ensayados, los rendimientos obtenidos, el contenido de lignina inicial y residual y el grado de deslignificación alcanzado. También se utilizaron como referencia los resultados de la aplicación de este proceso a aserrín de pino sin pretratamiento obtenidos por Imlauer et al. 
El rendimiento alcanzado en estos procesos fue de 55,2\% para el aserrín pretratado con HAD y de $42,5 \%$ para el material tratado con EV. Es decir, que aproximadamente el 50\% del aserrín en esta etapa fue solubilizado.

Tabla IV.27 Materiales deslignificados con Soda/AQ, rendimiento de la etapa de deslignificación, lignina en el material inicial sobre base seca (\% bs), lignina residual sobre base inicial (\% sbi) y grado de deslignificación como porcentaje.

\begin{tabular}{|l|c|c|c|c|}
\hline Material & $\begin{array}{c}\text { Rendimiento } \\
(\mathbf{\%})\end{array}$ & $\begin{array}{c}\text { Lignina } \\
\text { inicial (\%) } \\
\text { bs) }\end{array}$ & $\begin{array}{c}\text { Lignina } \\
\text { Residual (\% } \\
\text { sbi) }\end{array}$ & $\begin{array}{c}\text { \% } \\
\text { Deslignificación }\end{array}$ \\
\hline Aserrín original & 42,20 & 27,70 & 1,70 & 93,86 \\
\hline APA-HAD & 55,20 & 38,53 & 21,27 & 44,80 \\
\hline APA-EV & 42,48 & 42,40 & 19,77 & 53,37 \\
\hline
\end{tabular}

El proceso produjo un elevado grado de deslignificación en el aserrín original. Sin embargo, la remoción de lignina de los materiales sometidos a etapas de pretratamiento fue significativamente menor. La deslignificación del material tratado con EV fue casi 10\% superior a la deslignificación del tratamiento con HAD. Durante los pretratamientos se producen reacciones de condensación de la lignina que la hacen menos reactivas y por lo tanto se dificulta su posterior extracción. Este resultado indicaría que la lignina es menos reactiva luego de la HAD que posterior a un tratamiento EV.

En la Figura IV.33 se indica la composición química de las pulpas obtenidas y del aserrín original. El contenido de hemicelulosas es bajo y más aún en el caso de los aserrines que fueron sometidos a un tratamiento ácido de extracción de hemicelulosas. En la figura se aprecia que la pérdida de glucanos que se produce en esta etapa es significativa. A su vez, si se compara la composición del aserrín solamente deslignificado con el deslignificado y pretratado con EV (APA-EVSoda/AQ), el contenido de glucanos de este material es mayor debido a que en la etapa ácida se produce depolimerización de la celulosa que luego es más susceptible de solubilizarse durante el proceso alcalino de deslignificación. El material sometido a HAD mostró un comportamiento diferente a los otros materiales indicando el grado de recalcitrancia del mismo hacia la deslignificación. Es interesante notar que la solubilización de celulosa fue a su vez inferior. Este resultado estaría en concordancia con lo reportado por Reguant at al. quienes encontraron que a mayor severidad del pretratamiento el grado de deslignificación alcanzado durante el proceso Soda/AQ es mayor (Reguant et al., 1997). 


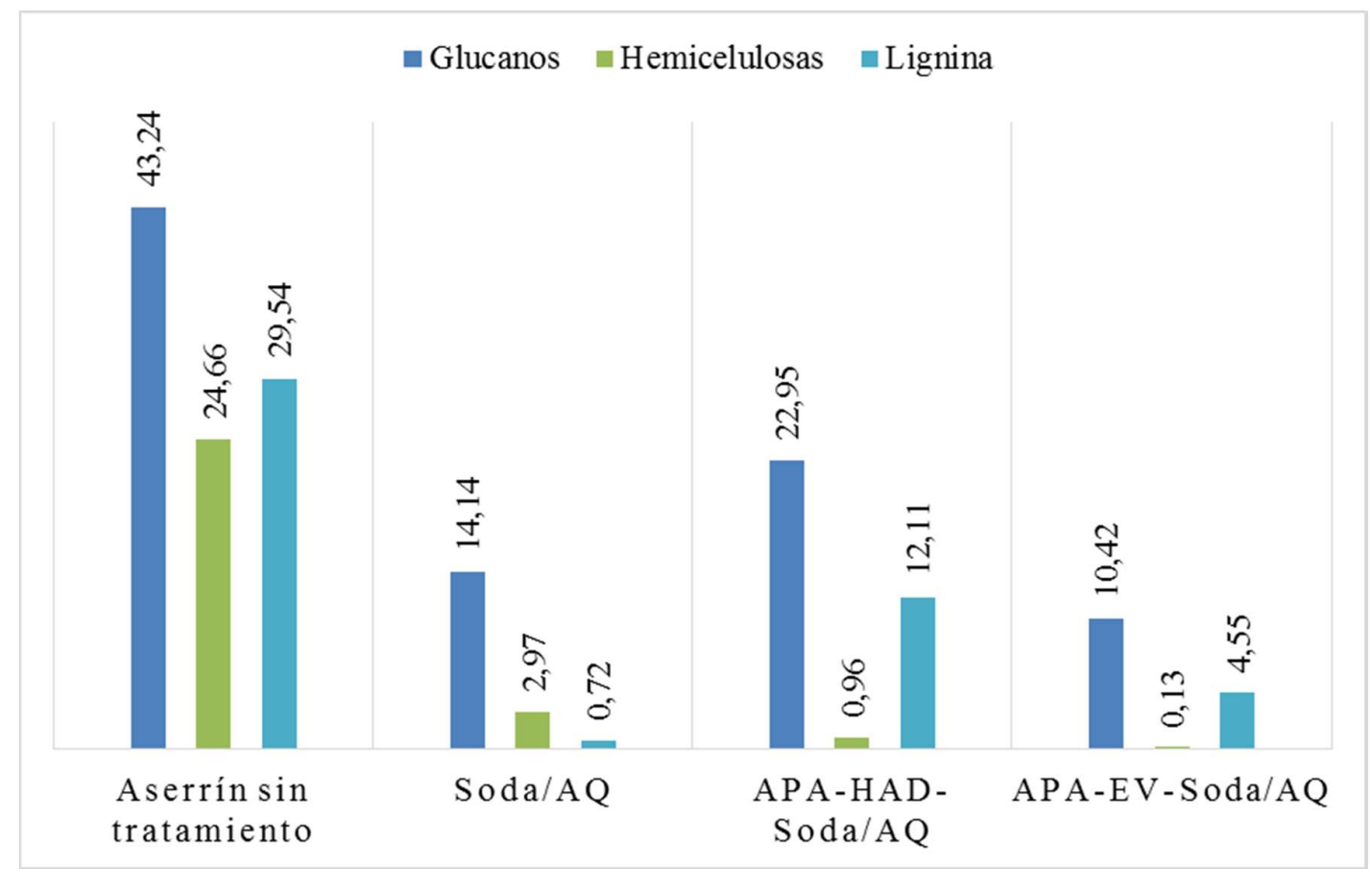

Figura IV.33. Composición química de química del aserrín original y de las pulpas obtenidas con el proceso de deslignificación Soda/AQ (expresado como \% sobre aserrín inicial).

El proceso Soda/AQ permite obtener una celulosa de alta pureza pero el rendimiento de recuperación es muy bajo, 33\% para el aserrín con solo una etapa de deslignificación, $60 \%$ para el aserrín tratado bajo la secuencia HAD-Soda/AQ y 24\% para el tratado con explosión de vapor.

\section{IV.2.5.2 Deslignificación Organosolv alcalino}

El material fibroso resultante del punto óptimo de la secuencia APA-EV fue sometido a una etapa de deslignificación con una mezcla etanol-agua en medio alcalino. Las condiciones se seleccionaron de acuerdo a un trabajo previo de optimización del tratamiento organosolv de este aserrín de pino elliottii: relación etanol-agua de $23 / 77$ y $28 \%$ bs de hidróxido de sodio, a $170^{\circ} \mathrm{C}$, por $140 \mathrm{~min}$ (Kruyeniski et al.,2015).

En la Tabla IV.28 se indican los puntos ensayados, los rendimientos obtenidos, el contenido de lignina inicial y residual y el grado de deslignificación alcanzado. También se utilizó como referencia los resultados obtenidos por Imlauer et al. de la aplicación de este proceso a este aserrín de pino sin pretratamiento (Imlauer et al., 2015). 
Tabla IV.28 Rendimiento de la etapa organosolv alcalino, lignina del material inicial (\% bs, sobre base seca), lignina residual (\% sbi, sobre base inicial) y grado de deslignificación como porcentaje.

\begin{tabular}{|l|c|c|c|c|}
\hline \multicolumn{1}{|c|}{ Material } & $\begin{array}{c}\text { Rendimiento } \\
(\%)\end{array}$ & $\begin{array}{c}\text { Lignina inicial } \\
\text { (\% bs) }\end{array}$ & $\begin{array}{c}\text { Lignina } \\
\text { Residual (\% } \\
\text { sbi) }\end{array}$ & \% Deslignificación \\
\hline Aserrín original & 41,4 & 30,1 & 3,35 & 88,9 \\
\hline APA-EV & 42,2 & 42,4 & 18,1 & 57,4 \\
\hline
\end{tabular}

El grado de deslignificación alcanzado fue similar al obtenido mediante el proceso Soda/AQ. Al igual que lo que ocurría en con el proceso Soda/AQ, el material pretratado resultó más difícil de deslignificar probablemente debido a la condensación durante el tratamiento ácido.

Imlauer et al estudiaron el fraccionamiento de chips de pino radiata mediante la combinación de explosión de vapor (autohidrólisis) y deslignificación organosolv (etanol:agua sin adición de álcali). El rendimiento de deslignificación obtenido fue inferior al obtenido en este trabajo (37,2\% en la etapa organosolv) y al igual que lo que sucedía con el proceso Soda/AQ a mayor severidad del pretratamiento el material resultó más fácil de deslignificar en el subsecuente tratamiento de deslignificación (Imlauer et al., 2015). El menor rendimiento obtenido probablemente esté relacionado a que el proceso de deslignificación se llevó a cabo sin la adición de un catalizador.

En la Figura IV.34 se indica a modo de comparación la composición química del aserrín original y del aserrín tratado bajo la secuencia: desresinación alcalina-explosión de vapor-organosolv alcalino. El material pretratado está prácticamente libre de hemicelulosas y el contenido de lignina es bajo pero la pérdida de glucanos en la etapa de deslignificación es significativa ( $74 \%$ de remoción de glucanos).

En conclusión, con el proceso se consigue un alto grado de deslignificación pero la pérdida de celulosa es demasiado elevado. 


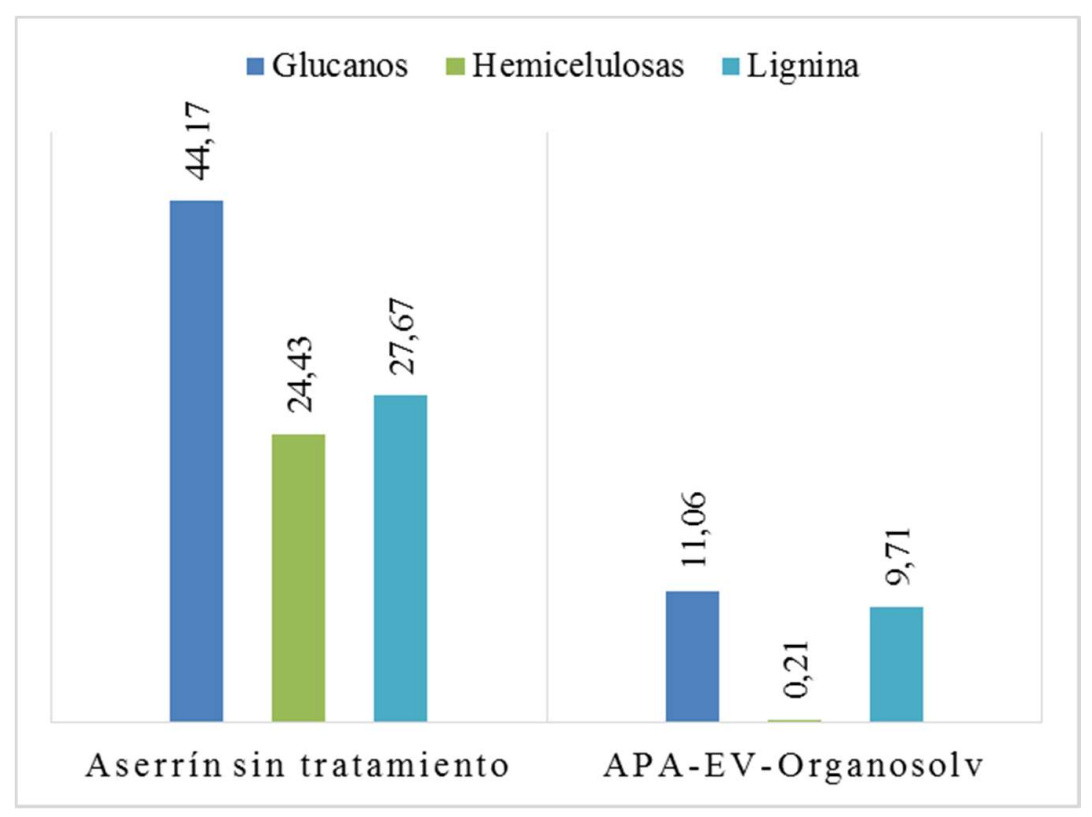

Figura IV.34. Composición química del aserrín original y de la pulpas obtenida con el proceso organosolv (expresado como \% sobre aserrín inicial).

\section{IV.2.5.3 Deslignificación con Peróxido de Hidrógeno alcalino}

El tratamiento con peróxido alcalino ha sido reportado como un proceso altamente efectivo en la remoción de lignina y que produce una mejora de la hidrólisis enzimática de varias coníferas pretratadas con vapor (Maekawa, 1996), (Yang et al., 2002), (Schwald et al., 1989). El material resultante de la explosión de vapor fue sometido a una etapa con peróxido de hidrógeno alcalino para aumentar la digestibilidad de los materiales pre-tratados. El tratamiento se llevó a cabo a $90^{\circ} \mathrm{C}$ ajustando el $\mathrm{pH}$ con $\mathrm{NaOH}$ a un valor de 11,5, variando la carga de peróxido de hidrógeno y el tiempo como se aprecia en la tabla IV.29. A su vez, en esta tabla se indican el rendimiento, la composición química del material sólido (expresado como \% sobre aserrín inicial), el porcentaje de deslignificación alcanzado y el peróxido de hidrógeno presente en el licor posterior al tratamiento y el $\mathrm{pH}$. La deslignificación fue calculada considerando el contenido inicial de lignina del material sometido a esta etapa $(49,86 \%)$. 
Tabla IV.29 Tratamiento con peróxido alcalino del material APA-EV: condiciones, rendimiento, composición química (expresada como \% sobre madera inicial) y características del licor $\left(\% \mathrm{H}_{2} \mathrm{O}_{2}\right.$ residual y $\mathrm{pH}$ final)

\begin{tabular}{|c|c|c|c|c|c|c|c|c|c|}
\hline \multicolumn{2}{|c|}{} & \multicolumn{2}{|c|}{ Composición del sólido } & \multicolumn{2}{|c|}{ Características del licor } \\
\hline Ensayo & $\begin{array}{c}\mathbf{H}_{\mathbf{2}} \mathbf{O}_{\mathbf{2}} \\
\mathbf{( \%} \text { bs) }\end{array}$ & $\begin{array}{c}\text { Tiempo } \\
\text { (min) }\end{array}$ & Rendimiento & Glucanos & Hemicelulosas & $\begin{array}{c}\text { Lignina } \\
\text { Residual }\end{array}$ & $\begin{array}{c}\text { \% } \\
\text { Deslignifica-a } \\
\text { ción }\end{array}$ & $\begin{array}{c}\mathbf{H}_{\mathbf{2}} \mathbf{O}_{2} \\
\text { residual en } \\
\text { el licor (\%) }\end{array}$ & pH \\
\hline 1 & 5 & 60 & 94,7 & 46,5 & 2,42 & 42,7 & 14,4 & 0,99 & 8,04 \\
\hline 2 & 10 & 60 & 94,4 & 44,6 & 2,68 & 42,4 & 15,1 & 2,67 & 7,91 \\
\hline 3 & 5 & 120 & 96,2 & 44,0 & 1,74 & 43,4 & 13,0 & 0,99 & 8,11 \\
\hline 4 & 10 & 120 & 95,4 & 39,8 & 1,71 & 42,1 & 15,6 & 1,06 & 8,47 \\
\hline
\end{tabular}

En las condiciones estudiadas los factores no tienen influencia significativa ni en la composición química ni en el grado de deslignificación. Es decir, que los rendimientos obtenidos en los distintos ensayos no fueron significativamente diferentes. En general, se logró un rendimiento de deslignificación de 15\% aproximadamente. La degradación de glucanos y hemicelulosas no fue significativa en estas condiciones. La aplicación del tratamiento con peróxido alcalino a chips de abeto Douglas a $180^{\circ} \mathrm{C}$ con $4 \%$ de $\mathrm{H}_{2} \mathrm{O}_{2}$ durante 60 min alcanzó un rendimiento de deslignificación de $22 \%$ causando una pequeña degradación de celulosa (Alvarez-Vasco et al., 2013). Este resultado indicaría que tal vez se podría llevar a cabo el tratamiento a una temperatura más alta mejorando la deslignificación del aserrín sin afectar significativamente la celulosa.

Cuando en la explosión de vapor se utiliza dióxido de azufre como catalizador en lugar de ácido sulfúrico se consiguen mejores resultados en el post tratamiento con peróxido de hidrógeno. Por ejemplo, el tratamiento con peróxido alcalino de abeto Douglas pretratado (impregnado con $\mathrm{SO}_{2}$ y explosión de vapor) con una carga de peróxido de hidrógeno de $1 \% \mathrm{p} / \mathrm{p} \mathrm{a} 80^{\circ} \mathrm{C}$ por $45 \mathrm{~min}$ a $\mathrm{pH}$ 11,5 permitió solubilizar más del 90\% de la lignina residual e hidrolizar la fracción celulósica obtenida completamente a las 48 horas con una carga enzimática de $20 \mathrm{FPU} / \mathrm{g}$ de celulosa (Yang et al., 2002).

\section{IV.2.5.4 Deslignificación con oxígeno alcalino}

La deslignificación con oxígeno es ampliamente utilizada en la industria de la pulpa y el papel como etapa deslignificante intermedia entre el pulpado y el blanqueo. No se han encontrado muchos trabajos relacionados al estudio de la aplicación de este proceso a materiales con alto contenido de lignina, como los sustratos obtenidos posterior a la explosión de vapor. El tratamiento con oxígeno fue aplicado a la fracción sólida resultante del tratamiento EV. En este 
caso, las condiciones ensayadas fueron seleccionadas de datos bibliográficos (Pan et al., 2004). Se trabajó con una carga alcalina de $15 \%$, consistencia de $10 \%$ y $0,1 \%$ de $^{\mathrm{MgSO}_{4}}$ con un tiempo de residencia de 2 horas, temperatura de $100^{\circ} \mathrm{C}$, manteniendo la presión de $\mathrm{O}_{2}$ a $6 \mathrm{Kg} / \mathrm{cm}^{2}$. En la Tabla IV.30 se indica el rendimiento de la etapa, la composición química y el grado de deslignificación obtenido.

Tabla IV.30. Rendimiento y composición química del aserrín tratado con oxígeno en medio alcalino.

\begin{tabular}{|c|c|c|c|c|}
\hline Rendimiento & Glucanos & Hemicelulosas & $\begin{array}{c}\text { Lignina } \\
\text { Residual }\end{array}$ & $\begin{array}{c}\% \\
\text { Deslignifica- } \\
\text { ción }\end{array}$ \\
\hline 68,65 & 32,74 & 1,21 & 30,33 & 39,17 \\
\hline
\end{tabular}

Como se observa en la Tabla IV.30 se obtuvo un alto grado de deslignificación mientras que la pérdida de glucanos fue del $23 \%$ que es baja en comparación a lo obtenido con los procesos Soda/AQ y organosolv. Los resultados obtenidos en esta etapa son similares a los obtenidos por Pan et al. en las mismas condiciones (Pan et al., 2004).

Ek et al. encontraron que la aplicación de una etapa de pre-hidrólisis de las hemicelulosas es beneficiosa en la etapa posterior de deslignificación con oxígeno por la modificaciones que se producen en las uniones lignina-carbohidratos como resultado de la extracción de las hemicelulosas (Ek et al., 2014).

La deslignificación con oxígeno es afectada por varios parámetros incluyendo la carga alcalina, la temperatura, la consistencia, el tiempo de reacción y la presión de oxígeno (Charles, 2002). Por ejemplo, un incremento en la temperatura y de la carga alcalina podría incrementar el grado de deslignificación, sin embargo hay un incremento simultáneo del riesgo en la degradación de celulosa (Pan et al., 2004). Por lo tanto, esta etapa es susceptible de optimización para encontrar las condiciones que maximicen la extracción de lignina sin afectar mayormente a la celulosa en el caso del aserrín de pino tratado mediante el tratamiento de explosión de vapor. 


\section{IV.2.5.5 Hidrólisis Enzimática de Materiales Deslignificados}

Según se ha reportado, la remoción de lignina mejora la accesibilidad de la celulosa y reduce las uniones no productivas de las enzimas y en consecuencia el rendimiento de la hidrólisis enzimática aumenta (Yang et al., 2011). Con el objetivo de evaluar el efecto de la lignina, los materiales deslignificados fueron sometidos a hidrólisis enzimática por $72 \mathrm{~h}$ con una concentración de enzimas de 20 FPU/g de glucanos (Figura IV.35). A modo de comparación se incluyeron en la figura los rendimientos de los materiales pretratados sin deslignificar y de un material deslignificado sin pretratamiento (Kruyeniski et al, 2014).

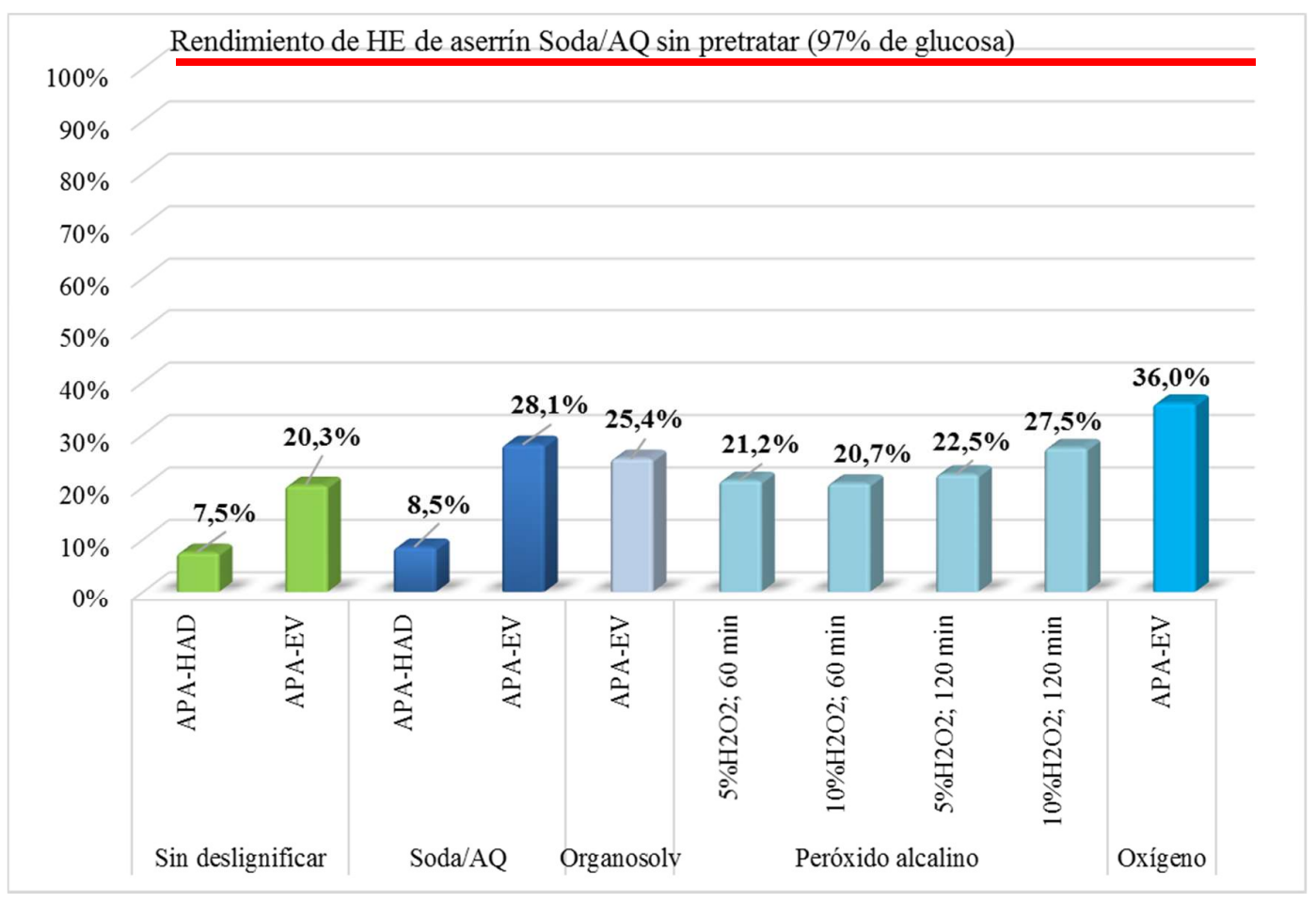

Figura IV.35. Rendimiento de la hidrólisis enzimática a las 72 horas de los materiales deslignificados y sin deslignificar.

Con la aplicación del proceso Soda/AQ al material tratado con hidrólisis ácida diluida no se produce una mejora significativa del rendimiento. A su vez, el rendimiento obtenido con este material ( $8,5 \%$ de glucanos) es muy bajo comparando con los otros materiales deslignificados con otros métodos de deslignificación. 
El rendimiento de los materiales deslignificados posterior al tratamiento EV aumentó en todos los casos. Los rendimientos alcanzados en los procesos con oxígeno y peróxido de hidrógeno resultan interesantes debido a la baja severidad utilizada en los mismos.

El máximo rendimiento (36\%) se alcanza en la HE posterior a la etapa con oxígeno a pesar del alto contenido de lignina de este material $(44,2 \%$ bs de lignina). Se ha demostrado que la lignina tiene un efecto negativo para la hidrólisis enzimática por dos motivos: disminuye la accesibilidad de la celulosa y se une irreversiblemente a las enzimas (Mansfiled et al., 1999). Por este motivo, aunque algunos pretratamientos no logran extraer la lignina, ésta se redistribuye en las fibras de forma que disminuye la adsorción de enzimas. A su vez, los grupos fenólicos libres de la lignina tienen un rol crítico en la adsorción de las enzimas ya que actúan como mediadores entre la lignina y las proteínas. Pan et al. concluyeron que como el tratamiento con oxígeno reduce el número de grupos fenólicos libres en la lignina por las reacciones de condensación, las uniones no productivas de las enzimas se ven limitadas haciendo más eficiente la hidrólisis enzimática (Pan et al., 2004).

El rendimiento de glucanos de la $\mathrm{HE}$ en los materiales tratados con peróxido de hidrógeno aumenta, alcanzándose el máximo rendimiento (27,5\%) en el ensayo $4\left(10 \% \mathrm{H}_{2} \mathrm{O}_{2}\right.$ y $\left.120 \mathrm{~min}\right)$. De la misma manera que en el caso anterior, este sustrato posee alto contenido de lignina, sugiriendo que se producen cambios físicos y químicos en la lignina que favorecen la HE. Otros autores encontraron que el fraccionamiento de abeto mediante la combinación de explosión de vapor con $\mathrm{SO}_{2}$ y peróxido de hidrógeno permite obtener elevados rendimientos de deslignificación (90\% de deslignificación) e hidrólisis enzimática (75-100\% a las 48 h con 10 FPU/g de celulosa) (Schwald et al., 1989) (Yang et al., 2002). El mayor rendimiento de la HE probablemente se debe a que el grado de deslignificación es mayor debido a la sulfonación de la lignina durante la etapa de EV. La sulfonación reduce la temperatura de transición vítrea de la lignina e incrementa su carácter hidrofílico promoviendo a su vez el ablandamiento de la lámina media y mejorando la separación de las fibras (Fardim et al., 2012).

Los procesos organosolv y Soda/AQ permiten obtener un grado de separación de lignina significativo y al mismo tiempo una mejora en el rendimiento de la HE, aunque inferior a lo obtenido con los procesos oxidativos con oxígeno y peróxido de hidrógeno. Kruyeniski et al. concluyeron que existe una correlación negativa entre el rendimiento de la HE y el contenido de lignina de materiales tratados con etanol e hidróxido de sodio (Kruyeniski et al., 2015). La deslignificación de aserrín de pino mediante el proceso Soda/AQ en las mismas condiciones utilizadas en este trabajo fue de $94 \%$ y el rendimiento de la HE de 97\% (Kruyeniski et al. 2014) (Imlauer et al., 2014). Este resultado indica el efecto negativo que tiene la lignina en la HE. 
La ventaja de los proceso de pulpado (organosolv y Soda/AQ) es que la lignina disuelta en el licor podría ser separada y utilizada para la producción de otros productos de alto valor como la vainillina pero las principales desventajas de estos procesos es la elevada pérdida de glucanos y su elevado costo. La celulosa representa casi el 50\% de la composición de la biomasa lignocelulósica, por lo que la optimización de la recuperación de este componente es de suma importancia para que una biorrefinería sea atractiva económicamente (Avellar \& Glasser, 1998).

\section{IV.2.6 PROPUESTA DE FRACCIONAMIENTO PARA EL ASERRÍN DE PINO}

En base a los resultados obtenidos en este trabajo, en la Figura IV.36 se propone un esquema simplificado de fraccionamiento de aserrín de pino en el marco de una biorrefinería forestal.

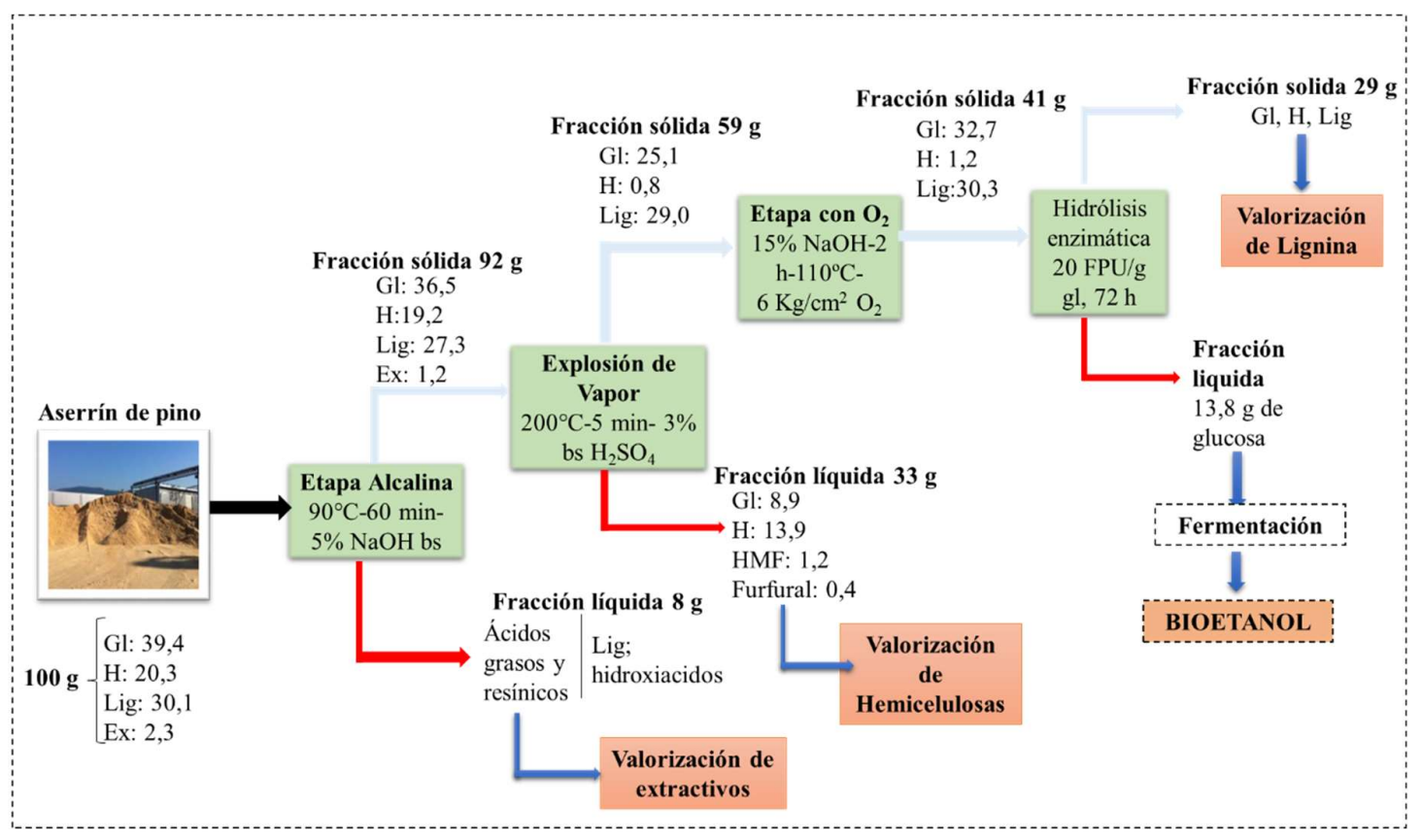

Figura IV.36. Propuesta de fraccionamiento de aserrín de pino para la producción de bioetanol

(Gl: glucanos; H: hemicelulosas; Lig: lignina; Ex: extractivos)

En síntesis, el objetivo del fraccionamiento consiste en la separación selectiva de la biomasa en sus componentes principales para su posterior valorización. La secuencia de fraccionamiento planteada en este trabajo involucra cuatro etapas: 
1. Etapa alcalina de desresinación: el objetivo de esta etapa consiste en remover los extractivos del aserrín de pino debido a que los mismos podrían causar problemas operacionales en la etapa ácida posterior y para su posterior valorización. Las condiciones que optimizan la remoción de extractivos son $90^{\circ} \mathrm{C}, 5 \%$ bs $\mathrm{NaOH}$ por $1 \mathrm{~h}(47 \%$ de remoción de extractivos). A pesar de haber obtenido buenos resultados en esta etapa, la misma puede ser optimizada. Se debería disminuir la relación licor:madera para facilitar la recuperación de extractivos, con una simultánea reducción de agua y energía. A su vez, habría que diseñar un sistema de lavado más eficiente para minimizar el efecto del álcali residual en la etapa ácida posterior (consumo de ácido en la neutralización parcial de carboxilatos de sodio y álcali remanente del lavado).

2. Explosión de vapor catalizada con $\mathrm{H}_{2} \mathrm{SO}_{4}$ : el objetivo de esta etapa consiste en extraer las hemicelulosas conservando la fracción celulósica. En este trabajo se encontró que se puede alcanzar una extracción casi completa de las hemicelulosas a $200^{\circ}, 5$ min y $3 \%$ bs $\mathrm{H}_{2} \mathrm{SO}_{4}$. La recuperación de hemicelulosas en el licor es de 50\% aproximadamente y de $64 \%$ de glucanos en la fracción sólida.

3. Tratamiento con $\mathrm{O}_{2}$ en medio alcalino: el objetivo de este tratamiento consiste en deslignificar paracialmente el material sólido pretratado para mejorar la digestibilidad enzimática, conservando la fracción celulósica. En las condiciones estudiadas se logró un porcentaje de deslignificación de 36\%, mientras que la recuperación de glucanos en la fracción sólida (celulosa) fue de $77 \%$.

4. Hidrólisis Enzimática: el objetivo de esta etapa es hidrolizar la celulosa a glucosa. El rendimiento de la hidrólisis enzimática con una concentración de enzimas de 20 FPU/g de glucanos fue de $36 \%$.

La producción de bioetanol es viable solamente si se aplica el concepto de aprovechamiento integrado o biorrefinería de la biomasa lignocelulósica, que tiene como objetivo aprovechar todos los componentes del material y no solo la celulosa. En este contexto, habría que recuperar los componentes (extractivos, hemicelulosas y lignina) que fueron disueltos en las etapas del fraccionamiento. La aplicación de esta secuencia de fraccionamiento permite obtener fracciones líquidas y sólidas constituidas por los principales componentes de la madera. A continuación se enumeran diferentes alternativas de valorización de las corrientes líquidas y sólidas obtenidas con este proceso.

Valorización de extractivos: los extractivos son recuperados en la fracción líquida como ácidos resínicos y grasos. Debido a la alta cantidad de agua utilizada, la primera etapa necesaria para el aprovechamiento de estos compuestos es la concentración del licor. Posteriormente podría utilizarse un proceso similar al utilizado en la industria de pulpa Kraft para la obtención de tall- 
oil (Hillis, 1962) (Demirbas, 2011). Como el licor está muy diluido habría que buscar otras alternativas de separación de los extractivos, como la flotación (Tanase et al., 2010). Los extractivos (ácidos resínicos y grasos) tienen potencial para la producción de productos químicos como surfactantes, adhesivos, insumos de la industria farmacéutica, de pinturas, cosmética e incluso los ácidos grasos pueden ser utilizados para biodiesel.

Valorización de hemicelulosas: las hemicelulosas son recuperadas como azúcares y productos de degradación (furfural, HMF, ácido levulínico, ácido fórmico, etc.). Una de las principales ventajas de la explosión de vapor es que se puede obtener un licor concentrado debido a la utilización de vapor directo. Existen dos alternativas de aprovechamiento de esta fracción: la vía biológica y la vía química. La vía biológica involucraría, por ejemplo, la fermentación de las hexosas para la producción de bioetanol o químicos como 1,2,4-butanotriol (Fiserova \& Opalena, 2012). La vía química consiste en la deshidratación controlada de los carbohidratos para la generación de ácidos orgánicos, como por ejemplo, el ácido levulínico (Delidovich et al., 2014).

Valorización de glucosa: la glucosa producida en la hidrólisis enzimática puede ser fermentada por levaduras para la producción de bioetanol.

$\checkmark$ Valorización de lignina: posterior a la hidrólisis enzimática se obtiene un residuo sólido rico en lignina. Este material puede ser aprovechado a través de la vía térmica o de la vía biológica. La vía térmica implica la pirolisis de este material para la producción de bio-carbón y bio-oil. El bio-carbón puede ser utilizado como combustible, como mejorador del suelo y como precursor del carbón activado. Al mismo tiempo, el bio-oil puede reemplazar fenoles derivados del petróleo en la fabricación de adhesivos, resinas y polímeros (Wild et al., 2012). Otra alternativa es la producción de pellets. Estudios sobre la producción de pellets a partir del residuo de la HE han demostrado que los pellets producidos a partir de este material tienen menor tendencia a la escoración que los pellets de madera sin pretratar y además mayor poder calorífico debido a la mayor concentración de lignina (Ohman \& Boman, 2006). Por otro lado, la vía biológica involucra el tratamiento de la lignina con enzimas capaces de oxidarla y producir un intermediario llamado polihidroxialcanoato que se utiliza en la producción de bioplásticos (Linger et al., 2014). Otra alternativa interesante es la producción de

Las características químicas de cada componente determinarán cual es la alternativa de producción más viable. Por lo tanto, estas alternativas hipotéticas requieren de estudios posteriores. 


\section{CAPÍTULO 5. \\ CONCLUSIONES}




\section{CAPÍTULO V. CONCLUSIONES}

\section{$\underline{\text { Materia prima }}$}

Para desarrollar este trabajo se utilizó aserrín de pino, uno de los residuos forestales generados en la industrialización primaria de la madera con mayor importancia en la provincia de Misiones

- Se determinó la composición química de aserrines provenientes de un aserradero del norte de Misiones (Forestal Eldorado) y de un aserradero del sur de la provincia (Forestal AM). A pesar de provenir de dos industrias diferentes, los aserrines no presentaron diferencias significativas en su composición química, que fue típica de una conífera, con un alto contenido de lignina insoluble (30\%), extractivos (4\%) y de hexosas (56\%) (valores promedios de ambas muestras).

- Las muestras de aserrín presentaron variabilidad en cuanto al contenido de corteza pero la granulometría resultó similar. La determinación granulométrica indica que la fracción que pasa aberturas de 18 mesh (P18) y queda retenida en aberturas de 40 mesh (R40), es la que se encuentra en mayor proporción con respecto a las otras fracciones. Por lo tanto, el aserrín presenta una ventaja adicional en cuanto a su granulometría ya que el tamaño inicial de partícula en los procesos de fraccionamiento es un factor importante en cuanto a la efectividad de la penetración de los reactivos y la disolución de los componentes de la madera.

\section{$\underline{\text { Remoción de extractivos }}$}

Debido a las características químicas de los extractivos de las coníferas, se decidió aplicar una etapa alcalina de desresinación previa a los tratamientos ácidos, para evitar problemas operacionales, como la formación de pitch en la posterior etapa ácida.

- En la etapa alcalina se logró extraer la mayor parte de los ácidos resínicos y grasos sin afectar significativamente los demás componentes de la madera. La concentración de álcali resultó ser el factor más influyente en la remoción de extractivos. La máxima remoción de extractivos $(90,7 \%$ sbi, sobre base inicial) se alcanzó $90^{\circ} \mathrm{C}, 1$ h y $5 \%$ de $\mathrm{NaOH}$ sobre base seca.

- La composición química del material resultante de la etapa alcalina fue $57 \%$ bs de hexosas, $8 \%$ bs de pentosas, $0,5 \%$ bs de extracticos y $29 \%$ bs de lignina.

- A pesar del alto rendimiento de extractivos obtenido, esta etapa es susceptible de optimización. Las experiencias posteriores debieran incluir relaciones líquido:sólido más bajas para facilitar la 
recuperación de los componentes del licor (extractivos y ácidos orgánicos) disminuyendo a su vez el consumo de agua y energía.

\section{$\underline{\text { Extracción de Hemicelulosas }}$}

Para la extracción de hemicelulosas se probaron dos procesamientos ácidos: una hidrólisis con ácido diluido y un tratamiento de explosión de vapor.

- La temperatura, el tiempo y la concentración resultaron significativos en la hidrólisis con ácido diluido (HAD). La etapa ácida produce un máximo en la extracción de hemicelulosas debido a la degradación de azúcares en condiciones más severas. La máxima extracción de hemicelulosas ( $57 \%$ smi, sobre madera inicial) se alcanzó a $150^{\circ} \mathrm{C}, 7,5 \mathrm{~g} / \mathrm{L} \mathrm{H}_{2} \mathrm{SO}_{4}$ y 30 min que corresponde a una severidad combinada (SC) de 2,09. En estas condiciones se obtiene un material lignocelulósico compuesto por $53 \%$ bs de hexosas, $2,43 \%$ bs de pentosas y $35 \%$ bs de lignina.

- La máxima extracción de hemicelulosas del aserrín original en la HAD (74\% sobre madera inicial) se produce en las mismas condiciones $\left(150^{\circ} \mathrm{C}, 7,5 \mathrm{~g} / \mathrm{L} \mathrm{H}_{2} \mathrm{SO}_{4}\right.$ y $\left.30 \mathrm{~min}\right)$ pero corresponde a una severidad combinada ligeramente mayor $(\mathrm{SC}=2,14)$.

- En la explosión de vapor (EV), la concentración de ácido sulfúrico y la temperatura fueron influyentes, mientras que el tiempo no resultó estadísticamente significativo. La máxima extracción de hemicelulosas ( $>$ al $90 \%$ sbi) se alcanza a $200^{\circ} \mathrm{C}, 3 \% \mathrm{H}_{2} \mathrm{SO}_{4}$ bs (sobre base seca) y 5 min, correspondientes a un factor de severidad combinada de 3,32. En estas condiciones se obtiene un material lignocelulósico compuesto por $55 \%$ bs de hexosas, $0,8 \%$ bs de pentosas y $42 \%$ bs de lignina.

- En general, en los tratamientos ácidos aplicados en las condiciones más suaves de temperatura, tiempo y concentración de ácido sulfúrico, la glucosa, xilosa, manosa y galactosa se extraen principalmente como polímeros.

- La extracción de hemicelulosas resultó más efectiva con el proceso de explosión de vapor pero a una severidad mayor. A pesar de esto, la degradación de azúcares no fue significativa en esta etapa.

- En el tratamiento ácido, el menor rendimiento de vainillina obtenido con oxidación con nitrobenceno de los materiales pretratados indicó condensación de la lignina. La condensación aumenta en las condiciones más severas de tratamiento y es mayor en los materiales resultantes de la HAD. A su vez, este rendimiento es menor para los materiales que han sido sometidos a una 
etapa de extracción alcalina previa indicando que en esta etapa se produce condensación de la lignina.

- El rendimiento de glucosa (24\% de glucosa) obtenido en la hidrólisis enzimática de los materiales tratados con explosión de vapor fue mayor que en el caso del material tratado con hidrólisis con ácido diluido (7,5\% de glucosa). La mejora de la digestibilidad enzimática de materiales tratados con explosión de vapor es atribuida a tres factores principales: el incremento de área superficial causado por la fragmentación de las fibras, el incremento de la porosidad debido a la hidrólisis y remoción de las hemicelulosas y el incremento de la porosidad debido a la redistribución de la lignina

\section{Deslignificación}

Para la deslignificación se probaron: el proceso a la soda/AQ, un proceso alcalino con etanol, un proceso alcalino con peróxido de hidrógeno y un proceso alcalino con oxígeno.

- En cuanto a la extracción de lignina, los procesos soda/AQ y organosolv alcalino fueron los más eficientes (\% de deslignificación superiores al 60\%). La desventaja de estos procesos es la gran pérdida de celulosa ( $75 \%$ de pérdida de glucanos).

- El proceso alcalino con peróxido de hidrógeno prácticamente no produjo cambios en la composición química del aserrín. El máximo grado de deslignificación alcanzado fue de 15,6\% con $10 \%$ de $\mathrm{H}_{2} \mathrm{O}_{2}$ durante dos horas.

- El proceso con oxígeno en medio alcalino permitió alcanzar una deslignificación del 39\% mientras que la pérdida de celulosa $(23 \%)$ fue baja en comparación a los procesos de deslignificación evaluados en este trabajo.

- Ambas etapas oxidativas son susceptibles de optimización para encontrar las condiciones que maximizan la extracción de lignina sin afectar mayormente a la celulosa en el caso del aserrín de pino tratado mediante el tratamiento de explosión de vapor.

- El rendimiento de los materiales deslignificados posterior a la EV aumentó en todos los casos. A pesar del alto contenido de lignina, el material tratado con oxígeno resultó con el mayor rendimiento de glucanos en la hidrólisis enzimática ( $36 \%$ a las 72 h con $20 \mathrm{FPU} / \mathrm{g}$ de glucanos). 


\section{Conclusión general}

El objetivo de este trabajo consistió en el diseño y optimización de un proceso de fraccionamiento para el aserrín de pino bajo la hipótesis de que es posible separar los componentes de este residuo aplicando procesos de fraccionamiento rentables y de baja contaminación. Dado que la producción de bioetanol es viable solamente si se aplica el concepto de aprovechamiento integrado o biorrefinería de la biomasa lignocelulósica hace necesario aprovechar todos los componentes del material y no solo la celulosa.

El fraccionamiento del aserrín de pino es complejo debido a la presencia de resina y al elevado contenido de lignina. La secuencia de fraccionamiento más adecuada para este residuo consiste en la aplicación de una etapa alcalina $\left(90^{\circ} \mathrm{C}, 1\right.$ h y $5 \%$ de $\mathrm{NaOH}$ sobre base seca) de desresinación, seguida de una etapa de explosión de vapor $\left(200^{\circ} \mathrm{C}, 3 \% \mathrm{H}_{2} \mathrm{SO}_{4}\right.$ bs y $\left.5 \mathrm{~min}\right)$ para extraer las hemicelulosas y un post tratamiento con oxígeno en medio alcalino.

En el tratamiento de explosión de vapor las hemicelulosas fueron extraídas principalmente como azúcares. Estos azúcares pueden ser concentrados y luego fermentados para la producción de bioetanol. La escasa generación de productos de degradación (furfural y HMF) y la ausencia de ácido acético, es una ventaja adicional para la fermentación ya que estos compuestos inhiben los microorganismos.

Posterior a la etapa de deslignificación con oxígeno se obtiene un material celulósico con menor contenido de lignina que es adecuado para la producción de hexosas mediante hidrólisis enzimática que posteriormente pueden ser fermentadas a bioetanol.

Los extractivos se encuentran como jabones de sodio en el licor. Los ácidos resínicos y grasos podrían ser recuperados como tall-oil crudo mediante la tecnología actualmente utilizada en la industria de pulpado Kraft. Además se podrían utilizar otras técnicas como flotación, nano y ultrafiltración e intercambio iónico. Los ácidos grasos pueden ser utilizados para la producción de biodiesel y los ácidos resínico son ampliamente utilizados en la industria de las pinturas, entre otros.

La corriente líquida que contiene las hemicelulosas hidrolizadas en la etapa de explosión de vapor (mayoritariamente hexosas) podría ser aprovechada para la producción de otros productos de alto valor como por ejemplo bioetanol (mediante concentración y fermentación) o ácidos levúlinico (mediante hidrólisis ácida o fermentación). Otra alternativa de aprovechamiento consiste en la producción de ácidos orgánicos a partir de la deshidratación controlada de los carbohidratos.

La lignina queda retenida en el residuo de la hidrólisis enzimática. Este material puede ser aprovechado a través de la vía térmica para la producción de bio-carbón y bio-oil o de la vía biológica para la producción de intermediarios utilizados en la elaboración de bioplásticos. 
En conclusión, la secuencia de fraccionamiento planteada resultó efectiva para la remoción de extractivos y hemicelulosas. Es de gran importancia poder recuperar los componentes (extractivos, hemicelulosas y lignina) que fueron disueltos en las etapas del fraccionamiento. El material lignocelulósico resultante tiene gran potencial para la producción de bioetanol dado su alto contenido de hexosas.

\section{Trabajo futuro}

- Optimización de la relación licor:madera de la etapa alcalina de desresinación para disminuir el consumo del agua del proceso.

- Optimización de la etapa de impregnación del tratamiento de explosión de vapor para disminuir la concentración de ácido sulfúrico utilizado y aumentar la homogeneidad de la reacción.

- Optimización de la etapa de oxígeno para encontrar las condiciones que maximicen la extracción de lignina aumentando el rendimiento de la hidrólisis enzimática sin afectar la fracción celulósica.

- Evaluación y diseño las etapas de separación y purificación necesarias para la recuperación de los componentes presentes en cada una de las fracciones obtenidas.

- Evaluación de las características químicas de los componentes recuperados para determinar su mejor alternativa de aprovechamiento. 


\section{REFERENCIAS BIBLIOGRÁFICAS}

1. Aguilera, J., San Martin, R. «Steam Hydrolysis of Pine ( Pinus radiata) sawdust.» Biomass 8 , 1985: 301-313.

2. Akerholm, M., Salmén, L. «Interactions between wood polymers studied by dynamic FT-IR spectroscopy.» Polymer 42, 2001: 963-969.

3. Alén, R. «Chapter 3A - Pulp Mills and Wood-Based Biorefineries.» En Industrial Biorefineries \& White Biotechnology, de Pandey, A., Hofer, R., Larroche, C., Taherzadeh, M., Nampoothiri, M., 91-126. Elsevier, 2015.

4. Alén, R. «Structure and chemical composition of wood.» En Forest Products Chemistry, de Stenius, P., 12-57. Finland: Gummerus Printing, 2000.

5. Alonso-Sande, M., Teijeiro-Osorio, D., Remuñán-López, C., Alonso, M.J. «Glucomannan, a promising polysaccharide for biopharmaceutical purposes.» European Journal of Pharmaceutics and Biopharmaceutics 72, 2009: 453-462.

6. Alvarez Vasco, C., Guo, M., Zhang, X. «Dilute Acid Pretreatment of Douglas Fir Forest Residues: Pretreatment Yield, Hemicellulose Degradation, and Enzymatic Hydrolysability.» Bioenerg. Res. 8, 2015: 42-52.

7. Anglés Neus, M., Reguant, J., Garcia Balls, R., Salvadó, J. «Characteristics of lignin obtained from steam-exploded softwood with soda/ anthraquinone pulping.» Wood Sci Technol 37, 2003: 309-320.

8. Area, M.C., Vallejos, M.E. «La biorrefinería Forestal.» En Biorrefinería a partir de residuos lignocelulósicos, de Area, M.C., Vallejos, M.E., 183. Saarbrücken, Alemania: Editorial Académica Española, 2012.

9. ArgenBio, (Consejo Argentino para la Información y el Desarrollo de la Biotecnología). «Logran switchgrass con menor contenido de lignina para la producción de bioetanol.» 2011. http://www.argenbio.org/index.php?action=notas\&note=5683 (último acceso: 12 de Septiembre de 2015).

10. Arshadi, M., Backlund, I., Geladi, P., Bergsten, U. «Comparison of fatty and resin acid composition in boreal lodgepole pine and Scots pine for biorefinery applications.» Industrial Crops and Products 49, 2013: 535- 541. 
11. Asada, C., Sasaki, C., Hirano, T., Nakamura, Y. «Chemical characteristics and enzymatic saccharification of lignocellulosic biomass treated using high-temperature saturated steam: Comparison of softwood and hardwood.» Bioresource Technology 182 , 2015: 245-250.

12. ASTM, American Society for Testing and Materials. «ASTM E11: Standard Specification for Wire Cloth and Sieves for Testing Purposes.» 1995. ftp://law.resource.org/pub/us/cfr/ibr/003/astm.e11.1995.pdf.

13. Avellar, B., Glasser,W. «Steam assisted biomass fractionation. I. Process considerations and economic evaluation.» Biomass and Bioenergy Vol. 14, No. 3, 1998: 205-218.

14. Bacovsky, D., Dallos, M., Wörgetter, M. Status of 2nd Generation Biofuels Demonstration Facilities in June 2010. Report to IEA Bionergy Task 39, 2010.

15. Baptista, C., Belgacem, N., Duarte A. «The effect of wood extractives on pulp properties of maritime pine kraft pulps.» Appita Journal Vol. 59, N4, , 2006: 311-316.

16. Barker, T. Quality by Experimental Design, 1st ed. New York: Marcel Dekker Inc, 1985.

17. Behera, S., Arora, A., Nandhagopal, N., Kumar, S. «Importance of chemical pretreatment for bioconversion of lignocellulosic biomass.» Renewable and Sustainable Energy Reviews 36, 2014: 91-106.

18. Boucher, J., Chirat,C., Lachenal, D. «Comparison Between Acid Hydrolysis and Two step Autohydrolysis form hemicellulose ethanol production.» Cellulose Chemestry and Technology 49 (3-4), 2015: 303-308.

19. Boudeur-Campbell, M., Jensen, J., Morinelly, J., Shonnard, D. «Effects of dilute acid hydrolysis conditions on total sugar yields from enzymatic hydrolysis of North Central forest feedstocks.» AIChE 100 - 2008 AIChE Annual Meeting, Conference Proceedings. Philadelphia, PA; United States, 2008.

20. Brodeur, G., Yau, E., Badal, K., Collier, J. , Ramachandran, B., Ramakrishnan, S. «Chemical and Physicochemical Pretreatment of Lignocellulosic biomass: A review.» Enzyme Research 2011, 2011: 1-17.

21. Burkhardt, S. Forest residues as a potential feedstock for a biorefinery: material balance and pretreatment strategies. Msc Thesis. University of Washington, 2010.

22. Bylin, S., Wells, T., Sun, Q., Ragauskas, A., Theliander, H. «Lignin Structure and Aggregation Behavior in a Two Component Ionic Liquid Solvent System.»Bioresources 9(4), 2014: 6002-6018. 
23. Caperos Sierra, A., Salvador Romero, A., Soria Gracía-Ochoa, F. «Extraction of wood with solvents.» TAPPI Journal, 1990: 221-224.

24. Carrasco, J., Saíz, M., Navarro, A., Soriano, P., Saez, F., Martínez, J. «Effects of Dilute Acid and Steam Explosion Pretreatments on the Cellulose Structure and Kinetics of Cellulosic Fraction Hydrolysis by Dilute Acids in Lignocellulosic Materials.» Applied Biochemistry and Biotechnology 45/46, 1994: 23-34.

25. Chacha, N., Toven, K., Mtui, G., Katima, J., Mrema, G. «Steam Pretreatment of Pine (Pinus patula) wood residue for the production of reducing sugars.» Cellulose Chem. Technol., 45 (7-8), 2011: 495-501 .

26. Chandra, R., Bura, R., Mabee, W., Berlin, A., Pan, X.,Saddler, J. «Substrate Pretreatment: The Key to Effective Enzymatic Hydrolysis of Lignocellulosics?» En Advances in Biochemical Engineering/Biotechnology, de Belkin, S., Doran, P., Hu, W., Mattiasson, B., Nielsen, J., Stephanopoulos, G., 67-93. Springer-Verlag Berlin Heidelberg, 2007.

27. Charles, N. Oxygen delignification as a pretreatment for the enzymatic hydrolysis of lignocellulosic materials. Master Thesis. The University of British Columbia, 1998.

28. Chen, X., Shekiro, S., Franden, M., Wang, W., Zhang, M., Kuhn, E., Johnson, D., Tucker, M. «The impacts of deacetylation prior to dilute acid pretreatment on the bioethanol process.» Biotechnology for Biofuels 5:8, 2012: 1-14.

29. Chum, H., Johnson, D., Black, S., Overend, R. «Pretreatment-Catalyst Effects and the Combined Severity Parameter». Applied Biochemestry and Biotechnology, Vol 24/25, 1990, $1-14$.

30. Cherubini, F. «The biorefinery concept: Using biomass instead of oil for producing energy and chemicals.» Energy Conversion and Management 51, 2010: 1412-1421.

31. Clark, T., Mackie,K. «Steam Explosion of the softwood pinus radiata with sulfur dioxide extraction. I Process Optimization.» Journal of Wood Chemestry and Technology 7(3), 1987: 373-403.

32. Clayton, D., Easty, D., Einspahr, D., Lonsky, W., Malcolm, E., McDonough, T., Schroeder, L., Thompson, N. «Alkaline Pulping, Chap. IV». En Pulp and Paper Manufacture. Vol 5. de Malcolm, E., Grace, T., Kokurek, M. Joint Textbook Commitee of Paper Industry, Atlanta, Montreal, p.49-55, 1989. 
33. Conner, A., Rowe, J. «Neutrals in Southern Pine Tall Oil.» Journal of the American oil chemists' society 52, 1975: 334-338.

34. Cotana, F., Cavalaglio, G., Gelossia, M., Coccia, V., Petrozzi, A., Nicolini, A. «Effect of Double-Step Steam Explosion Pretreatment in Bioethanol Production from Softwood.» Appl Biochem Biotechnol 174, 2014: 156-167.

35. Cullis, I. The effect of steam explosion pretreatment parameters on softwood delignification efficiency. Thesis of Master of Science, Vancouver, Canadá: Tesis de Maestría no publicada. University of British Columbia, 2003.

36. Da Silva, A., Teixeira, R., de Oliveira Moutta,R., Ferreira Leitao, V., da Rocha Olivieri de Barros, R., Ferrara, M., Pinto da Silva Bon, E. «Chapter 3: Sugarcane and Woody Biomass Pretreatments for Ethanol Production.» En Sustainable Degradation of Lignocellulosic Biomass - Techniques, Applications and Commercialization, de Silvéiro da Silva, S., Chandel A., 47-88. InTech, 2013.

37. Debzi, E., Chanzy, H., Sugiyama, J.,Tekely, P., Excoffier, G. «The I-alpha to I-betha Transformation of Highly Crystalline Cellulose by Annealing in Various Mediums.» Macromolecules 24 , 1991: 6816-6822.

38. Delidovich, I, Leonhard, K., Palkovits, R. «Cellulose and hemicellulose valorisation: an integrated challenge of catalysis and reaction engineering.» Energy Environ. Sci. 7, 2014: 2803-2830 .

39. Demirbas, A. «Methylation of wood fatty and resin acids for production of biodiesel.» Fuel 90, 2011: 2273-2279.

40. Donaldson, L.,Wong, K., Mackie, K. «Ultrastructure of steam-exploded wood.» Wood Sci. Technol. 22, 1988: 103-114.

41. Dos Santos, J. Seminario de Tesis Doctoral: Obtención de vainillina a partir de lignina de pino. Posadas: Doctorado en Ciencias Aplicadas, Universidad Nacional de Misiones, 2014.

42. Draude, K., Kurniawan, C., Duff, S. «Effect of oxygen delignification on the rate and extent of enzymatic hydrolysis of lignocellulosic material .» Bioresource Technology 79, 2001: 113120.

43. Drew, J. Estados Unidos: Patente "Turpentine recovery by steam distilling woodchips while they are inmersed", 3.871.951. 1975. 
44. Ek, M., Chirat, C., Fogelstrom, L., Iversen, T., Li, D., Malmstrom, E., Norstrom, E., Sixta, H., Testova, L., Toivari, T., Wawro, D. «WOBAMA-Wood Based Materials and Fuels.» Cellulose Chemestry and Technology 48 (9-10), 2014: 773-779.

45. Fahlén, J. The cell wall ultrastructure of wood fibres - effects of the chemical pulp fibre line. Tesis de doctorado, Stockholm, Sweden: Royal Institute of Technology (KTH), Department of Fibre and Polymer Technology, 2005.

46. Fahler, J. «Plan Estratégico del Sector Foresto Industrial de Corrientes.» Power Point, 2012.

47. Fan, L. Lee, Y., Gharpuray, M. «The nature of lignocellulosics and their pretreatments for enzymatic hydrolysis.» Adv. Biochem. Eng. 23, 1982: 157-187.

48. FAO. «Terminología Unificada de Bionergía.» Capítulo 7: Definición de los principales términos. ftp://ftp.fao.org/docrep/fao/009/j6439s/j6439s08.pdf (último acceso: Septiembre de 12 de 2015).

49. Fardim, P., Liebert, T., Heinze, T. «Pulp Fibers for Papermaking and Cellulose Dissolution.» En The European Polysaccharide Network of Excellence (EPNOE). Reasearch Initiatives and Results, de Navard, P. 253-282. New York: Springer Wien Heidelberg, 2012.

50. Fengel, D., Wegener, G. Wood - Chemistry, Ultrastructure, Reactions. Berlín: Walter de Gruyter, 1989.

51. Fišerová, M., Opálená,E. «Hemicellulose extraction from beech wood with water and alkaline solutions.» Wood Reasearch 57 (4), 2012: 505-514.

52. FitzPatrick, M., Champagne, P., Cunningham, M., Whitney, R. «A biorefinery processing perspective: Treatment of lignocellulosic materials for the production of value-added products.» Bioresource Technology 101, 2010: 8915-8922.

53. Foston M, Ragauskas AJ. «Changes in lignocellulosic supramolecular and ultrastructure during dilute acid pretreatment of Populus and switchgrass.» Biomass Bioenerg 34, 2010: $1885-1895$.

54. Frederick, W., Lien, Jr.,S., Courchene, C., DeMartini, N., Ragauskas, A., Iisa, K. «Coproduction of ethanol and cellulose fiber from southern pine: a technical and economic assesment.» Biomass and bioenergy 32, 2008: 1923-1302.

55. French, A., Cintrón, M. «Cellulose polymorphy, crystallite size, and the Segal Crystallinity Index.» Cellulose 20, 2013: 583-588. 
56. Galbe, M., Zacchi G. «A review of the production of ethanol from softwood.» Appl. Microbiol. Biotechnol. 59, 2002: 618-628.

57. Garrote, G., Domínguez, H., Parajo, J. «Mild autohydrolysis: an environmentally friendly technology for xylooligosaccharide production from wood. » J. Chem Technol Biotechnol 74, 1999, 1101-1109

58. Glasser, W., Northey, R., Schultz, T. Lignin: Historical, Biological and Material Perspectives. American Chemical Society, 2000.

59. Grace, M., Malcolm, E. «Alkaline pulping.» Pulp and paper Manufacture, Vol 5, Joint Executive Committee of the Vocational Educational Committees of the Pulp and Paper, 1989.

60. Grethlein, H., Converse, A. «Common Aspects of Acid Prehydrolysis and Steam Explosion for Pretreating Wood.» Bioresource Technology 36, 1991: 77-82.

61. Gupta, R. Alkaline pretreatment of biomass for ethanol production and understanding the factors influencing the cellulose hydrolysis. Tesis Doctoral. Auburn University, 2008.

62. Hames, B., Ruiz, R., Scarlata, C., Sluiter, A.,Sluiter, J.,Templeton, D. Preparation of Samples for compositional Analysis. Laboratory Analytical Procedures, National Renewable Energy Laboratory. NREL/TP-510-42620, 2005.

63. Hamilton, K. «The behaviour of wood Carbohydrates in Technical Pulping Processes.» Pure Appl. Chem. 5 (1-2), 1962: 197-218.

64. Harmsem, P., Huijgen, W., López Bermúdez, L., Bakker, R. Literature Review of Physical and Chemical Pretreatment Processes for Lignocellulosic Biomass. Energy Research Centre of the Netherlands, 2010.

65. Hellstén, S., Lahti, J., Heinonen, J., Kallioinen,M., Mänttäri,M., Sainio, T. «Purification process for recovering hydroxy acids from soda black liquor.» Chemical Engineering Research and Design 91 (12), 2013: 2765-2774.

66. Hillis, W., Wood Extractives and Their Significance To The Pulp and Paper Industries. New York: Academic Press INC, 1962.

67. Hu, F., Jung, S., Ragauskas, A. «Pseudo-lignin formation and its impact on enzymatic hydrolysis.» Bioresource Technology 117, 2012: 7-12.

68. Hu, F., Ragauskas, A. «Pretreatment and Lignocellulosic Chemistry.» Bioenerg. Res. 5, 2012: 1043-1066. 
69. Huang, F., Ragauskas, A. (a) «Chemical Pretreatment Techniques for Biofuels and Biorefineries from Softwod.» En Pretreatment Techniques for Biofuels and Biorefineries, de Fang, Z., 151-179. Berlin: Springer-Verlag, 2013.

70. Huang, F., Ragauskas, A. (b) «Extraction of Hemicellulose from Loblolly Pine Woodchips and Subsequent Kraft Pulping.» Ind. Eng. Chem. Res. 52, 2013: $1743-1749$.

71. Huang, F., Ragauskas,A. «Dilute $\mathrm{H}_{2} \mathrm{SO}_{4}$ and $\mathrm{SO}_{2}$ pretreatments of Loblolly pine wood residue for bioethanol production.» Industrial Biotechnology Vol.8, $N^{o} 1$, 2012: 22-30.

72. Imlauer, C., Felissia, F., Area, M. Fractionation of Pinus radiata wood by combination of steam explosion and solvent delignification. Córdoba, España: 1st International Workshop on Biorefinery of Lignocellulosic Materials, 2015.

73. Imlauer, C., Kruyeniski,J., Area, M., Felissia, F. «Fraccionamiento a la Soda-AQ de aserrín de pino para la biorrefinería forestal.» Proceedings of the VIII IberoAmerican Congress on Pulp and Paper Research, Medellín, Colombia, 2014.

74. Izurieta, C. «Latin American Network Information Center.» Estrategia forestal de la provincia de misiones: instrumentos para el diseño de politicas. 2004. http://lanic.utexas.edu/project/etext/llilas/cpa/spring04/argbrazil/izurieta.pdf (último acceso: 06 de Agosto de 2014).

75. Janga, K., Hägg, M., Moe, S. «Influence of acid concentration, temperature, and time decrystalization in two-stage concentrated sulfuric acid hydrolysis of pinewood and aspenwood: A statical approach .» BioResources 7 (1), 2012: 391-411.

76. Janzon, R., Schütt, F., Oldenburg, F., Fischer, E.,Körner, I., Saake, B. «Steam pretreatment of spruce forest residues: Optimal conditions for biogas production and enzymatic hydrolysis.» Carbohydrate Polymers 100 , 2014: 202-210.

77. Jensen, J., Morinelly, J., Gossen, K., Campbell-Brodeur, M., Shonard, D. «Effects of dilute acid pretreatment conditions on enzymatic hydrolysis monomer and oligomer sugar yields for aspen, balsam, and switchgrass.» Bioresource Technology 101, 2010: 2317-2325.

78. Jørgensen, H., Kristensen,J., Felby, C. «Enzymatic conversion of lignocellulose into fermentable sugars: challenges and opportunities.» Biofuels, Bioprod. Bioref. 1, 2007: 119134 .

79. Jung, H., Kim, K. «Acidic Pretreatment.» En Pretreatment of biomass: Process and Technologies, de Pandey, A., Negi, S., Binod, P., Larroche, C., 27-50. Elsevier, 2015. 
80. Kaar, W., Cool, L., Merriman, M., Brink, D. «The complete analysis of wood polysaccharides using HPLC.» Journal of Wood Chemestry and Technology 11 (4), 1991: 447-463.

81. Kamide, K. «Cellulose and cellulose derivatives» Elsevier, 2005.

82. Kamm, B., Kamm, M., Gruber, P., Kromus, S. «Biorefinery Systems - An Overview.» En Biorefineries-Industrial Processes and Products. Status Quo and Future Directions. Vol. 1, de Kamm M., Gruber P. Kamm B., 3-33. Weinheim: WILEY-VCH Verlag GmbH \& Co. KGaA, 2006.

83. Kim, K. «Two-stage dilute acid-catalyzed hydrolytic conversion of softwood sawdust into sugars fermentable by ethanologenic microorganisms.» Journal of the Science of Food and Agriculture 85, 2005: 2461-2467.

84. Klass, D. Biomass for Renewable Energy, Fuels, and Chemicals. New York: Academic Press, 1998.

85. Knez, Z., Markocic, E., Leitgeb, M., Primozic, M., Knez, M.,Skerget, M. «Industrial applications of supercritical fluids: A review.» Energy, 2014: 1-9.

86. Kobayashi, T., Kohn, B., Holmes, L., Faulkner, R., Davis, M. «Molecular-level consequences of biomass pretreatment by dilute sulfuric acid at various temperatures.» Energy Fuels 25, 2011: 1790-1797.

87. Koch, G. «Raw Material for Pulp.» En Handbook of Pulp. Volume I., de Sixta, H. 21-61. Weinheim: WILEY-VCH Verlag GmbH \&Co. KGaA, 2006.

88. Kokta, B., Ahmed, A. «Steam Explosion Pulping.» En Environmentally Friendly Technologies for the Pulp and Paper Industry, de Masood, Young, R., 191-214. New York: John Wiley \& Sons, Inc, 1998.

89. Kruyeniski, J., Felissia, F., Stoffel, R., Imlauer, C., Area, M. Influencia del pretratamiento sobre la hidrólisis enzimática de aserrín de pino. Proceedings of the VIII IberoAmerican Congress on Pulp and Paper Research, Medellín, Colombia, 2014.

90. Kruyeniski, J., Felissia, F., Area, M. Enzymatic hydrolysis of pine pretreated with ethanol amd sodium hydroxide. Concepción, Chile: $3^{\circ}$ Congreso Iberoamericano, $4^{\circ}$ Congreso Latinoamericano sobre Biorrefinerías, $2^{\circ}$ Simposio Internacional de Materiales Lignocelulósicos, 2015. 
91. Kumar Gupta, V., Tuohy, M. Biofuel Technologies. Recent Developments. Berlin: SpringerVerlag, 2013.

92. Kumar, J., Arantes, V., Chandra, R., Saddler, J. «The lignin present in steam pretreated softwood binds enzymes and limits cellulose accesibility.» Bioresource Technology 103, 2012: 201-208.

93. Kumar, L. Steam pretreatment as an effective front end for a softwwod based biorefinery. Vancouver: Thesis of PhD. University of British Columbia, 2013.

94. Kumar, L., Chandra, R., Chung, P., Saddler, J. «Can the same steam pretreatment conditions be used for most softwoods to achieve good, enzymatic hydrolysis and sugar yields?» Bioresource Technology 101 , 2010: 7827-7833.

95. Kumar, P., Barret, D., Delwiche, M., Stroeve, P. «Methods for Pretreatment of Lignocellulosic Biomass for Efficient Hydrolysis and Biofuel Production.» Ind. Eng. Chem. Res. 48, 2009: 3713-3729.

96. Kundu, C., Lee, H., Lee, J. «Enhanced bioethanol production from yellow poplar by deacetylation and oxalic acid pretreatment without detoxification.» Bioresource Technology , 2014.

97. Lachenal, D. «Section IV: The Thecnology of Chemical Pulp Bleaching. Chapter 6: Hydrogen Peroxide as a Delignifying Agent.» En Pulp Bleaching: Principles and Practice, de Dence, C., Reeve, D., 349-359. TAPPI Press , 1996.

98. Larsson, S., Palmqvist, E., Hagerdal-Hanh, B., Tengborg, C., Stenberg, K., Zacchi, G., Nilvebrant, N. «The generation of fermentation inhibitors during dilue acid hydrolysis of softwood.» Enzyme and Microbial Technology 24, 1999: 151-159.

99. Lawoko, M. Lignin Polysaccharide Networks inSoftwood and Chemical Pulps: Characterisation, Structure and Reactivity. Stockholm : Doctoral Dissertation, 2005.

100. Lee, Y., Iyer, P., Torget, R. Dilute-Acid Hydrolysis of Lignocellulosic Biomass. Berlín: Springer-Verlag, 1999.

101. Li, J., Gellerstedt, G., Toven, K. «Steam explosion lignins; their extraction, structure and potential as feedstock for biodiesel and chemicals.» Bioresource Technology 100, 2009: 2556-2561. 
102. Li, J., Henriksson, G., Gellerdted, G. «Lignin depolymerization/repolymerization and its critical role for delignification of aspen wood by steam explosion.» Bioresource Technology 98, 2007: 3061-3068.

103. Lim, W., Lee, J. «Influence of pretreatment condition on the fermentable sugar production and enzymatic hydrolysis of dilute acid-pretreated mixed softwood.» Bioresource Technology 140, 2013: 306-311.

104. Lin, S., Dence, C. Methods in Lignin Chemistry. Hong Kong: Springer-Verlag Berlin Heidelberg, 1992.

105. Linger, J., Vardon,D., Guarnieri,M., Karp,E., Hunsinger,G., Franden,M., Johnson,C., Chupka,G., Strathmann,T., Pienkos,P., Beckman,G. «Lignin valorization through integrated biological funneling and chemical catalysis .» Proc Natl Acad Sci U S A. 111(33), 20014: 12013-12018.

106. Liu, S. «Woody biomass: Niche position as a source of sustainable renewable chemicals and energy and kinetics of hot-water extraction/hhydrolysis.» Biotechnology Advances 28, 2010: 563-582.

107. Mackie, K., Brownell, H., West, K., Saddler, J. «Effect of Sulphur Dioxide and Sulphuric Acid on Steam Explosion of Aspenwood.» Journal of Wood Chemistry and Technology 5 (3), 1985: 405-425.

108. Maekawa, E. «On an available pretreatment for the enzymatic saccharification of lignocellulosic materials.» Wood Science and Technology 30 , 1996: 133-139.

109. Mansfiled, S., Mooney, C., Saddler, J. «Substrate and Enzyme Characteristics that Limit Cellulose Hydrolysis.» Biotechnol. Prog. 15, 1999: 804-816.

110. Mänttäri, M., Lahti, J., Louhi-Kultanen, M., Kallioinen, M. «Separation phenomena in UF and NF in the recovery of organic acids from kraft black liquor.» Journal of Membrane Science 490, 2015: 84-91.

111. Marzialetti, T., Valenzuela Olarte, M.B., Sievers,C., Hoskins, T.J.C. «Dilute Acid Hydrolysis of Loblolly Pine: A Comprehensive Approach.»Ind. Eng. Chem. Res. 47, 2008: 7121-7140.

112. Mcdonough, T. The chemestry of organosolv delignification. Massachusetts: TAPPI Solvent Pulping Seminar, 1992. 
113. Meng, X., Foston, M., Leisen, J., DeMartini, J., Wyman, C., Ragauskas, A. «Determination of porosity of lignocellulosic biomass before and after pretreatment by using Simons' stain and NMR techniques.» Bioresource Technology 144, 2013: 467-476.

114. Meng, X., Ragauskas, A. «Recent advances in understanding the role of cellulose accessibility in enzymatic hydrolysis of lignocellulosic substrates.» Current Opinion in Biotechnology 27, 2014: 150-158.

115. Meng, X., Wells, T., Sun, Q., Huang, F., Ragauskas, A. «Insights into the effect of dilute acid, hot water or alkaline pretreatment on the cellulose accessible surface area and the overall porosity of Populus.» Green Chemestry 17, 2015: 4239-4246.

116. Mogollón, G., García Hortal, J., Leon, W. «Materia Primas Fibrosas.» En Panorama de la Industria de Celulosa y Papel en Iberoamérica 2008, de M.C. Area. Misiones: Red Iberoamericana de Docencia e Investigación en Celulosa y Papel-Riadicyp, 2008.

117. Monavari, S., Galbe, M., Zacchi, G. «Impact of impregnation time and chip size on sugar yield in pretreatment of softwood for ethanol production.» Bioresource Technology 100, 2009: 6312-6316.

118. Montagna, P., Inalbon, M., Paananen, M., Sixta, H., Zanuttini, M. «Chemical Reactions and dynamic capillarity changes in Kraft impregnation of pinus sylvestris.» Proceedings of the ABTCP 2012 + VII CIADICYP, 2012.

119. Mosier, C., Wyman, B. Dale, B., Elander, R., Lee, Y., Holtzapple, M., Ladisch, M. «Features of promising technologies for pretreatment of lignocellulosic biomass.» Bioresource Technology 96, 2005: 673-686.

120. Muzamal, M., Jedvert, K., Theliander, H., Rasmuson, A. «Structural changes in spruce wood during different steps of steam explosion pretreatment.» Holzforschung 2015, 2015: 61-66.

121. Nakagame, S. The influence of lignin on the enzymatic hydrolysis of pretreated biomass substrates. Vancouver: PhD Thesis. The University of British Columbia, 2010.

122. Negro, M., Manzanares, P., Oliva, J., Ballesteros, I., Ballesteros, M. «Changes in various physical/chemical parameters of Pinus pinaster wood after steam explosion pretreatment.» Biomass and Bioenergy 25, 2003: $301-308$.

123. Nguyen, Q., Tucker, M., Boynton, B., Keller, F., Schell, D. «Dilute acid pretreatment of softwoods.» Applied Biochemestry and Biotechnology Vol. 70-72, 1998: 77-87. 
124. Nguyen, Q.A., Tucker, M.P., Boynton, B.L., Keller,F.A., Schell,D.J. «Dilute Acis Pretreatment of Softwoods.» Applied Biochemestry and Biotechnology Vol. 70-72, 1998: 7787.

125. NREL. 2009. http://www.nrel.gov/biomass/biorefinery.html (último acceso: 25 de Julio de 2014).

126. Nuñez, C. «Extractivos.» 2008. http://www.cenunez.com.ar/archivos/66PulpayPapelIDcimaParte.pdf (último acceso: 14 de 08 de 2014).

127. Ohman, M., Boman, C. «Residential Combustion Performance of Pelletized Hydrolysis Residue from Lignocellulosic Ethanol Production.» Energy \& Fuels 2006, 20, 1298-1304.

128. Ostle, G. «Ben Thorp on the biorefinery concept.» Paper $360^{\circ}$, 1(5), 2006: 25-27.

129. Overend, R., Chornet, E., Gascoigne,J . «Fractionation of Lignocellulosics by SteamAqueous Pretreatments .» Philosophical Transactions of the Royal Society of London. Series A, Mathematical and Physical Sciences, Vol. 321, No. 1561, Technology in the 1990s: Utilization of Lignocellulosic Wastes, 1987: 523-536.

130. Palonen, H., Thomsen, A., Tenkanen, M., Schmitd, A., Viikari, L. «Evaluation of Wet Oxidation Pretreatment for Enzymatic Hydrolysis of Softwood.» Applied Biochemistry and Biotechnology Vol.117, 2004: 1-17.

131. Pan, X., Xie, D., Yu, R., Lam, D., Saddler, J. «Pretreatment of Lodgepole Pine Killed by Mountain Pine Beetle Using the Ethanol Organosolv Process: Fractionation and Process Optimization.» Ind. Eng. Chem. Res. 46, 2007: 2609-2617.

132. Pan, X., Xie, D., Gilkes, N., Gregg, D., Saddler, J. «Strategies to Enhance the Enzymatic Hydrolysis of Pretreated Softwood with High Residual Lignin Content.» Applied Biochemistry and Biotechnology Vol. 121-124, 2005: 1069-1079.

133. Pan, X., Zhang, X., Gregg, D., Saddler, J. «Enhanced Enzymatic Hydrolysis of SteamExploded Douglas Fir Wood by Alkali-Oxygen Post-treatment.» Applied Biochemistry and Biotechnology Vol 113-116, 2004: 1103-1114.

134. Park, N., Kim, H., Koo, B., Yeo, H., Choi ,I. «Organosolv pretreatment with various catalysts for enhancing enzymatic hydrolysis of pitch pine (Pinus rigida).» Bioresource Technology 101 , 2010: 7046-7053. 
135. Park, S., Baker, J., Himmel, M., Parilla, P., Johnson, D. «Cellulose crystallinity index: measurement techniques and their impact on interpreting cellulase performance.» Biotechnology for Biofuels 3:10, 2010: 2-10.

136. Pedersen, M., Meyer, A. «Lignocellulose pretreatment severity-relating $\mathrm{pH}$ to biomatrix opening.» New Biotechnology 27 (6), 2010: 739-750.

137. Peng, F., Peng, P., Xu, F., Sun, R. «Fractional purification and bioconversion of hemicelluloses.» Biotechnology Advances 30, 2012: 879-903.

138. Pereira Ramos, L. «The chemestry involved in the steam treatment of lignocellulosic materials.» Quim. Nova Vol 26, No. 6, 2003: 863-871.

139. Pereira Ramos, L., Breuil, C., Saddler, J. «Comparison of Steam Pretreatment of Eucalyptus, Aspen, and Spruce Wood Chips and Their Enzymatic Hydrolysis.» Applied Biochemistry and Biotechnology 34/35, 1992: 37-48.

140. Pettersen, R. «The Chemical Composition of Wood.» En The Chemistry of Solid Wood, de R. Rowell, 57-126. American Chemical Society, 1984.

141. Pitarelo, A. Produção de etanol celulósico a partir do bagaço de cana pré-tratado por explosão a vapor. Tesis Doctoral, Universidad Federal do Paraná, Curitiba, Brasil, 2013.

142. Program, USDA National Organic. «Technical Evaluation Report-Wood RosinHandling/Proccesing.» 2014. http://www.ams.usda.gov/AMSv1.0/getfile?dDocName=STELPRDC5107941 (último acceso: 8 de Septiembre de 2014).

143. Pu, Y., Hu, F., Huang, F., Davison, B., Ragauskas, A. «Assessing the molecular structure basis for biomass recalcitrance during dilute acid and hydrothermal pretreatments.» Biotechnology for Biofuels ,6:15, 2013: 1-13.

144. Pu, Y., Hu, F., Huang, F., Ragauskas, A. «Lignin Structural Alterations in Thermochemical Pretreatments with Limited Delignification.» Bioenerg. Res., 2015.

145. Quattrocchi,O., Abelaira de Andrizzi, S., Laba, R., Introducción a la HPLC. Aplicación y Práctica. Buenos Aires: Ed. Artes Gráficas Farro; 1992. pp. 301-327.

146. Quiroz-Castañeda, R., Folch-Mallol, J. «Hydrolysis of Biomass Mediated by Cellulases for the Production of Sugars .» En Sustainable Degradation of Lignocellulosic Biomass Techniques, Applications and Commercialization Anuj Chand, de Chandel, A., Da Silva, S. Intech, 2013. 
147. Ragauskas, A. «Georgia Institute of Technology.» Renewable Bioproducts Institute. 2015. http://ipst.gatech.edu/faculty/ragauskas_art/technical_reviews/Basics\%20of\%20Kraft\%20P ulping.pdf (último acceso: 09 de Abril de 2015).

148. Ragauskas, A. «Lignin Valorization: Improving Lignin Processing in the Biorefinery.» Science 344, 2014: 709-719.

149. Rasmussen, H., Sorensen, H., Meyer, A. «Formation of degradation compounds from lignocellulosic biomass in the biorefinery: sugar reaction mechanisms.» Carbohydrate Research 385, 2014: 45-57.

150. Reguant, J., Martínez, J., Montané, D., Salvadó, J., Farriol, X. «Cellulose from softwood via prehydrolysis and soda/AQ pulping.» Journal of Wood Chemestry and Technology 17, 1997: (91-110).

151. Rojas, O., Lucia, L., Kelley, S., Phillips, R. Biorrefinerías y (bio)materiales a partir del recurso forestal. Valdivia, Chile: Taller RIADICYP para una acción estratégica regional de celulosa y papel en países del MERCOSUR, 2006.

152. Salmén, L., Olsson, A. «Interaction Between Hemicelluloses, Lignin and Cellulose: Structure-Property Relationships.» Journal of Pulp and Paper Science 24 (3), 1998: 99-102.

153. Sánchez-Ramírez, J., Martínez-Hernández, J., Segura-Ceniceros, E., Contreras Esquivel, J., Medina-Morales, M., Aguilar, C., Iliná, A., «Inmovilización de enzimas lignocelulolíticas en nanopartículas magnéticas.» Quim. Nova, Vol. 37, No. 3, 2014, 504-512.

154. Sannigrahi, P., Hu, F., Pu, Y., Ragauskas, A. «A Novel Oxidative Pretreatment of Loblolly Pine, Sweetgum, and Miscanthus by Ozone.» Journal of Wood Chemistry and Technology, 32:4, 2012: 361-375.

155. Sannigrahi, P., Kim, D. H., Jung, S., Ragauskas, P. «Pseudo-lignin and pretreatment chemestry.» Energy snd Enviromental Science, 2011: 1306-1310.

156. Sannigrahi, P., Miller, S., Ragauskas, A. «Effects of organosolv pretreatment and enzymatic hydrolysis on cellulose structure and crystallinity in Loblolly pine.» Carbohydrate Research 345, 2010: 965-970.

157. Sannigrahi, P., Pu, Y., Ragauskas, A. «Cellulosic biorefineries-unleashing lignin opportunities.» Current Opinion in Environmental Sustainability 2, 2010: 383-393. 
158. Sannigrahi, P., Ragauskas, A. «Effects of Two-Stage Dilute Acid Pretreatment on the Structure and Composition of Lignin and Cellulose in Loblolly Pine.» Bionergy Resource 1, 2008: 205-214.

159. Sannigrahi, P., Ragauskas, A. «Chapter 10: Fundamentals of Biomass Pretreatment by fractionation.» En Aqueous Pretreatment of Plant Biomass for Biological and Chemical Conversion to Fuels and Chemicals, First Edition., de C. Wyman, 201-222. John Wiley \& Sons, Ltd, 2013.

160. Santi Junior, C., Ferreira Milagres, A., Ferraz, A., Carvalho, W. «The effects of lignin removal and drying on the porosity and enzymatic hydrolysis of sugarcane bagasse.» Cellulose 20, 2013: 3165-3177.

161. Santos, R., Hart, P., Jameel, H., Chang, H. «Wood Based Lignin Reactions Important to the Biorefinery and Pulp and Paper Industries.» BioResources 8 (1), 2013: 1456-1477.

162. Sarkanen K., Ludwig C. Lignins: Ocurrence, Formation, Structure and Reactions. John Wiley \& Sons, 1971.

163. Schell, D., Nguyen, Q., Tucker, M., Boynton, B. «Pretreatment of softwood by acidcatalized steam explosion followed by alkali extraction.» Applied Biochemestry and Biotechnology Vol. 70-72, 1998: 17-24.

164. Schild, G., Sixta, H.,Testova, L. «Multifunctional Alkaline Pulping, delignification and hemicellulose extraction.» Cellulose Chem. Technol., 44 (1-3), 2010: 35-45.

165. Schwald, W., Smaridge,T., Chan,M., Breuil,C., Saddler,J. «The influence of SO2 impregnation and fractionation on product recovery and enzymic hydrolysis of steam-treated spruce.» En Enzyme Systems for Lignocellulosic Degradation, de Coughlan, M., 231-242. England: Elsevier Science Publisher LTD., 1989.

166. Schwarz, G. «Fundación Mediterránea-Instituto de Estudios sobre la Realidad Argentina y Latinoaméricana (IERAL).» Una Argentina Competitiva, Productiva y Federal. Actualidad $y$ desafios en la cadena forestoindustrial. 2010. afoa.org.ar/descargar_adjunto.php? $p=84$ (último acceso: 06 de Agosto de 2014).

167. Selig, M., Weiss, N., Ji, Y. «Enzymatic Saccharification of Lignocellulosic Biomass: Laboratory Analytical Procedure, National Renewable Energy Laboratory, NREL/TP-51042629.» 2008. 
168. Shahbazi, A., Li,Y., Mims, M. «Application of Sequential Aqueous Steam Treatments to the Fractionation of Softwood.» (Applied Biochemistry and Biotechnology Vol. 121-124, 973-987) 2005.

169. Shuai, L., Yang, Q., Zhu, J.Y., Lu, F.C., Weimer, P.J., Ralph, J., Pam, X.J. «Comparative study of SPORL and dilute-acid pretreatments of spruce for cellulosic ethanol production.» Bioresource Technology 101 , 2010: 3106-3114.

170. SIFIP, Sistema de Información Foresto Industrial de la Provincia de Misiones. 2009. http://extension.facfor.unam.edu.ar/sifip/index.html.

171. Singh, J., Suhag, M., Dhaka, A. «Augmented digestion of lignocellulose by steam explosion, acid and alkaline pretreatment methods: A review.» Carbohydrate Polymers 117 , 2015: 624-631.

172. Sixta, H., Potthast, A., Krotschek, A. «Chemical Pulping Processes.» En Handbook of Pulp. Vol I, de Sixta, H., 109-509. Weinheim: WILEY-VCHVerlagGmbH\&Co., 2006.

173. Sjöström, E. «The behavior of wood polysaccharides during alkaline pulping process.» Tappi 60 (9), 1977: 151-155.

174. Sjöström, E. Wood Chemistry-Fundamentals and Applications. California: Academic Press, Inc., 1993.

175. Sluiter, A., Hames,B., Hyman, D., Payne, C.,Ruiz, R., Scarlata, C., Sluiter, J., Templeton, D., Wolfe, J. Determination of Total Solids in biomass and Total Dissolved Solids in Liquid Process Samples. Laboratory Analytical Procedures,National Renewable Energy Laboratory. NREL/TP-510-42621, 2008.

176. Sluiter, A., Hames, B., Ruiz, R., Scarlata, C., Sluiter, J., Templeton. D. Determination of Ash in Biomass. Laboratory Analytical Procedures, National Renewable Energy Laboratory. NREL/TP-510-42622, 2005.

177. Sluiter, A., Hames, B., Ruiz, R., Scarlata, C., Sluiter, J., Templeton. D., Crocker. D. Determination of Structural Carbohydrates and Lignin in Biomass. Laboratory Analytical Procedures, National Renewable Laboratory Patente NREL/LP-510-42618, 2008.

178. Sluiter, A.,Ruiz, R., Scarlata, C., Sluiter, J.,Templeton. D. Determination of Extractives in biomass. Laboratory Analytical Procedures, National Renewable Energy Laboratory. NREL/LP-510-42619, 2005. 
179. Söderström, J., Pilcher, L., Galbe, M., Zacchi, G. «Two-step steam pretreatment of softwood with SO2 impregnation for ethanol production.» Appl Biochem Biotechnol. (98) 100, 2002: 5-21.

180. Speaks, U., Campbell, R., Veal, M. Estados Unidos Patente "Pretreatment of wood particulates for removal of wood extractives", 5.698.667. 1997.

181. Stenberg, K., Tengborg, T., Galbe, M., Zacchi, G. «Optimisation of Steam Pretreatment of $\mathrm{SO}_{2}$ Mixed Softwoods for Ethanol Production.» J. Chem. T echnol. Biotechnol. 71, 1998: 299-308.

182. Sun, Q., Pu, Y., Meng, X., Wells, T., Ragauskas, A. «Structural Transformation of Isolated Poplar and Switchgrass Lignins during Dilute Acid Treatment.» ACS Sustainable Chemistry \& Engineering 3 (9), 2015: 2203-2210.

183. Taherzadeh, M., Eklund,R., Gustafsson,L., Niklasson, Lidén, G. «Characterization and Fermentation of Dilute-Acid Hydrolyzates from Wood.» Ind. Eng. Chem. Res. 1997, 1997: 4659-4665.

184. Taherzadeh, M., Karimi, K. «Acid-based hydrolysis processes for ethanol from lignocellulosic materials: a review.» Bioresources 2(3), 2007: 472-499.

185. Tanase, M., Stenius, P., Gregersen, Ø., Johansson, L., Hill, J. «Removal of extractives from TMP process water using dissolved air flotation.» 7th International Seminar on Fundamental Mechanical Pulp Research, 2010.

186. Tengborg, C., Stenberg, K., Galbe, M., Zacchi, G., Larsson, S., Palmqvist, E., HahnHargedal, B. «Comparison of $\mathrm{SO}_{2}$ and $\mathrm{H}_{2} \mathrm{SO}_{4}$ Impregnation of Softwood Prior to Steam Pretreatment on Ethanol Production.» Applied Biochemistry and Biotechnology Vol. 1, Issue $70-72, \mathrm{~N}^{\mathrm{o}} 3-15$ (1998): 3-15.

187. Tolbert, A., Akinosho, H., Khunsupat, R., Naskar, A., Ragauskas, A. «Characterization and analysis of the molecular weight of lignin for biorefining studies.» Biofuels, Bioprod. Bioref. 8, 2014: 836-856.

188. Trigo, E., Mentaberry, A., Cap, E., Zelada, A., Villarreal, F. «Argentina Innovadora 2020MINCYT.» 2011.http://www.argentinainnovadora2020.mincyt.gob.ar/?wpfb_dl=25 (último acceso: 19 de 08 de 2014).

189. Uasuf, A., Hilbert, J. El uso de la biomasa de Origen Forestal con destino a bioenergía en la Argentina. Informe Técnico, Castelar: Ediciones INTA, 2012. 
190. UPV, Universidad Politécnica de Valencia. Biología. La Pared Celular Vegental. 2015. http://www.euita.upv.es/varios/biologia/Temas/Pared\%20celular\%20ampliada.htm (último acceso: 22 de 06 de 2015).

191. van Lierop, B., Skothos, A., Libergott, N. «Ozono Delignification.» En Pulp Bleaching: Principle and Practice, de C., Reeve, D. Dence, 321-340. TAPPI Press, 1996.

192. Vera Candioti, L., De Zan, M., Cámara, M., Goicoechea, H. «Experimental design and multiple response optimization. Using the desirability function in analytical methods development.» Talanta 124, 2014: 123-138.

193. von Schenck, A., Berglin, N., Uusitalo, J. «Ethanol from Nordic wood raw material by simplified alkaline soda cooking pre-treatment.» Applied Energy 102 , 2013: 229-240.

194. Werpy, T., Petersen, G. Top Value Added Chemicals From Biomass. Volume I: Results of Screening for Potential Candidates from Sugars and Synthesis Gas. Informe, Pacific Northwest National Laboratory (PNNL) and National Renewable Energy Laboratory (NREL) , 2004.

195. Wijaya, Y., Putra, R., Widyaya, V., Ha, J., Suh, D., Kim, C. «Comparative study on twostep concentrated acid hydrolysis for the extraction of sugars from lignocellulosic biomass.» Bioresource Technology 164, 2014: 221-231.

196. Wild, P., Huijgen, W., Heeres, H. «Pyrolysis of wheat straw-derived organosolv lignin.» Journal of Analytical and Applied Pyrolysis 93, 2012: 95-103.

197. Wong, K., Deverell, K., Mackie, K., Clark, T., Donaldson, L. «The Relationship Between Fiber Porosity and Cellulose Digestibility in Steam-ExpIod ed Pinus radiata.» Biotechnology and Bioengineering, Vol. 31, 1988: 447-456.

198. Wyman, C,E. «Ethanol from lignocellulosic biomass: technology, economics, and opportunities.» Bioresource Technology 50, 1994: 3-15.

199. Xu, C., Baoqiang, L., Shi, W. «Organosolv Pretreatment of Pine Sawdust for Bio-ethanol Production.» En Pretreatment Techniques for Biofuels and Biorefineries, de Z. Fang, 435458. Springer-Verlag Berlin Heidelberg, 2013.

200. Xu, F., Shi, Y., Wang,D. «Structural features and changes of lignocellulosic biomass during thermochemical pretreatments: A synchrotron X-ray scattering study on photoperiodsensitive sorghum.» Carbohydrate Polymers 88, 2012: 1149-1156. 
201. Yang, B., Boussaid, A., Mansfield, S., Gregg, D., Saddler, J. «Fast and efficient alkaline peroxide treatment to enhace the enzymatic digestibility of seam-exploded softwood substrates.» Biotechnology and Bioengineering Vol. 77, No. 6, 2002: 678-684.

202. Yang, B., Dai, Z., Ding, S., Wyman, C. «Enzymatic hydrolysis of cellulosic biomass.» Biofuels 2 (4) , 2011: 421-450.

203. Yoon, H., Macewam, K., Van Heiningen, A. «Hot-Water Pre-extraction from loblolly pine (Pinus taeda) in an integrated forest products biorefinery.» TAPPI, 2008: 27-31.

204. Yoon, S., Han, S., Shin, S. «The effect of hemicelluloses and lignin on acid hydrolysis of cellulose.» Energy 77 , 2014: 19-24.

205. Yu, Z., Jameel, H., Chang, H.,Park, S. «The effect of delignification of forest biomass on enzymatic hydrolysis.» Bioresource Technology 102, 2011: 9083-9089.

206. Yuanlin, Z. Extraction of Scot Pine by polar solvents. Imatra: Bachelor's Thesis-Saimaa University of Applied Sciences, 2011.

207. Yuman, L. Extraction of Scots Pine with Non-polar solvents. Imatra: Bachelor ThesisSaimaa University of Applied Sciences, 2011.

208. Zhang, B., Shahbazi, A. «Recent developments in pretreatment thechnologies for production of lignocellulosic biofuels.» J Pet Environ Biotechnol 2:108, 2011.

209. Zhao, X., Zhang, L., Liu, D. «Biomass recalcitrance. Part I: the chemical compositions and physical structures affecting the enzymatic hydrolysis of lignocellulose.» Biofuels, Bioprod. Bioref. 6 , 2012: 465-482.

210. Zheng, Y., Pan, Z., Zhang, R. «Overview of biomass pretreatment for cellulosic ethanol production.» I nt J Agri c \& Biol Eng, 2 (3), 2009: 51-68.

211. Zinkel, D., Russell, J. Naval Stores: Production, Chemistry and Utilization. Estados Unidos: Pulp Chemicals Association, Inc., 1989.

212. Zviely, M. «Converting Lignocellulosic Biomass to Low-Cost Fermentable Sugars.» En Pretreatment Techniques for Biofuels and Biorefineries, de Fang, Z., 133-150. SpringerVerlag Berlin Heidelberg, 2013. 